\title{
On the consolidation quality in laser assisted fiber placement The role of the heating phase
}

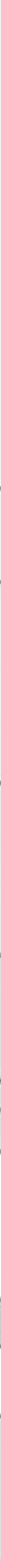




\section{ON THE CONSOLIDATION QUALITY IN LASER ASSISTED FIBER PLACEMENT}

The role of the heating phase

Thijs Kok 
De promotiecommissie is als volgt samengesteld:

Voorzitter en secretaris:

prof.dr. G.P.M.R. Dewulf

Universiteit Twente

Promotor:

prof.dr.ir. R. Akkerman Universiteit Twente

Assistent promotor:

dr.ir. W.J.B. Grouve

Universiteit Twente

Leden (in alfabetische volgorde):

prof.dr.ir. G. Brem

Universiteit Twente

prof. C.A. Dransfeld

Technische Universiteit Delft

prof. K. Potter

prof.dr.ir. G.R.B.E. Römer

University of Bristol

Universiteit Twente

This research project was financially supported by the ThermoPlastic composite Research Center (TPRC).

On the consolidation quality in laser assisted fiber placement, Kok, Thijs

PhD Thesis, University of Twente, Enschede, The Netherlands

September 2018

ISBN 978-90-365-4606-5

DOI 10.3990/1.9789036546065

(C) 2018 by T. Kok, Enschede, The Netherlands

Printed by Gildeprint, Enschede, The Netherlands

Cover: Illustration of the laser assisted fiber placement process with a focus on the heating phase. 


\title{
ON THE CONSOLIDATION QUALITY IN LASER ASSISTED FIBER PLACEMENT
}

\section{PROEFSCHRIFT}

\author{
ter verkrijging van \\ de graad van doctor aan de Universiteit Twente, \\ op gezag van de rector magnificus, \\ prof.dr. T.T.M. Palstra, \\ volgens besluit van het College voor Promoties \\ in het openbaar te verdedigen \\ op donderdag 6 september 2018 om 14:45 uur
}

door

Thijs Kok

geboren op 26 december 1988

te Harderwijk, Nederland 
Dit proefschrift is goedgekeurd door de promotor:

prof.dr.ir. R. Akkerman

en door de assistent promotor:

dr.ir. W.J.B. Grouve 


\section{Summary}

Laser assisted fiber placement (LAFP) is a promising additive manufacturing technique for large aerospace structures. The process involves the use of a robot to place thermoplastic composite prepreg tapes to build-up a component ply by ply. The prepreg tape is heated using a laser and subsequently bonded to previously placed plies under pressure applied by a roller. LAFP has the potential to reduce manufacturing time and costs by consolidating the prepreg tape in-situ, that is during placement. This way an expensive post-consolidation step in for example an autoclave can be omitted, provided that sufficient consolidation quality is obtained after placement. The consolidation quality achieved by LAFP at high placement rates does, however, not meet the high consolidation quality required by the aerospace industry yet. Especially, the void content exceeds the limit set by the aerospace industry. Voids can be classified according to their location in intralaminar and interlaminar voids. The latter are mainly originating from the LAFP processing and are the focus of this thesis. These interlaminar voids can be considered to be a lack of intimate contact between plies during the placement process. Furthermore, the presence of gaps and overlaps between adjacent tapes impedes the development of intimate contact resulting in a higher interlaminar void content.

The LAFP process has been subjected to a lot of research over the past decades. However, the effect of the heating phase on the tape has received little to no attention. This thesis aims to investigate the effect of the heating phase on the consolidation state of the incoming tape and its consequences on the governing mechanisms during consolidation. For this purpose, an experimental research has been performed to analyze the state of the tape during the process, the development of intimate contact and the deformation of the tape during LAFP.

The tape is heated with the laser above its melting temperature in milliseconds. Although this heating time is short, the tape deconsolidates before entering the nip-point. The experimental research showed that this deconsolidation resulted in a rough and fiber-rich surface and an increase in intralaminar void content. The severity of the deconsolidation has been quantified using image analysis. The matrixpoor surface of the tape hinders interlaminar bond development, which consists of intimate contact development followed by healing. Currently models describe development of intimate contact as the deformation of surface asperities. Such a 
description is, however, not applicable to the deconsolidated tape, which is matrixpoor. Instead a percolation flow of matrix is required to wet the surface in order to obtain intimate contact and for healing to occur. Therefore, an intimate contact model based on percolation has been developed for the deconsolidated tape. An experimental analysis on intimate contact development has been performed and the results show that the proposed model is better capable predicting the trends for varying process settings than the available intimate contact models.

Prevention of gaps and overlaps requires, apart from a consistent tape width and an accurate robot, knowledge of the tape deformation during the process. An experimental analysis was performed to show that tape spreading was, for the range of settings investigated, not dependent on the applied pressure but only on the tape temperature. A quasi static tape deformation model has been developed based on these observations. This model is capable of predicting the trends in tape deformation for various process settings.

The experimental results in this thesis help to better understand the consolidation process during LAFP. This knowledge was used to develop consolidation models which together form a valuable tool to further improvement of the tape material and optimization of the LAFP process. 


\section{Samenvatting}

Het laser-verwarmd fiber-placementproces is een veelbelovende productietechniek voor grote structurele onderdelen voor de luchtvaartindustrie. Vezelversterkte thermoplastische geïmpregneerde tapes worden door middel van een robot geplaatst om een onderdeel laag voor laag op te bouwen. De tape wordt verwarmd met een laser en onder druk van een roller gelast aan eerder geplaatste lagen. Het laserverwarmd fiber-placementproces kan potentieel de productie van grote structurele onderdelen goedkoper maken met in-situ consolideren, dat is het consolideren tijdens het plaatsen van tapes. Als de bereikte consolidatiekwaliteit hoog genoeg is, dan kan een kostbare post-consolidatie stap worden uitgespaard. Echter voldoet de behaalde consolidatiekwaliteit op hoge plaatsingssnelheden nog niet aan de eisen van de luchtvaartindustrie. Met name de behaalde porositeit overschrijdt de gevraagde limiet. Er kan onderscheid gemaakt worden tussen intra-laminaire en inter-laminaire luchtinsluitingen. De focus van dit proefschrift ligt op de interlaminaire luchtinsluitingen. Deze ontstaan vooral tijdens het laser-verwarmd fiberplacementproces als een gebrek aan intiem contact tussen de lagen in een laminaat. Daarnaast kan de aanwezigheid van ruimtes tussen, en overlappingen van, tapes het ontwikkelen van intiem contact bemoeilijken, wat resulteert in een hogere interlaminaire porositeit.

Er is al veel onderzoek gedaan naar het laser-verwarmd fiber-placementproces, echter is de fase waarin de tape verwarmd wordt onderbelicht gebleven. Dit proefschrift is specifiek gericht op deze verwarmingsfase en beschouwt de veranderende consolidatiestaat van de tape als deze verwarmd wordt. Daarnaast is er gekeken naar de consequenties van deze verandering op de mechanismen die een rol spelen tijdens het consolidatieproces. Hiervoor zijn verschillende experimenten uitgevoerd, namelijk naar de verandering van de consolidatiekwaliteit van de tape tijdens het proces, het ontwikkelen van intiem contact en het verbreden van de tape tijdens het laserverwarmd fiber-placementproces.

De tape wordt tijdens het proces in milliseconden verwarmd boven zijn smelttemperatuur en hoewel deze tijd erg kort is, verandert de consolidatiekwaliteit van de tape alvorens deze onder druk komt van de roller. De experimentele resultaten laten zien dat deze deconsolidatie resulteert in een ruw en vezelrijk oppervlak en een toename in intra-laminaire porositeit in het uiteindelijke laminaat. De mate 
van deconsolidatie tijdens de verwarmingsfase is gekwantificeerd door middel van beeldanalyse. Het lasproces onder de roller, bestaande uit de ontwikkeling van intiem contact en aansluitend het diffunderen van polymeerketens, wordt beïnvloed door het vezelrijke oppervlak van de tape. Beschikbare consolidatiemodellen beschouwen het ontwikkelen van intiem contact als het vervormen van oneffenheden op het tapeoppervlak. Deze modellen lijken niet toepasbaar voor de gedeconsolideerde tape, aangezien een toevoer van matrix naar het vezelrijke oppervlak nodig lijkt voor het ontwikkelen van intiem contact. Daarom is een model ontwikkeld voor het ontwikkelen van intiem contact tijdens het laser-verwarmd fiber-placementproces, gebaseerd op de impregnatie van het vezelrijke oppervlak. Dit model blijkt beter de geobserveerde trends in de resultaten van de experimenten naar het ontwikkelen van intiem contact te voorspellen dan de beschikbare modellen.

Om het ontstaan van ruimtes tussen, en overlappingen, van tapes te voorkomen, is naast een consistente tapebreedte en een accurate robot, kennis van de breedte van de tape na het leggen benodigd. De resultaten van het experiment naar het vervormen van de tape tijden het proces laten zien dat de uiteindelijke breedte alleen afhankelijk is van de temperatuur van de tape en niet van de uitgeoefende druk. Een quasistatisch tapevervormingsmodel is ontwikkeld gebaseerd op deze observatie en dit model liet dezelfde trends zien als de experimentele resultaten.

De beschreven experimenten in dit proefschrift helpen het ontstaan van interlaminaire luchtinsluitingen tijdens het laser-verwarmd fiber-placementproces beter te begrijpen. Deze kennis is gebruikt om verschillende modellen te ontwikkelen om het consolidatie proces beter te beschrijven. Deze modellen zijn geschikt om in-situ consolidatie beter te onderzoeken en daarmee het tapemateriaal verder te ontwikkelen als wel het laser-verwarmd fiber-placementproces verder te optimaliseren. 


\section{Contents}

Summary i

$\begin{array}{ll}\text { Samenvatting } & \text { iii }\end{array}$

$\begin{array}{ll}\text { Contents } & \mathbf{v}\end{array}$

$\begin{array}{ll}\text { Nomenclature } & \text { ix }\end{array}$

1 Introduction 1

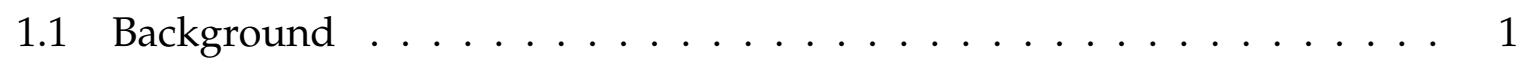

1.2 Laser assisted fiber placement . . . . . . . . . . . . . . . . 3

1.3 Void development during LAFP . . . . . . . . . . . . . 7

1.4 Motivation . . . . . . . . . . . . . . . . . . 8

1.5 Objective and scope . . . . . . . . . . . . . . 8

1.6 Outline .............................. 9

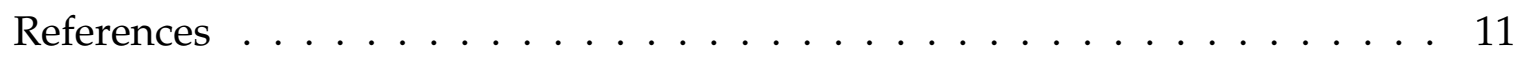

2 Thermal modeling of Laser Assisted Fiber Placement 15

2.1 Introduction . . . . . . . . . . . . . . . 16

2.2 Combined model . . . . . . . . . . . . . . . . . . . 17

2.3 Geometrical sub-model . . . . . . . . . . . . . . . . . . . . 18

2.4 Optical sub-model . . . . . . . . . . . . . . . . . . . 22

2.5 Heat transfer model . . . . . . . . . . . . . . . . . . . . . 24

2.6 Thermal model validation . . . . . . . . . . . . . . . . 26

2.6.1 Experimental procedure . . . . . . . . . . . . . 27

2.6.2 Tape placement experiment . . . . . . . . . . . . . 28

2.6 .3 Results . . . . . . . . . . . . . . . . . 28

2.7 Roller deformation . . . . . . . . . . . . . . . . . . 30

2.8 Conclusion . . . . . . . . . . . . . . . . . . 32

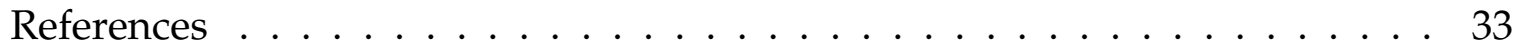

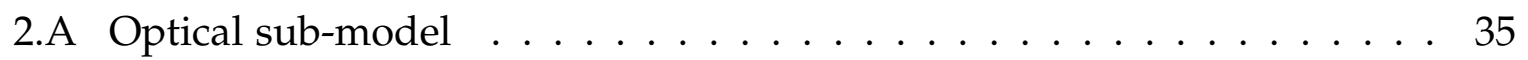

2.B Heat transfer sub-model . . . . . . . . . . . . . . . . . . . 37

2.C Thermal camera calibration . . . . . . . . . . . . . . 45 
3 Tape Deconsolidation during Laser Assisted Fiber Placement 51

3.1 Introduction . . . . . . . . . . . . . . . . . . . 52

3.2 Experimental work . . . . . . . . . . . . . . . . 54

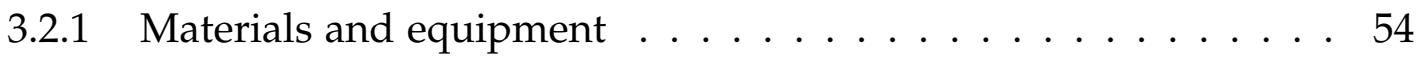

3.2.2 Specimen preparation . . . . . . . . . . . . . . 54

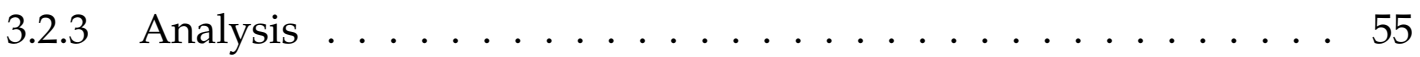

3.3 Results ........................ 56

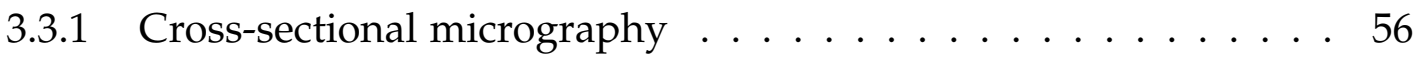

3.3.2 Surface micrography . . . . . . . . . . . . . . . . 63

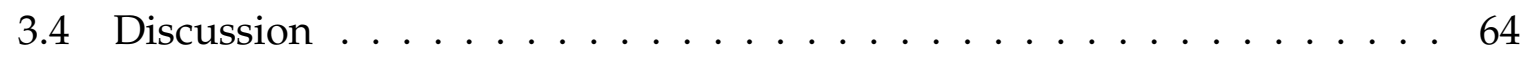

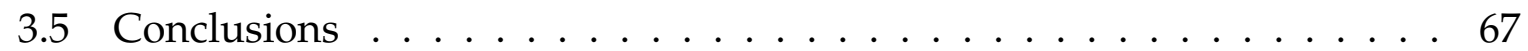

References .............................. 68

4 Intimate contact development during laser assisted fiber placement $\quad 73$

4.1 Introduction . . . . . . . . . . . . . . . . . 74

4.2 Experimental work . . . . . . . . . . . . . . . 75

4.2.1 Experimental procedure . . . . . . . . . . . . 75

4.2.2 Experimental results . . . . . . . . . . . . . . 78

4.3 Current modeling strategies . . . . . . . . . . . . . . 80

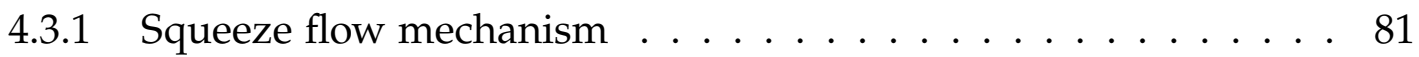

4.3 .2 Viscosity . . . . . . . . . . . . . . . . 82

4.3.3 Surface representation and resulting intimate contact development models . . . . . . . . . . . . . . . . 83

4.3 .4 Modeling results . . . . . . . . . . . . . . . . 84

4.3 .5 Discussion . . . . . . . . . . . . . . 87

4.4 Intimate contact model based on impregnation . . . . . . . . . . . . 88

4.4 .1 Problem statement . . . . . . . . . . . . . . . . 89

4.4.2 Intimate contact model based on 1D impregnation . . . . . . . . 91

4.4.3 Thickness of the dry fiber bed and relation to the degree of intimate contact . . . . . . . . . . . . . . 94

4.4 .4 Solution procedure . . . . . . . . . . . . . 96

4.5 Results . . . . . . . . . . . . . . . . . . . . 97

4.5.1 Model convergence and parametric study . . . . . . . . . . . 97

4.5.2 Comparison with available intimate contact model and experimental results . . . . . . . . . . . . . . . . . 99

4.6 Discussion . . . . . . . . . . . . . . . . . . . . 100

4.7 Conclusion . . . . . . . . . . . . . . . . . . . . . 102

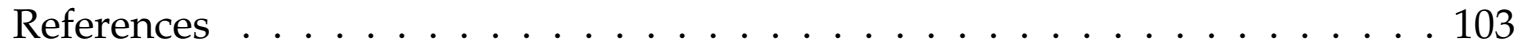

4.A Derivation impregnation model . . . . . . . . . . . . . 105 
5 Tape deformation during laser assisted fiber placement 109

5.1 Introduction . . . . . . . . . . . . . . . . . . . . . . . 110

5.2 Experimental work . . . . . . . . . . . . . . . . . . 111

5.2.1 Experimental procedure . . . . . . . . . . . . . 111

5.2 .2 Experimental results . . . . . . . . . . . . . . . . . 113

5.3 Transverse squeeze flow modeling of tape deformation . . . . . . . . . 115

5.3 .1 Model definition . . . . . . . . . . . . . . . . . . . 115

5.3 .2 Solution procedure . . . . . . . . . . . . . . . . 117

5.3 .3 Results ....................... 117

5.4 Discussion . . . . . . . . . . . . . . . . . . . . . . . . . 119

5.4.1 Transverse squeeze flow model for tape deformation . . . . . . . 119

5.4.2 Alternative tape deformation models . . . . . . . . . . . . . . 121

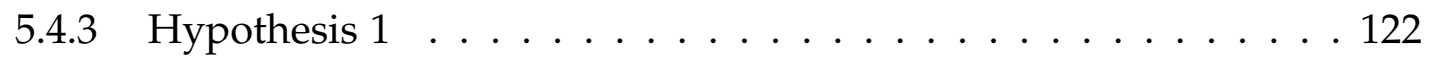

5.4 .4 Hypothesis $2 \ldots \ldots \ldots \ldots$

5.4 .5 Hypothesis $3 \ldots \ldots . \ldots \ldots . \ldots \ldots$

5.5 Conclusion . . . . . . . . . . . . . . . . . . . . . . 127

References . . . . . . . . . . . . . . . . . . . 128

5.A Transverse squeeze flow . . . . . . . . . . . . . . . . . . . . . . 129

5.B Squeeze flow including spreading-induced fiber stresses with an infinitely stiff roller . . . . . . . . . . . . . . . . . . . . 132

5.C Squeeze flow including spreading-induced fiber stresses with a Hertzian contact . . . . . . . . . . . . . . . . . . 136

5.D Quasi static tape deformation model . . . . . . . . . . . . 137

6 Discussion 139

6.1 Governing mechanisms for in-situ consolidation with Laser Assisted

Fiber Placement . . . . . . . . . . . . . . . . . . . 139

6.2 Tape properties - consolidation quality . . . . . . . . . . . . . . . . 142

6.3 Process parameters - consolidation quality . . . . . . . . . . . . 145

6.4 Process optimization . . . . . . . . . . . . . . . . . . . . . 148

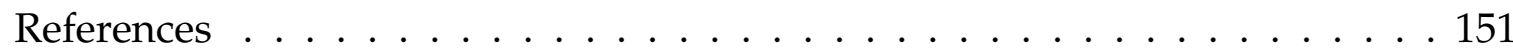

7 Conclusions and recommendations 155

7.1 Conclusions . . . . . . . . . . . . . . . . . . . . . 155

7.2 Recommendations . . . . . . . . . . . . . . 156

$\begin{array}{ll}\text { Dankwoord } & 159\end{array}$

$\begin{array}{ll}\text { Publications } & 163\end{array}$ 


\section{Nomenclature}

The symbols used in this thesis are classified into a Greek or a Roman symbol group. Although some symbols can represent multiple quantities, its intended meaning follows from the textual context.

\section{Greek symbols}

$\begin{array}{llr}\alpha & \text { Fiber spreading angle } & {\left[{ }^{\circ}\right]} \\ \beta & \text { Ratio of wavelength of fiber waviness } & {[-]} \\ \varepsilon & \text { Strain } & {[-]} \\ \epsilon & \text { Emissivity } & {[-]} \\ \theta_{\mathrm{i}}, \theta_{\mathrm{r}}, \theta_{\mathrm{t}} & \text { Incident, reflection and transmission angle } & {\left[{ }^{\circ}\right]} \\ \theta_{\mathrm{L}} & \text { Laser angle with respect to the substrate } & {\left[{ }^{\circ}\right]} \\ \theta_{\mathrm{LA}} & \text { Angle of linkage A with respect to the end effector } & {\left[{ }^{\circ}\right]} \\ \theta_{\mathrm{tilt}} & \text { Tilt angle of the end effector } & {\left[{ }^{\circ}\right]} \\ \mu & \text { Viscosity } & {[\mathrm{Pa} \mathrm{s}]} \\ \mu_{\mathrm{mf}} & \text { Fiber-matrix viscosity } & {[\mathrm{Pa} \mathrm{s}]} \\ \xi & \text { Spatial coordinate } & {[\mathrm{m}]} \\ \Delta \xi & \text { Spatial step size } & {[\mathrm{m}]} \\ \rho & \text { Density } & {\left[\mathrm{kg} / \mathrm{m}^{3}\right]} \\ \sigma & \text { Boltzmann constant } & {[\mathrm{J} / \mathrm{K}]} \\ \sigma, \sigma_{\mathrm{c}} & \text { Fiber bed compaction stress } & {[\mathrm{Pa}]} \\ \sigma_{\mathrm{fx}}, \sigma_{\mathrm{x}} & \text { Normal stress } & {[\mathrm{Pa}]} \\ \tau, \tau_{\mathrm{zx}} & \text { Shear stress } & {[\mathrm{Pa}]}\end{array}$

\section{Roman symbols}

$A$
$a, a_{0}$
$b, b_{0}$
$c_{\mu}$
$c_{b}$
$c_{p}$

Absorbed energy 


\begin{tabular}{|c|c|}
\hline$D$ & Fractal dimension \\
\hline$D_{\text {IC }}$ & Degree of intimate contact \\
\hline$E_{\mathrm{f}}$ & Young's modulus of fiber \\
\hline$E_{\mathrm{r}}$ & Roller stiffness \\
\hline$F, F_{\mathrm{x}}, F_{\mathrm{y}}$ & Force in fiber, $\mathrm{x}$ an $\mathrm{y}$ direction \\
\hline $\mathbf{F}_{\mathbf{B}}$ & Body force \\
\hline$F_{\mathrm{C}}$ & Compaction force \\
\hline$f_{\mathrm{L}}$ & Fraction of the laser beam on the tape \\
\hline$f$ & Fractal scaling parameter \\
\hline$H$ & Height of the laser spot \\
\hline$h$ & Heat transfer coefficient \\
\hline$h$ & Tape thickness \\
\hline$\dot{h}$ & Rate of change in tape thickness \\
\hline$h_{\text {air }}, h_{\mathrm{r}}, h_{\mathrm{t}}$ & Heat transfer coefficient (air, roller, tool) \\
\hline$h_{\mathrm{i}}, h_{\mathrm{f}}$ & Initial and final tape thickness \\
\hline$h_{0}$ & Largest asperity height \\
\hline$I$ & Energy of a ray \\
\hline K & Permeability \\
\hline$k$ & Transverse thermal conductivity \\
\hline$k_{0}$ & Kozeny constant \\
\hline$L_{\mathrm{A}}, L_{\mathrm{B}}$ & Length of linkages connecting the laser to the head \\
\hline$L_{\mathrm{C}}$ & Contact length \\
\hline$L_{\mathrm{h}}$ & Heated tape length \\
\hline$L_{1}$ & Distance between laser center line and nip-point \\
\hline$L_{0}$ & Largest asperity width \\
\hline$N_{\text {no }}, N_{\text {ro }}$ & Number of rays and nodes in the optical sub-model \\
\hline$N_{\mathrm{nt}}$ & $\begin{array}{l}\text { Number of nodes through the thickness of the tape } \\
\text { in the thermal sub-model }\end{array}$ \\
\hline$n$ & Number of generations in the fractal Cantor set \\
\hline$n_{1}, n_{2}$ & Refractive index of air and the composite \\
\hline$\dot{Q}_{\text {tape }}, \dot{Q}_{\text {lam }}$ & Laser influx for tape and substrate \\
\hline$\dot{q}$ & Heat flux \\
\hline$r_{\mathrm{r}}$ & Roller radius \\
\hline$P$ & Pressure \\
\hline$P_{\mathrm{a}}$ & Applied pressure \\
\hline$P_{\mathrm{L}}$ & Laser power \\
\hline$R, R_{\mathrm{s}}, R_{\mathrm{p}}$ & Reflectance, for s- and p-polarized light \\
\hline$r_{\mathrm{f}}$ & Fiber radius \\
\hline$r_{\mathrm{r}}$ & Roller radius \\
\hline$r_{\mathrm{x}}, r_{\mathrm{y}}$ & Semi major and semi minor axis \\
\hline$s$ & Fractal number of asperities per generation \\
\hline
\end{tabular}




$\begin{array}{llr}s & \text { Distance from ray point of incidence to node } & {[\mathrm{m}]} \\ T & \text { Temperature } & {[\mathrm{K}]} \\ T & \text { Transmittance } & {[-]} \\ T_{\mathrm{N}} & \text { Nip-point temperature } & {[\mathrm{K}]} \\ T_{\mathrm{tool}} & \text { Tool temperature } & {[\mathrm{K}]} \\ T_{\infty} & \text { Far field temperature } & {[\mathrm{K}]} \\ t & \text { Time } & {[\mathrm{s}]} \\ \Delta t & \text { Time step size } & {[\mathrm{s}]} \\ t_{\mathrm{tape}}, t_{\text {lam }} & \text { Tape and laminate thickness } & {[\mathrm{m}]} \\ u_{\mathrm{l}}, u_{\mathrm{s}} & \text { Velocity of the liquid and solid phase } & {[-]} \\ V_{\mathrm{f}} & \text { Fiber volume fraction } & {[-]} \\ V_{\mathrm{f}}^{\mathrm{c}} & \text { Fiber volume fraction under pressure } & {[-]} \\ V_{0}, V_{\mathrm{f} 0}, V_{\mathrm{a}} & \text { Minimum, initial and maximum fiber volume } & {[-]} \\ & \text { fraction } & {[\mathrm{m} / \mathrm{s}]} \\ v & \text { Placement velocity } & {[\mathrm{m} / \mathrm{s}]} \\ v, v_{\mathrm{x}}, v_{\mathrm{z}} & \text { Velocity, in x and } \mathrm{z} \text { direction } & {[\mathrm{m} / \mathrm{s}]} \\ \mathbf{v} & \text { Velocity vector } & {[\mathrm{m}]} \\ W & \text { Width of the laser spot } & {[\mathrm{m}]} \\ w, w_{0} & \text { Height and initial height of asperities } & {[\mathrm{m}]} \\ w & \text { Tape width } & {[\mathrm{m} / \mathrm{s}]} \\ \dot{w} & \text { Rate of change of tape width } & {[\mathrm{m}]} \\ w_{\mathrm{i}}, w_{\mathrm{f}} & \text { Initial and final tape width } & {[\mathrm{m}]} \\ x, y, z & \text { Cartesian coordinates } & {[\mathrm{m}]} \\ x_{\mathrm{L}}, y_{\mathrm{L}} & \text { Coordinates defining the position of the laser } & {[\mathrm{m}]} \\ y_{\mathrm{r}} & \text { Vertical distance between roller center and substrate } & {[\mathrm{m}]} \\ z_{\mathrm{D}}, z_{\mathrm{I}} & \text { Dry and impregnated fiber bed thickness } \\ z_{\mathrm{imp}} & \text { Impregnation distance } & {[\mathrm{m}]}\end{array}$




\section{Abbreviations}

$\begin{array}{ll}\text { AFP } & \text { Automated fiber placement } \\ \text { ATL } & \text { Automated tape laying } \\ \text { C/PEEK } & \text { PEEK with carbon fiber reinforcements } \\ \text { C/PPS } & \text { PPS with carbon fiber reinforcements } \\ \text { DOE } & \text { Design of experiments } \\ \text { IR } & \text { Infrared (thermal) camera } \\ \text { LAFP } & \text { Laser assisted fiber placement } \\ \text { PEEK } & \text { poly(ether ether ketone) } \\ \text { PEKK } & \text { poly(ether ketone ketone) } \\ \text { PI } & \text { poly(imide) } \\ \text { PPS } & \text { poly(phenylene sulfide) } \\ \text { PTFE } & \text { poly(tetrafluoroethylene) } \\ \text { RMS } & \text { Root mean square } \\ \text { SEM } & \text { Scanning electron microscope } \\ \text { TC } & \text { Thermocouple } \\ \text { UD } & \text { Unidirectional }\end{array}$




\section{Chapter 1}

\section{Introduction}

\subsection{Background}

The aerospace industry is continuously striving to reduce fuel consumption and to improve the performance of commercial aircraft. A reduction in structural weight is key to achieving both. The higher specific properties of composites, in comparison with metals, are attractive in the development of optimized lightweight structures. A significant part of the metal structures of the previous generation of commercial aircraft has been replaced with lighter composite counterparts in the latest generation. This has resulted in composites accounting for over $50 \%$ of the aircraft weight of the recent Boeing 787 and the Airbus A350 [1, 2]. These composite structures, in combination with more efficient engines and improved aerodynamics, have led to a new generation of aircraft with a significantly reduced fuel consumption and increased performance.

Currently, mainly composites based on carbon fiber reinforced thermoset polymers are being used. This type of composites is characterized by long production cycle times, limited shelf life and non-recyclability. However, higher production rates are required to satisfy the growing global demand of aircraft, and these can only be achieved with reduced cycle times [3]. In recent decades, thermoplastic composites have been developed into a feasible competitor for thermoset composites [3-5]. This type of composite is processed by softening the matrix by heating, followed by consolidation and cooling. As such, no curing of the matrix is required, allowing for short cycle times. Additionally, the suitability for automation, near infinite shelf life of the raw material and no requirement for refrigerated storage, further reduce production costs. Furthermore, the higher fracture toughness and the possibility of welding and recycling are other advantages of thermoplastic over thermoset based composites [4]. 
Thermoplastic components are already being used for structural applications in aircraft [6]. The advantages of thermoplastic composites are utilized for small components, such as the thousands of stamp formed clips used in the A350 [7]. The size of these components is, however, limited and other manufacturing technologies are required to manufacture large sized components.

Laser Assisted Fiber Placement (LAFP) is a promising automated manufacturing technique for large thermoplastic composite structural components. The fact that thermoplastic composites do not require a cure cycle can be fully capitalized by consolidating the plies during placement. Full consolidation during placement, termed in-situ consolidation, would be the ultimate goal in composite manufacturing of large structures, as a costly post-consolidation step can be omitted. Furthermore, LAFP can be considered as an additive manufacturing technique offering possibilities of improving part performance by tailoring of the lay-up, curvilinear fiber paths or local stiffening, which are not all possible by traditional manufacturing techniques. The potential of the technology for manufacturing large structures has been demonstrated in projects such as TAPAS2, in which a pylon spar was made, and the Arches Box TP project in the CORCAC platform, where a fuselage section was developed, both shown in Figure 1.1. In-situ consolidation was, however, not achieved in these projects and a costly post-consolidation step was required to achieve a sufficiently high consolidation quality.

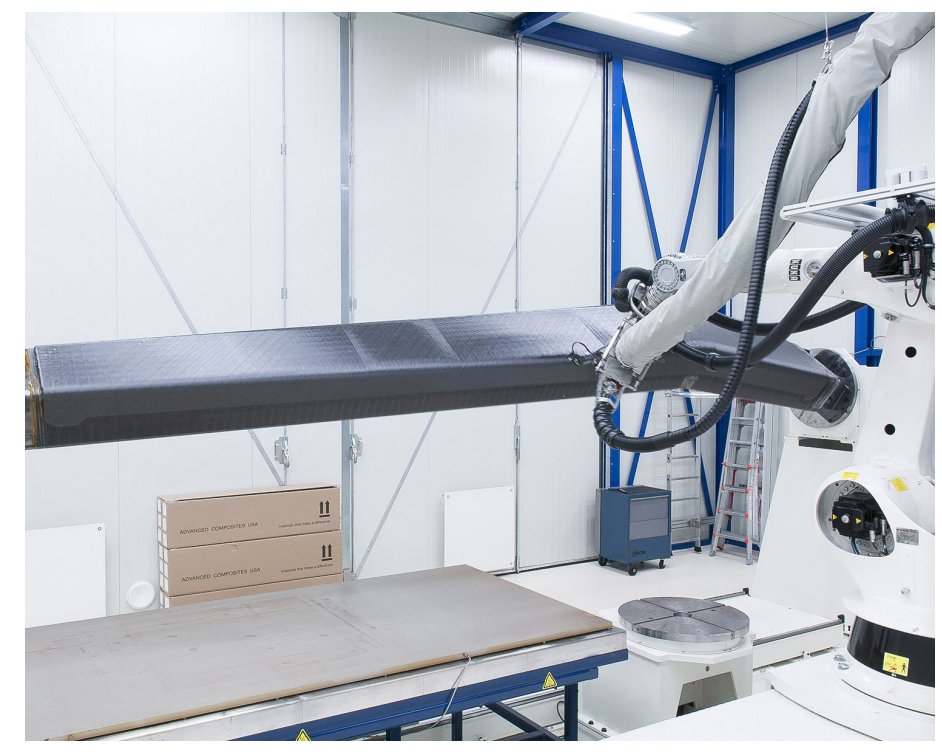

(a)

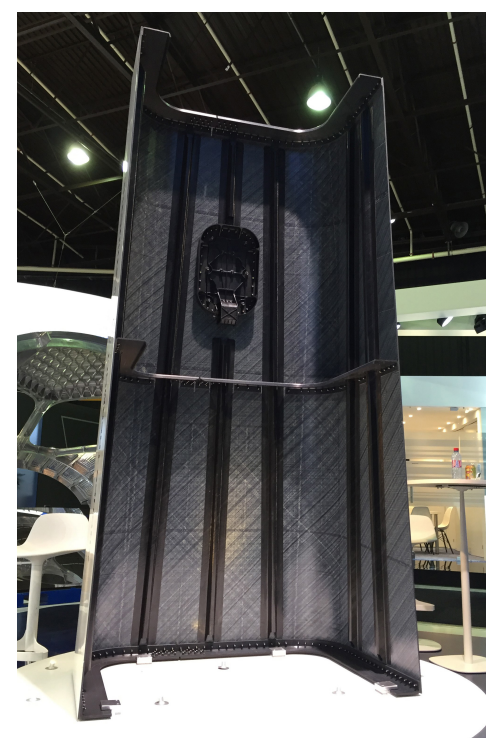

(b)

Figure 1.1 Demonstrators of large structural components made by LAFP. (a) Pylon upper spar developed in the TAPAS2 program (copyrights NLR) [8]. (b) The Arches Box TP fuselage demonstrator developed in the CORAC platform (source: JEC composites) [9].

The mechanical performance of thermoplastic composite structures depends on 
the achieved consolidation quality. The achieved quality is defined by a number of measures, such as the void content, the dimensional accuracy, the degree of crystallinity and the interlaminar bond strength. In-situ consolidation is difficult to achieve, especially at the required production rates for large parts with a complex geometry. This is illustrated by the fact that it has been under research for more than 30 years, but not yet commercially applied in aerospace. Several challenges still exist in order to obtain sufficient consolidation quality.

\subsection{Laser assisted fiber placement}

Laser assisted fiber placement is an additive manufacturing technique for thermoplastic composites. A thermoplastic composite prepreg tape is heated above its melting temperature using a laser and subsequently pressurized using a roller, as is shown in Figure 1.2. The melted tape is bonded and consolidated with previously placed plies under the applied pressure, thereby building up a part ply-by-ply. The setup, shown schematically in Figure 1.2, is mounted on a robot, which allows for the manufacturing of large complex structural components. The process is closely related to tape winding and Automated Tape Laying (ATL) techniques, collectively known as Automated Fiber Placement (AFP) processes. Hot gas torches used to be the most common heat source for AFP processes, though current developments focus on laser as a heat source. The higher energy density and better controllability offered by laser are beneficial for process control and productivity [10].

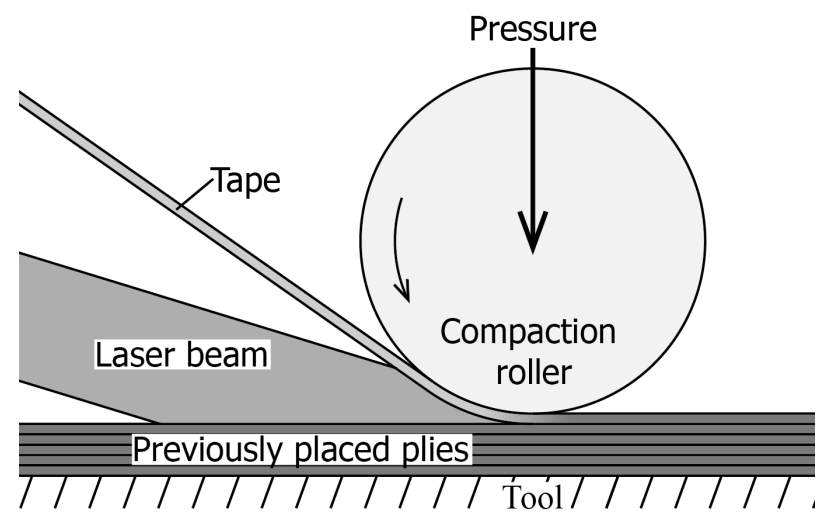

Figure 1.2 Schematic illustration of the LAFP process.

In traditional thermoplastic composite manufacturing techniques, such as press or autoclave consolidation, the material is stacked and subsequently the complete component is heated above the melting temperature. Pressure is applied for more than ten minutes to consolidate the component after which it is cooled slowly. These techniques are characterized by low heating and cooling rates and long consolidation 
times. Moreover, pressure is applied on the complete component. The manufacturing time is considerably reduced in techniques such as press-forming, where a laminate is heated and quickly formed by the application of pressure. The size of press-formed components, however, is limited. LAFP has a high potential for larger thermoplastic composite structures, especially when the material can be consolidated in-situ during placement. At high deposition rates, this requires high heating and cooling rates, while only tenths of a second are available for consolidation as heat and pressure are applied locally. The LAFP robot used in this thesis, for example, allows for a heating and a consolidation time of around $0.25 \mathrm{~s}$ at a placement rate of $100 \mathrm{~mm} / \mathrm{s}$, which reduces even further at higher placement rates. Nevertheless, the same high quality, in terms of interlaminar bond strength, void content, degree of crystallinity and residual stresses, required for aerospace application has to be obtained.

The consolidation process is governed by a number of physical mechanisms to achieve the final consolidation quality. These mechanisms affect the state of the tape during the process. The process can be divided into three phases, namely heating, consolidation and release. Figure 1.3 gives an overview on the currently accepted description of the governing mechanisms during these three phases in AFP, based on the available literature. To illustrate the acting mechanisms, a piece of tape is followed through the phases of the process of consolidation.

\section{Heating phase}

The tape enters the heating phase, where it is heated by the laser, with the as-received consolidation state. The heat input depends on the intensity, local incidence angle and wavelength of the light and the optical properties of the material [11]. In the case of carbon fibers and a diode laser, the heat is absorbed by the fibers at the surface and conducted into the tape and substrate. At the end of the heating phase the tape temperature should exceed its melting temperature to ensure bonding in the subsequent consolidation phase.

Voids and volatiles present in the tape can expand, as the tape is heated without pressure [12]. Furthermore, the matrix in the tape can degrade, which can involve chain scission and cross-linking, in case the tape is overheated [13, 14]. Overheating should be avoided as the induced degradation will hinder bonding and reduce part performance.

At the end of the heating phase, just prior to entering the nip-point, the tape is heated above its melting temperature. The tape consolidation state may have changed, as the void fraction may have increased and the matrix may have degraded. 


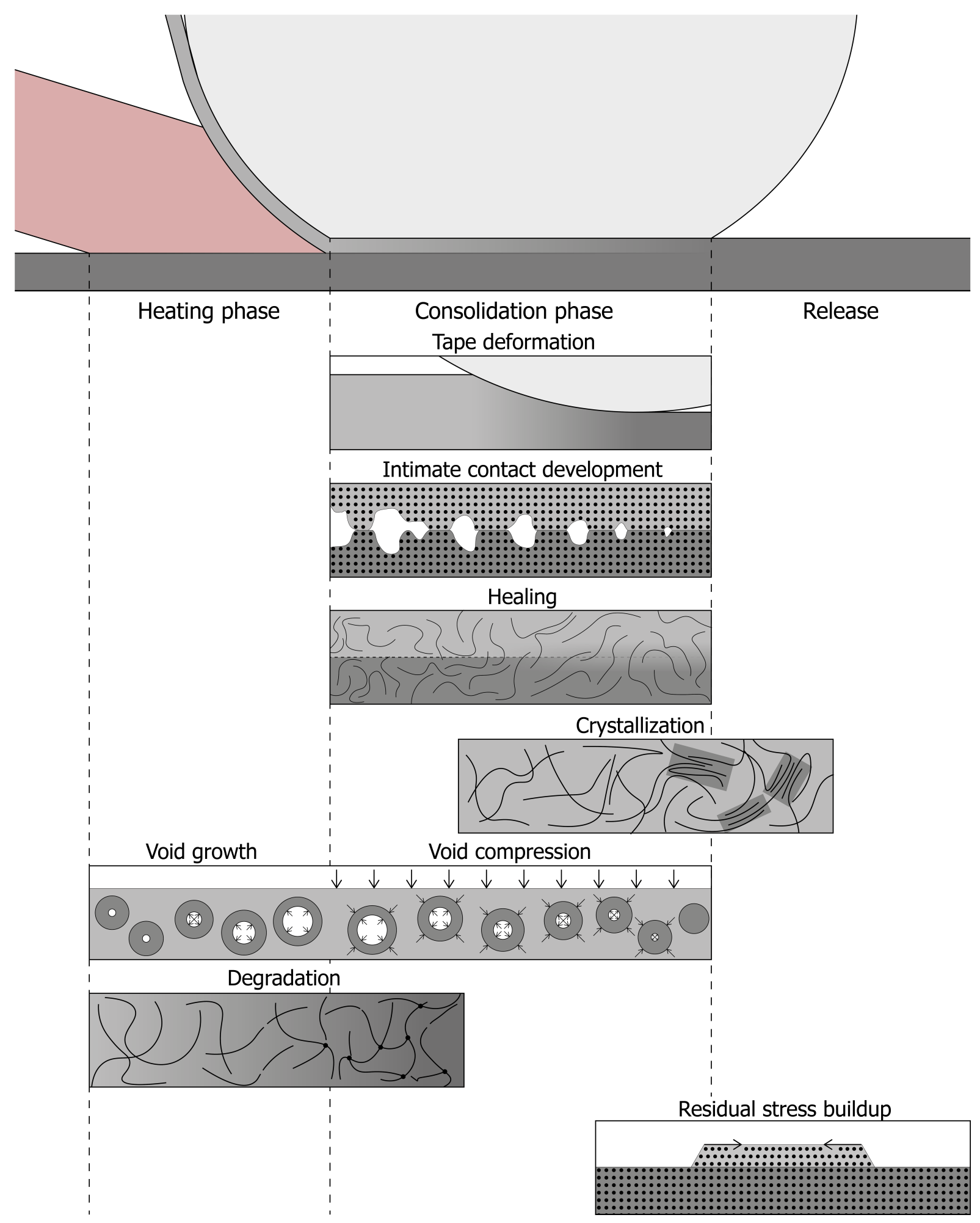

Figure 1.3 An overview of the established description of the governing mechanisms during LAFP.

\section{Consolidation phase}

The melted tape is brought into contact with the previously placed plies, which also have been heated above their melting temperature by the laser, at the nip-point. No 
more heat is applied in the consolidation phase, while pressure is applied by the compaction roller. Asperities on the tape surface are flattened under the applied pressure and intimate contact is created between the tape and previously placed plies [15-17]. Where intimate contact has been achieved, polymer chains can diffuse across the interface, gradually dissolving the interface and bonding the tape to the substrate [18-21]. Furthermore, the expanded voids inside the tape as well as voids in previously placed plies may migrate, coalesce, or be compressed as a result of the applied pressure $[22,23]$. The tape is also deformed under the applied pressure, which is described by transverse squeeze flow [22].

Besides, the tape cools down underneath the roller, as a result the viscosity increases and the matrix solidifies. Consequently, intimate contact development, healing and void compression are inhibited. The matrix may crystallize, in case of a semicrystalline matrix, depending on the observed cooling rates [16, 24, 25]. Furthermore, thermal residual stresses are build up in the tape, since the material is only heated locally and due to the anisotropic nature of the thermal expansion of the composite tape [26].

Ideally, the tape should be fully consolidated at the end of the consolidation phase. It should have a near zero void content and should be perfectly bonded with the underlying plies.

\section{Release}

No more pressure is applied after the contact between the tape and the roller is released. The tape and underlying plies should have cooled down sufficiently underneath the roller to prevent void growth after release of contact with the roller. The crystallization and the build-up of thermal stress continue in the cooling phase, depending on the temperature at release.

\section{Final quality}

In-situ consolidation requires that sufficient consolidation quality is achieved during placement. The void content should be near zero, while complete bonding and full crystallization are achieved. Furthermore, degradation needs to be prevented and the thermal stresses are at a minimum. Currently, however, this can not be achieved at high placement rates, and complex structures make it even more difficult to achieve in-situ consolidation, and a post-consolidation step is required to improve the consolidation quality. Though all quality measures should be fulfilled, the void content limit is the most stringent requirement for certification of in-situ 
consolidation for the aerospace industry. Therefore, this thesis focuses on the void development during LAFP.

\subsection{Void development during LAFP}

Voids are defined as pockets of gas enclosed in a composite [27]. Within this loose definition, different types of voids of varying origins can be considered. Figure 1.4 shows schematically the void types that are considered in LAFP in this work, namely intralaminar, interlaminar and intertape voids. Intralaminar voids are voids within plies, originating mainly from voids already present in the as-received prepreg tape material. These voids are difficult to remove with the LAFP process due to the limited time available [28]. Interlaminar voids are voids between plies and originate from the LAFP process, although their occurrence also depends on the as-received tape morphology. These voids may be caused partially by incomplete intimate contact development during consolidation. Overlaps, tapes placed too close together, hinder a uniform pressure distribution and intimate contact development resulting in an increase in interlaminar void content. Intertape voids are the results of gaps, which are tapes placed too far apart.

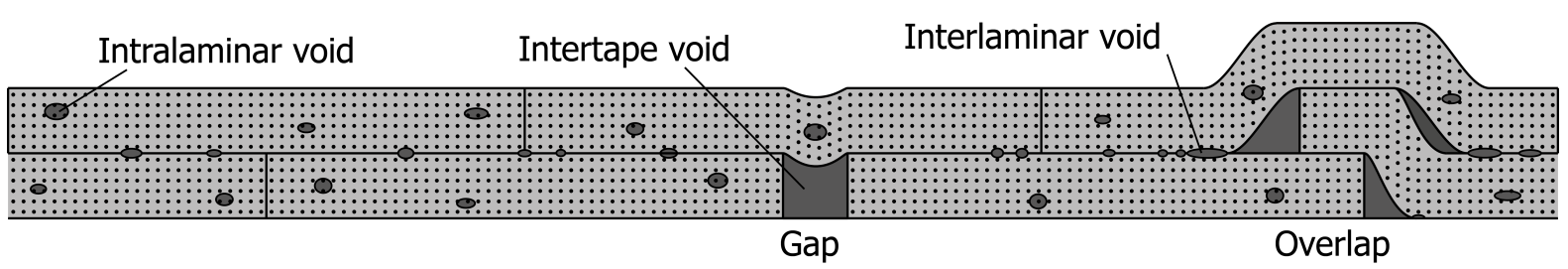

Figure 1.4 Types of voids in LAFP laminates

The intralaminar void content has been reduced over the past decades, due to the improved quality of the as-received tape, with a low initial intralaminar void content, uniform fiber distribution and smooth surfaces [4]. It was expected that smooth surfaces would promote intimate contact development and hence prevent creation of interlaminar voids [28]. Interlaminar voids, however, are still apparent in AFP laminates despite the smooth tapes [29]. More research into the physical mechanisms of intimate contact development is required to explain this.

Gaps introduce intertape voids, while overlaps hinder intimate contact development of subsequent plies [30]. Furthermore, the resulting surface irregularities of gaps and overlaps can cause local overheating. Therefore, each tape needs to be positioned correctly in order to prevent gaps and overlaps. As well as to accurate positioning of the tapes by the machine and consistent width of the tape material, the deformation of the tape during the process is required to avoid formation of gaps and overlaps. 


\subsection{Motivation}

The ultimate goal of the industry for AFP is to obtain in-situ consolidation at a commercially attractive placement velocity. This would reduce production costs, while increasing the productivity, and allow for further improvement of the performance of composite components by tailoring the layup and geometry. In previous sections an overview was given on the current description of the mechanisms governing in-situ consolidation. As an extension to these mechanisms, Table 1.1 provides an overview of the literature evaluating the effect of each phase of the process on the final quality. Unsurprisingly, most research focused on the effects of the consolidation phase on the obtained quality. Little attention has been paid to possible effects of the heating phase on consolidation.

Table 1.1 Overview of the available literature investigating the effect of the different phases on the obtained consolidation quality. A plus sign (+) indicate that literature is available. A cross $(\times)$ indicates that no effect is expected. A minus sign (-)indicates that there is no literature available while an effect is to be expected.

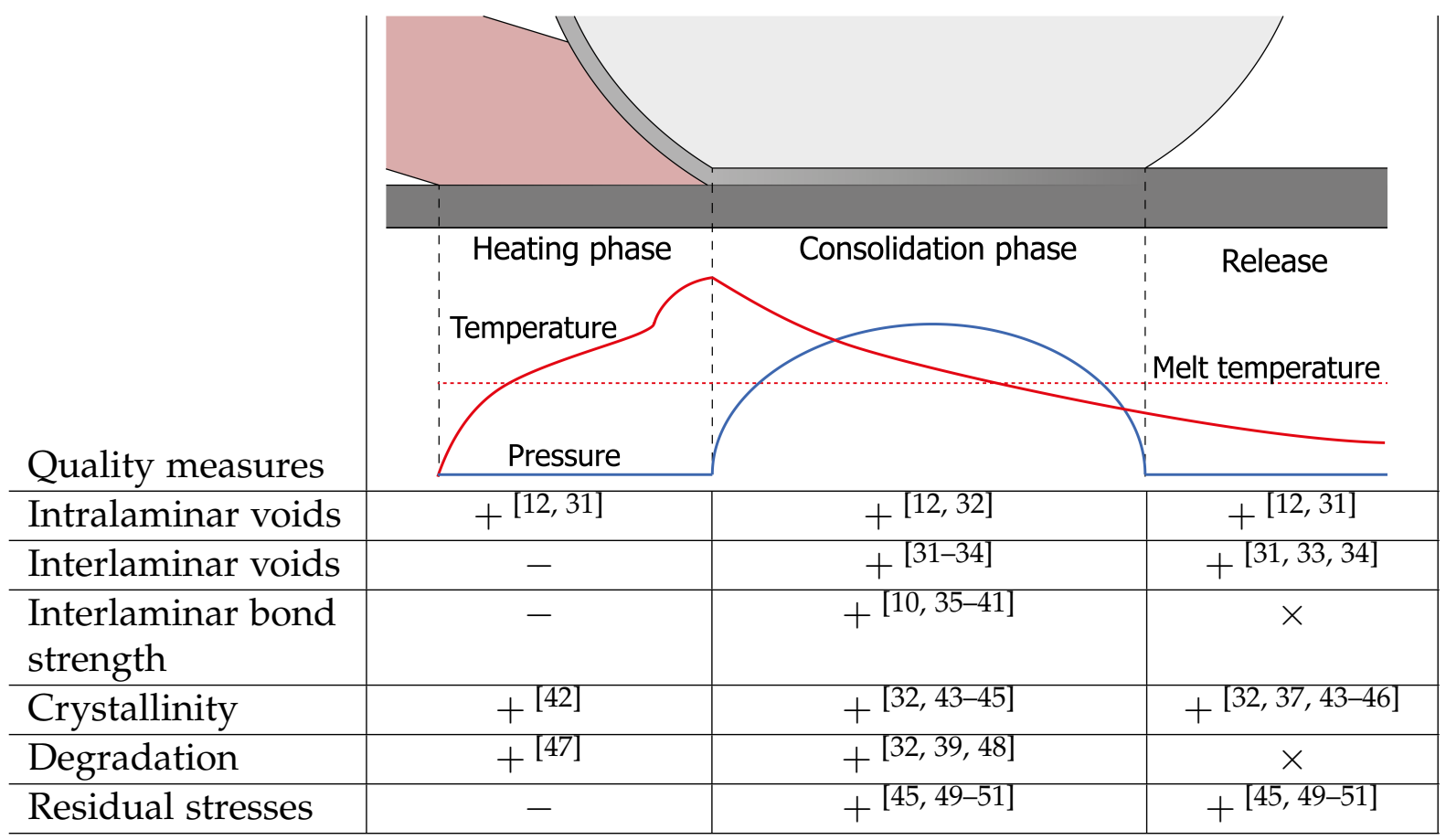

\subsection{Objective and scope}

The objective of this thesis is to identify and quantify the effects of the heating phase on the state of the thermoplastic tape and its consequences for subsequent void development. It is aimed to better describe the evolution of interlaminar voids, in 
order to improve the in-situ consolidation quality. Although the substrate plays an important role, the focus of this thesis is on the tape.

Several areas require attention to reach this objective. Before any consolidation mechanism can be researched, a thermal model is required to analyze the effects of several machine parameters on the temperature distribution and to obtain correct input for the consolidation models. Experiments should be performed to investigate the mechanisms governing interlaminar void occurrence. First an experimental procedure is needed to obtain the consolidation state of the tape after the heating phase, just prior to the nip-point. Second, the intimate contact development as a function of process parameters has to be investigated. Finally, the shape and size of the tape after placement may lead to gaps and overlaps with interlaminar voids as a result. Hence, also the tape deformation should be studied experimentally. The experimental observations form the basis to re-evaluate the currently established governing mechanisms involved in LAFP.

The consolidation is considered only for flat plates in this work. LAFP can be used for complex geometries and tailoring of laminates, with for example fiber steering, and these will affect the consolidation process. They are not considered here, however, the obtained knowledge can be applied to solve the problems induced by complex fiber placement.

The experimental work in this thesis was performed with carbon fiber reinforced poly(etheretherketone) (PEEK), which is a high-grade thermoplastic composite used in aerospace industry. The work was performed using a single tow Coriolis Composites LAFP robot, equipped with a $1 \mathrm{~kW}$ laser.

\subsection{Outline}

A schematic outline of the thesis is shown in Figure 1.5. The core consists of four chapters, three of which are reproduced from research papers. Consequently, some of the essential information is repeated in several chapters and the author apologizes for any inconvenience caused by the chosen format. However, this format enables for each chapter to be read independently while the work is put in a wider perspective in this thesis.

A thermal model developed for the Coriolis Composites end-effector is presented in Chapter 2. The presented model consists of a machine-specific geometrical, an optical and a heat transfer sub-model. The former is specifically developed for the Coriolis Composites end-effector including essential features such as orientation and position 


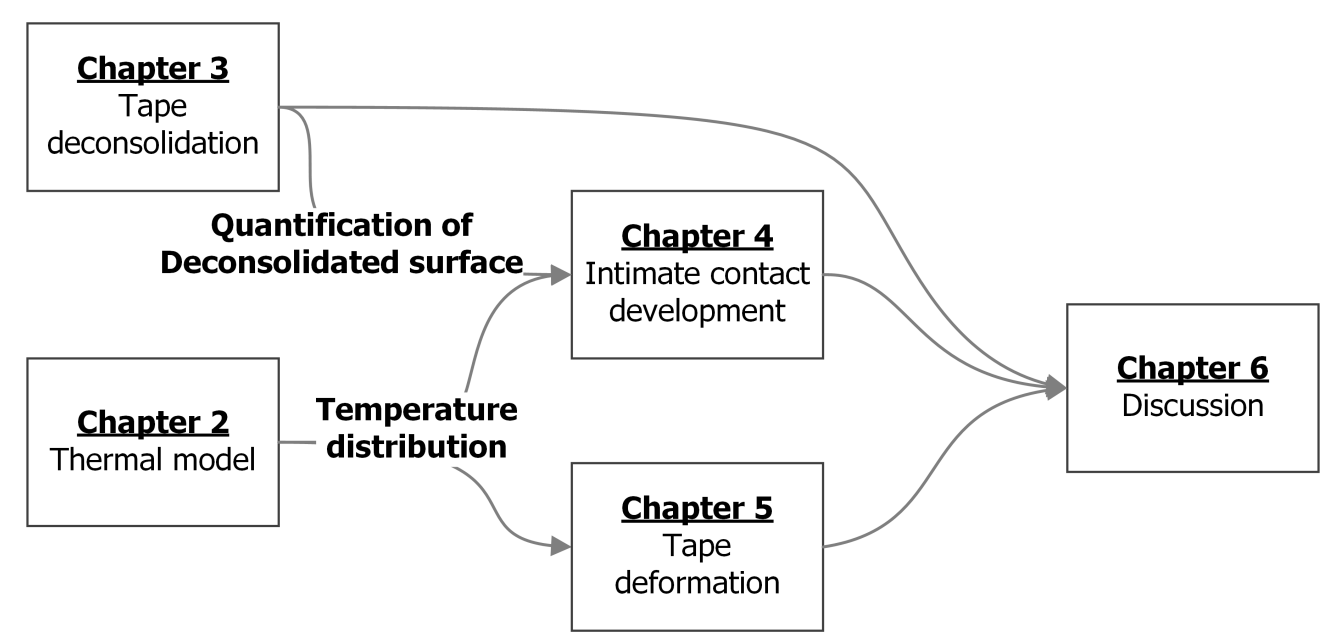

Figure 1.5 Outline of the thesis

of the laser as well as a deformable roller. The latter two are based on literature. Although the thermal model is based mainly on models presented in literature, it is indispensable in research of the LAFP process.

An experimental methodology was developed to investigate tape deconsolidation during the heating phase of LAFP. The method and results are described in Chapter 3. It is shown that the tape deconsolidates prior to reaching the nip-point. The result is a rough and fiber rich tape surface. A quantitative description of the deconsolidated tape in terms of fiber, matrix and void distribution is obtained based on image analysis of cross-sectional micrographs.

Intimate contact development is researched in Chapter 4. A set of experiments has been performed to find the key parameters affecting the obtained degree of intimate contact. The degree of intimate contact is estimated based on cross-sectional micrographs. It is proposed that intimate contact development comprises not only deformation of surface asperities but also percolation flow of matrix to wet the tape surface.

A predictive model for tape deformation is required in the prevention of gaps and overlaps. Chapter 5 describes an experimental research focused on tape deformation as a function of process parameters. It is shown that tape deformation is mainly a function of temperature and that the applied pressure hardly affects the deformation. Current transverse squeeze flow models are incapable of predicting the tape deformation correctly. An attempt is made to develop a new physics-based tape deformation model, which takes spreading induced fiber stresses into account.

In Chapter 6 the results of the previous chapters are combined to advance the 
description of the governing mechanisms in AFP. Furthermore, the experimental results of this thesis will be discussed in a broader perspective. Finally, the main conclusions of this thesis and recommendations for future research are presented in Chapter 7 .

\section{References}

[1] J. Hale. Boeing 787 from the ground up. Aero, 4(24):7, 2006.

[2] Airbus website. A350xwb family. URL http://www.airbus.com/aircraft/passengeraircraft/a350xwb-family.html, Retrieved on 1 June 2018.

[3] G. Gardiner. Consolidating thermoplastic composite aerostructures in place, part 1. URL www.compositesworld.com/articles/consolidating-thermoplastic-compositeaerostructures-in-place-part-1, Retrieved on 1 June 2018.

[4] G. Gardiner. PEEK vs. PEKK vs. PAEK and continuous compression molding. URL www.compositesworld.com/blog/post/peek-vs-pekk-vs-paek-and-continuouscompression-molding, Retrieved on 1 June 2018.

[5] G. Gardiner. Thermoplastic composite demonstrators - EU roadmap for future airframes. URL https://www.compositesworld.com/articles/thermoplastic-compositedemonstrators-eu-roadmap-for-future-airframes, Retrieved on 1 June 2018.

[6] G. Gardiner. TPCs on the Boeing 787 and Airbus A350. URL https://www.compositesworld.com/articles/tpcs-on-the-boeing-787-and-airbus-a350, Retrieved on 1 June 2018.

[7] S. Black. Thermoplastic composites "clip" time, labor on small but crucial parts. Composites World, May, 2015.

[8] NLR website. NLR designs large composite aircraft part. URL http://www.nlr.org/news/nlr-designs-large-composite-aircraft-part/, Retrieved on 1 June 2018.

[9] JEC website. Thermoplastic fuselage demonstrator. URL http://www.jeccomposites.com/knowledge/international-composites-news/thermoplasticfuselage-demonstrator, Retrieved on 1 June 2018.

[10] R. Schledjewski and A. Miaris. Thermoplastic tape placement by means of diode laser heating. In Proceedings of the 2009 SAMPE Symposium and Exhibition (SAMPE 2009), volume 54. SAMPE, Baltimore, Maryland, USA, 2009.

[11] C. M. Stokes-Griffin and P. Compston. Optical characterisation and modelling for oblique near-infrared laser heating of carbon fibre reinforced thermoplastic composites. Optics and Lasers in Engineering, 72:1-11, 2015.

[12] J. Tierney and J. W. Gillespie Jr. Modeling of heat transfer and void dynamics for the thermoplastic composite tow-placement process. Journal of Composite Materials, 37(19):1745-1768, 2003. 
[13] M. Day, T. Suprunchuk, J. D. Cooney, and D. M. Wiles. Thermal degradation of poly(aryl-ether-ether-ketone) (PEEK): A differential scanning calorimetry study. Journal of Applied Polymer Science, 36(5):1097-1106, 1988.

[14] J. D. Nam and J. C. Seferis. Generalized composite degradation kinetics for polymeric systems under isothermal and nonisothermal conditions. Journal of Polymer Science Part B: Polymer Physics, 30(5):455-463, 1992.

[15] P. H. Dara and A. C. Loos. Thermoplastic matrix composite processing model. Report, Virginia Polytechnic Institute and State University, 1985.

[16] W. I. Lee and G. S. Springer. A model of the manufacturing process of thermoplastic matrix composites. Journal of Composite Materials, 21(11):10171055, 1987.

[17] S. C. Mantell and G. S. Springer. Manufacturing process models for thermoplastic composites. Journal of Composite Materials, 26(16):2348-2377, 1992.

[18] P. G. de Gennes. Reptation of a polymer chain in the presence of fixed obstacles. The Journal of Chemical Physics, 55(2):572-579, 1971.

[19] L. J. Bastien and J. W. Gillespie Jr. A non-isothermal healing model for strength and toughness of fusion bonded joints of amorphous thermoplastics. Polymer Engineering \& Science, 31(24):1720-1730, 1991.

[20] F. Yang and R. Pitchumani. Nonisothermal healing and interlaminar bond strength evolution during thermoplastic matrix composites processing. Polymer Composites, 24(2):263-278, 2003.

[21] R. P. Wool and K. M. O'Connor. A theory of crack healing in polymers. Journal of Applied Physics, 52(10):5953-5963, 1981.

[22] S. Ranganathan, S. G. Advani, and M. A. Lamontia. Non-isothermal process model for consolidation and void reduction during in-situ tow placement of thermoplastic composites. Journal of Composite Materials, 29(8):1040-1062, 1995.

[23] P. Simacek, S. G. Advani, M. Gruber, and B. Jensen. A non-local void filling model to describe its dynamics during processing thermoplastic composites. Composites Part A: Applied Science and Manufacturing, 46:154-165, 2013.

[24] C. N. Velisaris and J. C. Seferis. Crystallization kinetics of polyetheretherketone (PEEK) matrices. Polymer Engineering \& Science, 26(22):1574-1581, 1986.

[25] A. Maffezzoli, J. M. Kenny, and L. Nicolais. A macrokinetic approach to crystallization modelling of semicrystalline thermoplastic matrices for advanced composites. Journal of Materials Science, 28(18):4994-5001, 1993.

[26] T. J. Chapman, J. W. Gillespie Jr, R. B. Pipes, J.-A. E. Manson, and J. C. Seferis. Prediction of process-induced residual stresses in thermoplastic composites. Journal of Composite Materials, 24(6):616-643, 1990.

[27] US Department of Defense. Composite material handbook Volume 3 Polymer matrix composites materials usage, design and analysis (MIL-HDBK-17-3F ). Boca Raton: CRC Press, 2002.

[28] M. B. Gruber, I. Z. Lockwood, T. L. Dolan, S. B. Funk, J. J. Tierney, P. Simacek, J. W. Gillespie Jr, S. G. Advani, B. J. Jensen, R. J. Cano, and B. W. Grimsley. 
Thermoplastic in situ placement requires better impregnated tapes and tows. In Proceedings of the 2012 International SAMPE Conference and Exhibition (SAMPE 2012). Baltimore, Maryland, USA, 2012.

[29] M. Tannous, A. Barasinski, C. Binetruy, and B. Courtemanche. Contribution of thermo-mechanical parameters and friction to the bonding of thermoplastic tapes in the tape winding process. Journal of Materials Processing Technology, 229:587-595, 2016.

[30] R. Schledjewski and A. K. Schlarb. In-situ consolidation of thermoplastic tape material effects of tape quality on resulting part properties. In Proceedings of the 2007 SAMPE Symposium and Exhibition (SAMPE 2007), volume 52. Baltimore, Maryland, USA, 2007.

[31] M. Di Francesco, M. A. Valverde, C. Ward, P. F. Giddings, G. Dell'Anno, and K. Potter. Influence of layup speed on the quality of thermoplastic preforms manufactured by laser-assisted automated fibre placement. In Proceeding of the 17th European Conference on Composite Materials (ECCM-17). ECCM, Copenhagen, Denmark, 2016.

[32] V. Agarwal, R. L. McCullough, and J. M. Schultz. The thermoplastic laserassisted consolidation process-mechanical and microstructure characterization. Journal of Thermoplastic Composite Materials, 9(4):365-380, 1996.

[33] M. A. Khan and R. Schledjewski. Influencing factors for an online consolidating thermoplastic tape placement process. In Proceedings of the 17th International Conferences on Composite Materials (ICCM- 17). Edinburgh, UK, 2009.

[34] Z. Qureshi, T. Swait, R. Scaife, and H. M. El-Dessouky. In situ consolidation of thermoplastic prepreg tape using automated tape placement technology: Potential and possibilities. Composites Part B: Engineering, 66:255-267, 2014.

[35] M. Brzeski, R. Holschuh, and R. Schledjewski. Effect of tool temperature on laminate properties during in situ consolidation placement process. In Proceedings of the 2010 SAMPE Symposium and Exhibition (SAMPE 2010). Seattle, Washington, USA, 2010.

[36] A. J. Comer, D. Ray, W. O. Obande, D. Jones, J. Lyons, I. Rosca, R. M. O' Higgins, and M. A. McCarthy. Mechanical characterisation of carbon fibrePEEK manufactured by laser-assisted automated-tape-placement and autoclave. Composites Part A: Applied Science and Manufacturing, 69:10-20, 2015.

[37] W. J. B. Grouve. Weld strength of laser-assisted tape-placed thermoplastic composites. Phd thesis, University of Twente, Enschede, The Netherlands, 2012.

[38] W. J. B. Grouve, L. L. Warnet, B. Rietman, H. A. Visser, and R. Akkerman. Optimization of the tape placement process parameters for carbon-PPS composites. Composites Part A: Applied Science and Manufacturing, 50(0):44-53, 2013.

[39] C. M. Stokes-Griffin and P. Compston. The effect of processing temperature and placement rate on the short beam strength of carbon fibre-PEEK manufactured using a laser tape placement process. Composites Part A: Applied Science and 
Manufacturing, 78:274-283, 2015.

[40] M. A. Lamontia and M. B. Gruber. Remaining developments required for commercializing in situ thermoplastic atp. In Proceedings of the International 2007 SAMPE Symposium and Exhibition (SAMPE 2007), volume 52. Baltimore, Maryland, USA, 2007.

[41] J. Tierney and J. W. Gillespie Jr. Modeling of in situ strength development for the thermoplastic composite tow placement process. Journal of Composite Materials, 40(16):1487-1506, 2006.

[42] J. J. Tierney and J. W. Gillespie Jr. Crystallization kinetics behavior of PEEK based composites exposed to high heating and cooling rates. Composites Part A: Applied Science and Manufacturing, 35(5):547-558, 2004.

[43] C. M. Pistor and S. I. Güçeri. Crystallinity of on-line consolidated thermoplastic composites. Journal of Composite Materials, 33(4):306-324, 1999.

[44] M. A. Lamontia and M. B. Gruber. Limitations on mechanical properties in thermoplastic laminates fabricated by two processes: automated thermoplastic tape placement and filament winding. In Proceedings of the 26th SAMPE Europe Conference. Paris, France, 2005.

[45] S. K. Mazumdar and S. V. Hoa. Experimental determination of process parameters for laser assisted processing of PEEK/carbon thermoplastic composites. In Proceedings of the 38th International SAMPE Symposium and Exhibition (SAMPE 1993), volume 38, 189-204. Anaheim, California, USA, 1993.

[46] D. Ray, A. J. Comer, J. Lyons, W. O. Obande, D. Jones, R. M. O. Higgins, and M. A. McCarthy. Fracture toughness of carbon fiber/polyether ether ketone composites manufactured by autoclave and laser-assisted automated tape placement. Journal of Applied Polymer Science, 132(11), 2015.

[47] T. Bayerl, M. Brzeski, M. Martínez-Tafalla, R. Schledjewski, and P. Mitschang. Thermal degradation analysis of short-time heated polymers. Journal of Thermoplastic Composite Materials, 2013.

[48] B. K. Fink, J. W. Gillespie Jr, and N. B. Ersoy. Thermal degradation effects on consolidation and bonding in the thermoplastic fiber-placement process. Report, DTIC Document, 2000.

[49] S. Van Hoa, M. Duc Hoang, and J. Simpson. Manufacturing procedure to make flat thermoplastic composite laminates by automated fibre placement and their mechanical properties. Journal of Thermoplastic Composite Materials, 30(12):16931712, 2017.

[50] H. Lü, M. Schlottermüller, N. Himmel, and R. Schledjewski. Effects of tape tension on residual stress in thermoplastic composite filament winding. Journal of Thermoplastic Composite Materials, 18(6):469-487, 2005.

[51] M. Schlottermüller, H. Lü, Y. Roth, N. Himmel, R. Schledjewski, and P. Mitschang. Thermal residual stress simulation in thermoplastic filament winding process. Journal of Thermoplastic Composite Materials, 16(6):497-519, 2003. 


\title{
Chapter 2
}

\section{Thermal modeling of Laser Assisted Fiber Placement}

\begin{abstract}
The governing mechanisms for consolidation during Laser Assisted Fiber Placement (LAFP) are dictated by the pressure and temperature distribution. The temperature distribution during the process is a function of a number of process settings and a thermal model is, therefore, essential for the analysis of the LAFP process. A thermal model consisting of a geometrical, an optical and a heat transfer sub-model has been developed for the Coriolis Composites end effector. The geometrical sub-model incorporated specific features such as the adjustable laser and the deformable roller. An experimental validation was performed and showed that the model is capable of predicting the temperature distribution during the process reasonably accurately.
\end{abstract}




\subsection{Introduction}

Laser Assisted Fiber Placement (LAFP) is an additive manufacturing technique for thermoplastic composites. A pre-impregnated tape is heated using a laser and subsequently pressurized using a compaction roller to consolidate the tape with previously placed plies. The consolidation quality is determined by the governing mechanisms, such as intimate contact development, void consolidation and healing, which are a function of the temperature as well as the pressure distribution. The LAFP process involves a great number of process settings affecting the temperature distribution and the effects of these settings are often interrelated. Therefore, a thermal model is required to evaluate the effect of single or multiple parameters on the temperature distribution. Moreover, the temperature distribution underneath the roller is required as an input for the consolidation models to predict the obtained consolidation quality.

Numerous models have been developed to predict the temperature distribution during the fiber placement process and the comparable tape winding process. The complexity of the models used varies, based on the purpose and requirements of the output of the thermal model. Essentially, all these models solve the energy balance of the system, but differ in the simplifying assumptions, the applied boundary conditions and solution methodology. Although analytical solutions are available, finite element and finite difference solutions are more common [1]. Generally, a 1D transient finite difference model to obtain the steady state temperature distribution during the process is used, as this is relatively easy to implement and is reasonably accurate [2-5]. More advanced 2D steady state finite difference [6] and finite element [7-9], and 3D finite element models [10,11] have also been developed. In terms of boundary conditions, the tool and roller are usually modeled as convective boundaries, for which a wide range of effective convective heat transfer coefficients are used [10,12,13]. Most models have been developed for the AFP process using hot gas as heat source and usually employ a constant convective heat transfer coefficient $[11,12]$. Laser heating has been modeled only by a limited number of researchers by either using a 2D or 3D ray-tracing model $[5,7,10,14]$, while others assumed a uniform heat influx $[6,8]$. A ray-tracing model is shown to be essential to be able to accurately model the temperature distribution in the material.

The complex geometry near the nip-point determines the absorption of the laser light and, thereby, the temperature distribution during the process. A ray-tracing model is required to correctly predict the incident heat flux, which requires a correct geometrical description of the nip-point area, i.e. the roller shape. The geometry of compliant rollers, which are mostly used since these are beneficial in terms of consolidation [15], is a function of the stiffness of the roller and the 
applied compaction force. Consequently, another process parameter affecting the temperature distribution during LAFP is added [16].

A thermal model is indispensable in the assessment of the governing consolidation mechanisms during LAFP. Moreover, a thermal model is convenient to easily analyze the effect of process settings on the temperature distributions for experimental research and process optimization. For this purpose, a thermal model was specifically developed for the Coriolis Composites LAFP robot to incorporate the specific features, such as an adjustable laser and deformable roller. The roller shape was obtained experimentally as a function of the roller stiffness and compaction force, which has not yet been applied in literature. The effect of roller shape on the temperature distribution is significant as will be shown in this Chapter. Furthermore, an experimental validation has been performed to assess the accuracy of the temperature distributions predicted by the model.

\subsection{Combined model}

The proposed model was developed specifically for the Coriolis Composites LAFP machine, which was used for the work presented in this thesis. It was developed in Matlab and an overview of the modeling approach, including the most important input parameters, is given in Figure 2.1. The first sub-model is a geometrical model. The position and orientation of the laser with respect to the roller center are determined, based on the machine settings used. Furthermore, the shape of the deformable roller, to define the nip-point geometry, is specified based on the compaction force and the stiffness of the roller. The second sub-model is a $2 \mathrm{D}$ ray-tracing model, which is used to calculate the incident heat flux based on the position and orientation of the roller and the geometry determined near the nippoint. Finally, the temperature distribution is calculated with a $1 \mathrm{D}$ heat transfer model, which is solved using a finite difference method. The geometric model is machine-specific, while the optical and thermal model are applicable to any laser assisted fiber placement machine and are taken from literature. The following sections will elaborate on the geometrical model. The optical and heat transfer model are commonly used and only shortly discussed, while a more elaborate description is given in Appendix 2.A and 2.B. 


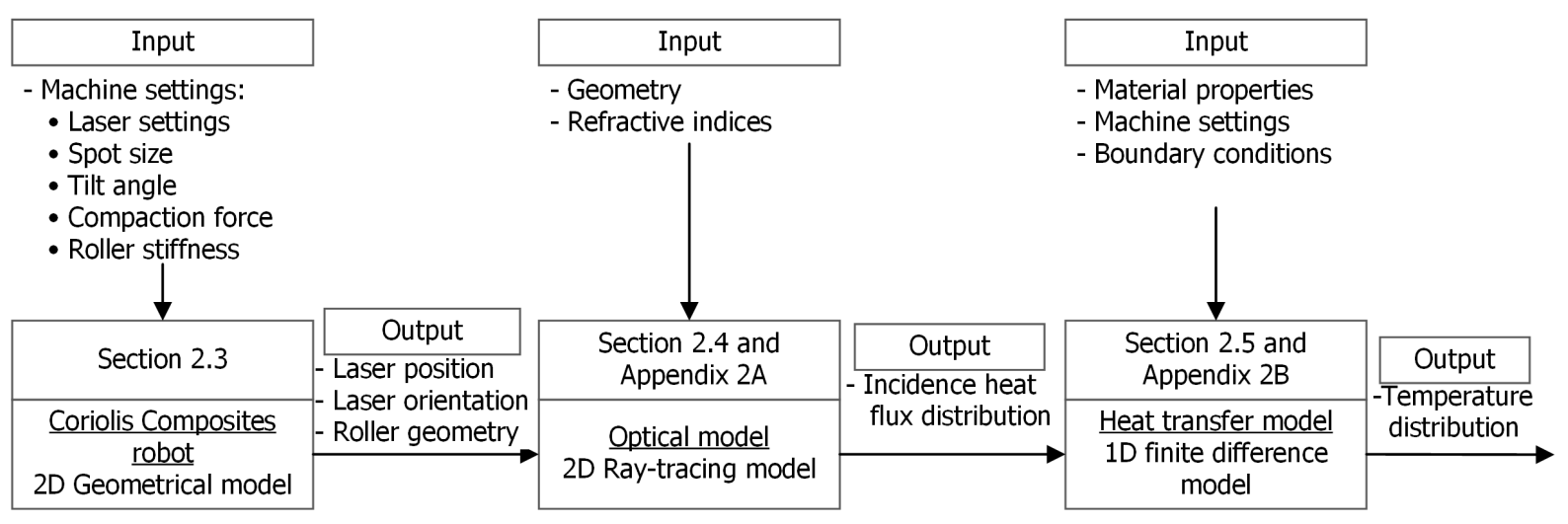

Figure 2.1 Flow diagram of the combined geometrical, optical and thermal model.

\subsection{Geometrical sub-model}

The temperature distribution during LAFP can be altered by changing the position and orientation of the laser. The geometrical sub-model is used to calculate the position and orientation of the laser, based on the geometry of the Coriolis Composites machine and the process settings used. The machine allows for adjusting the position of the laser optics using a set of linkages. This affects not only the distribution of laser light between the tape and substrate, but also the incident angle of the laser light. Furthermore, the geometry near the nip-point determines the reflection and absorption of the laser light on the tape and the laminate. The geometry of near the nip-point is determined based on the shape of the roller as a function of the roller stiffness and the applied compaction force.

\section{Modeling approach}

The Coriolis Composites LAFP end effector is shown in Figure 2.2(a). The optics of the laser system are supported on the end effector by four connecting linkages, two at each side. The orientation and position of the optics can be altered by changing the inclination of the end effector as a whole or by adjusting the length of the connecting linkages manually. Furthermore, the optics itself can be replaced to change the laser spot size $\mathrm{H}$.

A 2D geometrical representation of the end effector is given in Figure 2.2(b). The center of the roller is used as the origin of the reference frame. The end effector is represented by three points, $p_{1}$ and $p_{2}$ and the roller center $p_{\mathrm{r}}$. The laser optics are represented by a grey box, connected at two hinges, $p_{3}$ and $p_{4}$, with two linkages, $L_{\mathrm{A}}$ and $L_{\mathrm{B}}$, to the points on the end effector. The length of the linkages can be adjusted to displace and rotate the laser optics. Linkage $L_{\mathrm{B}}$ is connected by a hinge on the 
end effector and is free to rotate, while linkage $L_{\mathrm{A}}$ is clamped on the end effector under a fixed angle $\theta_{\text {LA }}$. Furthermore, the inclination of the whole end effector can be adjusted with an angle $\theta_{\text {tilt }}$, as indicated in Figure 2.2(b), termed the tilt angle. The dimensions of the end effector were provided by Coriolis Composites. The position and orientation of the laser, with respect to the roller center, are calculated based on the described geometry, the length of the linkages and the tilt angle.

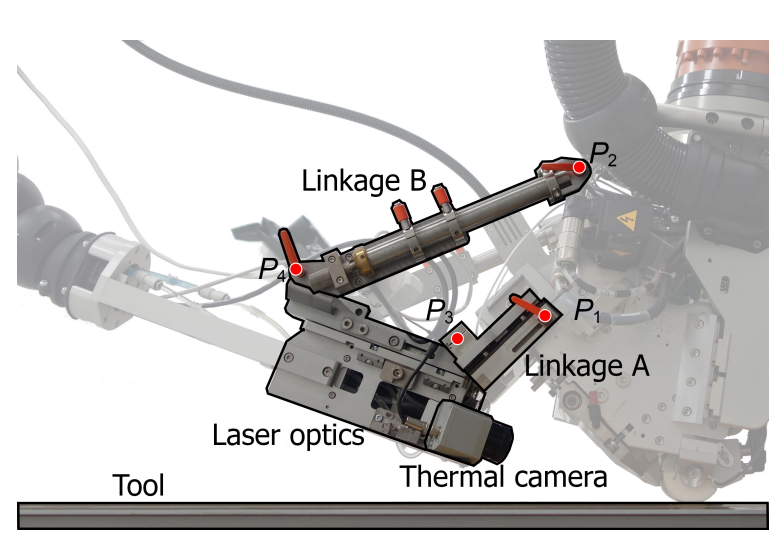

(a)

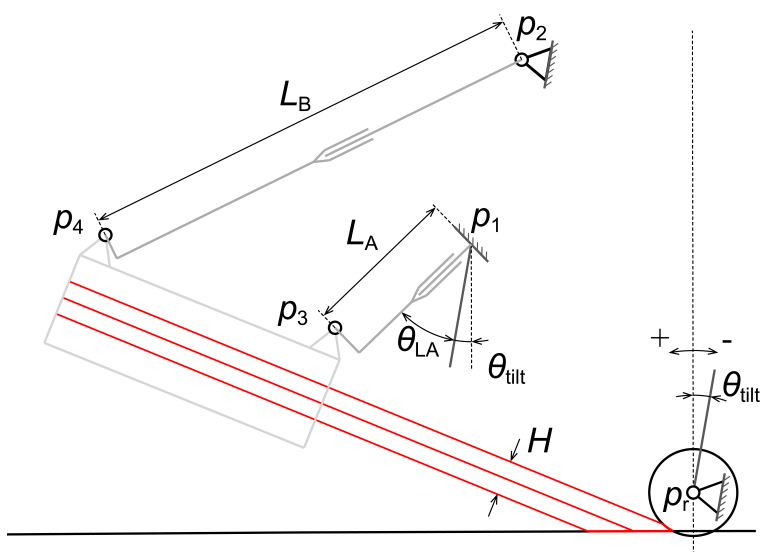

(b)

Figure 2.2 (a) The Coriolis AFP end effector and $(\boldsymbol{b})$ the geometrical representation.

The shape of the roller was determined experimentally utilizing image analysis of pictures for various compaction forces and two rollers with different stiffnesses. It was approximated as a truncated ellipse in order to be able to describe its deformation under the consolidation force. Four variables are used to describe the shape of the roller, as shown in Figure 2.3(a): 1. the vertical distance of the roller center to the tool $y_{\mathrm{r}}, 2$. the semi minor axis $r_{\mathrm{y}}$ and 3 . the semi major axis $r_{\mathrm{x}}$ of the ellipse of the heated side of the roller, and 4 . the contact length $L_{C}$ between the roller and the tool. These were found by fitting an ellipse to the heated side of the roller and by determining the contact length of the roller and the tool. A typical example of one of the measurements is shown in Figure 2.4. The compaction force can be adjusted on the robot from 0 to $1200 \mathrm{~N}$, though calibrations measurements showed that the actual force on the tool is $335 \mathrm{~N}$ higher than the pre-set compaction force on the machine. Two rollers provided by Coriolis Composites with a stiffness of 40 and 60 shore A (sh) were analyzed for a compaction force in a range from 345 to $1535 \mathrm{~N}$ (10 to $1200 \mathrm{~N}$ was set on the machine) and a tilt angle in ranging from -3 to $-10^{\circ}$.

Figure 2.3 shows the results of the analysis of the change in shape of the rollers as a function of the compaction force. The measurements are shown including a linear fit for each of the four variables. No correlation between the shape of the roller and the tilt angle was found and, therefore, the varying tilt angle was ignored in this analysis. 


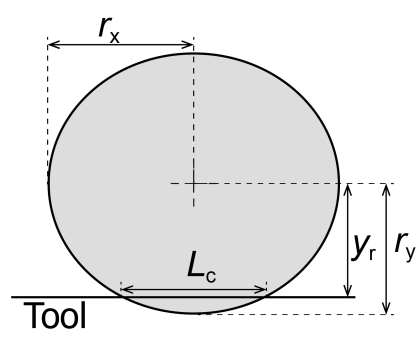

(a)

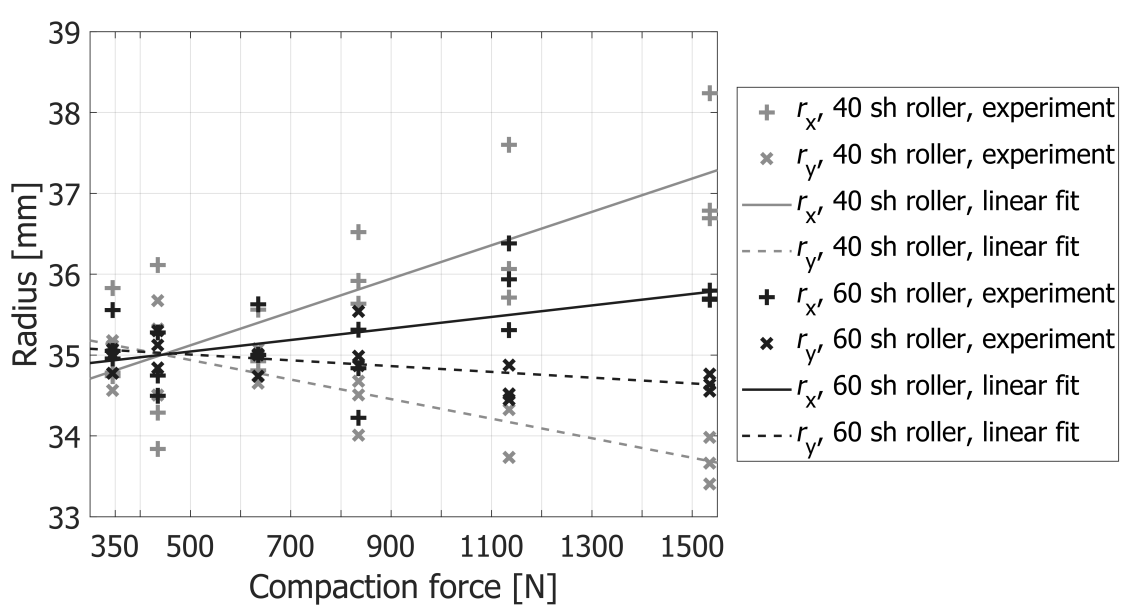

(b)

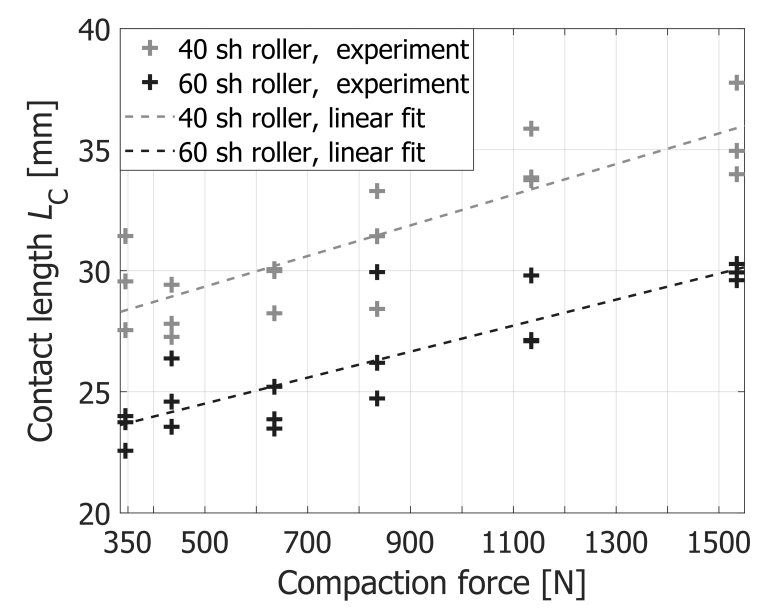

(c)

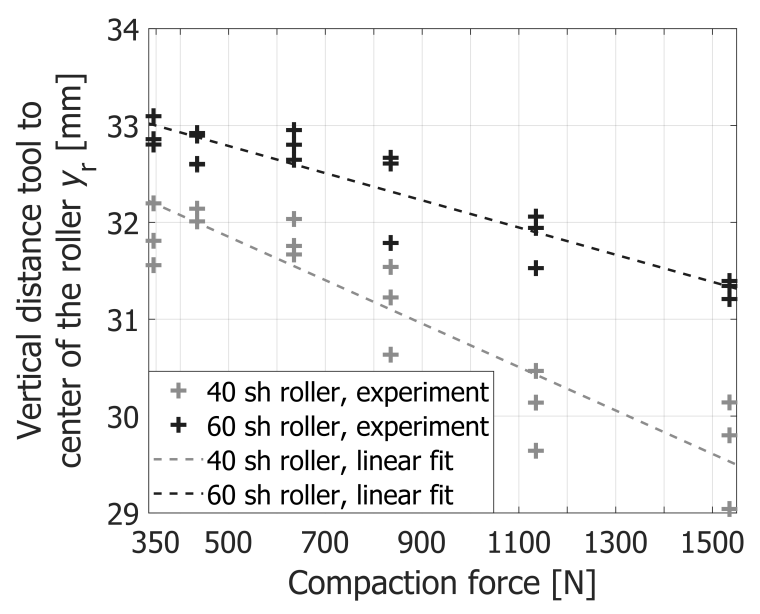

(d)

Figure 2.3 The deformation of the geometry of the roller under the applied pressure. (a) The assumed roller shape and the variables used to define the shape. The deformation as a function of the compaction force for two roller stiffnesses for $(\boldsymbol{b})$ the semi major axis $r_{x}$ and semi minor axis $r_{y},(c)$ the contact length $L_{C}$ and $(d)$ the vertical distance $y_{r}$ between the center of the roller and the tool.

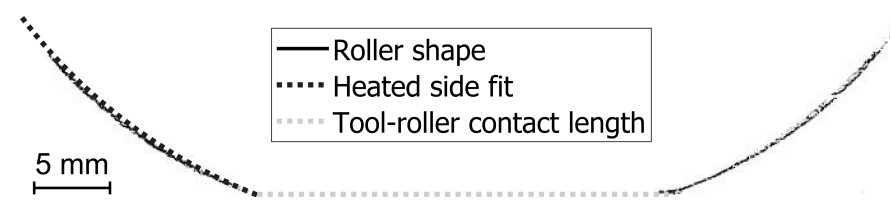

Figure 2.4 Shape of the 60 sh roller at $1135 \mathrm{~N}$, including the fit of the heated side and the contact length.

The 60 sh roller is stiffer than the 40 sh roller and this can be observed in the relation between the compaction force and the shape of the roller. Figure 2.3(b) shows that $r_{\mathrm{x}}$ 
increases and $r_{\mathrm{y}}$ decreases with increasing compaction force and the roller becomes more elliptical with increasing compaction force. This effect is more apparent for the softer 40 sh roller.

Figure 2.3(c) shows the results of the contact length $L_{C}$ of the roller with the tool as a function of the compaction force. The contact length increases with increasing compaction force and the rate is the same for both the 40 and 60 sh roller. This means that pressure is applied for a longer duration during the process and more time is available for consolidation. The average pressure applied does not, however, increase at the same rate as the compaction force, due to the increase in contact length. The pressure can be increased with a stiffer roller, as for the 60 sh roller the contact length is shorter than for the 40 sh roller at the same compaction force. Furthermore, it should be noted the position of the nip-point is not constant and moves with a change in contact length.

Figure 2.3(d) shows the vertical distance from the center of the roller to the tool $y_{\mathrm{r}}$. The distance between the center of the roller and the tool decreases with increasing force, as the roller deforms more under an increasing force. Again the stiffer $60 \mathrm{sh}$ roller deforms less than the 40 sh roller as the distance between the roller center and the tool is larger for the $60 \mathrm{sh}$ roller. The slope is not equal for both rollers as the distance decreases faster for the 40 sh roller. The distance between the roller center and the tool is an important parameter, as the laser optics are on a fixed position with respect to the roller center. Therefore, the position of the laser beam with respect to the tool is a function of the applied compaction force. Although the changes in roller shape seem to be small, it will be shown in Section 2.7 that the effect of roller deformation on the temperature distribution is significant.

\section{Input and output of the geometrical sub-model}

The process settings required as input for the geometrical sub-model are given in Table 2.1 and the possible range of values of the variables is also indicated. The indicated range for the linkages is based on a scale provided on both linkages and does not indicate the total length of both linkages.

Figure 2.5 provides a schematic representation of the output of the geometrical model. The position of the laser beam is defined as an arbitrary point on the center line of the laser beam with coordinates $x_{\mathrm{L}}$ and $y_{\mathrm{L}}$ with respect to the center of the roller. Furthermore, the laser orientation $\theta_{\mathrm{L}}$ as well as the geometry of the compaction roller are provided. 
Table 2.1 Machine settings required as input for the geometrical model.

\begin{tabular}{lccc}
\hline \multicolumn{4}{c}{ Geometrical model input parameters } \\
Parameter & Symbol & Unit & Range \\
\hline Linkage A & $L_{\mathrm{A}}$ & {$[\mathrm{mm}]$} & $0-50$ \\
Linkage B & $L_{\mathrm{B}}$ & {$[\mathrm{mm}]$} & $0-54$ \\
Spot size & $H$ & {$[\mathrm{~mm}]$} & 16 and 28 \\
Tilt angle & $\theta_{\mathrm{tilt}}$ & {$\left[{ }^{\circ}\right]$} & $-15-0$ \\
Compaction force & $F_{\mathrm{C}}$ & {$[\mathrm{N}]$} & $335-1535$ \\
Roller stiffness & $E_{\mathrm{r}}$ & {$[\mathrm{sh}]$} & 40 and 60 \\
\hline
\end{tabular}

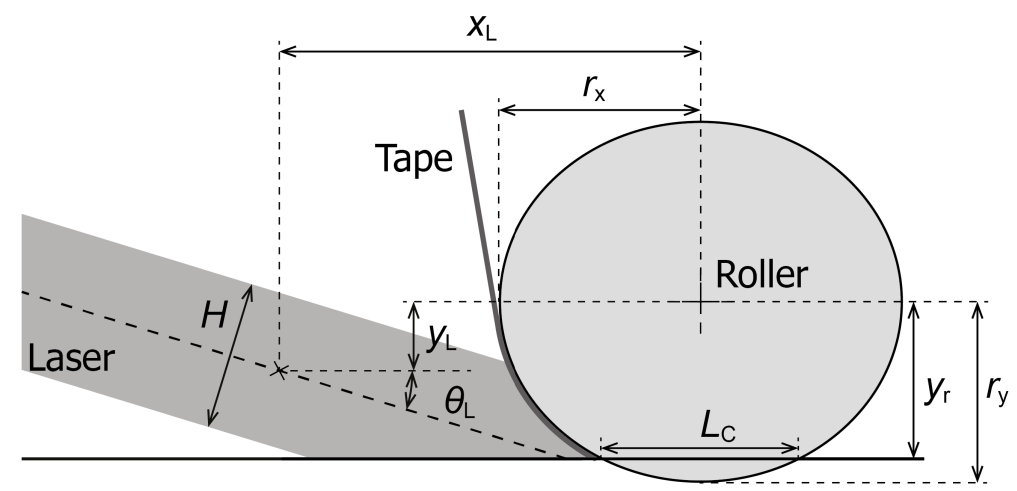

Figure 2.5 Output of the geometrical model: the shape of the roller, the orientation of the laser and the position of the laser as a point on the center line.

\subsection{Optical sub-model}

The first applications of AFP for thermoplastic composites employed hot gas torches to heat the material. Either a constant incident heat flux was assumed or convective models were used to calculate the applied heat $[2,8,11,12]$. Lasers were introduced as a heat source in order to increase the controllability and the heat density, with a view to increasing the process rate [15]. In the case of laser heating, the incident heat flux is not constant near the nip-point, as was assumed by several researchers $[6,8]$. The absorption and reflection of the laser light depends on the local incident angle of the light, and the complex geometry around the nip-point results in a complex incident heat flux distribution. 2D or 3D ray tracing models have been used to calculate the incident heat flux distribution on the tape and the laminate to obtain more accurate temperature predictions $[5,7,10]$. A 2D ray-tracing model was selected for the proposed model. Although 3D models are more accurate, these models are much more computationally expensive while the most important effects can be captured with a $2 \mathrm{D}$ ray-tracing model. As much as 10 million rays required for a 3D model have been reported, while the used 2D model requires only 10 thousand rays for sufficient accuracy [7]. 


\section{Modeling approach}

The optical sub-model uses a 2D representation of the LAFP process, as shown in Figure 2.6. The roller is modeled as an ellipse, while the substrate is modeled as a circle, with a very large radius in the case of flat tooling. The model can also be used for tape winding and curved tooling using this approach. The basis of the optical model is given in this section, while a more comprehensive description is given in Appendix 2.A.

The laser beam is divided into a number of rays, and the path of each ray, with an energy $I$, is traced until it hits either the laminate or the tape, which is shown schematically in Figure 2.6. The local normal is calculated at the incident point and based on the law of reflection and the reflection angle $\theta_{\mathrm{r}}$ equals the incidence angle $\theta_{\mathrm{i}}$. The reflectance $R$ can be calculated using the Fresnel equations, for which the transmittance angle $\theta_{\mathrm{t}}$, calculated using Snell's law, is required. The absorbed energy $A$ is the energy of the incoming ray I minus the energy of the reflecting ray, as the transmittance $T$ through the material is neglected [17].

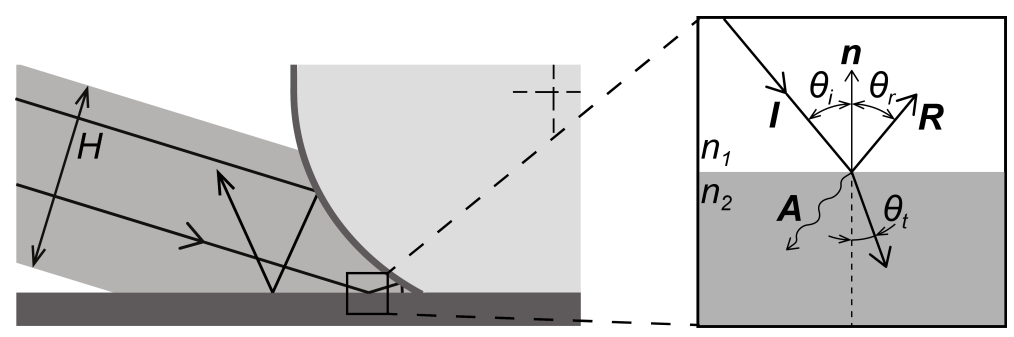

Figure 2.6 Basis of the optical model. A 2D geometry of the process is used for the ray tracing. The amount of energy of a ray absorbed by the material is calculated based on the incidence angle of the ray.

\section{Input and output of the optical sub-model}

The required input for the optical model is listed in Table 2.2. The reflectivity of the composite material, which can be found in literature and is assumed to be independent of temperature [5, 17], is the only material parameter required. The other input parameters required are provided by the geometrical model. Besides, the number of nodes and the number of rays used are required for the discretization. A convergence study was performed and the results are given in Appendix 2.B. The results showed that 10000 rays and 1000 nodes are required in the optical sub-model to obtain an accuracy of less than $0.5^{\circ} \mathrm{C}$. The output of the model is an incident heat flux distribution for both the tape and the laminate at $1 \mathrm{~W}$ of power, which can be multiplied by the applied laser power to obtain the actual incidence heat 
flux distribution. An example flux distribution obtained by the optical sub-model is shown in Appendix 2.B.

Table 2.2 Required input parameters for the optical model.

\begin{tabular}{|c|c|c|c|}
\hline \multicolumn{4}{|c|}{ Geometrical model output parameters } \\
\hline Parameter & Symbol & Unit & Range \\
\hline Spot size height & $H$ & {$[\mathrm{~mm}]$} & 16 and 28 \\
\hline Spot size width & $W$ & {$[\mathrm{~mm}]$} & 11 \\
\hline Roller geometry & $r_{\mathrm{x}}, r_{\mathrm{y}}$ & {$[\mathrm{mm}]$} & $33.5-37.5$ \\
\hline Laser position & $x_{\mathrm{L}}$ & {$[\mathrm{mm}]$} & $480-510$ \\
\hline Laser position & $y_{L}$ & {$[\mathrm{~mm}]$} & $65-195$ \\
\hline Laser orientation & $\theta_{\mathrm{L}}$ & {$\left[{ }^{\circ}\right]$} & $10-26.5$ \\
\hline Distance roller center to substrate & $y_{\mathrm{r}}$ & {$[\mathrm{mm}]$} & $29.5-35$ \\
\hline \multicolumn{4}{|c|}{ Material parameters - C/PEEK } \\
\hline Parameter & Symbol & Unit & Value Reference \\
\hline Refractive index & $n_{2}$ & {$[-]$} & 1.95 \\
\hline \multicolumn{4}{|c|}{ Model parameters - C/PEEK } \\
\hline Parameter & Symbol & Unit & Value \\
\hline Number of nodes & $N_{\text {no }}$ & {$[-]$} & 1000 \\
\hline Number of rays & $N_{\text {ro }}$ & {$[-]$} & 10000 \\
\hline
\end{tabular}

\subsection{Heat transfer model}

Numerous heat transfer models have been described in literature. Analytical [1], 1D transient finite difference [2-5], 2D steady state finite difference [6], 2D finite element [7-9], and 3D finite element models have been developed to predict the temperature distribution for AFP [10,11]. The roller and tool are usually incorporated using convective boundary conditions, although conductive boundary conditions have been used as well $[10,12,13]$. For the present work a 1D finite difference model based on a Eulerian framework was selected. This approach is reasonably accurate and computationally inexpensive. A general description of the model used is given in this section and a more elaborate description is given in Appendix 2.B

\section{Modeling approach}

The temperature distribution during LAFP is assumed to be governed by the throughthickness heat conduction, while the heat conduction in and perpendicular to the 
direction of placement are neglected. Furthermore, the heat required and generated for melting and formation of the crystalline structure in the C/PEEK material is neglected and the material properties are assumed to be independent of temperature.

The LAFP process is divided in four domains: the tape before the nip-point, the laminate before the nip-point, the combined tape and laminate underneath the roller and the combined tape and laminate after the roller. For each of these domains different boundary conditions are used to simulate the heat added by the laser and contact with the roller and tool. An overview is given in Figure 2.7 and the symbols used are listed in Table 2.3 and explained in Appendix 2.B.

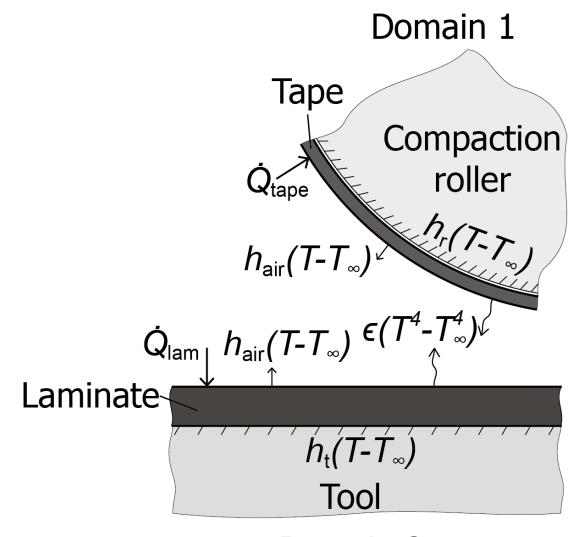

Domain 2

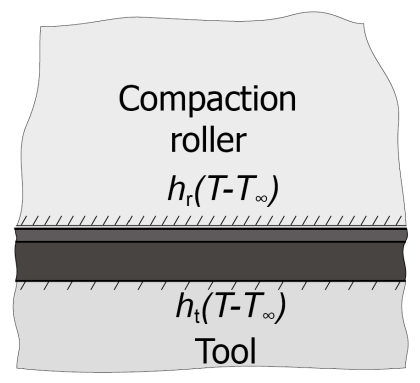

Domain 3

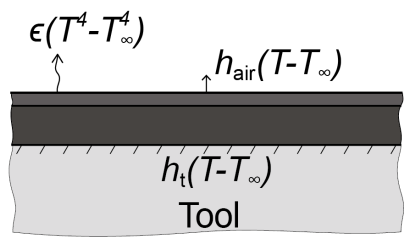

Domain 4

Figure 2.7 Domains considered in the heat transfer model.

\section{Input and output parameters of the heat transfer sub-model}

The input parameters required for the heat transfer sub-model are given in Table 2.3. The majority of the parameters is required to define the boundary conditions of the problem for the heat input, the tool, the roller and the air. Several material parameters are required which govern the heat conduction through the thickness and these values are taken from literature. A sensitivity analysis has been performed to assess the sensitivity of the model to variations in material properties and the results are presented in Appendix 2.B. Variations of 5\% for the volumetric heat capacity and $2.5 \%$ for the transverse conductivity are taken into account for the validation of the model, based on the sensitivity analysis. Furthermore, variations of $+100 \%$ and $-50 \%$ are taken into account for the heat transfer coefficients for the roller and air. Finally, the time step size and the number of nodes through the thickness of the tape are required to define the model. An equal distance between the nodes is used for the laminate. A time step of $10^{-3} \mathrm{~s}$ and 20 elements through the thickness are sufficient for an accuracy of less than $0.1^{\circ} \mathrm{C}$ based on the convergence study given 
in Appendix 2.B. The output of the thermal model is the temperature distribution through the thickness of the tape and the laminate and over time.

Table 2.3 Required input parameters for the heat transfer model.

\begin{tabular}{|c|c|c|c|c|}
\hline \multicolumn{5}{|c|}{ Machine settings } \\
\hline Parameter & Symbol & Unit & Range & \\
\hline Laser power & $P_{\mathrm{L}}$ & {$[W]$} & $0-1000$ & \\
\hline Placement velocity & $v$ & {$[\mathrm{~mm} / \mathrm{s}]$} & $0-1000$ & \\
\hline Tool temperature & $T_{\text {tool }}$ & {$\left[{ }^{\circ} \mathrm{C}\right]$} & $0-300$ & \\
\hline \multicolumn{5}{|c|}{ Geometrical model output } \\
\hline Parameter & Symbol & Unit & Range & \\
\hline Contact length & $L_{C}$ & {$[\mathrm{~mm}]$} & $24-36$ & \\
\hline \multicolumn{5}{|c|}{ Optical model output } \\
\hline Parameter & Symbol & Unit & Range & \\
\hline Tape flux distribution & $\dot{Q}_{\text {tape }}$ & {$[\% \mathrm{~W} / \mathrm{mm}]$} & - & \\
\hline Laminate flux distribution & $\dot{Q}_{\text {lam }}$ & {$[\% \mathrm{~W} / \mathrm{mm}]$} & - & \\
\hline \multicolumn{5}{|c|}{ Boundary conditions - C/PEEK } \\
\hline Parameter & Symbol & Unit & Value & Ref. \\
\hline Heat transfer coefficient air-C/PEEK & $h_{\text {air }}$ & {$\left[\mathrm{W} \mathrm{K} / \mathrm{m}^{2}\right]$} & 20 & [18] \\
\hline Heat transfer coefficient tool-C/PEEK & $h_{\mathrm{t}}$ & {$\left[\mathrm{W} \mathrm{K} / \mathrm{m}^{2}\right]$} & 500 & [18] \\
\hline Heat transfer coefficient roller-C/PEEK & $h_{\mathrm{r}}$ & {$\left[\mathrm{W} \mathrm{K} / \mathrm{m}^{2}\right]$} & 200 & [18] \\
\hline \multicolumn{5}{|c|}{ Material parameters - C/PEEK } \\
\hline Parameter & Symbol & Unit & Value & Ref. \\
\hline Transverse thermal conductivity & $k$ & {$[\mathrm{~W} /(\mathrm{m} \mathrm{K})]$} & 0.72 & {$[10]$} \\
\hline Heat capacity & $c_{p}$ & {$[\mathrm{~J} /(\mathrm{kg} \mathrm{K})]$} & 1425 & [18] \\
\hline Density & $\rho$ & {$\left[\mathrm{kg} /\left(\mathrm{m}^{3}\right)\right]$} & 1560 & [18] \\
\hline Emissivity & $\epsilon$ & {$[-]$} & 0.9 & [19] \\
\hline Tape thickness & $t_{\text {tape }}$ & {$[\mathrm{mm}]$} & 0.15 & \\
\hline Laminate thickness & $t_{\text {lam }}$ & {$[\mathrm{mm}]$} & 3 & \\
\hline \multicolumn{5}{|c|}{ Model parameters } \\
\hline Parameter & Symbol & Unit & Value & \\
\hline Time step size & $\Delta t$ & [s] & $10^{-3}$ & \\
\hline $\begin{array}{l}\text { Number of nodes through the } \\
\text { thickness of the tape }\end{array}$ & $N_{\mathrm{nt}}$ & {$[-]$} & 20 & \\
\hline
\end{tabular}

\subsection{Thermal model validation}

An experimental study has been performed to validate the temperature distributions predicted by the thermal model. Different configurations were evaluated to validate 
the capability of the thermal model to predict the effect of varying process parameters on the temperature distribution. The experimental research consisted of two sets of experiments. The first set of experiments aimed to measure the surface temperature using a thermal camera, while the second set of experiments aimed to measure the through-the-thickness temperature distribution using thermocouples embedded in a laminate. In the following sections the experimental procedure will be described followed by the comparison of measured and predicted temperature distributions.

\subsubsection{Experimental procedure}

\section{Materials and equipment}

Pre-consolidated laminates were used as a basis to place tapes on in this experiment. The prepreg tape for the fiber placement and the laminates was TC1200 AS-4/PEEK tapes with a fiber volume content of $59 \%$ provided by TenCate. Prepreg tape of 12 inches in width was used for the laminates and tapes slitted to a quarter inch were used for fiber placement. For the first set of experiments laminates with a stacking sequence of $[0 / 90]_{2 s}$ were used. A laminate with a stacking sequence of $[0 / 90]_{6 s}$ was used for the second set of experiments with thermocouples embedded during stacking between the top 12 plies. The thermocouples with a thickness of 0.13 $\mathrm{mm}$ were welded and insulated with PI tape to prevent contact with the conductive fibers. The exact depth and location of the thermocouples was determined after consolidation using a standard ultrasonic technique. Al laminates were consolidated at 20 bars using the press-cycle recommended by the manufacturer.

A Micro-Epsilon thermalIMAGER TIM 400 thermal camera was mounted on the AFP head to measure the surface temperature. The measured temperature is based on the intensity of the emitted long wave infrared radiation. The geometry near the nip-point, however, causes reflections of the emitted infrared light, similar to the absorption and reflection of the laser light, which affect the measured temperature. The thermal camera was calibrated for this geometry by adapting the emissivity of the nip-point. An experimental analysis has been performed to estimate the emissivity and Appendix 2.C describes the experimental procedure and the results obtained. The resulting accuracy of the thermal camera calibration was determined to be within $2.5{ }^{\circ} \mathrm{C}$ for the nip-point temperature and within $5{ }^{\circ} \mathrm{C}$ for the tape and laminate temperature. 


\subsubsection{Tape placement experiment}

The pre-consolidated laminates had a shiny surface and the optical properties differed from the prepreg material. Therefore, one ply of tapes was placed on the laminates as a base ply. Tapes were placed subsequently over a length of $30 \mathrm{~cm}$ on the base ply, using different machine settings, during which the temperature was measured.

Three different configurations were used for the first set of experiments, as reported Table 2.4. Between one and three measurements were performed for each configuration. For the second set of experiments the settings of configuration o were used and three measurements were performed. For the first configuration a stiff PTFE roller was used.

Table 2.4 Settings for the validation trials.

\begin{tabular}{lccccc}
\hline & \multicolumn{3}{c}{ Machine settings } & \multicolumn{3}{c}{} \\
Parameter & Symbol & Unit & \multicolumn{2}{c}{ Configuration } \\
& & & 1 & 2 & 3 \\
\hline Linkage A & $L_{\mathrm{A}}$ & {$[\mathrm{mm}]$} & 0 & 2 & 7 \\
Linkage B & $L_{\mathrm{B}}$ & {$[\mathrm{mm}]$} & 0 & 4 & 9 \\
Spot size & $H$ & {$[\mathrm{~mm}]$} & 28 & 16 & 28 \\
Tiltangle & $\theta_{\text {tilt }}$ & {$\left[{ }^{\circ}\right]$} & -10 & -3 & -3 \\
Compaction force & $F_{\mathrm{C}}$ & {$[\mathrm{N}]$} & 435 & 435 & 835 \\
Roller stiffness & $E_{\mathrm{r}}$ & {$[\mathrm{sh}]$} & - & 40 & 60 \\
Laser power & $P_{\mathrm{L}}$ & {$[\mathrm{W}]$} & 550 & 500 & 950 \\
Placement velocity & $v$ & {$[\mathrm{~mm} / \mathrm{s}]$} & 100 & 100 & 200 \\
Tool temperature & $T_{\text {tool }}$ & {$\left[{ }^{\circ} \mathrm{C}\right]$} & 20 & 20 & 20 \\
\hline
\end{tabular}

\subsubsection{Results}

Figure 2.8 shows the surface temperature as a function of the distance to the nippoint for the three configurations for both the model and the thermal camera measurements. An error bar is shown for the standard deviation of three measurements. The variation within a measurement was about 5 to $10^{\circ} \mathrm{C}$. Furthermore, the grey area plotted indicates the effect of the variation of the material parameters and boundary conditions. It can be observed that the model matches the trends shown in the measurements. The thermal camera measurements are mostly within the variation of material parameters. Trends caused by changes in process settings, such as spot size, tool temperature or laser angle, are captured by the model. For example, as the heated length on the tape or the laminate is changed, this effect is observed in both 
the experimental and modeling results. Based on these results the model is found to be capable of analyzing the effect of changed process settings on temperature distribution during the process.

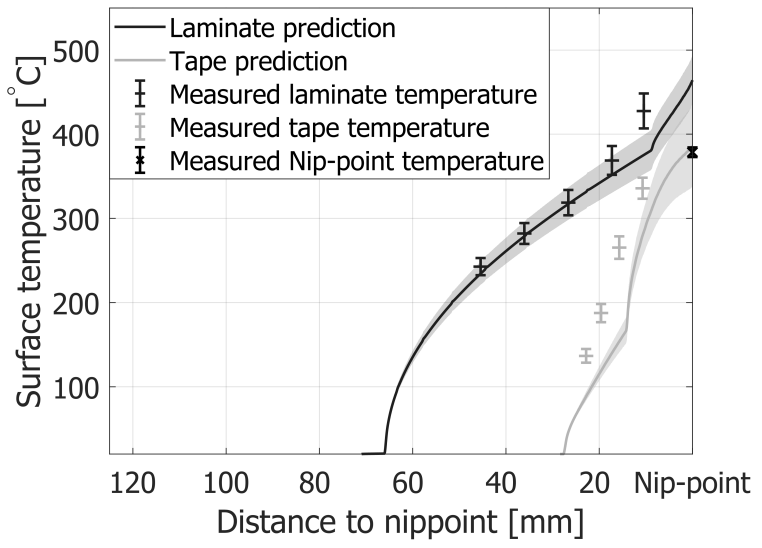

(a)

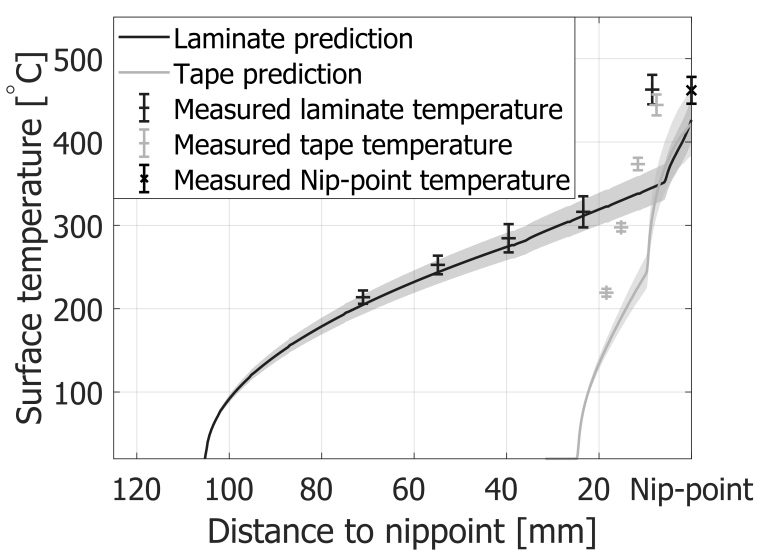

(c)

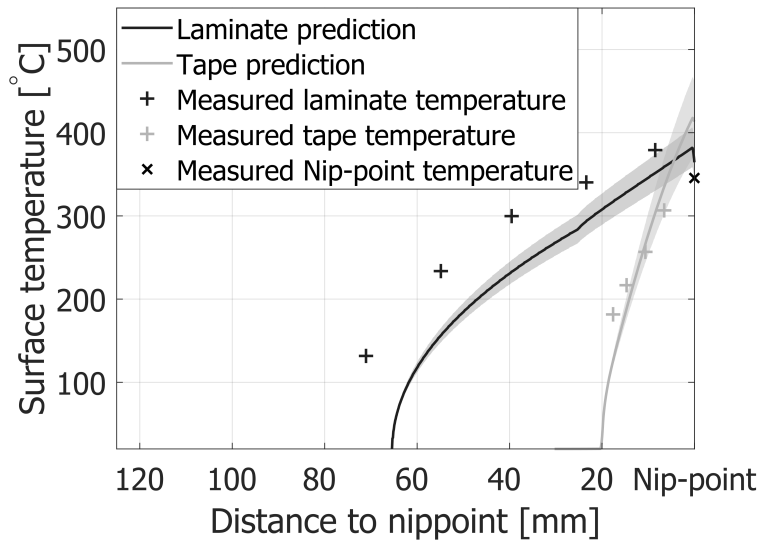

(b)

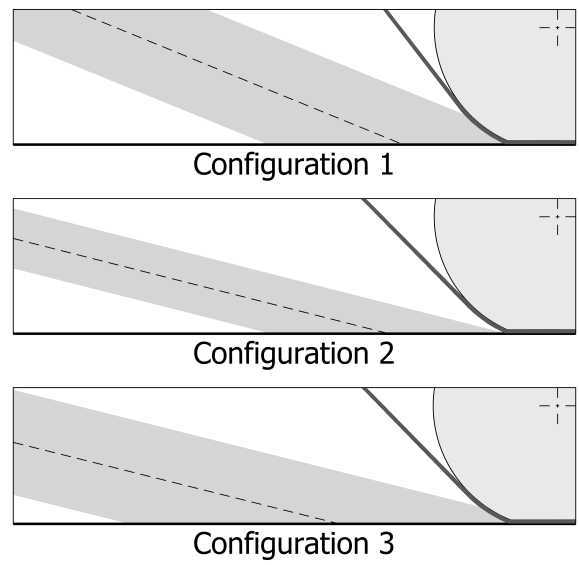

(d)

Figure 2.8 Measured and modeled surface temperature for (a) configuration 1, (b) configuration 2, (c) configuration 3. (d) Shows the nip-point geometry of these configurations.

Figure 2.9 shows the laminate temperature distributions as calculated by the model for configuration 1 and both the thermal camera and thermocouple measurements. The measured temperature is shown for a number of interfaces, including the standard deviation of two to four measurements. The thermocouple measurements of the $2^{\text {nd }}$ interface show strange behavior, which is probably a measurement error. Before the nip-point there is some deviation between the measurements and the model. After the nip-point the model correctly predicts the temperature distribution. The model underestimates the temperature distribution for the heating phase for the $4^{\text {th }}$ and $8^{\text {th }}$ interface. For the consolidation and cooling phase the model predictions closely match the experimental results. 


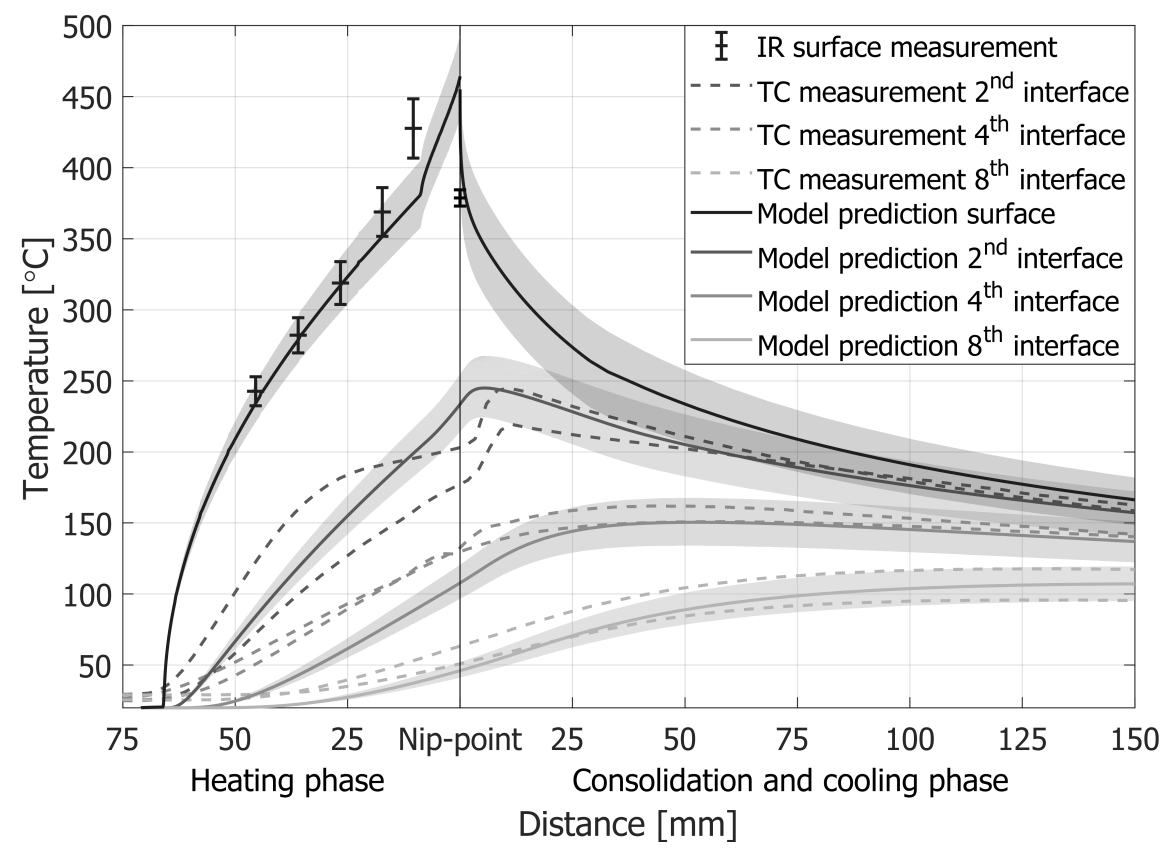

Figure 2.9 Measured and modeled surface and through-thickness temperature distributions for configuration 1.

The validation of the combined geometrical, optical and heat transfer model shows that the model is capable of predicting trends in temperature distribution as a function of process parameters. The reasonable accuracy of the optical and heat transfer model has already been demonstrated in literature. The results shown validate the accuracy of the geometrical model, as the effect of process settings on the temperature distribution are also shown to be captured well. The model was very capable of predicting the temperature distribution through the thickness of the laminate. The presented model is, therefore, a solid basis for providing the temperature distribution as an input for the consolidation models in the remainder of this thesis.

\subsection{Roller deformation}

It was observed during experiments, and described in literature [16], that deformation of the compaction roller has a significant effect on the measured temperature. The geometry of the deformable roller as a function of process settings was, therefore, incorporated in the proposed model. In Section 2.3 an analysis was shown on the shape of the deformable roller as a function of the roller stiffness and applied compaction force. The model is used to analyze the effect of a rigid roller and a roller 
with a stiffness of $40 \mathrm{sh}$ for both a compaction force of $435 \mathrm{~N}$ and $1335 \mathrm{~N}$. The settings of configuration 1 were used, as given in Table 2.4.

The resulting temperature distributions are shown in Figure 2.10. Figure 2.10(a) shows the temperature distribution as a function of the distance to the roller center line. It can be observed that the nip-point is shifted with increasing roller deformation. Consequently, the heated length on the tape is reduced, resulting in a reduction in final temperature of the tape, up to $50{ }^{\circ} \mathrm{C}$. The heated length on the laminate shifts with increasing compaction force, but is more or less constant. The interface temperature, resulting from the tape and laminate surface temperature, is shown in Figure 2.10(b). The consolidation mechanisms, such as intimate contact development and healing, are driven by the interface temperature. It can be seen that the lower tape temperature for the 40 sh roller and $435 \mathrm{~N}$ results in a faster drop in interface temperature. The nip-point temperature, which is the temperature used to control the process, differs significantly for the deformable and stiff roller, as is highlighted in Figure 2.10(c). The lower nip-point temperature obtained with the stiff roller results in a much lower interface temperature.

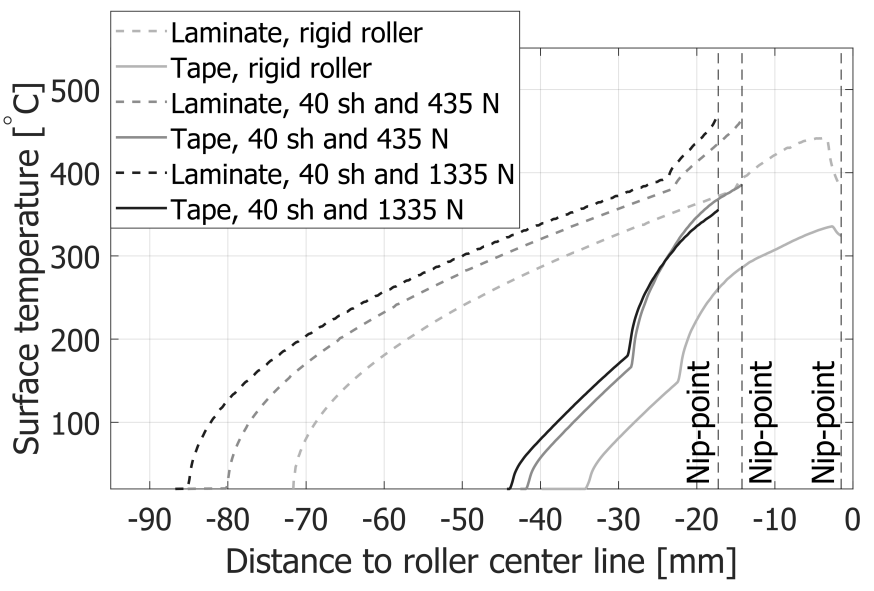

(a)

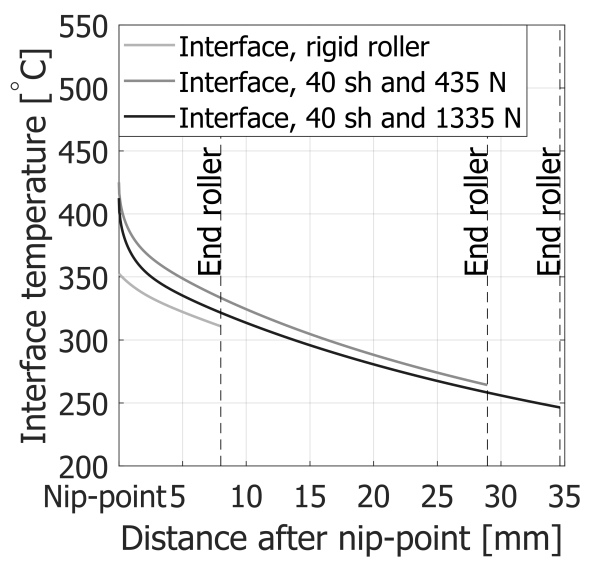

(b)

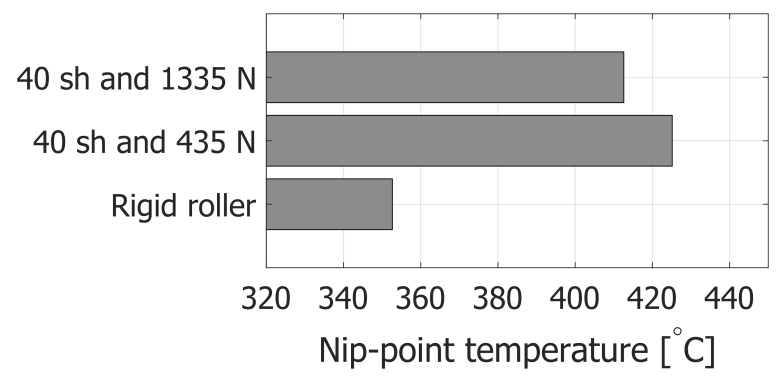

(c)

Figure 2.10 The effect of roller stiffness on the modeled (a) surface temperature distribution, (b) interface temperature distribution underneath the roller and (c) nip-point temperature. 
An interesting observation that can be made is the drop in temperature with the use of a rigid roller just before the tape and laminate enter the nip-point. This is due to a so-called shadow area, which is an area that is not illuminated by the laser and as a consequence cools down. This shadow area was not observed for the deformable roller, due to the change in local curvature of the roller [20]. The difference in nip-point geometry for both the rigid and the deformable roller is illustrated in Figure 2.11. A reduction of the shadow area is beneficial for the consolidation underneath the roller. The material cools down less before entering the nip-point and this higher nip-point temperature promotes the consolidation processes such as intimate contact development and healing.

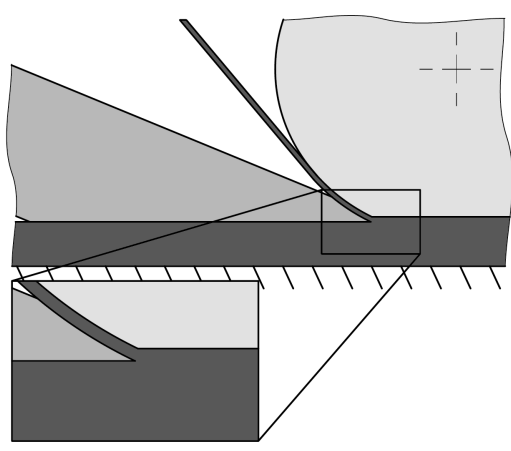

(a)

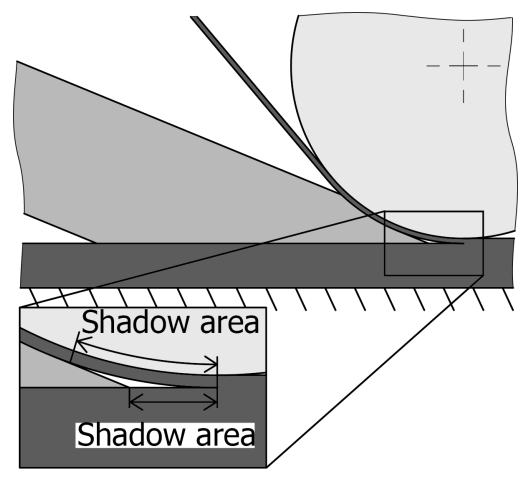

(b)

Figure 2.11 A comparison of the nip-point geometry of (a) a deformable roller without a shadow area and $(\boldsymbol{b})$ a rigid roller with a shadow area.

\subsection{Conclusion}

A thermal model has been developed for the Coriolis Composites LAFP end effector. The purpose of the model was to predict the temperature distribution for the process settings possible with this end effector specifically, including the compliant roller. The predicted temperature distributions will be used as input for consolidation models described in the remainder of this thesis. A geometrical model of the end effector has been developed to determine the position and orientation of the laser as well as the shape of the roller based on the machine settings. The deformation of the compliant roller used by Coriolis Composites has been implemented in order to obtain the correct geometry near the nip-point. A 2D ray-tracing model and a 1D heat transfer model were taken from literature to calculate the incident heat flux and temperature distribution during the process.

An experimental validation has been performed for varying process settings. The 
surface temperature was measured using a thermal camera and thermocouples were used to measure the through thickness temperature distribution. It was shown that the model predictions match the measurements quite well. The model is capable of predicting the effect of machine settings on the temperature distribution, which is required later on to assess the effect of machine settings on the consolidation.

The compliant roller was incorporated as a truncated ellipse and its shape is a function of the stiffness of the roller and the applied compaction force. A linear model was fitted to the results of an experimental evaluation of the roller shape. It was shown that the shape of the roller significantly affects the temperature distribution during the process. The shadow area, an area on the tape and the laminate just before the nip-point which is not hit by direct laser light, can be reduced by using a compliant roller. This is an advantage of a compliant roller, since a reduced shadow results in a higher nip-point temperature and a temperature distribution underneath the roller beneficial for consolidation.

\section{References}

[1] M. N. Ghasemi Nejhad, R. D. Cope, and S. I. Güçeri. Thermal analysis of insitu thermoplastic composite tape laying. Journal of Composite Materials, 4:20-45, 1991.

[2] J. Tierney and J. W. Gillespie Jr. Modeling of heat transfer and void dynamics for the thermoplastic composite tow-placement process. Journal of Composite Materials, 37(19):1745-1768, 2003.

[3] M. A. Khan, P. Mitschang, and R. Schledjewski. Parametric study on processing parameters and resulting part quality through thermoplastic tape placement process. Journal of Composite Materials, 47(4):485-499, 2013.

[4] J. Colton and D. Leach. Processing parameters for filament winding thick-section PEEK/carbon fiber composites. Polymer Composites, 13(6):427-434, 1992.

[5] W. J. B. Grouve. Weld strength of laser-assisted tape-placed thermoplastic composites. Phd thesis, University of Twente, Enschede, The Netherlands, 2012.

[6] E. P. Beyeler and S. I. Güçeri. Thermal analysis of laser-assisted thermoplasticmatrix composite tape consolidation. Journal of Heat Transfer, 110(2):424-430, 1988.

[7] C. M. Stokes-Griffin and P. Compston. A combined optical-thermal model for near-infrared laser heating of thermoplastic composites in an automated tape placement process. Composites Part A: Applied Science and Manufacturing, 75:104$115,2015$. 
[8] F. O. Sonmez and H. T. Hahn. Modeling of heat transfer and crystallization in thermoplastic composite tape placement process. Journal of Thermoplastic Composite Materials, 10(3):198-240, 1997.

[9] S. C. Mantell and G. S. Springer. Manufacturing process models for thermoplastic composites. Journal of Composite Materials, 26(16):2348-2377, 1992.

[10] S. M. Grove. Thermal modelling of tape laying with continuous carbon fibrereinforced thermoplastic. Composites, 19(5):367-375, 1988.

[11] Y. M. P. Toso, P. Ermanni, and D. Poulikakos. Thermal phenomena in fiberreinforced thermoplastic tape winding process: Computational simulations and experimental validations. Journal of Composite Materials, 38(2):107-135, 2004.

[12] H. J. Kim, S. K. Kim, and W. I. Lee. Flow and heat transfer analysis during tape layup process of APC-2 prepregs. Journal of Thermoplastic Composite Materials, 17(1):5-12, 2004.

[13] M. A. Khan, P. Mitschang, and R. Schledjewski. Tracing the void content development and identification of its effecting parameters during in situ consolidation of thermoplastic tape material. Polymers and Polymer Composites, 18(1):1-15, 2010.

[14] J. Reichardt, I. Baran, and R. Akkerman. New analytical and numerical optical model for the laser assisted tape winding process. Composites Part A: Applied Science and Manufacturing, 107:647-656, 2018.

[15] R. Schledjewski and A. Miaris. Thermoplastic tape placement by means of diode laser heating. In Proceedings of the 2009 SAMPE Symposium and Exhibition (SAMPE 2009), volume 54. SAMPE, Baltimore, Maryland, USA, 2009.

[16] C. M. Stokes-Griffin. A Combined Optical-Thermal Model for Laser-Assisted Fibre Placement of Thermoplastic Composite Materials. Phd thesis, The Australian National University, Canberra, Australia, 2015.

[17] C. M. Stokes-Griffin and P. Compston. Optical characterisation and modelling for oblique near-infrared laser heating of carbon fibre reinforced thermoplastic composites. Optics and Lasers in Engineering, 72:1-11, 2015.

[18] F. N. Cogswell. Thermoplastic Aromatic Polymer Composites. ButterworthHeinemann, 1992. ISBN 978-0-7506-1086-5.

[19] P. Berlin, O. Dickman, and F. Larsson. Effects of heat radiation on carbon/PEEK, carbon/epoxy and glass/epoxy composites. Composites, 23(4):235-243, 1992.

[20] C. M. Stokes-Griffin and P. Compston. Investigation of sub-melt temperature bonding of carbon-fibre/PEEK in an automated laser tape placement process. Composites Part A: Applied Science and Manufacturing, 84:17-25, 2016.

[21] M. Bass, C. DeCusatis, J. Enoch, V. Lakshminarayanan, G. Li, C. Macdonald, V. Mahajan, and E. Van Stryland. Handbook of Optics Volume I: Geometrical and Physical Optics, Polarized Light, Components and Instruments. McGraw-Hill, Inc., New York, NY, USA, 1995. ISBN 0071498893, 9780071498890. 


\section{A Optical sub-model}

A description of the optical sub-model used in this work is given in this appendix. The ray-tracing model is based on similar models found in literature [5, 10]. First the modeling assumptions are given and then the derivation and implementation of the ray tracing model are described.

\section{Modeling assumptions}

- The transmittance of the material studied, C/PEEK, is assumed to be negligible, as the fiber volume content is high and the transmittance of the carbon fiber is negligible.

- The absorption and reflection of the composite material is governed by the fibers as the thermoplastic polymer used, PEEK, is assumed to be transparent for the wavelength of $980 \mathrm{~nm}$ of the laser used on the Coriolis Composites robot.

- The composite material is assumed to reflect the light in a purely specular way.

- The refractive index is assumed to be independent of temperature and fiber orientation of the laminate.

- The laser spot is assumed to have a uniform energy distribution based on data of the intensity of the laser spot provided by Coriolis Composites.

- The light is assumed to be unpolarized, containing an equal amount of s- and p-polarized light.

- The power of the laser beam is $1 \mathrm{~W}$, which can be scaled with the applied power.

\section{Modeling approach}

The $2 \mathrm{D}$ representation of the LAFP process used in the optical model is shown in Figure 2.6. The roller is modeled as a truncated ellipse and the substrate is modeled as a circle, with a very large radius in the case of flat tooling.

The laser beam has a certain position and a certain orientation, obtained from the geometrical model described in the previous section. The beam, as is shown in Figure 2.6, is divided in a number of rays, which are uniformly distributed over its height $H$. The amount of energy of a ray is an equal fraction of the total energy of the beam. 


\section{Law of reflection}

Each ray is tracked from its origin and the intersection with the tape or substrate is calculated. At the incidence point the normal is calculated to be able to use the law of reflection to calculate the reflection angle $\theta_{\mathrm{r}}$ from the incidence angle $\theta_{\mathrm{i}}$ :

$$
\theta_{\mathrm{i}}=\theta_{\mathrm{r}}
$$

\section{Snell's law}

Although it is assumed that no light is transmitted, the transmittance angle $\theta_{t}$ is required to calculate the amount of heat absorbed. The transmittance angle is obtained from Snell's law:

$$
\frac{\sin \theta_{\mathrm{i}}}{\sin \theta_{\mathrm{t}}}=\frac{n_{2}}{n_{1}}
$$

based on the refractive index of air $n_{1}$, which is 1 , and the refractive index of the composite material $n_{2}$.

\section{Fresnel equations}

The absorptance and reflectance are defined as fractions of the energy of the incident light. The reflectance $R_{\mathrm{s}}$ for $\mathrm{s}$ - and $R_{\mathrm{p}}$ for p-polarized light can be calculated using the Fresnel equations:

$$
\begin{aligned}
& R_{\mathrm{s}}=\left[\frac{\sin \theta_{\mathrm{i}}-\theta_{\mathrm{t}}}{\sin \theta_{\mathrm{i}}+\theta_{\mathrm{t}}}\right]^{2}, \\
& R_{\mathrm{p}}=\left[\frac{\tan \theta_{\mathrm{i}}-\theta_{\mathrm{t}}}{\tan \theta_{\mathrm{i}}+\theta_{\mathrm{t}}}\right]^{2}
\end{aligned}
$$

[21]. The total reflectance $R$ is the average of the reflected s- and p-polarized light, as the light is assumed to be unpolarized:

$$
R=\frac{\left(R_{\mathrm{p}}+R_{\mathrm{s}}\right)}{2}
$$




\section{Absorption}

The absorbed energy $A$ can be calculated based on the reflectance $R$ and the energy of the incoming ray $I$,

$$
A=I(1-R)
$$

The path of the ray is traced until either the amount of energy of the ray is reduced to less than $0.1 \%$ of the amount of energy at the start or the ray is reflected away from the nip-point.

\section{Computational implementation}

The described ray-tracing method has been implemented in Matlab. The roller and substrate are discretized in a number of nodes. A ray is likely not to hit an exact node. Therefore, the absorbed energy at the incidence point is divided between the two closest nodes. The division is based on the distance between the intersection and the closest nodes, as shown in Figure 2.A.1. The amount of energy absorbed by point $X_{n}$ of the ray $i$, with the absorbed energy $A_{i}$ calculated with the method described before, is determined with

$$
A_{X_{n}}=A_{i} \frac{s_{n}}{s_{n-1}+s_{n}}
$$

where $s_{n}$ and $s_{n-1}$ are the distances to the closest nodes. Finally, the incident heat flux distribution is calculated by dividing the amount of energy absorbed at each node by the distance between nodes.

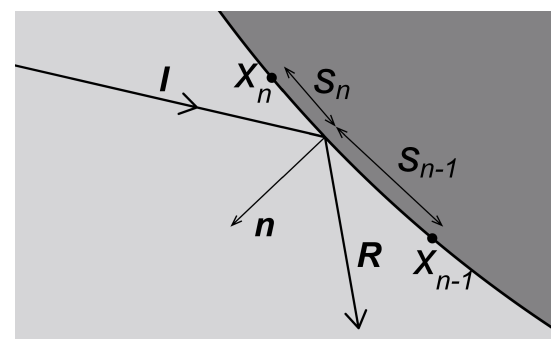

Figure 2.A.1 Geometrical representation of the division of energy between grid points.

\section{B Heat transfer sub-model}

A description of the heat transfer sub-model is given in this appendix. The 1D heat transfer model solved using a finite difference scheme is similar to models found in 
literature [2-5]. In the following sections the assumptions and modeling approach are described. Furthermore, the results of a convergence study are presented. Finally, a sensitivity analysis was done for the material parameters and heat transfer coefficients.

\section{Modeling assumptions}

- The material is assumed to be homogeneous and anisotropic on a macroscopic scale.

- Only through thickness heat conduction is considered.

- The heat conduction in the direction of placement is neglected as diffusion is slower than the placement velocity [5].

- The heat conduction perpendicular to the placement direction is neglected as the laser beam is much wider than the tape.

- The heat of melting and formation of the crystalline structures in the semicrystalline PEEK material is neglected.

- The material properties are assumed to be independent of temperature.

\section{Energy balance}

The general energy balance equation is solved to determine the temperature distribution during LAFP:

$$
c_{p} \rho \frac{\partial T}{\partial t}+\nabla(k \nabla T)=\dot{q}
$$

with this equation $c_{p}$ and $\rho$ are the heat capacity and density of the material, respectively, $k$ is the conductivity of the material and $\dot{q}$ is the change in energy of the system. The 1D energy balance formulation, which is solved to predict the temperature through the thickness of the tape and laminate, can be derived from the general energy balance:

$$
c_{p} \rho \frac{\partial T}{\partial t}-k \frac{\partial^{2} T}{\partial z^{2}}=\dot{q}
$$

The equation is subjected to varying boundary conditions. The heat supplied by the laser is applied as a heat flux boundary condition, while the contact of the composite material with the tool, the roller and the air, are represented as convective boundary conditions. An effective heat transfer coefficient is used for each contact 
type. Furthermore, radiative heat emission is assumed on all surfaces exposed to air. The boundary conditions can be generalized as:

$$
\dot{q}=\overbrace{\dot{Q}}^{\text {Heat flux }}+\overbrace{h\left(T-T_{\infty}\right)}^{\text {Convection }}+\overbrace{\sigma \epsilon\left(T^{4}-T_{\infty}^{4}\right)}^{\text {Radiation }}
$$

In this equation, $\dot{Q}$ is the incident heat flux, $h$ is an effective heat transfer coefficient, $\sigma$ is the Boltzmann constant and $\epsilon$ is the emissivity of the surface. The far field temperature is represented by $T_{\infty}$.

\section{Domains}

The thermal problem is subdivided into four domains, which are represented schematically in Figure 2.7 and the boundary conditions in these domains explained below.

\section{Domain 1}

The first domain describes the tape before the nip-point. The tape is heated by the laser on the bottom side and the applied flux $\dot{Q}_{\text {tape }}(t)$ was calculated with the optical model. Furthermore, the bottom side is exposed to the air, both a convection and radiation boundary condition are applied, using an effective heat transfer coefficient $h_{\text {air }}$ and an emissivity of $\epsilon$. The top surface is in contact with the roller and a convective boundary condition with an apparent heat transfer coefficient of $h_{\mathrm{r}}$ is used. The initial temperature of the tape is assumed to be uniform and equal to the far field temperature.

\section{Domain 2}

The second domain represents the laminate before the nip-point. The top surface of the laminate is heated by the laser and the supplied heat is applied as a heat flux $\dot{Q}_{\text {lam }}(t)$ as calculated with the optical model. The top surface is exposed to the air and, therefore, convection and radiation boundary conditions are applied, using an effective heat transfer coefficient of $h_{\text {air }}$ and an emissivity of $\epsilon$. The bottom surface is in contact with the tool, which is incorporated as a convective boundary condition with an effective heat transfer coefficient of $h_{\mathrm{t}}$. The tool can be heated and the temperature of the tool is specified in the model as $T_{\text {tool }}$. The initial temperature of the laminate is determined based on the specified tool temperature or the processing history.

\section{Domain 3}

The third domain corresponds to the tape and laminate underneath the roller and is considered to be the combination of the tape from domain 1 and the laminate from domain 2. No more heat is supplied in this domain. The bottom 
side is in contact with the tool, while the top side is in contact with the roller. Effective heat transfer coefficients of $h_{\mathrm{t}}$ and $h_{\mathrm{r}}$ are applied on the bottom and top surface respectively. The initial temperature is based on the combined domain 1 and 2 . The temperature of the interface node is the average temperature of the nodes at the bottom and top surface of the tape and laminate respectively. This is valid for temperature independent properties and the equal distance between nodes in both the tape and the laminate.

\section{Domain 4}

The fourth domain is after release of the pressure by the roller. The initial temperature is the final temperature of domain 3. The bottom surface is in contact with the tool and again the effective heat transfer coefficient of $h_{\mathrm{t}}$ is applied. The top surface is exposed to the air after release of the roller, and both convection and radiation heat loss with an effective heat transfer coefficient of $h_{\text {air }}$ and an emissivity of $\epsilon$ respectively are applied.

\section{Computational implementation}

The 1D heat balance equation was solved using an Eulerian approach. The control volume was followed throughout the process and the heat equation was solved through the thickness. A finite difference method was applied, using a Crank-Nicholson scheme. This is a numerical stable method scheme and only the convergence of the solution had to be checked.

\section{Convergence study}

The accuracy of the solution is based on the number of nodes and rays used in the optical model, the number of elements used for the 1D heat transfer model and the time step to obtain the temperature distribution. A convergence study was performed based on the settings for configuration 1 used in the validation. The settings are stated again in Table 2.B.1. The resulting flux and temperature distributions for these settings are shown as an example in Figure 2.B.1.

Figure 2.B.1(a) shows the incident heat flux distribution obtained and both the flux of the direct light and reflections are shown. It can be seen that reflections have a significant contribution to the total incident heat flux, which underlines the importance of an optical model in modeling the LAFP process. Furthermore, it can be seen that a noisy distribution is obtained and this is a consequence of the low number of nodes and rays used to reduce the computational time. The resulting temperature distribution is shown in Figure 2.B.1(b) and the temperature distribution is much smoother. It can be concluded that no perfectly smooth flux distribution, reducing 
Table 2.B.1 Settings for the convergence study.

\begin{tabular}{lccc}
\hline & Machine settings & & \\
Parameter & Symbol & Unit & Value \\
\hline Linkage A & $L_{\mathrm{A}}$ & {$[\mathrm{mm}]$} & 0 \\
Linkage B & $L_{\mathrm{B}}$ & {$[\mathrm{mm}]$} & 0 \\
Spot size & $H$ & {$[\mathrm{~mm}]$} & 28 \\
Tilt angle & $\theta_{\text {tilt }}$ & {$\left[{ }^{\circ}\right]$} & -10 \\
Compaction force & $F_{\mathrm{c}}$ & {$[\mathrm{N}]$} & 435 \\
Roller stiffness & $E_{\mathrm{r}}$ & {$[\mathrm{sh}]$} & 40 \\
Laser power & $P_{\mathrm{L}}$ & {$[\mathrm{W}]$} & 550 \\
Placement velocity & $v$ & {$[\mathrm{~mm} / \mathrm{s}]$} & 100 \\
Tool temperature & $T_{\text {tool }}$ & {$\left[{ }^{\circ} \mathrm{C}\right]$} & 20 \\
\hline & & & \\
Parameter & Model parameters & Unit & Value \\
\hline Number of nodes - optical model & $N_{\mathrm{no}}$ & {$[-]$} & 800 \\
Number of rays - optical model & $N_{\mathrm{ro}}$ & {$[-]$} & 10000 \\
Time step size - heat transfer model & $\Delta t$ & {$[\mathrm{~s}]$} & $10^{-3}$ \\
Number of nodes through the thickness of the & $N_{\mathrm{nt}}$ & {$[-]$} & 20 \\
tape - heat transfer model & & & \\
\hline
\end{tabular}

the computational time, is required to obtain a smooth and accurate temperature distribution.

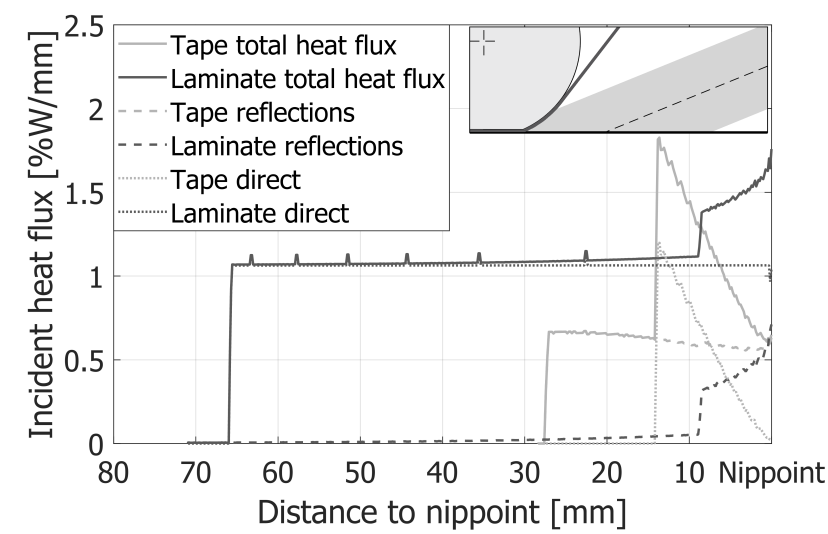

(a)

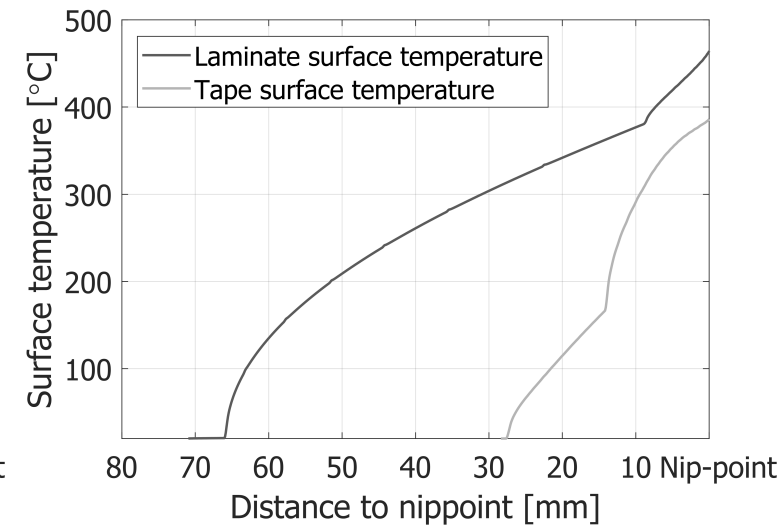

(b)

Figure 2.B.1 (a) The incident flux distribution obtained with 10000 rays and 800 nodes in the optical model and $(\boldsymbol{b})$ the temperature distribution obtained with 20 nodes through the thickness of the tape and a time step of $10^{-3} \mathrm{~s}$.

The convergence of the optical and heat transfer model is illustrated in Figure 2.B.2. A reference temperature distribution was obtained for each parameter with a high 
number of rays and nodes. Then a normalized temperature difference was defined as the average of the squared difference between the temperature distribution and the reference temperature distribution.

Figure 2.B.2(a) shows the effect of the number of rays and nodes in the optical model. A reference configuration with 250000 rays and 5000 nodes was used, with a time step of $10^{-3} \mathrm{~s}$ and 20 nodes through the thickness of the tape. An interrelation between the number of rays and number of nodes can be observed. A low number of nodes results in poor accuracy no matter how many rays are used. Increasing the number of nodes requires a sufficient increase in number of rays to improve the accuracy. For 1000 nodes at least 5000 rays are required, while for 4000 nodes about 100000 rays are required to obtain a similar accuracy. An error of less than $0.5{ }^{\circ} \mathrm{C}$ is sufficient for the purpose of the model and 1000 nodes and 10000 rays are selected.

Figure 2.B.2(b) shows the effect of the time step used in the thermal model, with a time step of $10^{-6} \mathrm{~s}$ for the reference temperature distribution. The model converges for the both the surface and through-thickness temperature and with a time step of $10^{-3} \mathrm{~s}$ the error is less than $0.1^{\circ} \mathrm{C}$.

Figure 2.B.2(c) shows the convergence of the temperature distribution for the number of elements used through the thickness of the tape. Elements with an equal size were used for the laminate. It can be observed that the temperature distributions quickly converge below an error of $0.1{ }^{\circ} \mathrm{C}$ and using 20 elements through the thickness of the tape is sufficient. To conclude, 1000 nodes and 10000 rays are selected for the optical sub-model and a time step of $10^{-3} \mathrm{~s}$ and 20 nodes through the thickness of the tape are selected for the heat transfer sub-model for an accuracy of less than $0.5^{\circ} \mathrm{C}$ in the thermal model. This results in a computational time of about $2.5 \mathrm{~s}$ on a laptop. 


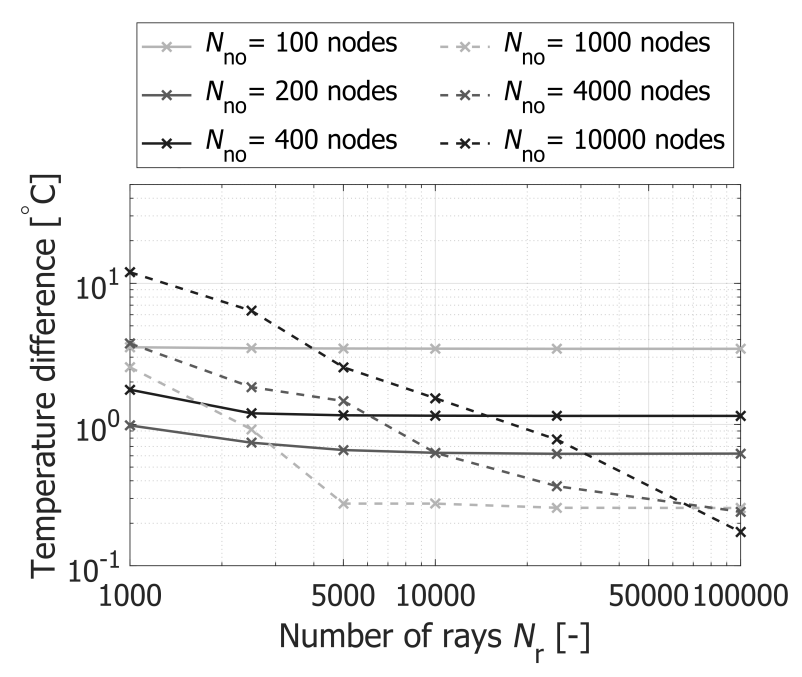

(a)

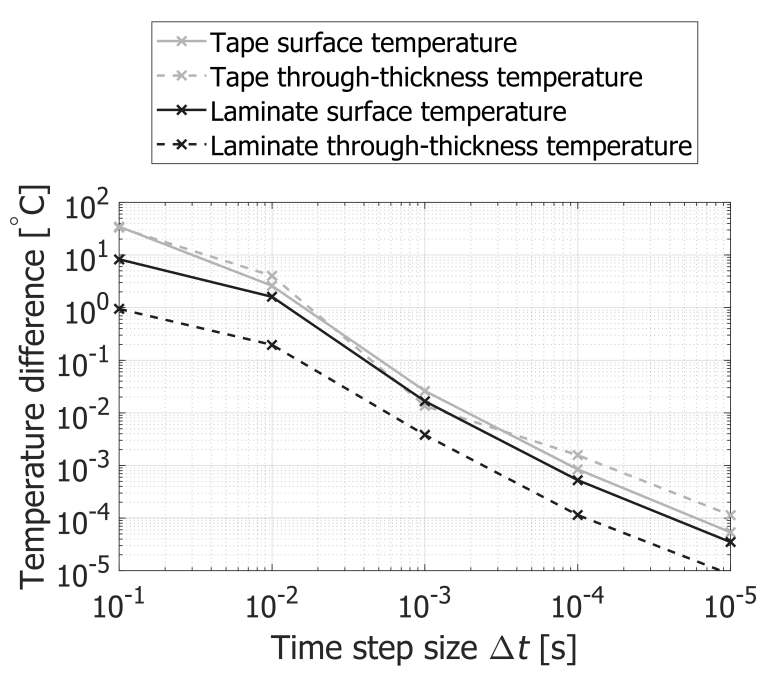

(b)

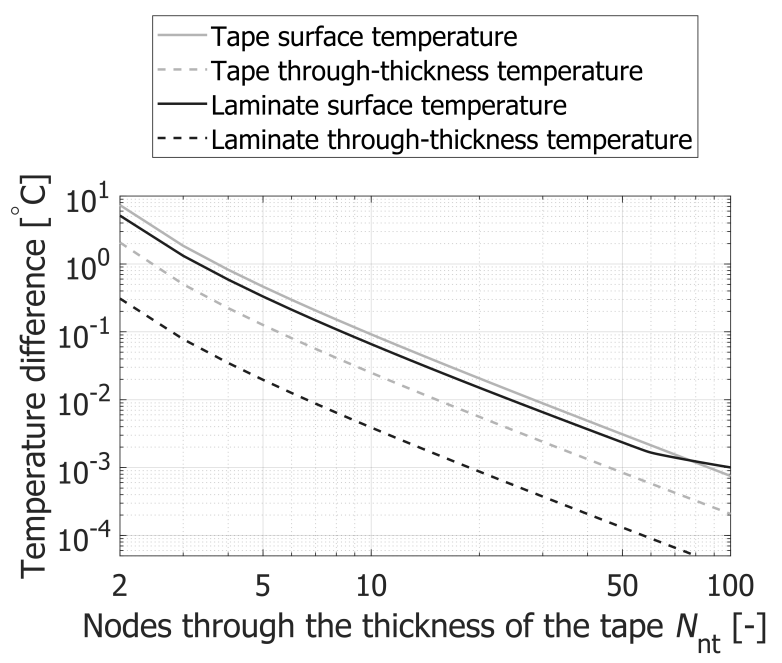

(c)

Figure 2.B.2 Convergence study of the thermal model. (a) The effect of the number of rays and nodes used in the optical model on the accuracy of the temperature distribution, $\Delta t$ of $10^{-3} \mathrm{~s}$ and $N_{n t}$ of 20 nodes. (b) The effect of the time step in the heat transfer model on the accuracy of the temperature distribution, $N_{r o}$ of 10000, $N_{n o}$ of 800 nodes and $N_{n t}$ of 20 nodes. (c) The effect of the number of elements through the thickness of the tape in the heat transfer model on the accuracy of the temperature distribution, $N_{r o}$ of 10000, $N_{n o}$ of 800 nodes and $\Delta t$ of $10^{-3} \mathrm{~s}$.

\section{Sensitivity analysis}

Limited data is available on the thermal properties of C/PEEK and most authors use the values provided by Cogswell $[5-7,13,18]$. The material properties are a function of temperature and the range of values over a temperature range from 0 to $400{ }^{\circ} \mathrm{C}$ is given in Table 2.B.2. The standard deviation from the value used to the 
range reported by Cogswell is also provided. The refractive index was taken from the work of Stokes et al. and they assumed that the refractive index is independent of temperature [7]. Grouve showed the minor effect of temperature on the refractive index on C/PPS, another high-performance polymer composite, and for C/PEEK it is also assumed that the refractive index is independent of temperature [5]. The heat transfer coefficients for C/PEEK with the air and steel tool are taken from Cogswell as well and shown in Table 2.B.3. The heat transfer coefficient for C/PEEK with the PTFE roller is estimated based on the values given by Cogswell [18]. The heat transfer coefficients used in literature have a large variation and, therefore, the sensitivity is checked for more variation than the material properties.

Table 2.B.2 Variation in material parameters for C/PEEK.

\begin{tabular}{|c|c|c|c|c|c|c|}
\hline Parameter & Symbol & Unit & Range & Value & $\begin{array}{c}\text { Standard } \\
\text { deviation } \\
{[\%]}\end{array}$ & Ref \\
\hline $\begin{array}{l}\text { Transverse } \\
\text { conductivity }\end{array}$ & $k$ & {$[\mathrm{~W} /(\mathrm{m} \mathrm{K})]$} & $0.34-0.75$ & 0.72 & 7 & [18] \\
\hline Density & $\rho$ & {$\left[\mathrm{kg} / \mathrm{m}^{3}\right]$} & $1524-1601$ & 1560 & 2 & 101 \\
\hline Specific heat & $c_{p}$ & {$[\mathrm{~J} /(\mathrm{kg} \mathrm{K})]$} & $800-1700$ & 1425 & 17 & \\
\hline Heat capacity & $\rho c_{p}$ & {$\left[\mathrm{~J} /\left(\mathrm{m}^{3} \mathrm{~K}\right)\right]$} & $0.34-0.75 \cdot 10^{6}$ & $2.22 \cdot 10^{6}$ & 15 & [18] \\
\hline Refractive index & $n_{2}$ & {$[-]$} & 1.95 & 1.95 & - & 7 \\
\hline Emissivity & $\epsilon$ & {$[-]$} & 0.9 & 0.9 & - & {$[5]$} \\
\hline
\end{tabular}

Table 2.B.3 Heat transfer coefficients for C/PEEK [18].

\begin{tabular}{lccc}
\hline Parameter & Symbol & Unit & Value \\
\hline Tape-compaction roller & $h_{\mathrm{r}}$ & {$\left[\mathrm{W} \mathrm{K} / \mathrm{m}^{2}\right]$} & 20 \\
Laminate-tool & $h_{\mathrm{t}}$ & {$\left[\mathrm{W} \mathrm{K} / \mathrm{m}^{2}\right]$} & 500 \\
Tape-air & $h_{\text {air }}$ & {$\left[\mathrm{W} \mathrm{K} / \mathrm{m}^{2}\right]$} & 200 \\
\hline
\end{tabular}

The effect of the material properties and heat transfer coefficients on the nip-point temperature is shown in Figure 2.B.3. A variation of plus and minus 5\% was applied to the material properties and a variation of plus $200 \%$ and minus $67 \%$ to the surface heat transfer coefficients. It can be seen that the model is most sensitive to the volumetric heat capacity, as a variation of $5 \%$ causes a change in nip-point temperature of more than $20{ }^{\circ} \mathrm{C}$. The model is less sensitive to the other material properties. A large variation in heat transfer coefficients also results in only a small 
change in nip-point temperature. The heat transfer to the tool is even negligible, as the conductivity of the material is relatively low and the laminate relatively thick.

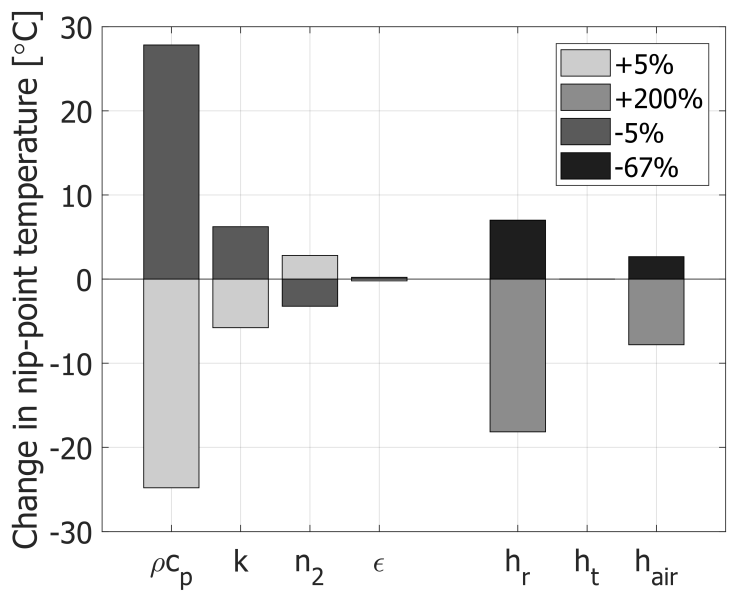

Figure 2.B.3 Sensitivity of the thermal model to a variation in material parameters and boundary conditions.

A variation in material parameters and heat transfer coefficients is taken into account in the validation of the thermal model to account for possible deviation of the material parameters. A variation of $\pm 5 \%$ is taken into account for the volumetric heat capacity and $\pm 2 \%$ for the transverse conductivity. The volumetric heat capacity varies more over a temperature range between 150 and $400{ }^{\circ} \mathrm{C}$ and, therefore, a larger variation is taken into account. A variation of $+100 \%$ and $-50 \%$ is taken into account for the heat transfer coefficients as the reported variation in literature is large.

\section{C Thermal camera calibration}

A thermal camera is used during LAFP to measure the temperature during the process. The heat is focused on the nip-point area, to heat the material up to over $500{ }^{\circ} \mathrm{C}$. The thermal camera measures the temperature based on the emitted infrared radiation (between 7.5 and $13 \mu \mathrm{m}$ wavelength). The relation between the amount of radiation and the surface temperature depends, among other things, on the emissivity of the material, reflections of other surfaces and the incidence angle of the camera with the surface. The nip-point has a complex geometry, with a hot tape and a hot substrate, and the measurements are highly affected by reflections of infrared radiation in this area. An experiment was designed to approximate the emissivity at different areas near the nip-point. The approximated emissivity can be used to improve the accuracy of thermal measurements during placement. In this 
appendix the experimental procedure will be explained and the resulting emissivities are given.

\section{Experimental procedure}

A setup, representing the nip-point area, was made and heated in an oven. Thermocouples were embedded in the material and the surface temperature was measured using the thermal camera. Two different orientations were used for the top ply of the substrate, in the direction of placement $\left(0^{\circ}\right)$ and perpendicular to the direction of placement $\left(90^{\circ}\right)$. Furthermore, three incidence angles of the camera were considered and measurements were taken over a range of temperatures.

\section{Materials and equipment}

The material used for this experiment was a C/PEEK UD prepreg tape provided by TenCate. The fiber volume content was $59 \%$ and the tape was slitted at a quarter inch. Thermocouples with a thickness of $0.013 \mathrm{~mm}$ were welded and insulated with polyimide tape. The thermal camera was Micro-Epsilon thermalIMAGER TIM 400. An Instron environmental chamber capable to reach $600{ }^{\circ} \mathrm{C}$ was used.

\section{Specimen preparation}

Two plies were placed with the LAFP robot to build up the substrate and three thermocouples were embedded below the top ply. A thermocouple was placed on the top ply at the nip-point. Then two single tapes were placed on top of each other on the substrate, to serve as the tape part of the process. Three thermocouples were embedded between these tapes. The resulting geometry is illustrated in Figure 2.C.1.

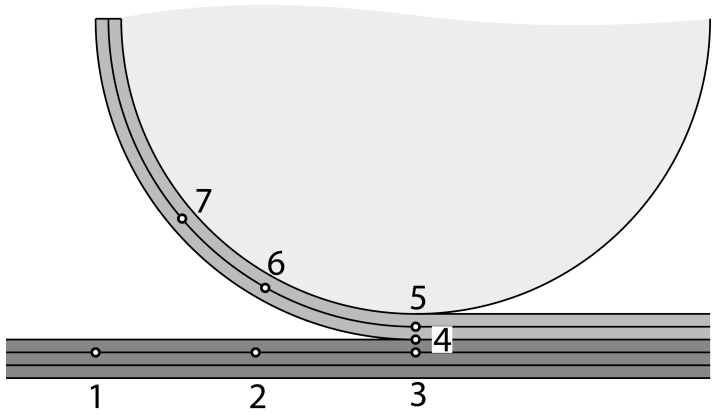

Figure 2.C.1 A sketch of the setup with the position of the thermocouple. 


\section{Measurement}

The setup was placed in an oven, as is shown in Figure 2.C.2(a) and heated until a constant temperature was read from the thermocouples, then the door of the oven was opened and a measurement of about $10 \mathrm{~s}$ was done by the thermal camera. An image of the thermal camera is given in Figure 2.C.2(b), including the measurement areas considered. This was done for two orientations of the substrate and three incidence angles of the camera over a range of temperatures.

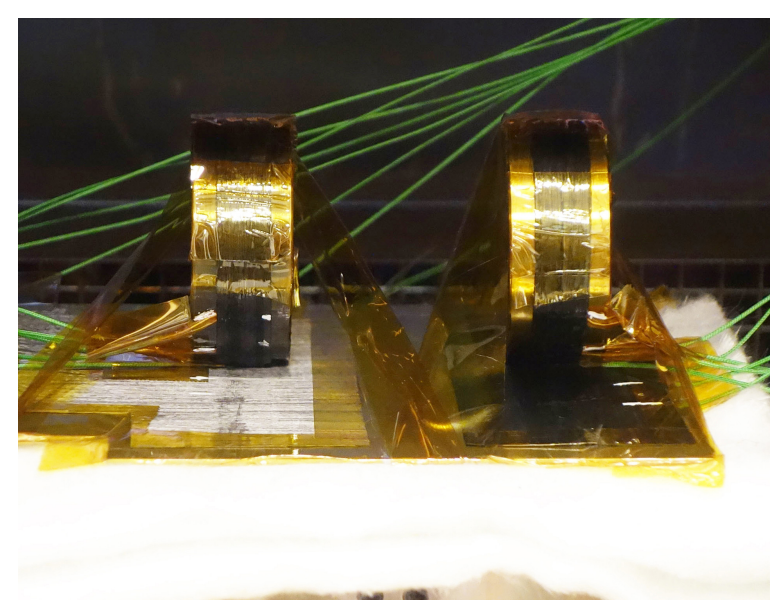

(a)

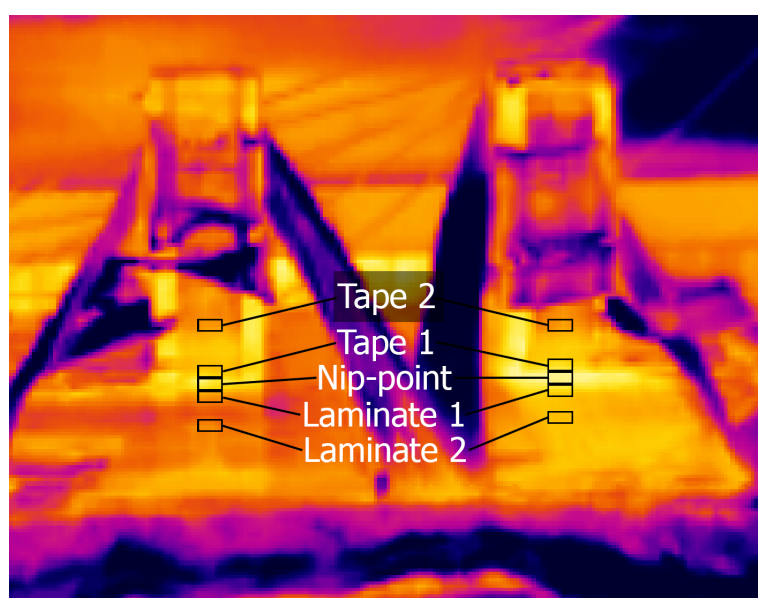

(b)

Figure 2.C.2 (a) The setup used to estimate the emissivity values in the nip-point region placed in an oven and (b) an image of the thermal camera measurement including the considered measurement areas.

\section{Analysis}

The temperature was measured with seven thermocouples and five measurement areas in the thermal camera for both of the two substrate orientations. The location of the measurement areas in the thermal camera image were based on the measurements areas used during LAFP. The positions of the thermocouples were not perfectly in line with the measurement areas and therefore an average was taken for each measurement area for a number of thermocouples. This is shown in Table 2.C.1.

The thermocouple and thermal camera measurements were compared over a range of between 5 and $10 \mathrm{~s}$. Then the emissivity of each measurement area was adjusted to better match the thermocouple results. An example is shown for the nip-point temperature at $375{ }^{\circ} \mathrm{C}$ in Figure 2.C.3. The temperature measured with the thermal camera shows the same trend as the thermocouple measurement, however, it deviates with about $10{ }^{\circ} \mathrm{C}$ at an emissivity of 1 . When the emissivity is corrected to 1.055 the 
Table 2.C.1 The thermocouples used in the comparison with the measurement areas of the thermal camera.

\begin{tabular}{lc}
\hline Measurement area & Average of thermocouple \\
\hline Tape 2 & 7 \\
Tape 1 & 5 and 6 \\
Nip-point & 3,4 and 5 \\
Laminate 1 & 2 and 3 \\
Laminate 2 & 1 \\
\hline
\end{tabular}

thermal camera measurement matches the thermocouple measurement. The fitting was done for each measurement. An emissivity was determined to minimize the deviation from the thermocouple measurement for each measurement area for each incidence angle and substrate orientation. The deviation was defined as the average difference between the thermocouple and thermal camera measurement.

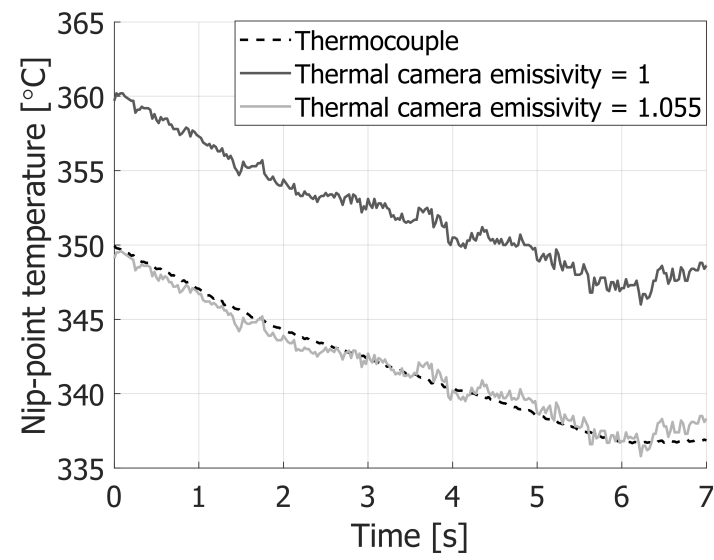

Figure 2.C.3 Comparison of the thermocouple measurement to the thermal camera measurement and the calibrated measurement of the nip-point area at $375^{\circ} \mathrm{C}$, a camera inclination of $17^{\circ}$ and a substrate orientation of $0^{\circ}$.

\section{Results}

The emissivity has been determined for each measurement area for the different substrate orientations. An emissivity above 1 means that the temperature is overestimated due to reflections compared to an emissivity of 1. Figure 2.C.4 shows the average difference in temperature for a number of measurement areas for an emissivity of 1 and a calibrated emissivity. In Figure 2.C.4(a) the results for the nip-point area are shown. It can be seen that with an emissivity of 1.055 , the difference between the thermocouple and thermal camera measurements is within 
$2.5^{\circ} \mathrm{C}$. A similar accuracy is obtained for the nip-point area for the $90^{\circ}$ substrate in Figure 2.C.4(b), but for the tape and laminate measurement areas the accuracy is usually a bit less with a deviation within $5^{\circ} \mathrm{C}$.

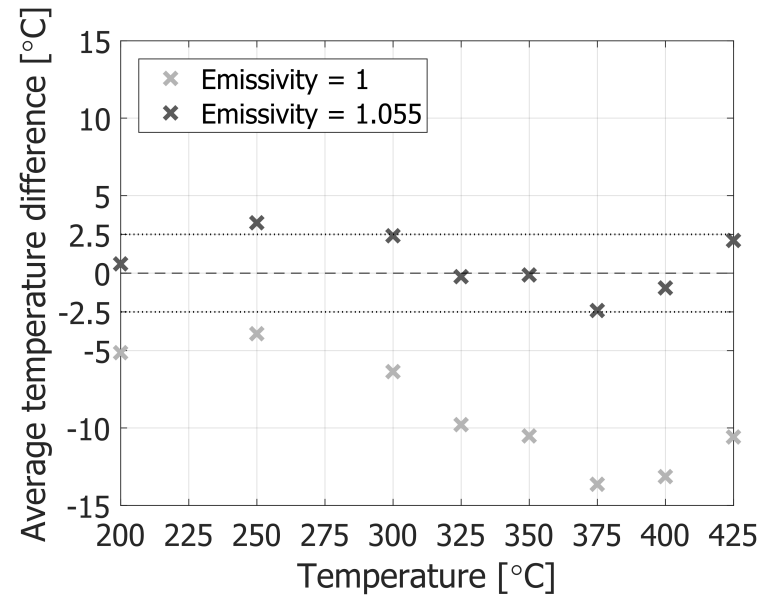

(a)

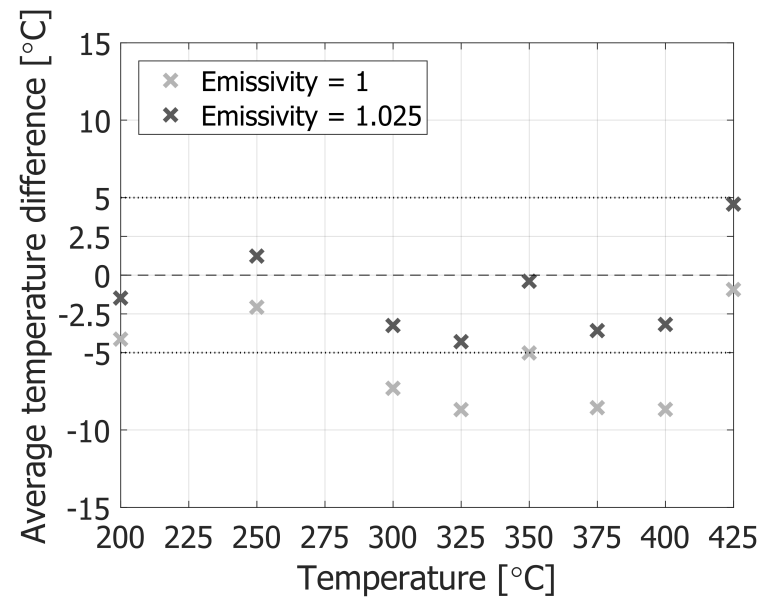

(c)

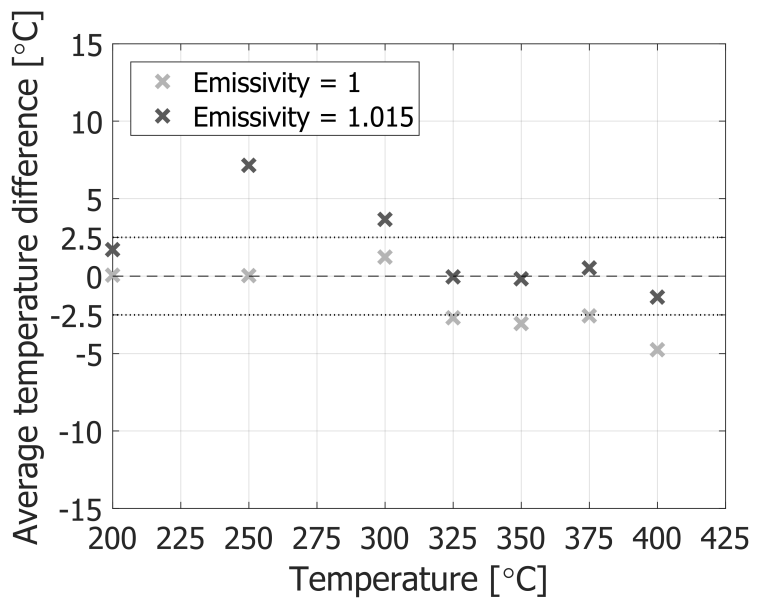

(b)

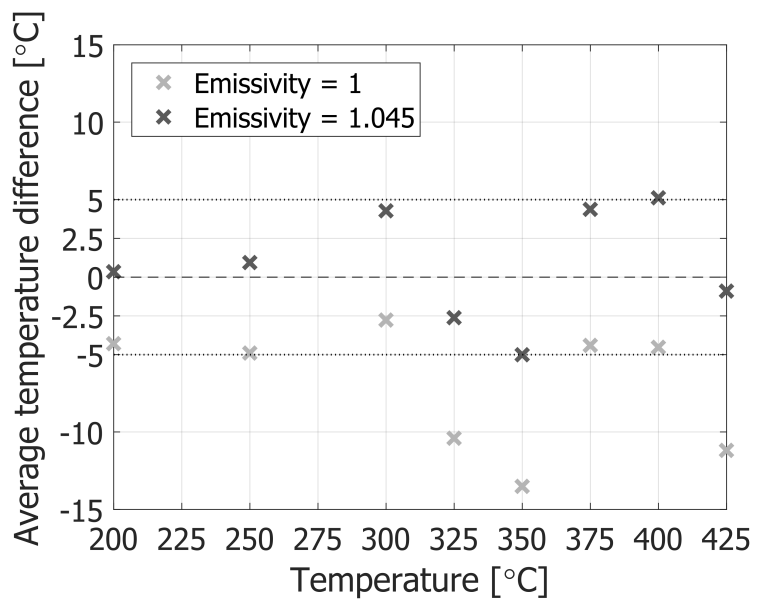

(d)

Figure 2.C.4 The average difference between the thermocouple and thermal camera measurement with an inclination of the camera of $17^{\circ}$ for the nip-point measurement area for the (a) $0^{\circ}$ substrate and (b) $90^{\circ}$ substrate, and (c) for the tape 1 measurement area for the $0^{\circ}$ substrate and (d) the laminate 1 measurement area for the $0^{\circ}$ substrate.

The resulting emissivity values to achieve an accuracy of within $2.5^{\circ} \mathrm{C}$ for the nippoint measurement areas and within $5{ }^{\circ} \mathrm{C}$ for the tape and laminate measurement areas are given in Table 2.C.2. It can be seen that the emissivity of the nip-point should always be greater than 1 and is a function of the substrate orientation and inclination of the camera. A different emissivity is required for the laminate depending on the substrate orientation. While the emissivity should be above 1 for a $0^{\circ}$ orientation, it should be smaller than 1 for a $90^{\circ}$ substrate orientation. Thus, the fibers in the material govern the emission of the measured infrared radiation. 
The effect of the substrate orientation is also observed for the nip-point and tape 1 measurement area, but the effect is smaller, as could be expected, for the tape- 2 measurement area.

The emissivity values to calibrate the thermal camera measurements have been determined for varying camera inclination and substrate orientation. The obtained values should be used in order to obtain accurate thermal camera measurements during LAFP.

Table 2.C.2 Calibrated emissivity based on thermocouple measurements for the different measurement areas.

\begin{tabular}{lccc|ccc}
\hline & \multicolumn{3}{c}{$0^{\circ}$ substrate } & \multicolumn{3}{c}{$90^{\circ}$ substrate } \\
& Camera inclination & \multicolumn{2}{c}{ Camera inclination } \\
Measurement area & $10^{\circ}$ & $17^{\circ}$ & $25^{\circ}$ & $10^{\circ}$ & $17^{\circ}$ & $25^{\circ}$ \\
\hline Nip-point & 1.055 & 1.055 & 1.065 & 1.025 & 1.015 & 1.015 \\
Tape 1 & 1.045 & 1.025 & 1.065 & 0.990 & 0.990 & 1.010 \\
Tape 2 & 0.990 & 0.980 & 1.025 & 0.965 & 0.970 & 1.025 \\
Laminate 1 & 1.035 & 1.045 & 1.040 & 0.915 & 0.960 & 0.930 \\
Laminate 2 & 1.030 & 1.035 & 1.045 & 0.945 & 0.955 & 0.945 \\
\hline
\end{tabular}




\title{
Chapter 3
}

\section{Tape Deconsolidation during Laser Assisted Fiber Placement *}

\begin{abstract}
The high interlaminar void content in in-situ consolidated parts by Laser Assisted Fiber Placement (LAFP) is one of the remaining challenges before it can be industrialized. One of the causes of interlaminar voids might be deconsolidation of the tape during the heating phase, prior to the nip-point, and this has not been considered in the past. An experimental investigation was performed on C/PEEK tapes of three tape manufacturers to analyze the tape consolidation state just prior to the nip-point. It was shown that the tape deconsolidates during the short time it is heated by the laser, resulting in an increased surface roughness and a matrix-poor surface.
\end{abstract}

${ }^{*}$ Reproduced from: T. Kok, W.J.B. Grouve, L.L. Warnet, R. Akkerman. Tape deconsolidation during laser assisted fiber placement, Submitted to: Composites B: Engineering 


\subsection{Introduction}

Laser Assisted Fiber Placement (LAFP) has potential for in-situ consolidation of thermoplastic composites parts for the aerospace industry. The process can be regarded as an additive manufacturing technique in which parts are built up ply by ply. Figure 3.1 shows the process schematically, a tape is heated by laser and pressure is applied to bond it to previously placed plies. Heat is applied using a laser to melt an incoming thermoplastic composite pre-impregnated tape and the previously placed plies. Subsequently, pressure is applied on the heated material using a compaction roller. As a result, intimate contact is created between the tape and the previously placed ply, followed by interdiffusion of polymer chains across the interface. The process is potentially cost-effective because an expensive post-consolidation step in an autoclave can be omitted, provided that sufficient consolidation quality is achieved. However, the consolidation quality obtained with conventional processes such as autoclave and press-consolidation cannot yet be achieved by LAFP in-situ consolidation.

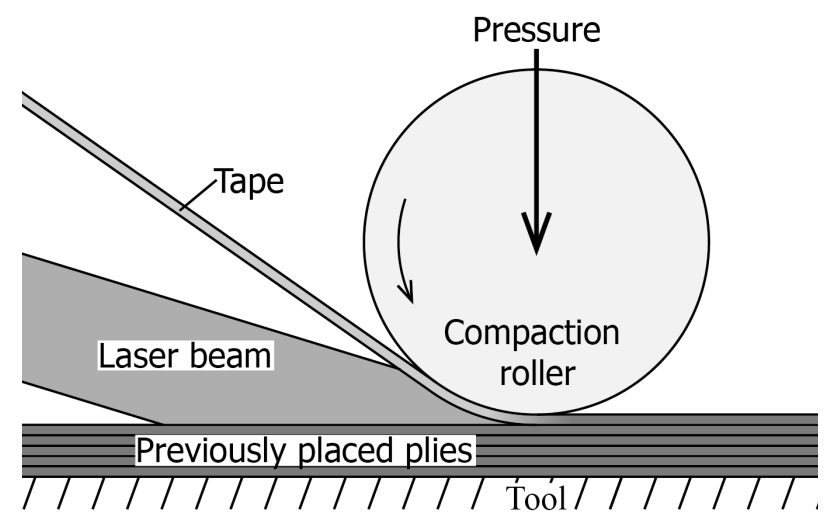

Figure 3.1 Schematic illustration of the LAFP process.

Major efforts have been spent the past decades on improving the consolidation quality achieved by Automated Fiber Placement (AFP). Material manufacturers, for example, have improved the tape quality and now offer tapes with smooth surfaces and a low void content to improve the processability [1-3]. In addition, AFP machines were further developed, for example with the use of efficient and better controllable laser heating in comparison with more conventional hot gas heating [4-6]. Furthermore, numerous predictive process simulation tools have been developed to assist in optimizing the process. Several models are available to predict the temperature distribution during the fiber placement process, ranging from simple 1D steady state approaches to more complex transient 3D finite element models [7-11]. Moreover, models are also available to predict degree of bonding, comprising intimate contact development and healing [12-14], the void content 
$[15,16]$ and degree of crystallinity $[9,17,18]$, using the aforementioned temperature distribution as an input. Despite these efforts, however, in-situ consolidation is not yet commercially applied in the production of aerospace structures.

One of the remaining challenges is the void content in components made by AFP, which still exceeds the aerospace limit $[19,20]$. One might expect that the introduction of high-quality tape materials would solve this issue. Although the amount of intralaminar voids, voids within a ply, is greatly reduced due to the improved consolidation quality of available tapes, interlaminar voids, voids between plies, are still apparent [21]. Interlaminar voids originate during processing and most likely from the lack of intimate contact between the tapes [22, 23]. The smooth surfaces of the currently available high quality tapes should facilitate the development of intimate contact, as is also shown with available intimate contact models. However, full intimate contact is not always achieved with these high-quality tapes.

This work investigates whether the tape consolidation quality is affected by the laser heating prior to the nip-point, i.e. before the tape is consolidated under the compaction roller, as a possible explanation for the aforementioned difficulty in obtaining intimate contact. Although the heating times are in the order of milliseconds, the tape is heated without the application of pressure. Morphological changes of the tape's meso structure during the heating phase possibly hinder the intimate contact development.

Morphological changes upon heating without applying pressure are well known in thermoplastic composite manufacturing and involve disintegration or deconsolidation of the meso structure [24]. This is characterized by an increase in surface roughness, an increase in thickness and an increase in void content. The latter is generally used to quantify the degree or severity of deconsolidation [25, 26]. Deconsolidation of thermoplastic composites has been studied for several material systems and was found to be mainly caused by fiber bed decompaction and expansion of moisture or volatiles [27]. However, the experimental work on this topic considered relatively low heating rates, representative for more conventional processing technologies, such as autoclave or press consolidation [24, 26, 27]. The heating times during LAFP are in the order of milliseconds and deconsolidation of the tape during the heating phase of LAFP is assumed to be negligible in literature. Hence, the effects of possible deconsolidation on the achieved consolidation quality were also not yet considered in literature.

The purpose of this research is to obtain both a qualitative and quantitative description of the tape morphology after the heating phase, just prior to the nip- 
point, to improve the understanding of material behavior during the LAFP process. Furthermore, a quantitative description of the consolidation state prior to the nippoint is required for improvement in intimate contact development predictions. For this purpose, experiments were performed to capture changes in the tape's consolidation state of three suppliers during the heating phase. The experimental method used to capture the tape's consolidation state prior to the nip-point is described in the following section. Subsequently, the resulting tape consolidation state was analyzed qualitatively using microscopy, followed by image analysis to obtain a quantitative description of the consolidation state. Then, the surface of the tape is analyzed using SEM images. In the final sections, the results are discussed and the conclusions and recommendations for future work are presented.

\subsection{Experimental work}

\subsubsection{Materials and equipment}

The experimental work was performed using a carbon fiber PEEK pre-impregnated tape with a 59\% fiber volume content from three different suppliers. A qualitative and quantitative analysis was performed on material from tape supplier A. The qualitative analysis has been performed on the materials supplied by supplier B and C, in order to compare the observations for different suppliers. The tapes were provided as slitted quarter-inch wide tape with a nominal thickness of $0.15 \mathrm{~mm}$, compatible with a Coriolis Composites fiber placement robot. The LAFP robot was equipped with a $1 \mathrm{~kW}$ laser as heating source, having a spot size of $28 \times 11 \mathrm{~mm}^{2}$ and a custom-made rigid PTFE roller.

\subsubsection{Specimen preparation}

The experimental work aimed to capture the tape consolidation state after being heated by the laser, prior to the nip-point. Therefore, it was necessary for 1) consolidation of the tape underneath the roller to be prevented and 2) the tape to be cooled quickly after heating to prevent further deconsolidation. Regarding the first point, consolidation of the tape was prevented by using brass shims and a rigid PTFE roller. As illustrated schematically in Figure 3.2, the shims ensure a fixed distance between the roller and the tool to provide space for the (deconsolidated) tape. Concerning the second point, a steel tool was used to provide quench cooling of the tape underneath the roller, thereby preventing further undesired deconsolidation under the roller. The challenge in this approach lies in selecting the appropriate shim thickness. On the one hand, the shims should be thick enough to prevent consolidation under the roller, while on the other hand the shims should be thin 
enough to ensure contact between the tape and the heat sink [28]. A custom-made roller was used to help select the appropriate shim thickness. The rigid PTFE roller featured an imprinted profile on its surface, as is also illustrated in Figure 3.2. The profile is imprinted on the tape surface, given that the tape is completely heated through, to provide an indication of the applied pressure on the tape. The shim thicknesses used are given in Table 3.1. As a reference, specimens were also manufactured without shims, hence there was full consolidation pressure both on a steel tool and on a steel tool covered with polyimide (PI) film. One specimen was made for each tape supplier and setting. The placement settings were constant for all specimens, aiming at a nip-point temperature of 400 to $450{ }^{\circ} \mathrm{C}(350 \mathrm{~W}$ of laser power) with a placement rate of $100 \mathrm{~mm} / \mathrm{s}$.

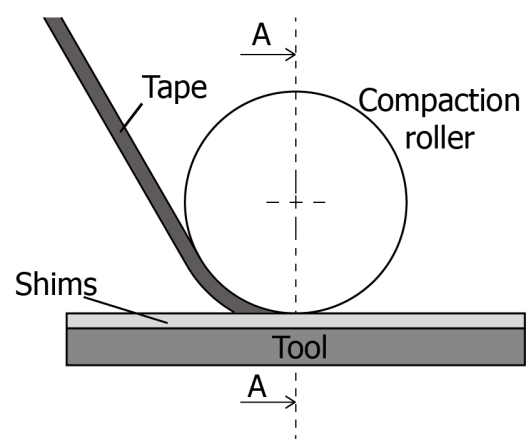

(a)

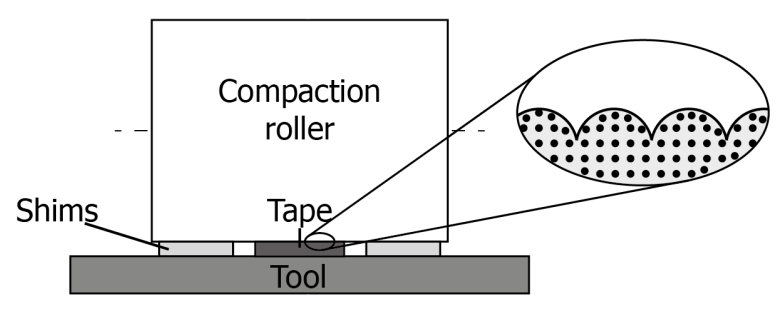

(b)

Figure 3.2 Setup used to place tapes with reduced pressure, including a roller with an imprinted pattern. (a) Side view and (b) view A-A.

Table 3.1 The tool and shim thickness used for the different specimens.

\begin{tabular}{lcc}
\hline Specimen & Tool material [-] & Shim thickness $[\mu \mathrm{m}]$ \\
\hline Polyimide film & Polyimide film on steel & 0 \\
Steel & Steel & 0 \\
$150 \mu \mathrm{m}$ & Steel & 150 \\
$160 \mu \mathrm{m}$ & Steel & 160 \\
$175 \mu \mathrm{m}$ & Steel & 175 \\
\hline
\end{tabular}

\subsubsection{Analysis}

The placed tapes were cut, embedded in epoxy and polished for cross-sectional microscopy purposes. Three measurements per specimen were performed and the full width of the quarter-inch tape was analyzed for the tape of supplier A. One measurement per specimen was taken for the tapes of suppliers B and C. The outer $10 \%$ of each tape was discarded to avoid any effects of geometrical variation in the 
edges of the tapes [29]. A Keyence VHX-5000 digital microscope was used to obtain high contrast cross-sectional microscopy images at a 1000x magnification, which were then analyzed both qualitatively and quantitatively. The qualitative analysis was performed on the tapes of all three suppliers. The quantitative analysis was only performed for the tape of supplier A and consisted of two parts. First, the distribution of the constituents (i.e. fiber, matrix and voids) over the thickness was obtained, following the procedure outlined in detail in a separate paper [30]. Second, the roughness of the heated surface was obtained from the microscopy images. For this purpose, the tape edge was identified from the image. Subsequently a high-pass filter was applied to remove any global curvature of the tape surface, after which the root mean square (RMS) roughness was determined [30]. Furthermore, SEM images were made of the heated surface of the tape, using a Jeol Neoscope JCM 5000, in order to qualitatively analyze the tape surfaces in terms of the amount of fibers and matrix.

\subsection{Results}

The experimental results are presented in this section. First, the cross-sectional microscopy analysis is provided, consisting of a qualitative and a quantitative analysis. Second, the heated surface of the tape is analyzed with the use of a SEM images.

\subsubsection{Cross-sectional micrography}

\section{Qualitative analysis of cross-sectional micrography}

Cross-sectional micrographs of the as-received and processed tapes were analyzed to describe the effects of the shim thickness on the tape morphology. More specifically, three features were analyzed, namely the morphology of the surface which was in contact with the roller, the morphology of the heated surface, which may have been in contact with the tool, and the global void content and distribution. First the tape of supplier $A$ is analyzed and then the tapes of suppliers B and C are compared with that of supplier A.

A typical selection of the analyzed cross-sections of tape provided by supplier A is shown in Figure 3.3. The upper surface of the processed tapes, which was in contact with the roller, is referred to as the top surface, while the lower surface, which was first heated by the laser and then brought in contact with the tool, is referred to as the heated surface. As a reference, Figure 3.3(a) shows the as-received tape, which has 
smooth surfaces and a low void fraction. The morphology of the tapes placed with shims, as shown in the micrographs in the right-hand column of Figure 3.3, clearly differs from the morphology of the as-received tape. The tapes have deconsolidated during the experiments, resulting in an increased void content and a rough heated surface. This deconsolidation is studied in more detail in the remainder of this section

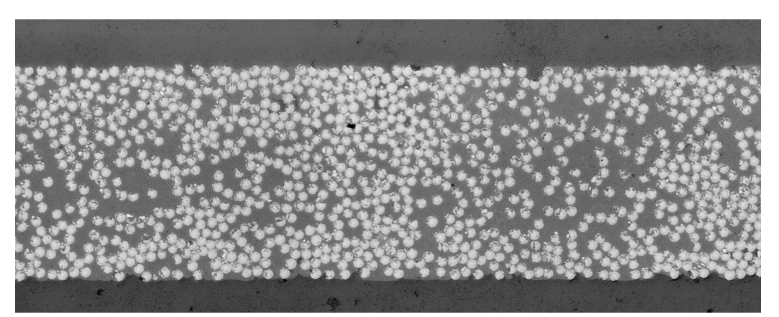

(a)

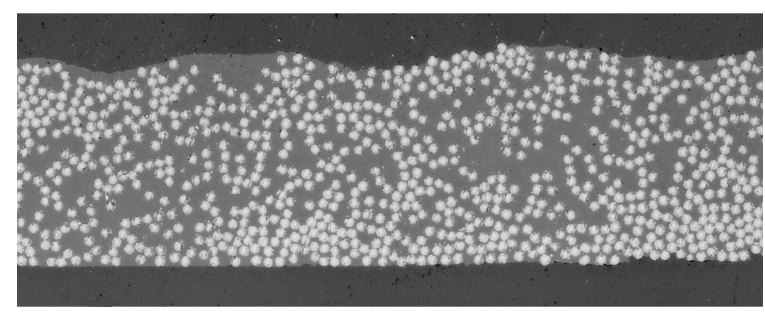

(c)

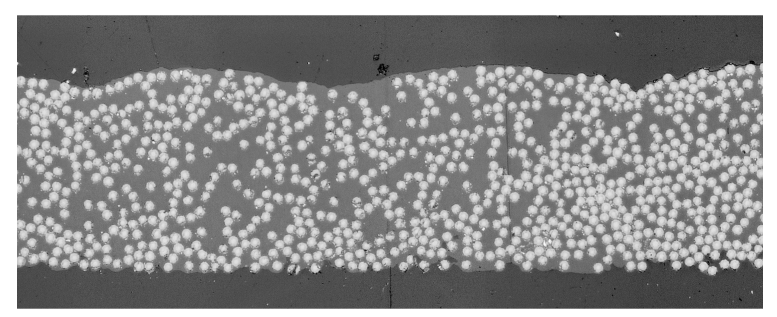

(e)

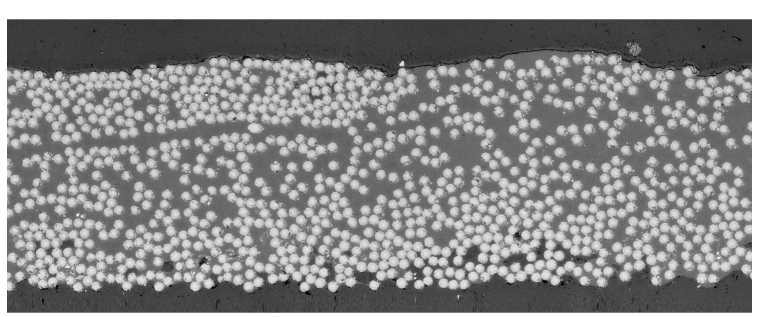

(b)

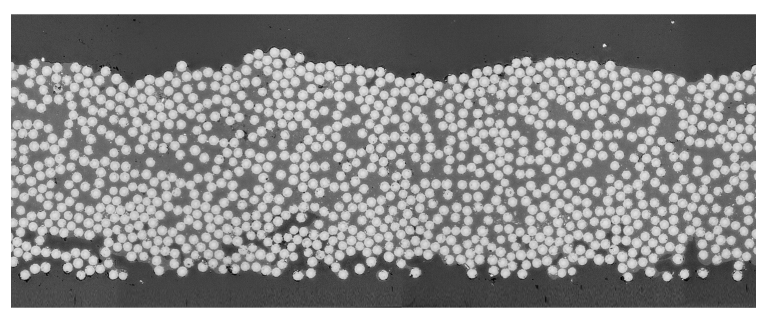

(d)

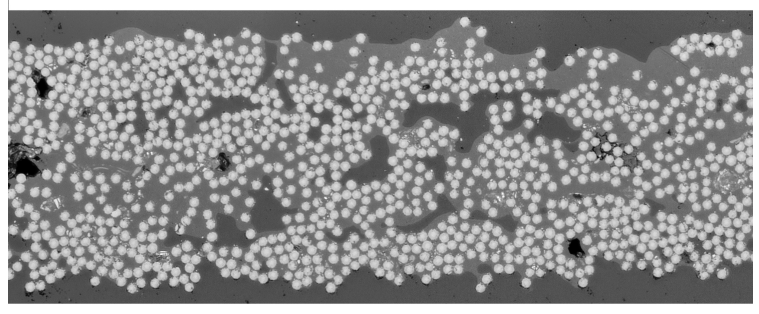

(f)

Figure 3.3 Cross-sections of the tape specimens of supplier A. For the processed tapes the top surface was in contact with the roller and the bottom surface was the heated surface, which was subsequently in contact with the tool. (a) As-received tape, (b) tape placed on steel tool with $150 \mu \mathrm{m}$ shims, (c) tape placed on steel tool covered with polyimide film, (d) tape placed on steel tool with $160 \mu \mathrm{m}$ shims, (e) tape placed on steel tool, $(f)$ tape placed on steel tool with 175 rm shims.

First, the morphology of the top surface of the different tapes of supplier A were analyzed. Compared to the as-received tape, with a nominal thickness of $150 \mu \mathrm{m}$, it can be seen that the top surfaces of the processed tapes show an imprint of the roller pattern in case no shims are used and with shims of $150 \mu \mathrm{m}$ and $160 \mu \mathrm{m}$. This indicates that the tape was fully heated through the thickness and sufficient pressure was applied to deform the top surface of the tape. The pattern cannot be observed 
on the tape placed with $175 \mu \mathrm{m}$ shims, as shown in Figure 3.3(f), indicating that no pressure or very little pressure was applied on the tape. As a result, the tape most probably had no proper contact with the tool underneath the roller.

Second, the morphology of the heated surface of the tapes was analyzed. The tape placed on smooth polyimide film without shims has a very smooth heated surface, as can be seen for the tape shown in Figure 3.3(c). The heated surface of the tape placed on a steel tool without shims has a higher surface roughness than the tape placed on polyimide film. This is probably due to limited reconsolidation of the tape under the roller, since the steel tool, acting as a heat sink, caused fast cooling of the tape surface. The roughness of the heated surface increases with the use of shims, as the amount of reconsolidation reduces with increasing shim thickness. Furthermore, a part of the fibers on the heated surface seem to pop out of the surface, which can be seen most clearly for the tape placed with $160 \mu \mathrm{m}$ shims.

Third, the void content in the tapes of supplier A was analyzed. Almost no voids can be observed in the tape placed on polyimide film without shims, shown in Figure 3.3(c), indicating that this tape was well consolidated under the applied pressure. However, some voids can be observed near the heated surface of the tape placed on the steel tool without shims. This is probably caused by steel tool which acts like a heat sink, resulting in a high cooling rate and limited time for reconsolidation. The void fraction near the heated surface of the tape increases with increasing shim thickness, and hence decreasing pressure, as can be seen in Figures 3.3(b) and 3.3(d). The tape placed with $175 \mu \mathrm{m}$ shims shows large voids throughout the thickness of the tape. The consolidation quality of this tape is much lower compared to the other tapes.

The cross-sections of tape from supplier A can be compared with cross-sections of the as-received and processed tapes of supplier B and C. Figure 3.4 shows a selection of typical cross-sections. Figure 3.4(a) and 3.4(b) depict the as-received tape for supplier B and C. Whereas the as-received tape of supplier B looks similar to tape of supplier $A$, the as-received tape of supplier $C$ is distinctly different. The fibers are less uniformly distributed over the cross-section and the middle of the tape shows a large resin rich area. Furthermore, the surface of the tape from supplier C, which are fiber-rich, are not completely impregnated.

The same features - the morphology of the top surface, and the morphology of the heated surface and void content - are now analyzed for the tapes of suppliers B and $\mathrm{C}$ as well. First, the top surfaces of tapes of suppliers B and C are compared with the tape of supplier A. The same imprint of the roller pattern can be observed on the processed tapes, except for the tapes placed with $175 \mu \mathrm{m}$ shims, which again 


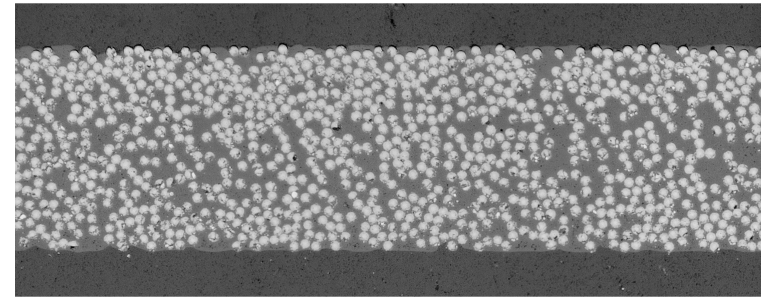

(a)

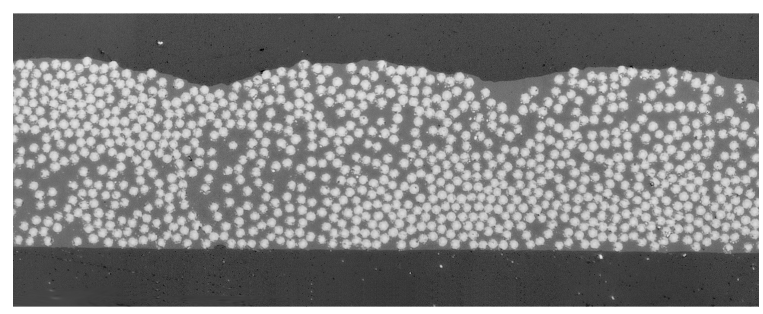

(c)

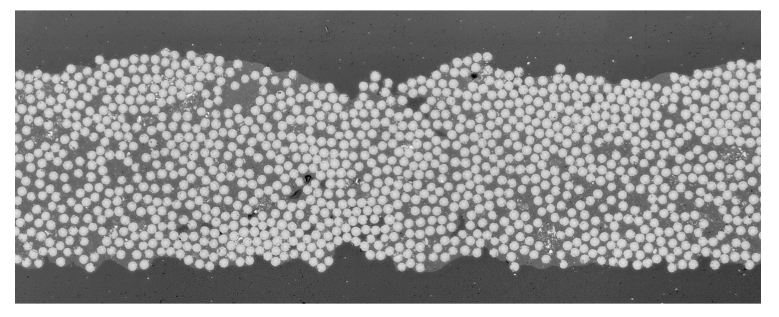

(e)

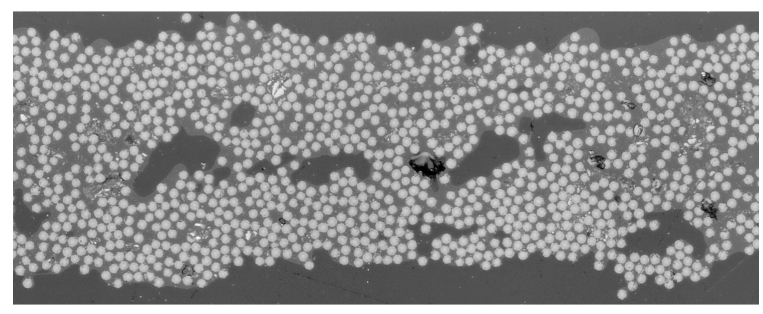

(g)

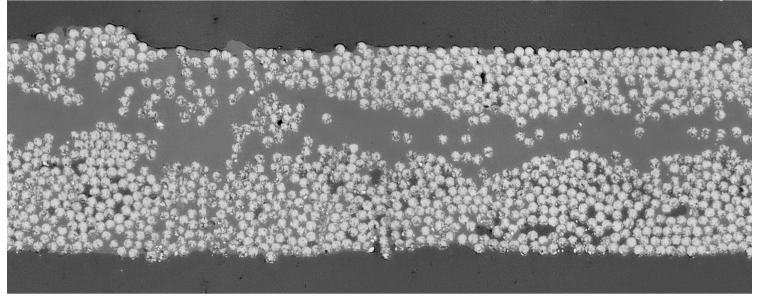

(b)

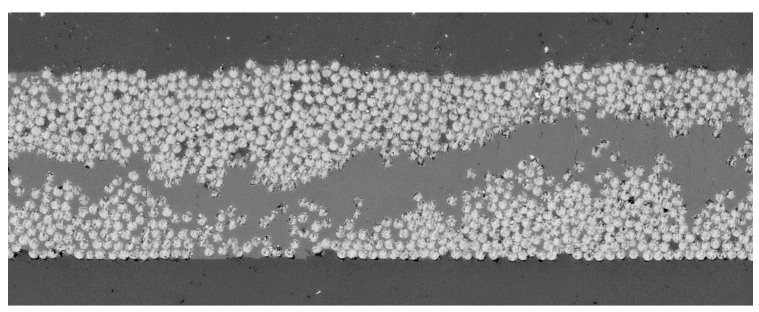

(d)

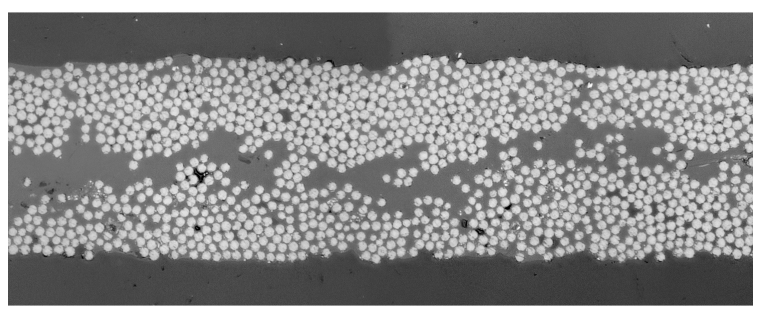

(f)

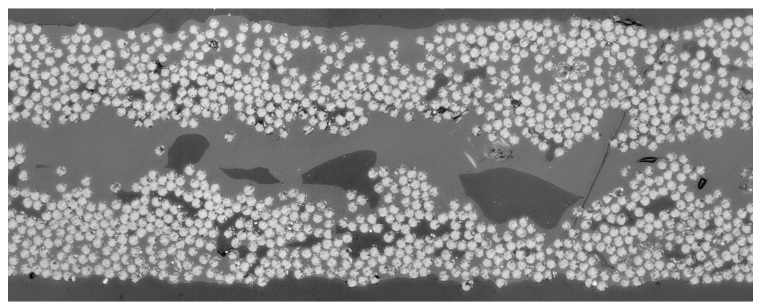

(h)

Figure 3.4 Cross-sections of the tape specimens from suppliers $B$ and C. For the processed tapes, the top surface was in contact with the roller and the bottom surface was the heated surface, which was subsequently in contact with the tool. Tapes from supplier B in the left column: (a) as-received, (c) placed on a steel tool covered with polyimide film, (e) placed on a steel tool with $160 \mu \mathrm{m}$ shims and (g) placed on a steel tool with 160. Tapes from supplier $C$ in the right column: (b) as-received, (d) placed on a steel tool covered with polyimide film, (f) placed on a steel tool with $160 \mu \mathrm{m}$ shims and $(\boldsymbol{h})$ placed on a steel tool with 160.

indicates a loss of consolidation pressure. However, the imprint is less pronounced for the tape of supplier C.

Second, the heated surfaces of the tapes of suppliers B and C are compared to the heated surfaces of the tape of supplier A. The tapes placed on polyimide film 
have a smooth surface, although the surface of tape of supplier $C$ seems to be less smooth and fiber-rich. The tapes placed with shims have a rough surface, as was also observed for supplier A. The heated surface of the tape of supplier B and supplier $C$ placed with $160 \mu \mathrm{m}$ shims of also has an increased roughness. The lose fibers, observed for the tape of supplier A, however, are less apparent for the tapes of suppliers B and C.

Finally, the void content of the tapes of suppliers B and C are compared with that of supplier A. The as-received tape of supplier B is similar to supplier A and almost void free. The tape placed with $160 \mu \mathrm{m}$ shims has small voids close to the heated surface, while large voids through the thickness can be observed when the tape is placed with $175 \mu \mathrm{m}$ shims. The void content is different for the tape of supplier C. The as-received tape already contains intralaminar voids, which are not completely removed after placement on polyimide film, as can be observed in Figure 3.4(d). These voids are also apparent in the tape placed with $160 \mu \mathrm{m}$ shims and expanded for the tape placed with $175 \mu \mathrm{m}$ shims.

The cross-sectional microscopy results showed distinct differences in terms of void content and fiber distribution for the as-received tapes. Despite these differences, it was shown that the tape of all three suppliers deconsolidated during the heating phase of LAFP prior to the nip-point. For the tapes of all three suppliers the deconsolidation resulted in a rough heated surface and increase in void content.

\section{Quantitative analysis of cross-sectional micrography}

Following the qualitative analysis of the tapes of suppliers A, B and C in the previous section, the present section provides a quantitative analysis of the tape of supplier A. For this purpose, the constituent distribution over the tape thickness was calculated based on image analysis of the cross-sectional micrographs. As an example, Figure 3.5 shows a part of the cross-section of the tape placed with $160 \mu \mathrm{m}$ shims, of which the original image is shown in Figure 3.3(d). The different constituents are identified, with the fibers shown in light grey, the matrix in dark grey and voids enclosed in the tape in black, while the air outside of the tape is shown in white. The constituent content and distribution as well as the roughness of the heated surface were determined from images like these and will be discussed in the remainder of this section.

The fiber, matrix and void content and the surface roughness of the heated surface are given in Table 3.2 for each of the test specimens. The average fiber volume content was close to the specifications of the manufacturer (59\%), except for the tapes placed with $175 \mu \mathrm{m}$ shims, which have a lower fiber volume content due to the high void 


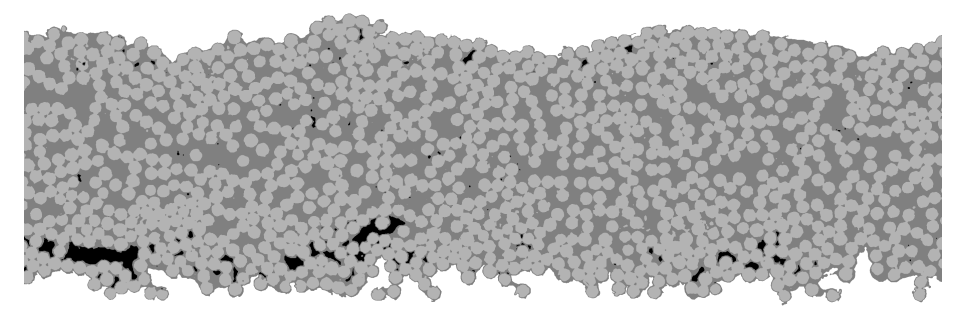

Figure 3.5 Image of a tape placed tape with $160 \mu \mathrm{m}$ shims where the different constituents are identified. Fibers are shown in light grey, matrix in dark grey, voids in black and outside air in white

content. It is good to mention that, when only the matrix and fibers are considered, the fiber volume content for all specimens is $59 \%$. In other words, this indicates that no matrix evaporated. The void content is, as expected from the qualitative analysis of the microscopy images, increasing with increasing shim thickness. The surface roughness of the heated bottom surface is the lowest for the tape placed on the tool covered with polyimide film and somewhat higher for the tape placed on a steel tool. The surface roughness increases with increasing shim thickness, with a maximum value for the tape placed with $175 \mu \mathrm{m}$ shims.

Table 3.2 Global properties of the different specimens of the tape of supplier A. Mean values are shown with standard deviation between brackets.

\begin{tabular}{lcccc}
\hline Specimen & \multicolumn{3}{c}{ Volume fractions } & RMS Roughness \\
& Fiber [\%] & Matrix [\%] & Void [\%] & {$[\mu \mathrm{m}]$} \\
\hline As-received & $57(2.4)$ & $42(2.4)$ & $0.75(0.2)$ & $2.2(0.5)$ \\
Polyimide film & $60(3.8)$ & $40(3.9)$ & $0.4(0.1)$ & $1.7(0.2)$ \\
Steel & $58(1.0)$ & $41(1.0)$ & $0.5(0.1)$ & $2.8(0.2)$ \\
$150 \mu \mathrm{m}$ & $58(1.6)$ & $40(1.5)$ & $1.0(0.2)$ & $3.9(0.6)$ \\
$160 \mu \mathrm{m}$ & $57(0.8)$ & $42(1.0)$ & $1.1(0.2)$ & $4.1(0.4)$ \\
$175 \mu \mathrm{m}$ & $55(1.6)$ & $38(1.7)$ & $6.9(0.9)$ & $7.8(0.7)$ \\
\hline
\end{tabular}

Fiber, matrix and void distributions over the thickness were obtained from three microscopy images of each specimen. The average distribution was calculated for each specimen and is shown in Figure 3.6. Although the average fiber volume content is about $59 \%$ as specified, the specimens showed a non-uniform fiber distribution over the thickness with a higher fiber content near the surfaces. This is observable both for the as-received tape and for each processed tape. The void content is low for the asreceived tape and the tape placed on polyimide film. The tape placed on a steel tool, shown in Figure 3.6(e), shows some voids near the heated surface of the tape. The void content increases when the pressure is reduced by increasing the shim thickness. The voids are located predominantly near the heated surface of the tape for the tapes placed with $150 \mu \mathrm{m}$ and $160 \mu \mathrm{m}$ shims, as shown in Figure 3.6(b) and 3.6(d). The tape 


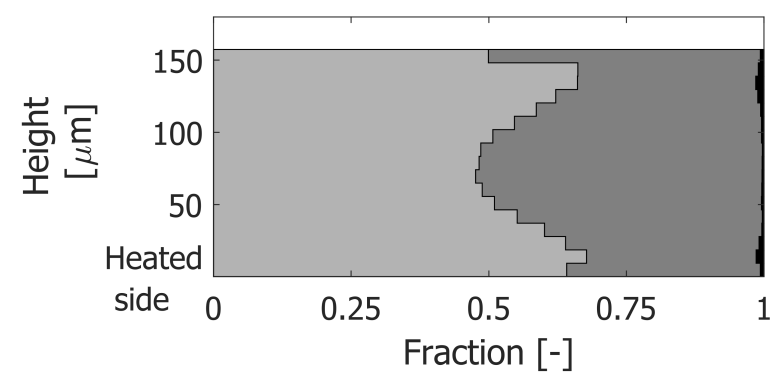

(a)

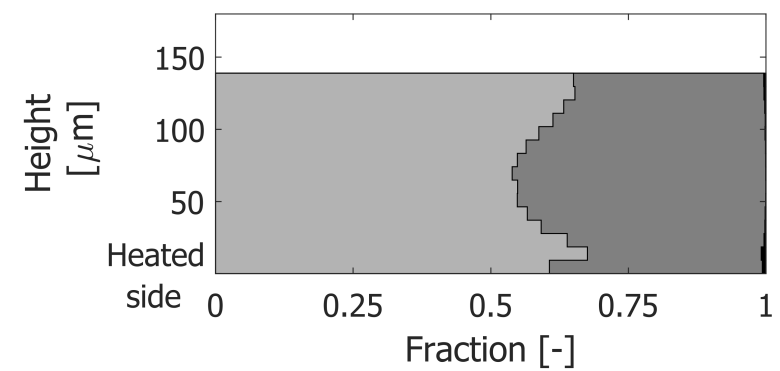

(c)

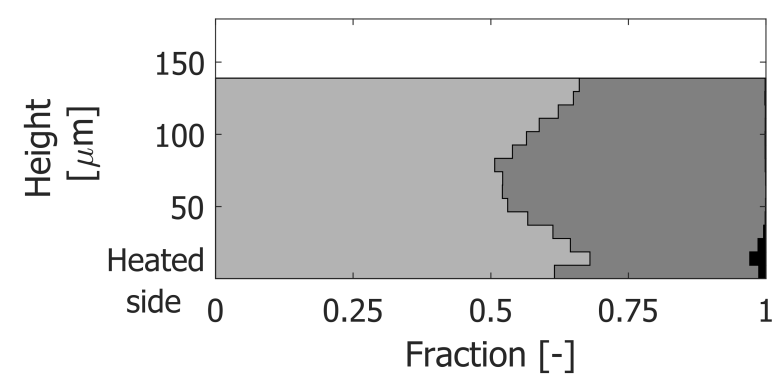

(e)

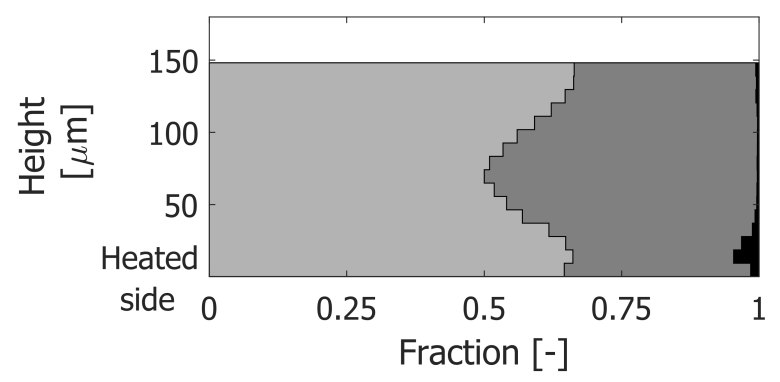

(b)

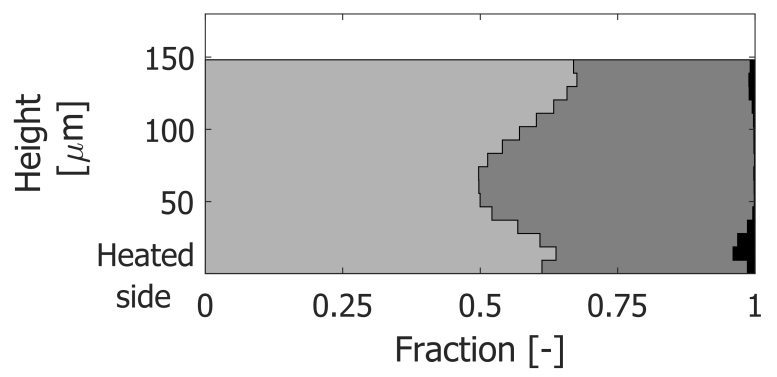

(d)

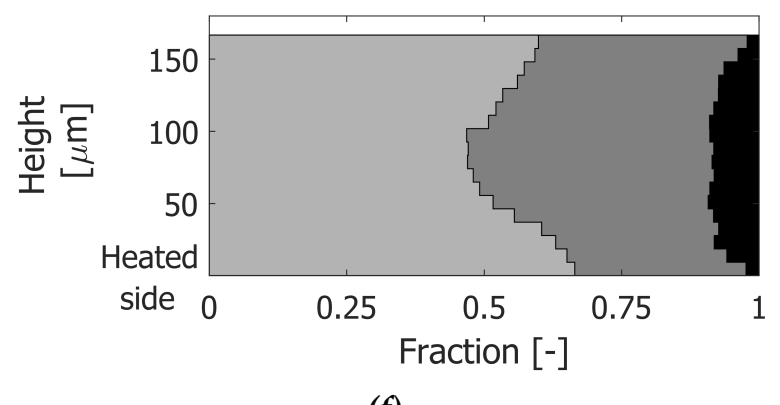

(f)

Figure 3.6 Through thickness constituent distributions of the tapes of supplier A. The fiber volume content is shown in light grey, the matrix content in dark grey and the void content in black. (a) As-received tape, (b) tape placed on steel tool using $150 \mu \mathrm{m}$ shims, (c) tape placed on steel tool covered with polyimide film, (d) tape placed on steel tool using $160 \mu \mathrm{m}$ shims, (e) tape placed on steel tool, $(f)$ tape placed on steel tool using $175 \mu \mathrm{m}$ shims.

placed with $175 \mu \mathrm{m}$ shims not only has a higher void content than the tapes placed with thinner shims, but also shows a more uniform void distribution. The increased void content for the tapes placed with shims, especially close to the heated surface, in combination with the high local fiber volume content, results in surfaces with a low matrix content. 


\subsubsection{Surface micrography}

The low matrix content near the heated surface of the tape, particularly for the tape of supplier A, might impede interlaminar bonding between the tape and previously placed tapes. Scanning Electron Microscopy (SEM) images were taken to investigate whether the heated surface of each tape of supplier A is still covered in matrix, as required for fusion bonding during LAFP.

The SEM images of the heated surfaces of each tape of supplier A are shown in Figure 3.7. Although some fibers can be distinguished on the surface of the asreceived tape, shown in Figure 3.7(a), most of the surface is covered with matrix. The tape placed on polyimide film without shims is shown in Figure 3.7(b). It can be seen that the complete surface is covered with a layer of matrix. The fibers can barely be distinguished and only very few small voids are visible.

The tape placed on a steel tool with shims show a different surface than the tape placed on polyimide film. The heated surface of the tape placed with $175 \mu \mathrm{m}$ shims, shown in Figure 3.7(d), is dominated by bare fibers. Only small areas are covered in matrix, while most of the surface consists of fibers. The surface of the tape placed with $160 \mu \mathrm{m}$ shims, as shown in Figure 3.7(c), shows an intermediate stage between the as-received tape and the tape placed with $175 \mu \mathrm{m}$ shims. Less matrix and more fibers can be distinguished compared to the as-received tape, although not as severe as the tape placed with $175 \mu \mathrm{m}$ shims. These images show that the heated surface of the tape is more matrix poor in comparison with the as-received tape. This is in line with the results of the constituent distributions, which indicated that the tapes had a low matrix content on the heated surface. As mentioned earlier, the overall fiber volume content and matrix volume content were approximately equal for both the as-received and processed tapes, which suggests that the fiber bed has decompacted, leaving the matrix behind, as opposed to the matrix having evaporated due to laser heating. To summarize, the heated surface of the tape is more matrix poor than the surface of the as-received tape. However, when pressure is applied during consolidation a flow of matrix can wet the interface. 


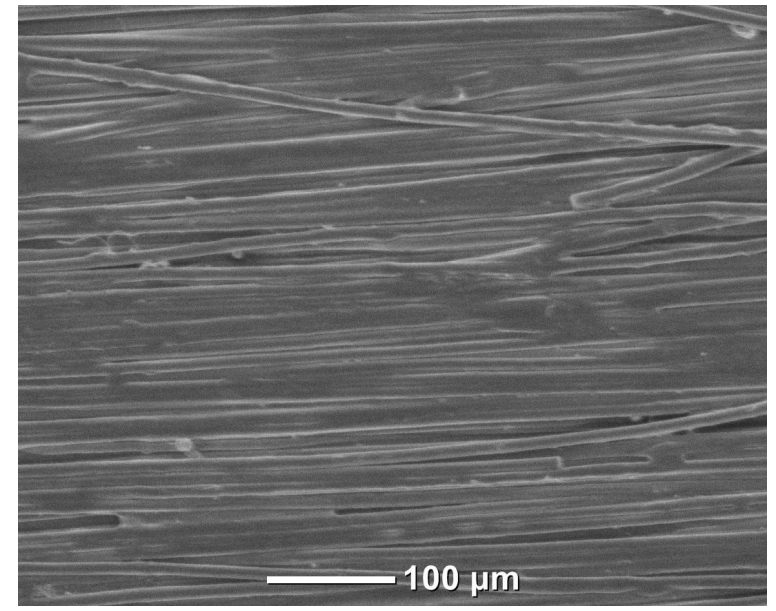

(a)

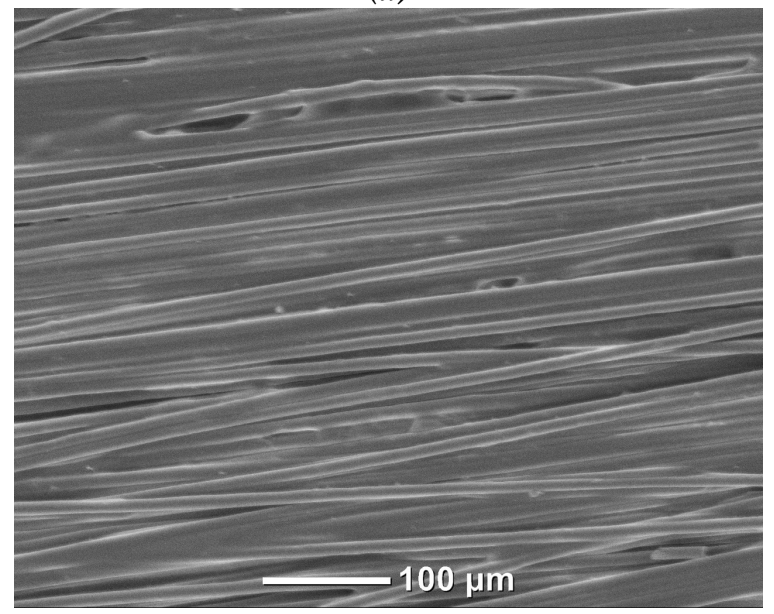

(c)

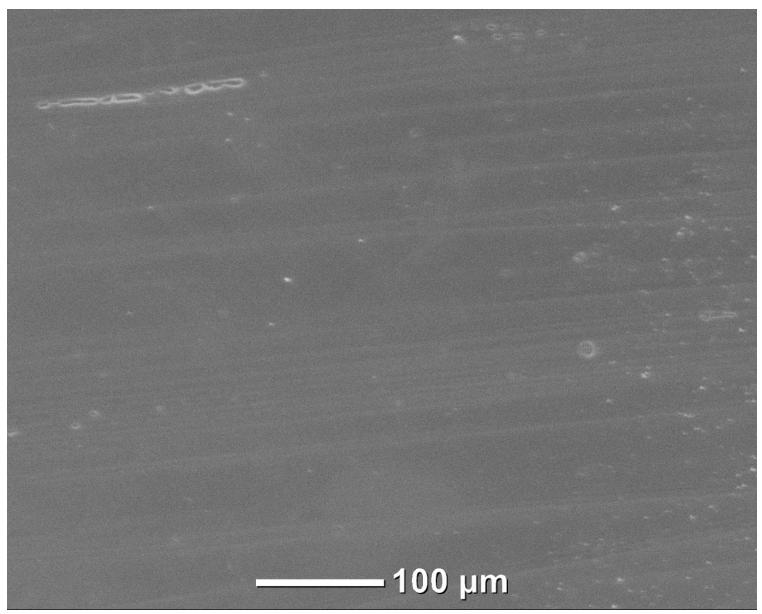

(b)

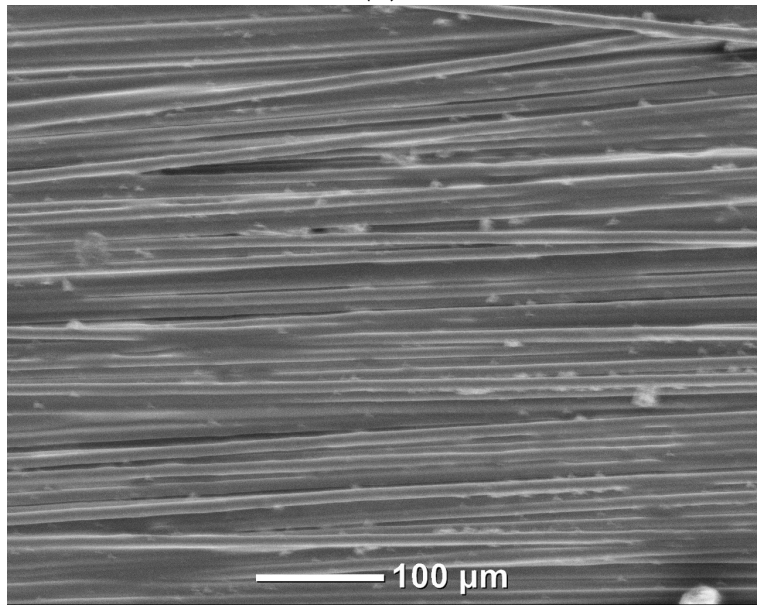

(d)

Figure 3.7 SEM images of the (heated) surfaces of the tapes of supplier A: (a) as-received, (b) placed without shims on polyimide film, (c) placed using $160 \mu \mathrm{m}$ shims on the steel tool and (d) placed using $175 \mu \mathrm{m}$ shims on the steel tool.

\subsection{Discussion}

The presented results showed that the morphology of a thermoplastic composite tape changes during LAFP before entering the nip-point. The quantitative analysis of the material of supplier A showed that roughness of the heated surface increased, the void content near the heated surface increased and the heated surface was matrix-poor. Deconsolidation of thermoplastic tapes has already been studied extensively,but deconsolidation in the short heating times observed in LAFP has, to the authors' knowledge, not yet been reported. These results and its consequences are discussed in this section. First, the selected experimental procedure will be reviewed, followed by a discussion of the obtained tape consolidation state. Then the mechanisms governing deconsolidation are reviewed in brief order to interpret 
the results. Next, the process conditions and the type of material that might affect tape deconsolidation are listed. Finally, the consequences of tape deconsolidation on AFP processing and process modeling are discussed in a broader perspective.

Tape deconsolidation as a result of heating during LAFP is difficult to investigate experimentally. Two challenges can be identified. Firstly, the thermal history of the tape during the process is difficult to reproduce in a controlled manner without using the actual machine. This is due to the fact that the thermal history strongly depends on the heat input and the thermal boundary conditions, with the former depending on the reflection of laser light which is governed by the specific geometry of the nippoint. The second challenge relates to capturing the consolidation state. As discussed earlier, this means that both reconsolidation and further deconsolidation should be prevented. Based on these two challenges, the authors have decided to stay as close as possible to the actual LAFP process. By using shims between the roller and the tool, consolidation was prevented, while the thermal boundary conditions were similar to those in the actual process.

Nevertheless, the adjustments to the LAFP process resulted in small deviations from the actual process. First, the optical properties of the substrate were different from normal processing, since during the experiments a steel tool was used instead of previously placed plies. However, this does affect the temperature distribution in the tape, as a result of a change in the incident heat flux due to the changed optical properties. Second, a rigid roller was used during the experiments, as opposed to a deformable roller during normal processing, in order to be able to reduce the pressure on the tape using shims. This may affect the temperature distribution in the tape in two ways. Firstly, the roller material directly affects the thermal boundary condition at the tape-roller contact and, secondly, the changed roller shape will influence the incident heat flux. The authors tried to minimize these effects by using a roller of the same material as the outside of the deformable roller and by adjusting to laser power to obtain a nip-point temperature similar as used in actual processing. Furthermore, the aim of normal processing is to consolidate a tape underneath the roller while consolidation, reconsolidation and further deconsolidation of the tape underneath the roller were not desired during the experiment. A steel tool was used to act as a heat sink, to freeze the tape consolidation state and prevent further reconsolidation or deconsolidation underneath the roller. Some pressure on the tape was required to ensure contact with the steel tool, to provide fast cooling. As a consequence there could have been some reconsolidation of the tape which could not be prevented and the use of the right shim thickness was crucial here.

A range of shim thickness was used to be able to select the most appropriate shim thickness based on two assumptions. First, the imprinted pattern of the roller had 
to be visible on the top surface as an indication that sufficient pressure was applied to ensure contact with the tool. If the imprinted pattern is not visible on the top surface, it is most likely that the heated surface was not in proper contact with the heat sink and no fast cooling was ensured, and as a consequence, deconsolidation could have continued under the roller. Second, the shim thickness had to be as large as possible to minimize the amount of reconsolidation under the roller, as the pressure exerted on the tape is reducing with increasing shim thickness. Based on these assumptions, a shim thickness of $160 \mu \mathrm{m}$ resulted in a tape consolidation state which was deemed representative of the tape consolidation state prior to the nippoint. This can be observed for the tapes of all three suppliers. The imprinted pattern on the top surface indicates that pressure was exerted on the tape to ensure contact with the tool to cool the tape quickly. Furthermore, pressure exerted on the tape was minimized, to prevent reconsolidation under the roller. Thicker shims resulted in further deconsolidation, probably due to loss of contact with the tool, while thinner shims resulted in more reconsolidation under the roller due to a higher pressure being exerted.

Now it is established that tape deconsolidation occurs during LAFP, it is worthwhile discussing the underlying mechanisms. The main sources of deconsolidation mentioned in literature are fiber bed decompaction and expansion of moisture or volatiles [27, 31]. Fiber bed decompaction is known to be a significant driving force for deconsolidation of woven fabrics. Elastic energy, stored in the undulated fiber bundles during the consolidation process, is released upon heating. Despite having no undulated bundles, elastic energy can also be stored in unidirectional fiber beds, especially if the fiber volume fraction is high [27, 32]. The cross-section of the tape of supplier A placed with $160 \mu \mathrm{m}$ shims, as shown in Figure 3.3(d), seems to show fibers popping out of the surface, indicating fiber bed decompaction, causing an increase in voids by cavitation. Furthermore, larger voids can be observed as well, mainly for the tapes placed with $175 \mu \mathrm{m}$ shims, which can be the result of expansion of moisture or volatiles and coalescence of voids which were already present in the as-received tape. More detailed research is required to quantify the contribution of these mechanism to the overall deconsolidation behavior. Such information could prove useful for the derivation of tape design guidelines for fiber placement.

Although the mechanisms governing tape deconsolidation as described above are generic, the tape material properties and tape manufacturing conditions will affect the deconsolidation behavior of the tape [33]. The qualitative analysis showed that deconsolidation can be observed for tapes provided by multiple suppliers and that the results are similar, namely tapes with a rough heated surface and intralaminar voids near the heated surface. The fiber-rich surface of the tape of supplier A, shown with the detailed analysis, was not confirmed for the other manufacturers. 
Furthermore, the heating time and temperature development in the tape, determined by process parameters such as the heated area and the placement rate, are most likely key conditions affecting tape deconsolidation. A shorter heating time, for example, would reduce the time available for deconsolidation and might reduce the amount of deconsolidation. More research is required for which the described methodology can be used to characterize the effects of the type of fiber or matrix material, material manufacturer and process conditions on tape deconsolidation during LAFP.

The tape deconsolidation observed during the heating phase prior to the nip-point has consequences for the consolidation phase. As deconsolidation of the tape during the heating phase of LAFP has not been considered before, the consequences on consolidation also have not been considered in consolidation models up to now. The detailed analysis of the tape from supplier A showed that the heated surface had an increased surface roughness and was matrix-poor, which impedes the development of intimate contact between plies and consequently the development of bond strength $[1,34]$. At least the increased roughness was confirmed for the tapes of supplier B and $\mathrm{C}$ and this increased surface roughness due to deconsolidation prior to the nippoint is not taken into account in intimate contact modeling. Furthermore, in current modeling strategies intimate contact development is regarded as the deformation of surface asperities based on a squeeze flow mechanism in which the asperities are considered to be a homogeneous fluid with a certain viscosity. The detailed analysis of the tape of supplier A, however, showed that these assumptions are questionable. First, the qualitative and quantitative analysis showed that the fiber and matrix distributions were not homogeneous through the thickness of the tape, especially near the heated surface. The validity of a fiber matrix viscosity obtained on the bulk material is, therefore, questionable. Second, deconsolidation results in a matrix poor surface for the tape of supplier A and it seems that some flow of matrix through the fiber bed is required to wet the surface before bonding with other plies can take place. The SEM images of the tape placed on polyimide film showed that the surface indeed can be wetted during placement. The tape of supplier $\mathrm{C}$ also has areas which seem to be dry and still need to be impregnated during placement. In a future paper, an intimate contact model based re-impregnation of the dry fibers on the surface of the deconsolidated tape will be developed, to take into account the deconsolidation during the heating phase of LAFP. The quantitative description of the deconsolidated tapes, as given in this work, will be used as an input for these models.

\subsection{Conclusions}

Experiments were performed to investigate the possible deconsolidation of the tape during the heating phase of the LAFP process prior to the nip-point. For this purpose, 
shims were used to reduce the pressure exerted on the tape during placement in order to prevent consolidation underneath the roller. Moreover, the consolidation state of the tape after the heating phase was frozen by quench cooling of the tape on a metal tool. Different shim thicknesses were used to obtain tapes with different consolidation states, which were then analyzed using image analysis on cross sectional micrographs. This was done for $\mathrm{C} / \mathrm{PEEK}$ tapes of three different suppliers.

It was found that, despite the short heating time, the tape deconsolidates during the heating phase of the LAFP process. This rather important observation was, to the best of the authors' knowledge, not made in any earlier publications in the field. Moreover, the effects of deconsolidation on intimate contact development have also not been considered before. The deconsolidated tape has an increase in intralaminar void content and a rough, matrix-poor surface on the heated surface of the tape. The rough, matrix-poor surface most likely impedes intimate contact development and, therefore, makes in-situ consolidation more difficult.

Looking forward, tape deconsolidation is not yet accounted for in the predictive simulation tools reported in literature. The experimental observations reported provide a good starting point for development of new or improvement of existing interlaminar bonding models, which are deemed necessary for the development of process design tools. Moreover, it is also recommended to extend the experimental work to tapes with a different fiber or matrix material and different processing conditions in order to ultimately arrive at proper tape design guidelines for fiber placement processes.

\section{References}

[1] M. B. Gruber, I. Z. Lockwood, T. L. Dolan, S. B. Funk, J. J. Tierney, P. Simacek, J. W. Gillespie Jr, S. G. Advani, B. J. Jensen, R. J. Cano, and B. W. Grimsley. Thermoplastic in situ placement requires better impregnated tapes and tows. In Proceedings of the 2012 International SAMPE Conference and Exhibition (SAMPE 2012). Baltimore, Maryland, USA, 2012.

[2] R. Schledjewski and A. K. Schlarb. Thermoplastic tape placement process challenges on the way to a fully automated lay-up of complex shaped parts. In Proceedings of the 2006 SAMPE Symposium and Exhibition (SAMPE 2006), volume 51. Long Beach, California, USA, 2006.

[3] M. A. Lamontia, M. B. Gruber, J. J. Tierney, J. W. Gillespie Jr, B. J. Jensen, and R. J. Cano. In situ thermoplastic atp needs flat tapes and tows with few voids. 
In Proceedings of the 30th International SAMPE Europe Conference (SEICO 09), volume 30. Paris, France, 2009.

[4] R. Schledjewski and A. Miaris. Thermoplastic tape placement by means of diode laser heating. In Proceedings of the 2009 SAMPE Symposium and Exhibition (SAMPE 2009), volume 54. SAMPE, Baltimore, Maryland, USA, 2009.

[5] M. Di Francesco, L. Veldenz, G. Dell'Anno, and K. Potter. Heater power control for multi-material, variable speed automated fibre placement. Composites Part A: Applied Science and Manufacturing, 101:408-421, 2017.

[6] C. M. Stokes-Griffin and P. Compston. Investigation of sub-melt temperature bonding of carbon-fibre/PEEK in an automated laser tape placement process. Composites Part A: Applied Science and Manufacturing, 84:17-25, 2016.

[7] C. M. Stokes-Griffin and P. Compston. A combined optical-thermal model for near-infrared laser heating of thermoplastic composites in an automated tape placement process. Composites Part A: Applied Science and Manufacturing, 75:104$115,2015$.

[8] M. N. Ghasemi Nejhad, R. D. Cope, and S. I. Güçeri. Thermal analysis of insitu thermoplastic composite tape laying. Journal of Composite Materials, 4:20-45, 1991.

[9] F. O. Sonmez and H. T. Hahn. Modeling of heat transfer and crystallization in thermoplastic composite tape placement process. Journal of Thermoplastic Composite Materials, 10(3):198-240, 1997.

[10] S. M. Grove. Thermal modelling of tape laying with continuous carbon fibrereinforced thermoplastic. Composites, 19(5):367-375, 1988.

[11] J. Tierney and J. W. Gillespie Jr. Modeling of heat transfer and void dynamics for the thermoplastic composite tow-placement process. Journal of Composite Materials, 37(19):1745-1768, 2003.

[12] L. J. Bastien and J. W. Gillespie Jr. A non-isothermal healing model for strength and toughness of fusion bonded joints of amorphous thermoplastics. Polymer Engineering E Science, 31(24):1720-1730, 1991.

[13] C. A. Butler, R. L. McCullough, R. Pitchumani, and J. W. Gillespie Jr. An analysis of mechanisms governing fusion bonding of thermoplastic composites. Journal of Thermoplastic Composite Materials, 11(4):338-363, 1998.

[14] F. Yang and R. Pitchumani. Nonisothermal healing and interlaminar bond strength evolution during thermoplastic matrix composites processing. Polymer Composites, 24(2):263-278, 2003.

[15] S. Ranganathan, S. G. Advani, and M. A. Lamontia. Non-isothermal process model for consolidation and void reduction during in-situ tow placement of thermoplastic composites. Journal of Composite Materials, 29(8):1040-1062, 1995.

[16] P. Simacek, S. G. Advani, M. Gruber, and B. Jensen. A non-local void filling model to describe its dynamics during processing thermoplastic composites. Composites Part A: Applied Science and Manufacturing, 46:154-165, 2013.

[17] J. J. Tierney and J. W. Gillespie Jr. Crystallization kinetics behavior of PEEK 
based composites exposed to high heating and cooling rates. Composites Part A: Applied Science and Manufacturing, 35(5):547-558, 2004.

[18] X. Guan and R. Pitchumani. Modeling of spherulitic crystallization in thermoplastic tow-placement process: spherulitic microstructure evolution. Composites Science and Technology, 64(9):1363-1374, 2004.

[19] A. J. Comer, D. Ray, W. O. Obande, D. Jones, J. Lyons, I. Rosca, R. M. O' Higgins, and M. A. McCarthy. Mechanical characterisation of carbon fibrePEEK manufactured by laser-assisted automated-tape-placement and autoclave. Composites Part A: Applied Science and Manufacturing, 69:10-20, 2015.

[20] Z. Qureshi, T. Swait, R. Scaife, and H. M. El-Dessouky. In situ consolidation of thermoplastic prepreg tape using automated tape placement technology: Potential and possibilities. Composites Part B: Engineering, 66:255-267, 2014.

[21] M. Tannous, A. Barasinski, C. Binetruy, and B. Courtemanche. Contribution of thermo-mechanical parameters and friction to the bonding of thermoplastic tapes in the tape winding process. Journal of Materials Processing Technology, 229:587-595, 2016.

[22] F. Yang and R. Pitchumani. A fractal cantor set based description of interlaminar contact evolution during thermoplastic composites processing. Journal of Materials Science, 36(19):4661-4671, 2001.

[23] M. A. Khan, P. Mitschang, and R. Schledjewski. Tracing the void content development and identification of its effecting parameters during in situ consolidation of thermoplastic tape material. Polymers and Polymer Composites, 18(1):1-15, 2010.

[24] L. Ye, Z. Chen, M. Lu, and M. Hou. De-consolidation and re-consolidation in CF/PPS thermoplastic matrix composites. Composites Part A: Applied Science and Manufacturing, 36(7):915-922, 2005.

[25] J. Wolfrath, V. Michaud, and J. A. E. Månson. Deconsolidation in glass mat thermoplastic composites: Analysis of the mechanisms. Composites Part A: Applied Science and Manufacturing, 36(12):1608-1616, 2005.

[26] F. Henninger, L. Ye, and K. Friedrich. Deconsolidation behaviour of glass fibrepolyamide 12 composite sheet material during post-processing. Plastics, Rubber and Composites Processing and Applications, 27(6):287-292, 1998.

[27] M. Brzeski and P. Mitschang. Deconsolidation and its interdependent mechanisms of fibre reinforced polypropylene. Polymers and Polymer Composites, 23(8):515-524, 2015.

[28] T. Kok, W. J. B. Grouve, L. L. Warnet, and R. Akkerman. Intimate contact development in laser assisted fiber placement. In Proceedings of the 17th European Conference on Composite Materials (ICCM-17). Münich, Germany, 2016.

[29] R. Schledjewski and A. K. Schlarb. In-situ consolidation of thermoplastic tape material effects of tape quality on resulting part properties. In Proceedings of the 2007 SAMPE Symposium and Exhibition (SAMPE 2007), volume 52. Baltimore, 
Maryland, USA, 2007.

[30] T. Kok, W. J. B. Grouve, L. L. Warnet, and R. Akkerman. Quantification of tape deconsolidation during laser assisted fiber placement. In Proceedings of the 3rd International Symposium on Automated Composites Manufacturing (ACM3). Montreal, Canada, 2017.

[31] L. Ye, M. Lu, and Y. W. Mai. Thermal de-consolidation of thermoplastic matrix composites - I. growth of voids. Composites Science and Technology, 62(16):21212130, 2002.

[32] T. G. Gutowski, Z. Cai, S. Bauer, D. Boucher, J. Kingery, and S. Wineman. Consolidation experiments for laminate composites. Journal of Composite Materials, 21(7):650-669, 1987.

[33] T. K. Slange, L. L. Warnet, W. J. B. Grouve, and R. Akkerman. Influence of prepreg characteristics on stamp consolidation. In Proceedings of the 20th International ESAFORM Conference on Material Forming (ESAFORM 2017). Dublin, Ireland, 2017.

[34] M. A. Khan, P. Mitschang, and R. Schledjewski. Parametric study on processing parameters and resulting part quality through thermoplastic tape placement process. Journal of Composite Materials, 47(4):485-499, 2013. 


\title{
Chapter 4
}

\section{Intimate contact development during laser assisted fiber placement ${ }^{*}$}

\begin{abstract}
An experimental investigation of intimate contact development was performed and the key process parameters were identified. The degree of intimate contact was based on the interlaminar void content observed via microscopy. Previous work showed that wetting of dry fibers at the surface is required to create intimate contact, which is not considered in available models based on flattening of surface asperities. An intimate contact model based on the percolation flow of matrix to impregnate dry fibers on the tape surface was proposed as an alternative. Although the model was not able to not quantitatively predict the degree of intimate contact, it was able to qualitatively predict the effect of process parameters. The proposed model should be further developed in order to obtain a predictive modeling strategy for laser assisted fiber placement.
\end{abstract}

${ }^{*}$ Reproduced from: T. Kok, W. J. B. Grouve, L. L. Warnet, R. Akkerman. Intimate contact development during laser assisted fiber placement. To be submitted to: Composites part A: Applied Science and Manufacturing 


\subsection{Introduction}

Laser Assisted Fiber Placement (LAFP) is a promising production technique for the aerospace industry. It has the potential for in-situ consolidation, which could reduce production costs since a costly post-consolidation step can be omitted. During the LAFP process, a thermoplastic pre-impregnated tape is heated above its melting temperature using a laser and subsequently pressure is applied using a roller to consolidate the tape with previously placed tapes. In this way, a product is built up ply-by-ply. Considerable effort has been spent on improving the consolidation quality by improving the equipment and materials used as well as by optimizing the process settings through process modeling. Despite all these efforts, in-situ consolidation has not yet seen large-scale application in the aerospace industry. One of the remaining challenges, which obstructs larger industrial implementation, is the unacceptably high void content in in-situ consolidated components.

Voids can be classified as intralaminar, i.e. voids within a ply, and interlaminar, i.e. voids between plies. The intralaminar void content has almost been eliminated by the introduction of high quality tape materials which have a virtually zero initial void content [1]. Interlaminar voids, however, are still present in parts made by LAFP [2,3]. These voids can be regarded as the result of incomplete wetting or intimate contact development between the tape and substrate during LAFP [4]. It was to be expected that the introduction of the currently available high quality tape materials, with smooth surfaces, would prevent the origination of interlaminar voids during LAFP [5]. However, the research presented in Chapter 2 has shown that these tapes may deconsolidate during the heating phase, prior to entering the nippoint, resulting in a rough fiber-rich surface. Interlaminar voids might be eliminated through process optimization and, preferably, this is achieved using predictive process modeling. Currently used intimate contact modeling strategies assume the governing mechanism to be the flattening of surface asperities through squeeze flow. These strategies are based on the collective effort of several researchers [6-9]. The models, however, seem to be inapplicable for deconsolidated tapes, which have a fiber-rich surface devoid of matrix. Here the governing mechanism seems to be the percolation flow of matrix through the fiber bed in order to wet the fiber-rich surface.

A novel intimate contact development model is proposed in this work, based on the percolation flow through the tape to impregnate a dry fiber bed, which can be described by Darcy's law. First, an experimental investigation of intimate contact development during LAFP as a function of process parameters is performed. Second, the available intimate contact models and their limitations are discussed. Then the proposed intimate contact model based in impregnation is derived. Finally, the experimental and model results are compared and discussed. 


\subsection{Experimental work}

An experimental investigation has been performed to identify the key parameters for intimate contact development during LAFP. Tapes were placed on a pre-consolidated laminate with varying settings and the degree of intimate contact was determined by analyzing the interlaminar void content in cross-sectional micrographs. The effect of process settings on the interlaminar void content was studied with two sets of experiments: The first aimed to identify the most important parameters, while the second served to obtain a better understanding of the effect of these key parameters. A Design of Experiments (DOE) approach was used to reduce the required number of specimens. In this section the experimental procedure and the results of the experimental investigation are described.

\subsubsection{Experimental procedure}

\section{Parameter selection}

The LAFP process involves a large number of process parameters. Seven parameters, expected to affect intimate contact development the most, were selected. These parameters and their effect on the process are listed below.

\section{- Laser spot size}

The height of the laser spot, $H$ in Figure 4.1, is the parameter that defines the size of the illuminated area on the tape and the laminate. The laminate and tape heating time are a function of the spot size and the placement velocity. A larger spot size results in a larger illuminated area, hence a longer heating time. Two different sets of optics were available with a spot height of $16 \mathrm{~mm}$ and 28 $\mathrm{mm}$ and both with a spot width of $11 \mathrm{~mm}$, which is wider than the quarter-inch tape.

\section{- Laser angle}

The angle of the laser with respect to the substrate, $\theta_{\mathrm{L}}$ in Figure 4.1, affects the reflection and absorption of the laser light for the tape and the substrate and, therefore, the temperature distribution. The angle can be varied by changing the position of the laser optics on the end effector of the robot. The laser angle can be varied between $10^{\circ}$ and $26^{\circ}$ to the substrate plane.

\section{- Fraction of energy supplied to the tape}

The heat supplied by the laser is distributed between the laminate and the tape. The division of energy between these two affects the maximum temperature and temperature distribution of both the tape and the laminate. A larger fraction of the energy on the tape, shown as $f_{\mathrm{L}}$ in Figure 4.1 , can improve the consolidation, though degradation needs to be prevented [10]. 


\section{- Nip-point temperature}

The nip-point temperature is the temperature measured with a thermal camera at the position where the tape and laminate are brought together. The laser power was not selected as a parameter since the variation in process settings was quite large. As a result, a certain laser power level could be insufficient to heat the material for one configuration while it would overheat the material for another configuration. The nip-point temperature is thus used to control the process and by adjusting the laser power the same nip-point temperature can be obtained for different process settings.

\section{- Tool temperature}

The tool on which the substrate is placed can be heated, affecting the temperature distribution in the laminate.

\section{- Compaction force}

The compaction force is the force applied on the compaction roller, which then pressurizes the tape and substrate to create intimate contact. The pressure distribution depends on the applied compaction force as well as on the stiffness of the compaction roller. A compliant roller will deform more than a stiff roller resulting in a larger contact area, hence a lower average pressure. Apart from the pressure, the contact length is important as well, as this, in combination with the placement velocity, determines the time available for consolidation. A low compaction force with a compliant roller and a high compaction force with a less compliant roller were selected. The forces and roller stiffness were selected, based on the analysis performed on roller deformation in Chapter 2, to yield two different pressure levels but similar roller shapes, in order to ensure similar heating, and contact lengths.

\section{- Placement velocity}

The placement velocity defines the productivity of the machine. By increasing the placement velocity, the time available for heating and for consolidation underneath the roller reduces. A certain minimum time for consolidation is required to be able to obtain sufficient consolidation, thereby limiting the maximum placement velocity. Furthermore, the velocity affects the heating time, which in turn affects the temperature distribution.

All seven parameters were analyzed for the first DOE. Eight configurations were defined, based on the Taguchi method, using a low and high level for each of the seven parameters [11]. The resulting test matrix is given in Table 4.1. Based on the results of the first DOE, which will be presented in the following section, a second DOE was defined. The three most interesting parameters, the nip-point temperature, the laser angle and the fraction of the heat on the tape, were selected. A test matrix with three levels for each parameter, shown in Table 4.2 was selected to obtain a better 
insight in the effect of these parameters.

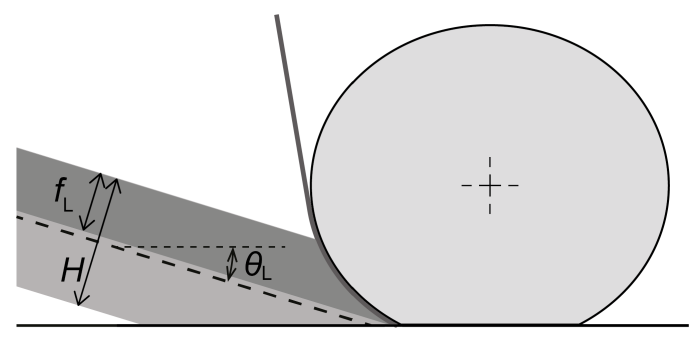

Figure 4.1 Sketch of part of the parameters of the DOE.

Table 4.1 The settings of the configurations used for the intimate contact experiment. The high levels are highlighted in grey.

\begin{tabular}{lcccccccccc}
\hline Parameters & Symbol & Unit & \multicolumn{10}{c}{ Configuration } \\
& & & 1.1 & 1.2 & 1.3 & 1.4 & 1.5 & 1.6 & 1.7 & 1.8 \\
\hline Spot size & $\mathrm{H}$ & {$[\mathrm{mm}]$} & 16 & 16 & 16 & 16 & 28 & 28 & 28 & 28 \\
Laser orientation & $\theta_{\mathrm{L}}$ & {$\left[{ }^{\circ}\right]$} & 13.6 & 21.7 & 13.6 & 21.7 & 21.7 & 13.6 & 21.7 & 13.6 \\
Fraction heat on tape & $f_{\mathrm{L}}$ & {$[\%]$} & 20 & 20 & 10 & 10 & 10 & 20 & 20 & 10 \\
Nip-point temperature & $T_{\mathrm{N}}$ & {$\left[{ }^{\circ} \mathrm{C}\right]$} & 350 & 350 & 450 & 450 & 450 & 450 & 350 & 350 \\
Tool temperature & $T_{\text {tool }}$ & {$\left[{ }^{\circ} \mathrm{C}\right]$} & 20 & 20 & 100 & 100 & 20 & 20 & 100 & 100 \\
Compaction force & $F_{\mathrm{C}}$ & {$[\mathrm{N}]$} & 100 & 500 & 100 & 500 & 100 & 500 & 100 & 500 \\
Roller & $E_{\mathrm{r}}$ & {$[\mathrm{sh}]$} & 40 & 60 & 40 & 60 & 40 & 60 & 40 & 60 \\
Placement velocity & $v$ & {$[\mathrm{~mm} / \mathrm{s}]$} & 100 & 200 & 200 & 100 & 100 & 200 & 200 & 100 \\
\hline
\end{tabular}

Table 4.2 The settings of the configurations used for the second intimate contact experiment. The different levels are highlighted in different shades of grey.

\begin{tabular}{lcccccccccccc}
\hline Parameters & Symbol & Unit & \multicolumn{1}{c}{ Configuration } \\
& & & 2.1 & 2.2 & 2.3 & 2.4 & 2.5 & 6 & 2.7 & 2.8 & 2.9 \\
\hline Spot size & $\mathrm{H}$ & {$[\mathrm{mm}]$} & & & & & 16 & & & & \\
Laser orientation & $\theta_{\mathrm{L}}$ & {$\left[{ }^{\circ}\right]$} & 14 & 19 & 24 & 14 & 19 & 24 & 14 & 19 & 24 \\
Fraction heat on tape & $f_{\mathrm{L}}$ & {$[\%]$} & 35 & 25 & 15 & 25 & 15 & 35 & 15 & 35 & 25 \\
Nip-point temperature & $T_{\mathrm{N}}$ & {$\left[{ }^{\circ} \mathrm{C}\right]$} & 400 & 400 & 400 & 450 & 450 & 450 & 500 & 500 & 500 \\
Tool temperature & $T_{\text {tool }}$ & {$\left[{ }^{\circ} \mathrm{C}\right]$} & & & & & 20 & & & & \\
Compaction force & $F_{\mathrm{c}}$ & {$[\mathrm{N}]$} & & & & & 500 & & & & \\
Roller & $E_{\mathrm{r}}$ & {$[\mathrm{sh}]$} & & & & 60 & & & & \\
Placement velocity & $v$ & {$[\mathrm{~mm} / \mathrm{s}]$} & & \multicolumn{1}{c}{200} & & & & & \\
\hline
\end{tabular}

\section{Material and equipment}

The material used was C/PEEK pre-preg tape with a fiber volume content of 59\%. The material used for the base laminates was 12 inches wide, while the tape used 
for placement was slitted to a quarter inch. Laminates with a layup of $[0 / 90]_{2 s}$ were press-consolidated at $385{ }^{\circ} \mathrm{C} 20$ bars for 15 minutes. A Coriolis Composites fiber placement robot, developed for placement of thermoplastic composites and equipped with a $1 \mathrm{~kW}$ laser, was used for the placement of tapes.

\section{Specimen preparation}

A pre-consolidated laminate was used as a basis for the specimens and two plies were placed by LAFP. The first ply was placed with fixed settings in order to have the same surface for each specimen, while the process settings for the second ply were varied. Specimens were cut from the laminates with the placed tapes and prepared for optical microscopy. Three quarter-inch tapes were placed or each configuration and two cross-sections were made per configuration.

\section{Analysis}

The interface between the two placed plies was analyzed for the interlaminar void content and the degree of intimate contact was estimated. It was assumed that no intimate contact was obtained in areas with interlaminar voids, while areas without interlaminar voids are assumed to have obtained full intimate contact. The degree of intimate contact was defined as the width of the bonded interface, thus excluding the areas with interlaminar voids, over the total width of the interface. An example of a cross-sectional micrograph is given in Figure 4.2.

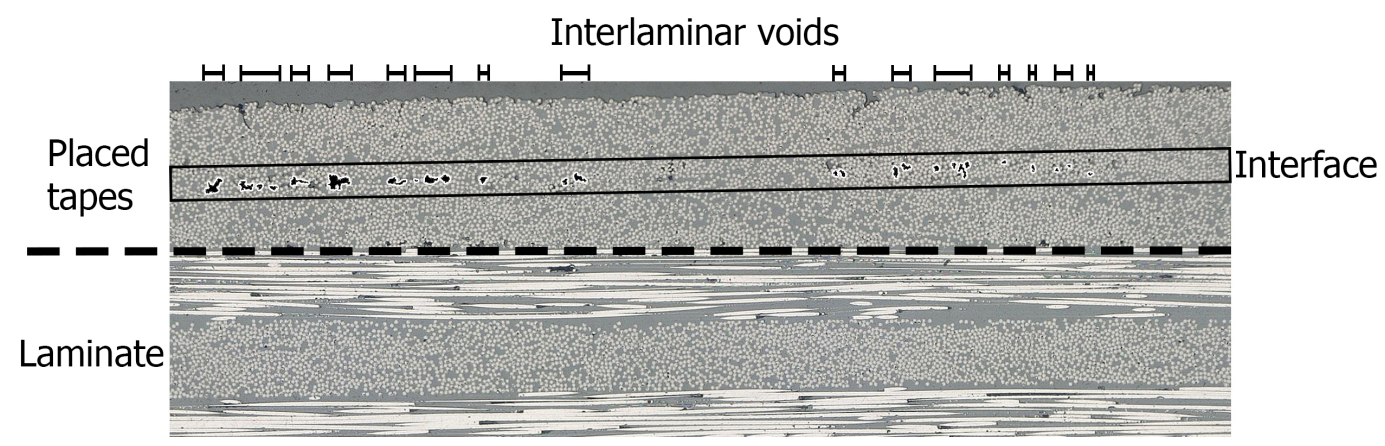

Figure 4.2 Example of the interlaminar void content analysis of a micrograph. The voids in the interface between the placed tapes are highlighted and the fraction of the width with interlaminar voids is indicated. The image shown has a degree of intimate contact of $68 \%$.

\subsubsection{Experimental results}

The analysis described in the previous section has been performed for each configuration and the results are shown in Figure 4.3(a). It can be observed that 
none of the configurations resulted in full intimate contact. However, this was not the goal of the experiment. Significant variation in the degree of intimate contact obtained can be observed for the different configurations, which indicates that the selected parameters do affect intimate contact development during LAFP.

The usage of a design of experiments approach allows for the analysis of the effects of the parameters on the intimate contact development. This is done by calculating the average degree of intimate contact for each configuration having a low value for a parameter and comparing this with the average of each configuration with a high value for the same parameter. For example, for the effect of the nip-point temperature, the average of configuration 1.1, 1.2, 1.7 and 1.8 (corresponding to the low value) and the average of 1.3, 1.4, 1.5 and 1.6 (corresponding to the high value) are calculated. The difference between these two averages is defined as the effect of increasing the nip-point temperature on the degree of intimate contact. The effect analysis was done for each single parameter, leading to the results given in Figure 4.3(b).

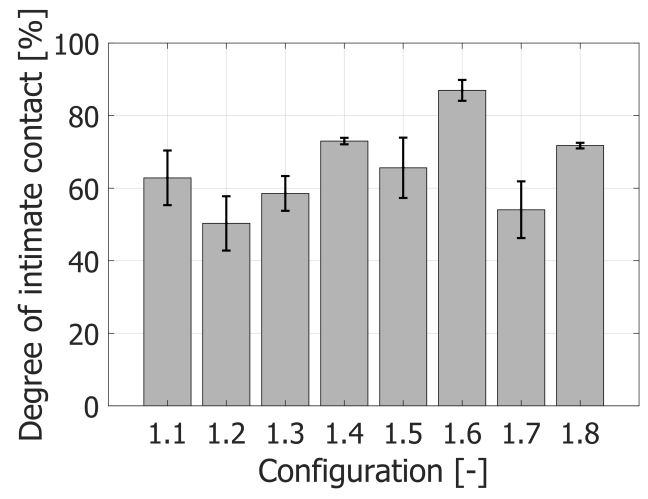

(a)

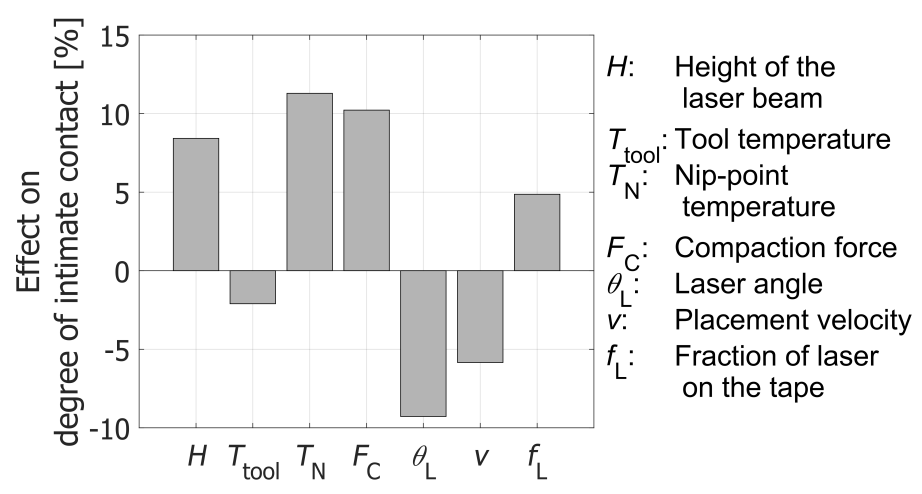

(b)

Figure 4.3 Results of the first DOE:(a) Degree of intimate contact for the different configurations including the standard deviation as error bars and(b) effect of the varied parameters on the degree of intimate contact.

Figure 4.3(b) shows that the parameters effecting intimate contact development during LAFP the most are the laser spot size, the nip-point temperature, the compaction force and the laser angle. The placement velocity and fraction of heat on the tape affect intimate contact development less in the range used. The effect of tool temperature is only about $2 \%$ in the range used.

Based on the results of the first DOE, a second DOE was performed. The smaller spot size, although resulting in a relatively low degree of contact, was selected for the second DOE as this spot size allows for a larger variation in laser position and orientation. Thereby, a better understanding of the effect of the nip-point 
temperature, the laser angle and the fraction of heat on the tape on intimate contact development could be obtained. The results of the second DOE are shown in Figure 4.4. Figure 4.4(a) shows the variation for the different configurations. A clear effect of the nip-point temperature can be observed, for the high variation between configuration 2.1-2.3 placed at a nip-point temperature of $400{ }^{\circ} \mathrm{C}$, as opposed to the smaller variation between configuration 2.6-2.9 placed at $500{ }^{\circ} \mathrm{C}$.

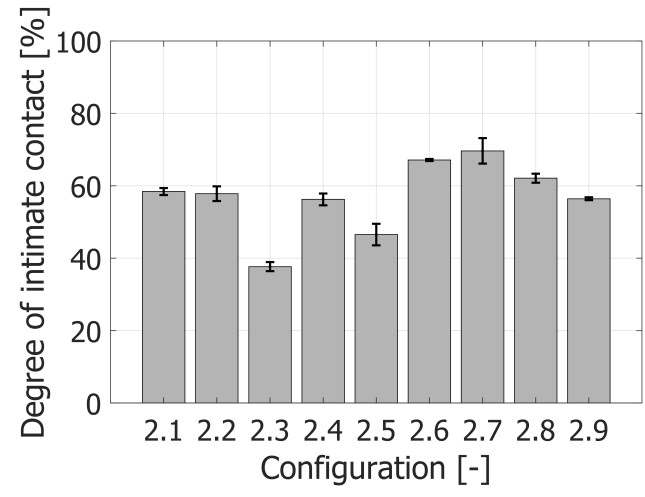

(a)
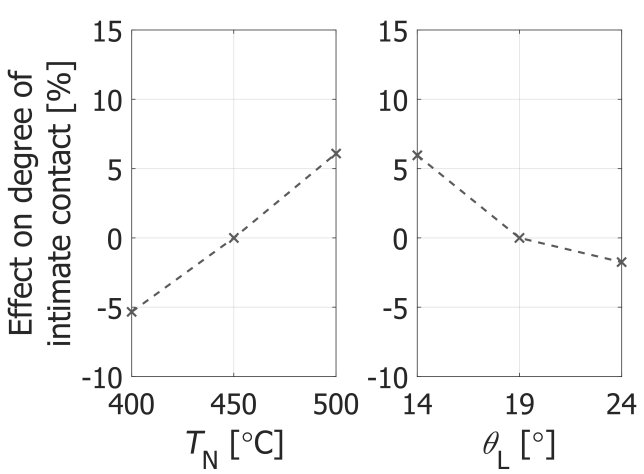

(b)

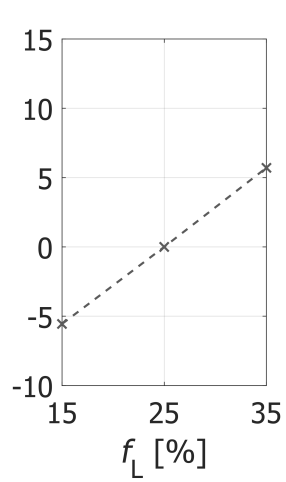

35

Figure 4.4 Results of the second DOE:(a) Degree of intimate contact for the different configurations including the standard deviation as error bars and $(\boldsymbol{b})$ effect of the varied parameters on the degree of intimate contact.

The effects of the different parameters, based on three levels, are shown in Figure 4.4(b). A linear effect of the nip-point temperature can be observed over this range. The effect of the laser angle shows also a linear trend, with a smaller angle promoting intimate contact development. Finally, increasing the fraction of energy aimed at the tape is beneficial for intimate contact development and a linear trend with increasing fraction is observed. These observed effects are in line with the first DOE.

\subsection{Current modeling strategies}

The currently accepted mechanism governing intimate contact development is the flattening of surface asperities based on transverse squeeze flow. Dara and Loos laid the basis for the development of currently available intimate contact models [6]. The available tape material at that time had considerable differences in thickness along the width. Flattening of the tapes was assumed to be required to develop intimate contact between plies and full intimate contact was obtained once the ply had a uniform thickness. Transverse squeeze flow was considered to be the most important deformation mechanism. Lee and Springer applied the concept of squeeze flow to the flattening of surface asperities on a ply [7]. The tape surface roughness 
was in this case represented by rectangular elements of equal size, which then need to be flattened under the application of heat and pressure. Both an isothermal and a non-isothermal model were developed [7, 8]. The geometry of the rectangular elements was either fitted to experimental results on intimate contact development or approximated from micrographs. Yang and Pitchumani improved these models by assuming that the surface roughness could be described by a fractal Cantor set [9]. This description was used to include the multi-scale nature of the roughness of the tape and to be able to define model parameters based on the surface profile of the actual tape material used. Therefore, it allowed different tapes to be compared and the required tape characteristics for intimate contact development to be obtained. The model of Yang and Pitchumani is used in this work and a short description is given in the following sections, including the assumed governing mechanism, the viscosity models required and the assumed surface representation. Then the model is used to predict the degree of intimate contact for the configurations used in the experiment. Finally, the model and experimental results are compared and discussed.

\subsubsection{Squeeze flow mechanism}

The aforementioned, and currently accepted, intimate contact models consider transverse squeeze flow of surface asperities as the governing mechanism. The surface asperities are modeled as rectangular elements. Other physical mechanisms, such as percolation flow or fiber bed compaction, are considered negligible. The material is assumed to be homogenous, isotropic and incompressible. The basic geometry of rectangular asperities, with an initial height $a_{0}$, an initial width $b_{0}$ and initial gap of $w_{0}$, considered for squeeze flow is shown in Figure 4.5. The degree of intimate contact is simply the ratio between the width of the rectangles and the distance between rectangles given by

$$
D_{i c}=\frac{b(t)}{b_{0}+w_{0}}
$$

where $b$ is the width of the elements varying over time. As a force is applied to squeeze the rectangular material element, the width of the surface element increases while the distance between elements decreases. Consequently the degree of intimate contact increases, up to the point where a surface element reaches the neighboring element and full intimate contact is obtained. The input required to calculate intimate contact include a surface representation to specify the dimensions of the element, the applied pressure and a viscosity. 


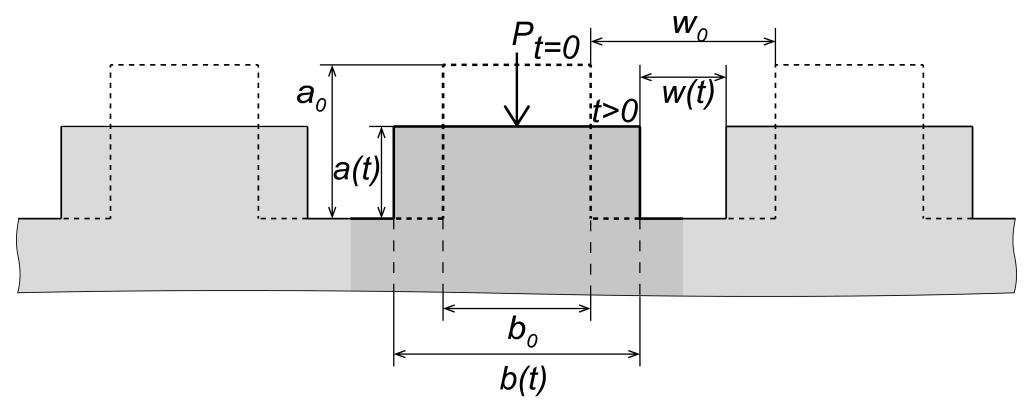

Figure 4.5 The basic rectangular element considered for squeeze flow modeling in intimate contact models.

\subsubsection{Viscosity}

The material parameter required in the squeeze flow model is the viscosity. The neat matrix or an apparent fiber-matrix viscosity can be used, depending on the morphology of the tape $[4,8,12,13]$. Usually, an Arrhenius type of model is used for the viscosity as a function of temperature,

$$
\mu=c_{\mu} \exp \left(\frac{c_{\mathrm{b}}}{T}\right)
$$

where $c_{\mu}$ and $c_{\mathrm{b}}$ are parameters to fit the model to experimental results and $T$ is the absolute temperature. An overview of the fiber-matrix viscosity models of PEEK and $\mathrm{C} / \mathrm{PEEK}$ reported in literature is given in Table 4.3. The variation in the models can be significant as can be observed in Figure 4.6. The difference in fiber-matrix viscosity can be a couple of decades. In the current work, both the matrix and fiber-matrix viscosity of Khan et al. are used [4].

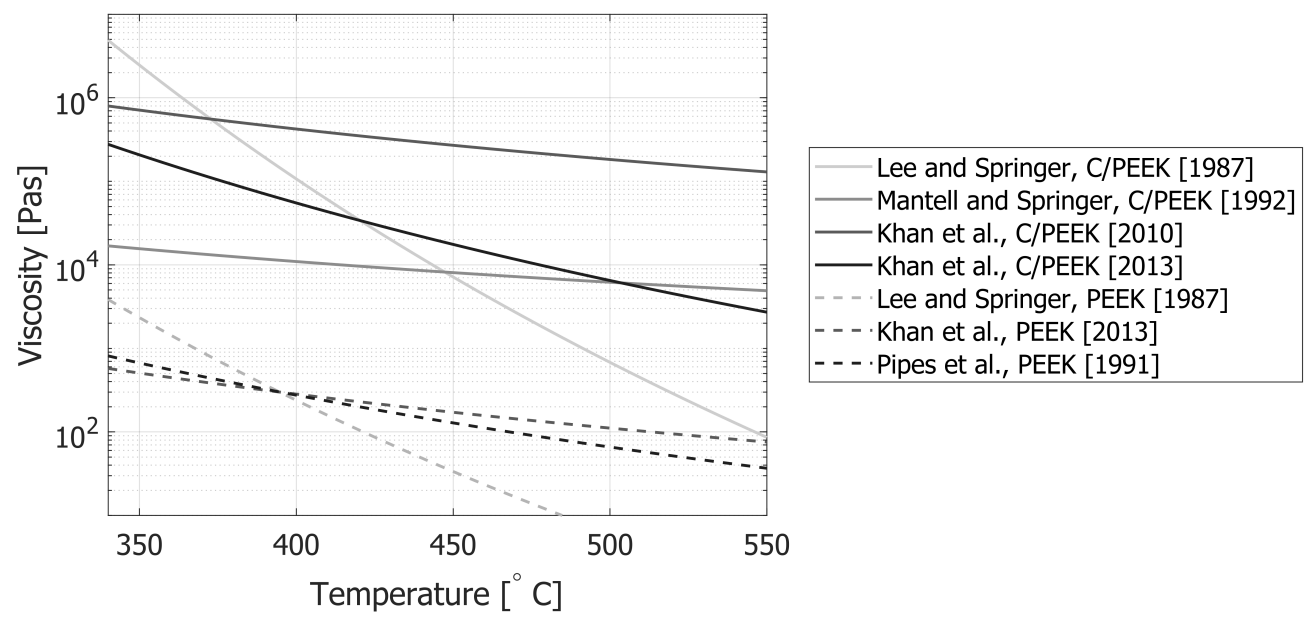

Figure 4.6 Fiber-matrix viscosity of C/PEEK by several researchers as function of temperature. 
Table 4.3 Fiber matrix viscosity models available in literature.

\begin{tabular}{|c|c|c|c|c|}
\hline \multicolumn{5}{|c|}{ C/PEEK } \\
\hline \multirow[t]{2}{*}{ Study } & \multirow[t]{2}{*}{ Material } & \multicolumn{2}{|c|}{ Parameters } & \multirow[t]{2}{*}{ Reference } \\
\hline & & $c_{\mu}[\mathrm{Pa} \mathrm{s}]$ & $c_{\mathrm{b}}[\mathrm{K}]$ & \\
\hline Lee and Springer [1987] & APC-2 & $1.14 \cdot 10^{-12}$ & 26300 & [7] \\
\hline Mantell and Springer [1992] & $\mathrm{APC}-2 / \mathrm{AS} 4$ & 132.95 & 2969 & [8] \\
\hline Khan et al. [2010] & Suprem C/PEEK & 643 & 4367 & [14] \\
\hline Khan et al. [2013] & Suprem C/PEEK & $3.7 \cdot 10^{-3}$ & 11115 & [4] \\
\hline \multicolumn{5}{|c|}{ PEEK } \\
\hline \multirow[t]{2}{*}{ Study } & \multirow[t]{2}{*}{ Material } & \multicolumn{2}{|c|}{ Parameters } & Reference \\
\hline & & $c_{\mu}[\mathrm{Pa} \mathrm{s}]$ & $c_{\mathrm{b}}[\mathrm{K}]$ & \\
\hline Lee and Springer [1987] & PEEK 150P & $1.13 \cdot 10^{-10}$ & 19100 & [7] \\
\hline Khan et al. [2013] & PEEK 150PF & $2.04 \cdot 10^{-1}$ & 4871 & [4] \\
\hline Pipes et al. [1994] & PEEK & $4.36 \cdot 10^{-3}$ & 7439 & [15] \\
\hline
\end{tabular}

\subsubsection{Surface representation and resulting intimate contact devel- opment models}

The intimate contact model is derived from the assumed surface representation. The roughness of the surface profile of a composite tape has multiple scales and is selfaffine [16]. This was recognized by Yang and Pitchumani, who proposed a fractal Cantor set to describe the surface. Although both a 2D and a 3D representation were developed, only the $2 \mathrm{D}$ representation was considered here $[9,17]$. The surface asperities are considered at different length scales, which are called generations in a fractal Cantor set. Figure 4.7 shows an illustration of the type of fractal Cantor set used. The fractal geometry is derived by starting with a rectangle with a width $L_{0}$ and height $f h_{0}$. The first generation of asperities is obtained by removing an element from this rectangle of width $L_{0}-L_{1}$ and height $h_{0}$. The second generation is obtained by removing elements of width $\frac{L_{1}}{2}-\frac{L_{2}}{2}$ and height $h_{1}$. This procedure can be continued for further generations, but typically about 10-15 generations are sufficient [9]. Each generation of asperities needs to be flattened to create complete intimate contact starting from the highest generation up to the first generation. The flattening of each generation is described by the aforementioned squeeze flow mechanism. The degree of intimate contact can then be calculated by integrating over each generation $n$ as follows

$$
\begin{array}{r}
D_{i c}^{(n)}(t)=\frac{1}{f^{n}}\left(1+\frac{5}{4}\left(\frac{h_{0}}{L_{0}}\right)^{2} \frac{f^{\frac{2 n D}{2-D}+n+4}}{(f+1)^{2}} \int_{\left(t_{n+1}\right)}^{t_{(n)}} \frac{P}{\mu_{\mathrm{fm}}} d t\right)^{\frac{1}{5}} . \\
\text { for } t_{(n+1)} \leq t \leq t_{(n)},
\end{array}
$$


where $t_{(n)}$ is the start time of the deformation of a generation.

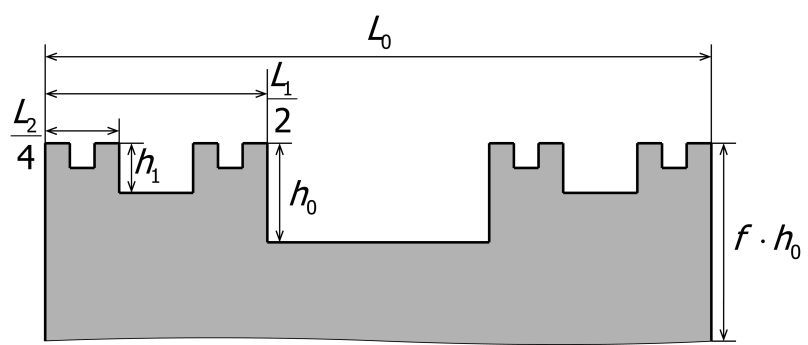

Figure 4.7 Illustration of the surface representation considered in the intimate contact model by Yang and Pitchumani [9].

The integration has to be done over the time required to flatten a generation, with the fiber-matrix viscosity $\mu_{\mathrm{fm}}$ as a function of time [9]. The parameters of the selfaffine fractal Cantor set are $h_{0}, L_{0}, s, f$ and $D . L_{0}$ and $h_{0}$ are respectively the width and height of the largest scale of asperities assumed on the surface. The ratio of the height to the width of an asperity $\frac{h_{0}}{L_{0}}$ highly affects the degree of intimate contact development in this model. The number of asperities per generation is defined by $s$ and $f$ is the scaling factor of the width and height of the next generation. $D$ is called the self-affine fractal dimension and is a measure off the difference in scaling for the height and width of the set. The relation between $D$ and $f$ to the parameter $s$ is given by

$$
s=f^{\frac{D}{2-D}}
$$

The resulting geometry of a fractal Cantor set with a value of 2 for $s$ is given in Figure 4.7. For a full explanation and description of determination of these parameters the reader is referred to $[9,16]$.

\subsubsection{Modeling results}

The parameters required to describe the surface of the tape were obtained from the surface profiles of microscopy images from Chapter 3 . In the literature the surface of the as-received tape is considered; however, in Chapter 3 it was shown that the tape deconsolidates during the heating phase. This deconsolidated tape surface is the actual tape surface that enters the nip-point. Therefore, this surface is used to determine the surface parameters and is termed laser-heated tape surface in the remainder of this chapter. The parameters required to describe the surface are obtained following the procedure provided by Yang and Pitchumani and these are given in Table 4.4 [9]. It can be seen that the increased roughness of the laser-heated tape results in higher and wider asperities and also the scaling factors increased. 
Table 4.4 Surface parameters of the intimate contact models.

\begin{tabular}{lcccc}
\hline \multicolumn{5}{c}{ Parameters Yang and Pitchumani model } \\
Parameter & Symbol & Unit & As-received tape & Laser-heated tape \\
\hline Largest asperity height & $h_{0}$ & {$[\mu \mathrm{m}]$} & 4.2 & 8.2 \\
Largest asperity width & $L_{0}$ & {$[\mu \mathrm{m}]$} & 11.0 & 15.3 \\
Fractal dimension & $D$ & {$[-]$} & 1.2 & 1.3 \\
Scaling parameter & $f$ & {$[-]$} & 1.1 & 1.3 \\
\hline
\end{tabular}

The thermal model described in Chapter 2 was used to obtain the temperature distribution during the process for each configuration in the DOE. The temperature at the interface of the tape and previous placed plies was used to calculate the viscosity. This has been done both for the as-received surface parameters and for the surface parameters of the laser-heated tape. The calculated intimate contact for each configuration in both DOEs and the effects of the various process parameters are given in Figure 4.8. Please note that for the second DOE only the low and the high levels were used to simplify the comparison.

Figure 4.8(a) and 4.8(c) show that the predicted degree of intimate contact is always higher for the deconsolidated surface than for the as-received surface. The latter has high and narrow asperities, which are easier to deform than the low and wide asperities on the as-received tape. Based on the description for both the as-received tape and the laser-heated tape the model underestimates the experimentally acquired degree of intimate contact.

The trends can be analyzed by Figure 4.8(b) and 4.8(d), which show the effects of the different process parameters on the intimate contact development. Figure 4.8(d) shows that part of the effects are predicted quite well.

Significant deviations can be observed, however, in the results for the first DOE in Figure 4.8(b). The effect of the tool temperature and fraction of heat on the tape was predicted to be the opposite. However, more surprisingly the model predicted a negative compaction force on the degree of intimate contact development, although the magnitude is negligible. It is generally presumed, and also shown in the experimental results, that increasing the compaction force improves intimate contact development. The difference in compaction force in this DOE is apparently too small to affect the model results and the slight negative effect is probably a flaw resulting from the DOE formulation due to the low number of configurations considered. Furthermore, the effect of the fraction of heat on the tape is predicted negative for the first DOE and positive for the second DOE, which is conform the experimental results. The predicted negative effect in the first DOE is probably also a flaw resulting 
from the DOE formulation.

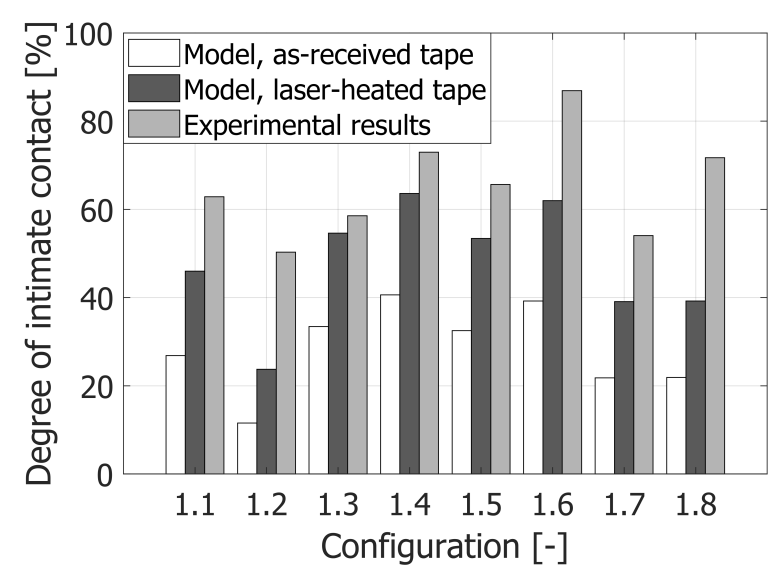

(a)

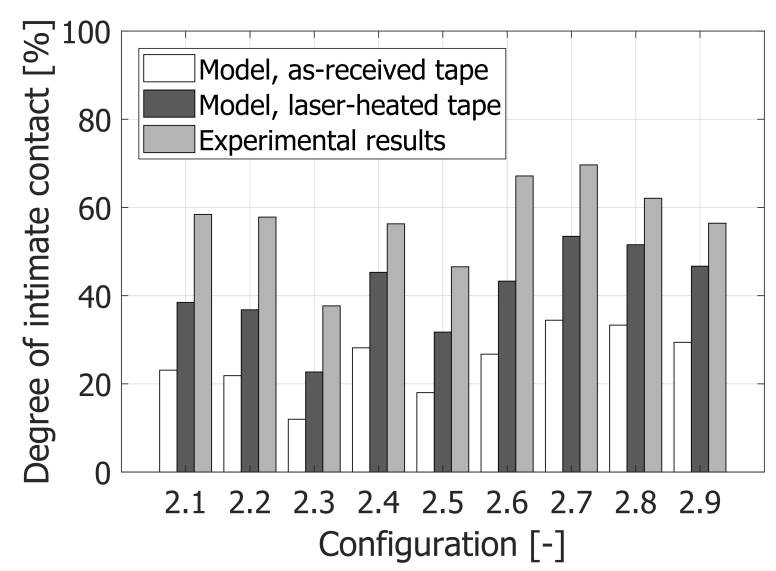

(c)

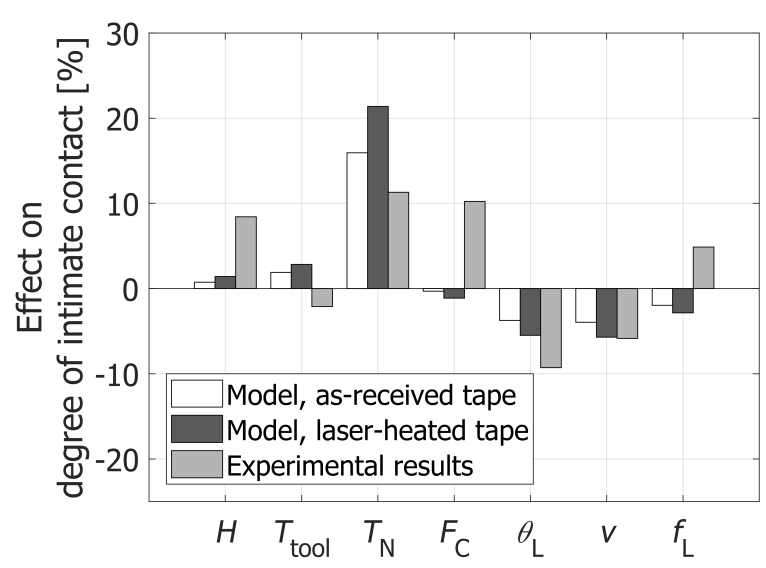

(b)

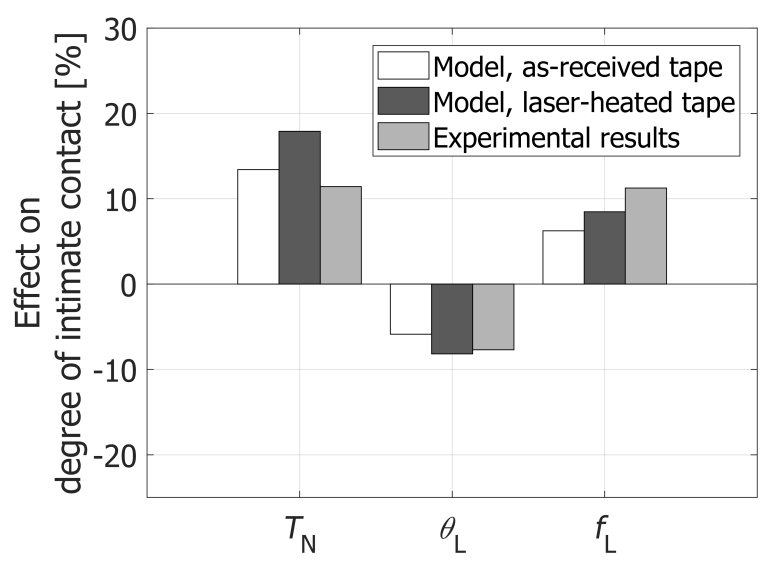

(d)

Figure 4.8 Experimental results and results of the Yang and Pitchumani model for both the as-received and laser-heated tape for the intimate contact experiments performed. (a) The degree of intimate contact and (b) the effects of the parameters for the first DOE. (c) The degree of intimate contact and (d) the effects of the parameters for the second DOE.

The nip-point temperature is clearly the most significant parameter, but its effect is overestimated. For the placement velocity both the sign and magnitude are predicted correctly. The sign of the effect of the laser angle and the spot size are predicted correctly, while the magnitude is underestimated. In general, the results of the model assuming the laser-heated surface are slightly better than that assuming the as-received tape surface. 


\subsubsection{Discussion}

In order to discuss the modeling results, the surface representations used in the intimate contact model are compared with cross-sectional micrographs. Figure 4.9(a) and 4.9(b) show representative parts of the cross-sectional micrographs of both the asreceived tape and the laser-heated tape, and the latter is the state of the tape entering the nip-point. The surface representations used in the intimate contact model are based on surface profiles obtained from such micrographs. Figure 4.9(c) and 4.9(d) show drawings based on these micrographs, to ease the comparison with the surface representations in the model. The cross-sections show that the as-received tape has a smooth surface with fibers covered in matrix. The surface of the laser-heated tape is much rougher with dry fibers on the surface, as was discussed in detail in Chapter 3.

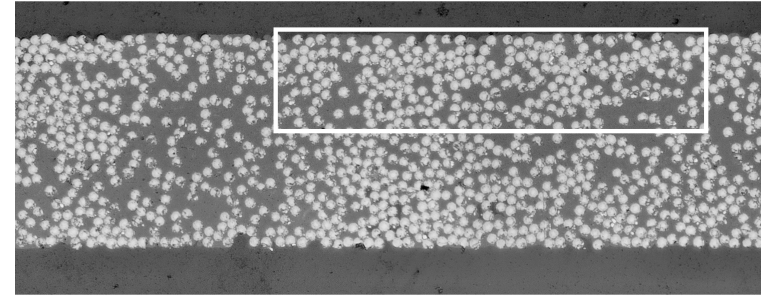

(a)

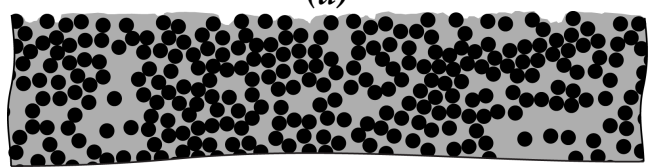

(c)

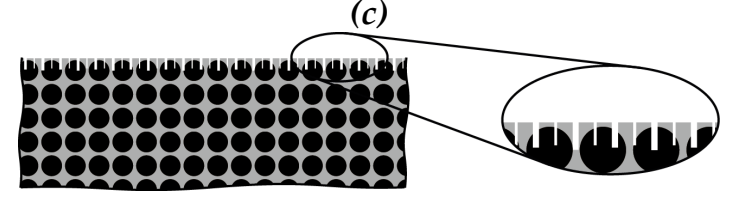

(e)

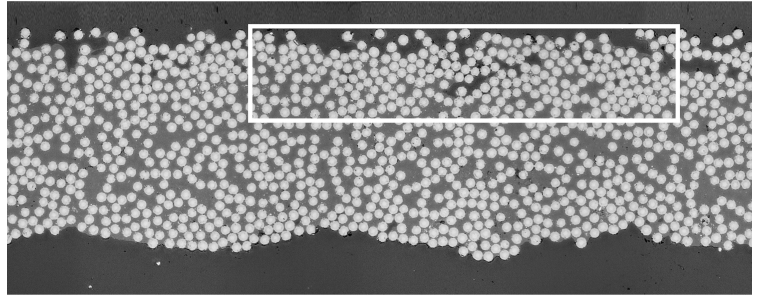

(b)

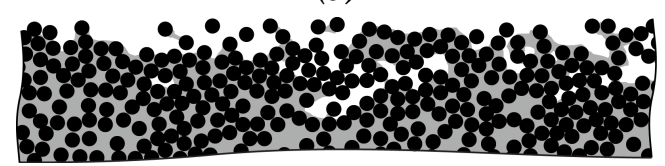

(d)

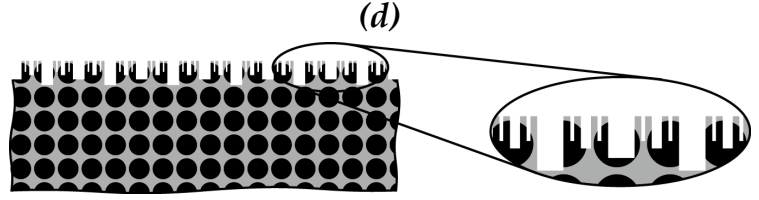

$(f)$

Figure 4.9 Comparison of cross-sectional micrographs with surface representations used in the intimate contact model of Yang and Pitchumani. (a) The as-received tape from which (c) a drawing is made from the area indicated and $(e)$ a sketch of its surface representation in the intimate contact model. (b) The laser-heated tape from which $(d)$ a drawing is made from the area indicated and $(f)$ a sketch of its surface representation in the intimate contact model.

The drawings can be compared with the surface representations used in the model. It can be seen that the surface of the as-received tape is smooth, with only a couple of small dimples of about half a fiber thickness in the surface. The surface representation, as shown in Figure 4.9(e), shows similar gaps of half a fiber thickness, but the distance between the gaps is smaller. The drawing of the laser-heated tape shows the rough tape surface and the resulting representation has higher asperities with larger gaps than in the representation of the as-received tape. However, there is 
no clear resemblance between the model representation and the drawing of the crosssection, as is shown in Figure 4.9(f). The laser-heated surface does not have surface asperities that have to be deformed to create intimate contact. Instead, intimate contact is inhibited by a lack of matrix on the surface.

The degree of intimate contact predicted for the as-received tape is smaller than for the laser-heated tape. As mentioned earlier, this can be explained by the difference in surface representation. The as-received tape representation has relatively wide asperities, which are, according to the model given by Equation 4.3, more difficult to deform than the high and narrow asperities of the laser-heated tape. Smooth tapes are generally thought to improve intimate contact development, but this cannot be described by the used intimate contact model [5].

The intimate contact model from Yang and Pitchumani was not capable to quantitatively predict the degree of intimate contact correctly. Qualitatively, it was able to predict the effect of part of the different process parameters. Surprisingly, it was unable to predict the effect of increasing the applied compaction force, which is generally expected to promote intimate contact development.

The generally accepted governing mechanism describing intimate contact development during LAFP is currently transverse squeeze flow of homogeneous surface asperities. The experimental results, however, show that the model developed by Yang and Pitchumani was not able to predict the degree of intimate contact quantitatively and also not able to predict all trends correctly. Furthermore, it was shown that the surface representations did not resemble the cross-sectional micrographs of the laser-heated tape. The rough and fiber-rich surface of the heated tape should be wetted with matrix to obtain intimate contact. A flow of matrix through the fiber bed is required to wet the surface, hence it is proposed to describe intimate contact development during LAFP with a model based on impregnation of dry fibers bed on the surface of the tape.

\subsection{Intimate contact model based on impregnation}

This section summarizes the derivation of an impregnation model to describe intimate contact development during LAFP. A more elaborate derivation is given in Appendix 4.A. The model is based on the work by Michaud et al. on the impregnation of deformable fiber beds [18]. 


\subsubsection{Problem statement}

The model by Michaud and co-workers describes the 1D impregnation of a deformable dry fiber bed [18]. In the case of intimate contact development, a large part of the tape is impregnated. Only the deconsolidated surface is dry and needs to be impregnated. Darcy's law is used to describe the flow rate of the matrix through the impregnated fiber bed under an applied pressure. The flow rate at the fluid boundary is the velocity at which the dry fiber bed is impregnated. The model is outlined schematically for a single control volume in Figure 4.10. The initial condition is shown in the image on the extreme left with an impregnated part $z_{\mathrm{I}}$ with a fiber volume content of $V_{\mathrm{f} 0}$, the control volume, and the dry part of the tape $z_{\mathrm{D}}$. In the second image, pressure is applied and the dry fiber bed is compressed. Under the applied pressure the melted matrix flows through impregnated fiber bed and the dry fiber bed is impregnated as shown in the third image, up to full impregnation in the fourth image.
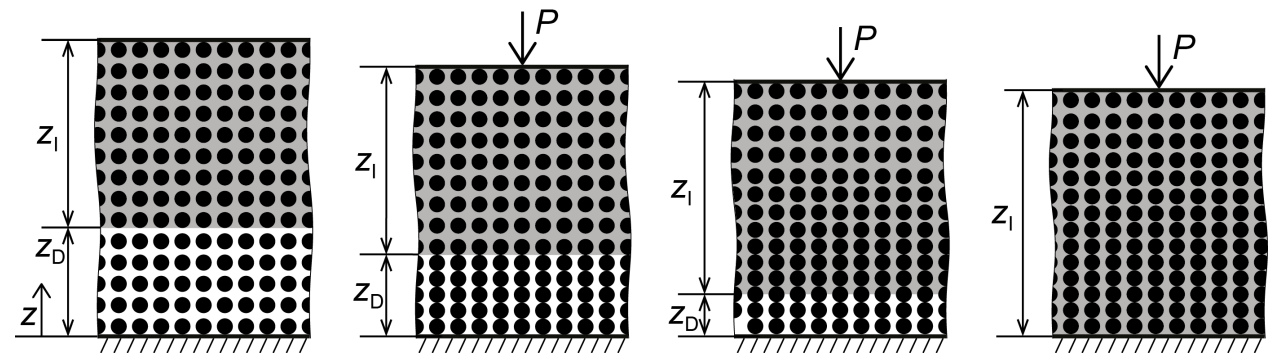

Figure 4.10 Schematic view of the model based on Darcy's law describing the impregnation of a dry fiber bed.

The surface of the laser-heated tape was shown in Figure 4.9(e) and it can be observed that the thickness of the dry fiber bed varies over the width of the tape. Therefore, the laser-heated surface is considered to be a series of the 1D control volumes in parallel, to incorporate the variation of the thickness of the dry fiber bed over the width and to obtain a degree of intimate contact based on the number of impregnated control volumes. For each single control volume, a different thickness of the dry fiber bed is considered, as illustrated in Figure 4.11(a). Then an equal pressure is applied on each element and the dry fiber bed is compacted, as shown in Figure 4.11(b), and gradually impregnated, as shown in Figures 4.11(c) and 4.11(d). The degree of intimate contact is defined as the ratio of the number of control volumes for which full impregnation of the dry fiber bed is achieved over the total number of control volumes.

The flow diagram of the proposed model is shown in Figure 4.12. The thermal model, described in Chapter 2, is used to calculate the temperature distribution through the thickness of the tape and over time. This is required as an input of the impregnation 


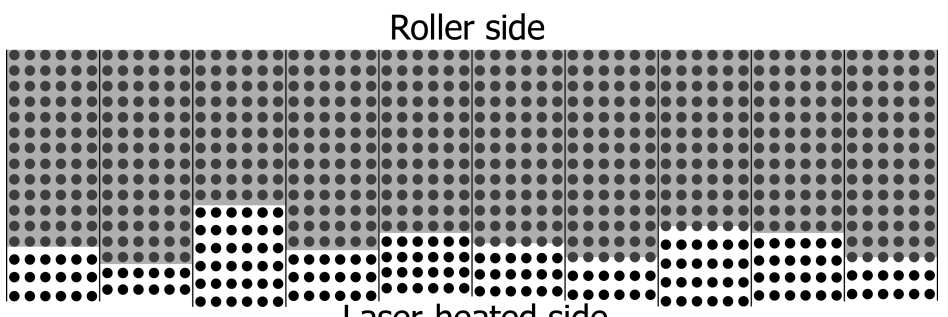

Laser-heated side

(a)

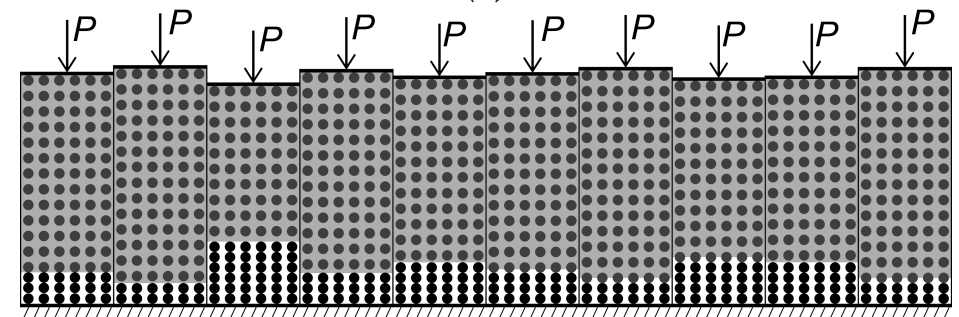

(b)

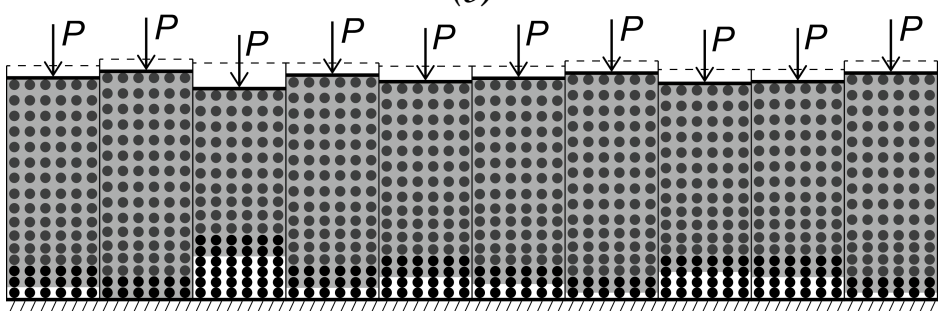

(c)

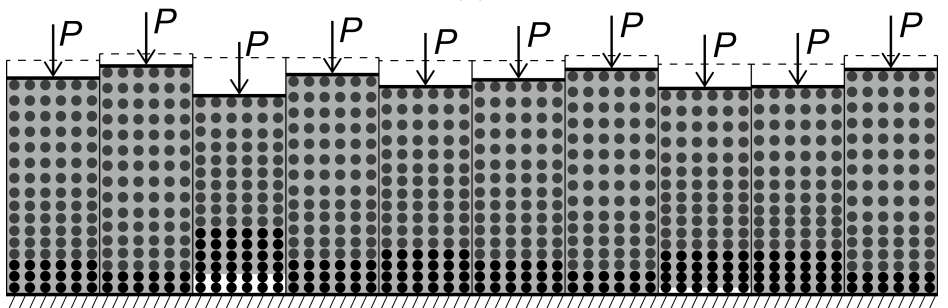

(d)

Figure 4.11 Intimate contact development as assumed in the impregnation model. (a) The varying dry fiber bed thickness over the width of the laser-heated tape, (b) pressure is applied an the dry fiber bed is compressed, (c) the dry fiber bed is impregnated and full impregnation is achieved in one of the control volumes, and $(d)$ the dry fiber bed is further impregnated and full impregnation is achieved in multiple control volumes.

model, to obtain the viscosity of the matrix. The impregnation model, of which the derivation is given in Section 4.4.2, describes the flow rate of the matrix through the fiber bed and the impregnation distance is obtained, based on the process settings and the used material models. The degree of intimate contact is calculated using the model that describes the relation between the impregnation distance and the degree of intimate contact, which is described in Section 4.4.3. 


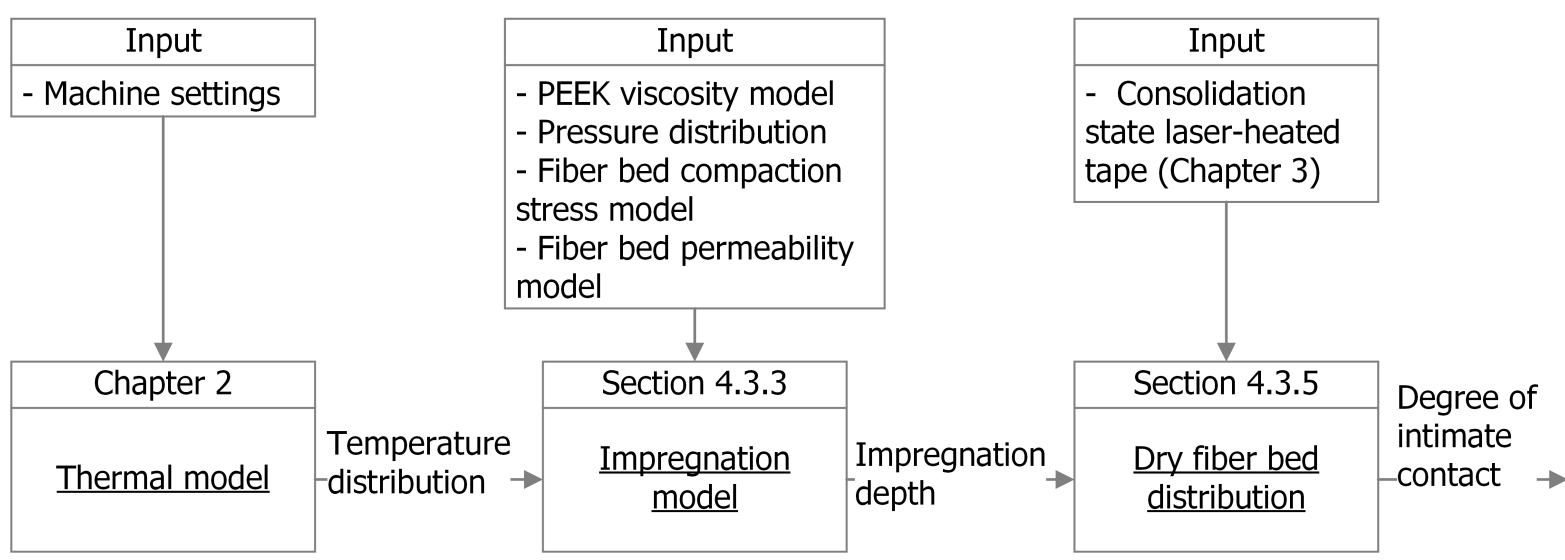

Figure 4.12 Flow diagram of the proposed impregnation model for intimate contact development.

\subsubsection{Intimate contact model based on 1D impregnation}

\section{Assumptions}

The control volume considered is the fully impregnated part of the tape with a thickness of about $150 \mu \mathrm{m}$ and an initial fiber volume fraction of $V_{\mathrm{f} 0}$. The control volume is considered to be $1 \mathrm{D}$, i.e. only the through-thickness flow is considered. The impregnation is assumed to be instantaneous, so the dry fiber bed is instantly fully impregnated when the impregnation front passes. Capillary and body forces were neglected as the pressure gradient is large and inertial forces were neglected as viscous forces are more dominant. Furthermore, the fiber bed is assumed to be a continuous medium, with a permeability as a function of the fiber volume fraction. The matrix is assumed to behave as a Newtonian fluid with a temperature dependent viscosity, described by Equation 4.2. The temperature varies through the thickness and over time and can be obtained using the thermal model described in Chapter 2. Only re-impregnation of the laser-heated tape surface is considered to predict intimate contact development; the substrate is neglected. Finally, the dry fiber bed is considered to be at atmospheric pressure as air can evacuate without resistance, while a Hertzian pressure model is used for the pressure distribution applied by the roller [18-21].

\section{Derivation}

Darcy's law describes the flow of a fluid in a porous medium and can be used to describe the flow in the impregnated part $z_{\mathrm{I}}$ of the tape as shown in Figure 4.10. The dry fiber bed is impregnated when the applied pressure is high enough. The rate at which the dry fiber $z_{\mathrm{D}}$ bed can be impregnated is based on the velocity of the fluid boundary of $z_{\mathrm{I}}$. Following Michaud et al., Darcy's law in 1D can be written as 


$$
u_{1}-u_{\mathrm{s}}=-\frac{K\left(V_{\mathrm{f}}\right)}{\mu\left(1-V_{\mathrm{f}}\right)} \frac{\partial P}{\partial z}
$$

where the velocity of the fluid and the solid are $u_{1}$ and $u_{\mathrm{s}}$ respectively. The permeability of the solid is $K$, which is a function of the fiber volume content $V_{\mathrm{f}}$, and $\mu$ is the matrix viscosity, which is a function of the temperature and $P$ is the applied pressure.

The mass conservation of the solid and the liquid are given by

$$
\begin{aligned}
& \frac{\partial V_{\mathrm{f}}}{\partial t}+\frac{\partial\left(V_{\mathrm{f}} u_{\mathrm{s}}\right)}{\partial z}=0, \text { and } \\
& -\frac{\partial V_{\mathrm{f}}}{\partial t}+\frac{\partial\left(\left(1-V_{\mathrm{f}}\right) u_{1}\right)}{\partial z}=0 .
\end{aligned}
$$

The stress equilibrium is given by

$$
\frac{\partial P}{\partial z}=-\frac{\partial \sigma_{\mathrm{c}}}{\partial z}
$$

where $\sigma_{\mathrm{c}}$ is the compaction stress of the fiber bed. A compressive stress is considered positive and the stress is averaged over the area of both the fiber and matrix. From these equations the governing partial differential equation of the $1 \mathrm{D}$ impregnation of a fluid in a porous medium can be obtained and the full derivation is given in Appendix 4.A. The result is

$$
\frac{\partial V_{\mathrm{f}}}{\partial t}+\frac{\partial}{\partial z}\left(-\frac{K\left(V_{\mathrm{f}}\right) V_{\mathrm{f}}}{\mu} \frac{\partial \sigma_{\mathrm{c}}}{\partial V_{\mathrm{f}}} \frac{\partial V_{\mathrm{f}}}{\partial z}\right)=0 .
$$

It can be seen from this equation that the permeability of the fiber bed, which is a function of the fiber volume content, and the fiber bed compaction stress, also as a function of the fiber volume content, are required to solve the problem. The models used in this work are taken from available literature, as will be explained in the following section.

The initial condition is the fiber volume fraction distribution in the impregnated tape and this is taken as a uniform fiber volume fraction $V_{\mathrm{f} 0}$ of $59 \%$. The fiber volume fraction at the fluid boundary, where the dry fiber bed is impregnated, is given by

$$
V_{\mathrm{f}}\left(z=z_{\mathrm{I}}\right)=V_{\mathrm{f}}^{\mathrm{c}}
$$

where $V_{\mathrm{f}}^{\mathrm{c}}$ is the fiber volume fraction of the compressed dry fiber bed. This can be 
calculated using the fiber bed compaction stress model described in the following section. A Neumann boundary condition described by

$$
\frac{\partial V_{\mathrm{f}}}{\partial z}(z=0)=0
$$

can be used at the roller face, at $z=0$ in Figure 4.10. However, in practice the time available for intimate contact development is too short to have an effect on the flow of matrix near the roller. Moreover, the roller at $z=0$ acts as a heat sink and the viscosity of the matrix increases as the matrix cools down near the roller, preventing the matrix from flowing. It is sufficient to consider only half of the tape, thereby reducing the number of nodes required in the model.

\section{Material models}

Three material models are required to solve the derived partial differential equation, namely the viscosity of the matrix as a function of temperature, the fiber bed permeability as a function of fiber volume fraction and the fiber bed compaction stress also as a function of fiber volume fraction. The polymer matrix considered is PEEK and a semi-empirical Arrhenius relation is used for the temperature dependent viscosity, as was given in Equation 4.2 using the material parameters given by Khan et al. from [4].

Several researchers have investigated the permeability of the unidirectional fiber bed [22-24]. These models are based on a theoretical analysis, as experimental validation of the permeability of unidirectional fiber beds is rather difficult. Consequently, the available models can vary significantly. The model selected in this analysis is the improved Carman-Kozeny model by Gutowski given by

$$
K\left(V_{\mathrm{f}}\right)=\frac{r_{\mathrm{f}}^{2}}{4 k_{0}} \frac{\left(\sqrt{\frac{V_{\mathrm{a}}}{V_{\mathrm{f}}}}-1\right)^{3}}{\frac{V_{\mathrm{a}}}{V_{\mathrm{f}}}+1},
$$

where $r_{\mathrm{f}}$ is the fiber diameter and $k_{0}$ is the Kozeny constant [22]. The parameter $V_{\mathrm{a}}$ is the fiber volume fraction where all flow is obstructed by the fibers. According to Gutowski $V_{\mathrm{a}}$ has a value of about $0.76-0.82$, based on fitting the model to experimental data [22].

The last material model required is the fiber bed compaction stress as a function of the fiber volume fraction. This material model is also difficult to obtain experimentally. The compression and relaxation stress of a wet fiber bed are required as a function of the fiber volume fraction. Compression of a dry fiber bed gives different results 
compared to a wet fiber bed due to lubrication effects of the matrix. The experimental data found in literature can vary significantly, based on the test method and the tested range of fiber volume fractions [25-27]. Gutowski et al. performed an extensive analysis of the fiber bed stresses of lubricated unidirectional AS4 carbon fiber beds $[26,28]$ and derived a model for the fiber bed compaction stress as

$$
\sigma_{\mathrm{c}}\left(V_{f}\right)=\frac{3 \pi E_{\mathrm{f}}}{\beta^{4}} \frac{\left(1-\sqrt{\frac{V_{\mathrm{f}}}{V_{0}}}\right)}{\left(\sqrt{\frac{V_{\mathrm{a}}}{V_{\mathrm{f}}}-1}\right)^{4}}
$$

where $\beta$ is a constant based on the assumed wavelength of waviness in the fiber, $E_{\mathrm{f}}$ is the tensile modulus of the fiber, $V_{0}$ the fiber volume fraction when no load is applied and $V_{\mathrm{a}}$ is the maximum fiber volume fraction. This model is based on the loading of a fiber bed and is also used, although it is conservative, for the unloading in this work. The aforementioned models are used in the impregnation model throughout this work and the used values of the required parameters are given in Table 4.5.

Table 4.5 Parameters used for the permeability and stress models.

\begin{tabular}{lcccc}
\hline Parameter & Symbol & Unit & Value & Reference \\
\hline Fiber E modulus & $E_{\mathrm{f}}$ & {$[\mathrm{GPa}]$} & 231 & Manufacturer \\
Wavelength waviness & $\beta$ & {$[-]$} & 350 & Gutowski [1987] [22] \\
Maximum fiber volume fraction & $V_{\mathrm{a}}$ & {$[-]$} & 0.829 & Gutowski [1987] [22] \\
Minimum fiber volume fraction & $V_{0}$ & {$[-]$} & 0.449 & Gutowski [1992] [26] \\
Pre-exponential factor & $c_{\mu}$ & {$[\mathrm{Pa} \mathrm{s}]$} & 0.204 & Khan et al. [2013] [4] \\
Free energy & $c_{\mathrm{b}}$ & {$[\mathrm{K}]$} & 4871 & Khan et al. [2013] [4] \\
\hline
\end{tabular}

\subsubsection{Thickness of the dry fiber bed and relation to the degree of intimate contact}

The degree of intimate contact was defined as the ratio of the number of control volumes for which the dry fiber bed is completely impregnated over the total number of control volumes. Initially the distribution of the dry fiber bed thickness over the width of the tape is required. This is derived from the constituent distributions of the fiber, matrix and void volume content over the thickness, which were obtained from micrographs of the laser-heated tapes in Chapter 3.

First, the cross-sectional micrographs of the tape are split into 50 slices. Figure 4.13 shows the distribution of the fiber, matrix and air volume content through the thickness in a single slice, accompanied by a sketch of the cross-sectional micrograph. The deconsolidated surface is shown, which was heated with a laser. It can be 
seen that above a height of $20 \mu \mathrm{m}$ the fiber volume fraction is about $59 \%$ and the matrix volume fraction is about $41 \%$, equal to the well consolidated as-received tape. Therefore, the initial fiber volume content $V_{\mathrm{f} 0}$ of the impregnated part of the tape is assumed to be $59 \%$. Below a height of about $20 \mu \mathrm{m}$, however, there is a steep increase in air content and a decrease in fiber and matrix volume content. This can also be observed in the drawing based on the micrograph, where a well impregnated tape can be observed above $20 \mu \mathrm{m}$, and a deconsolidated surface layer from 0 to approximately $20 \mu \mathrm{m}$. The deconsolidated layer was defined as the part of the tape where the air content is greater than $5 \%$. This layer is considered to be the dry fiber. As a conservative approach, the matrix in the surface layer is neglected.

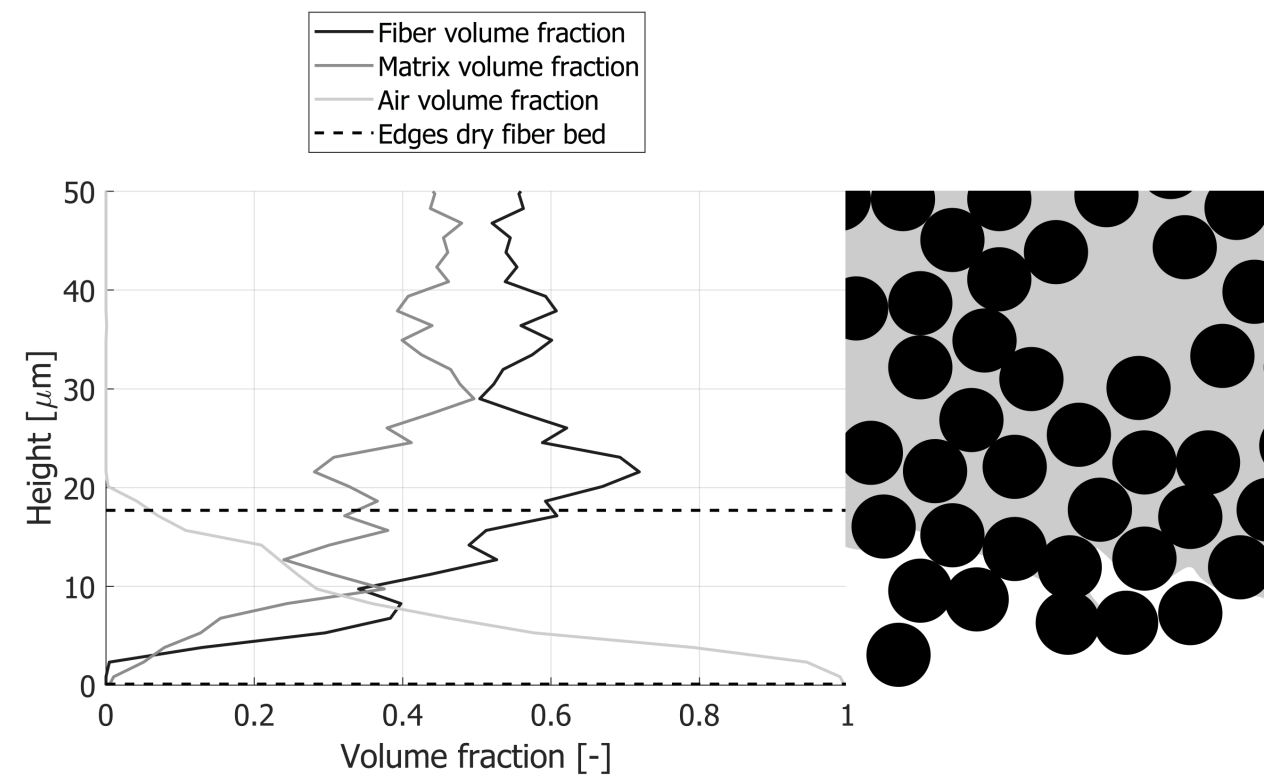

Figure 4.13 Constituent distributions through the thickness of the surface of the laser-heated tape, including a representation of the cross-section of the analyzed area.

The histogram of the distribution of the dry fiber bed thickness over the width of the tape is obtained from the dry fiber bed thickness of all slices of three tape specimens and is shown in Figure 4.14(a). The maximum dry fiber bed thickness is about $19 \mu \mathrm{m}$ and the largest part of the surface has a dry fiber bed thickness up to about $8 \mu \mathrm{m}$. The cumulative sum can be taken from the histogram to obtain the degree of intimate contact as a function of the (impregnated) thickness of the dry fiber bed, as shown in Figure 4.14(b) including the standard deviation as error bars. It can be seen that for a depth of impregnation exceeding $10 \mu \mathrm{m}$ a degree of intimate contact of more than $80 \%$ is obtained and above $15 \mu \mathrm{m}$ almost full intimate contact is obtained. A natural 
logarithmic fit given by

$$
D_{\text {ic }}=48.2 \ln \left(\frac{z_{\text {imp }}}{2.0}\right)
$$

is used to calculate the degree of intimate contact based on the thickness of the dry fiber bed that can be impregnated $z_{\text {imp. }}$.

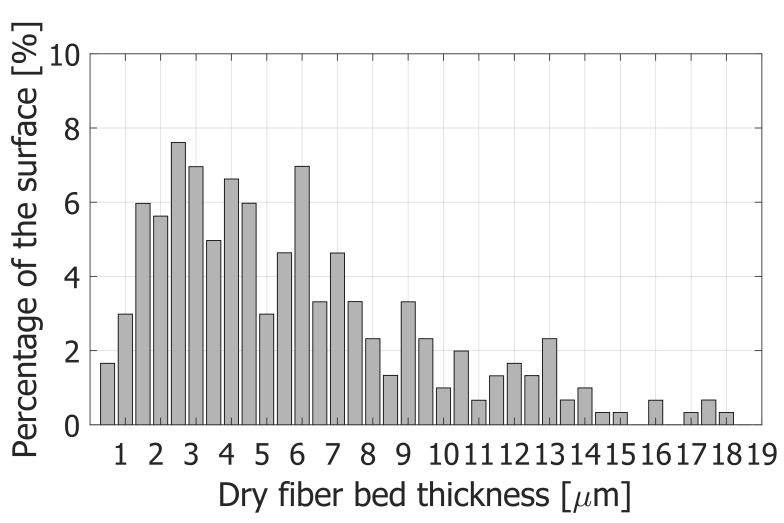

(a)

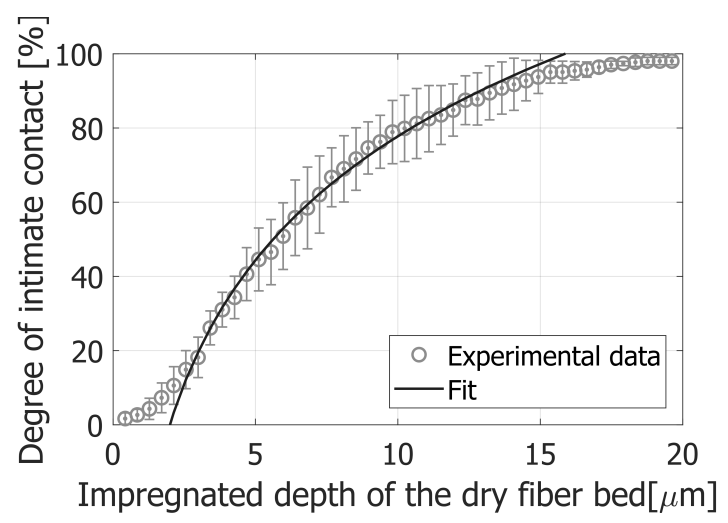

(b)

Figure 4.14 (a) The distribution of the thickness of the dry fiber bed of the analyzed tapes and (b) degree of intimate contact as a function of the impregnation depth in the dry fiber bed.

\subsubsection{Solution procedure}

Equation 4.9 is solved numerically using an explicit forward time, central space finite different scheme. A stability criterion given by

$$
2 \frac{D\left(V_{\mathrm{f}}\right) \Delta t}{(\Delta \xi)^{2}} \leq 1
$$

with $\Delta t$ and $\Delta \xi$ as the step size in time and space respectively, is used to ensure computational stability. $D$ is defined as

$$
D\left(V_{\mathrm{f}}\right)=-\frac{K\left(V_{\mathrm{f}}\right) V_{\mathrm{f}}}{\mu} \frac{\partial \sigma}{\partial V_{\mathrm{f}}}
$$

The minimum value of $D\left(V_{\mathrm{f}}\right)$ during the consolidation is used for the stability criterion. The differential equation is solved for the temperature distribution, based on the process settings, to calculate the maximum thickness of the dry fiber bed that can be impregnated. The degree of intimate contact can then be obtained from Equation 4.14 . 


\subsection{Results}

\subsubsection{Model convergence and parametric study}

A convergence study was performed to determine the number of grid points required for sufficient accuracy. A uniform and constant temperature of $450{ }^{\circ} \mathrm{C}$ and constant pressure of $0.67 \mathrm{MPa}$, equivalent to a compaction force of $835 \mathrm{~N}$, was used. The impregnation time was $0.26 \mathrm{~s}$ for an impregnation of $9 \mu \mathrm{m}$ using 1000 grid points. The difference to this result as a function of the number of grid points is given in Figure 4.15. About 200 grid points were sufficient to obtain a difference of less than $3 \%$ and a computational time of within $30 \mathrm{~s}$. Throughout this chapter 200 grid points are used for the intimate contact model based on impregnation.

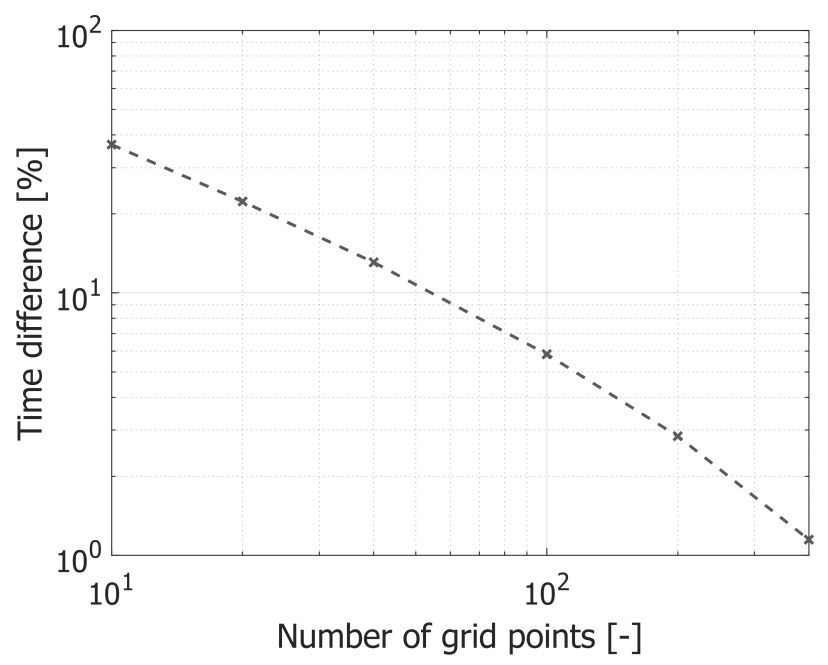

Figure 4.15 Convergence of the impregnation model.

A parametric study was then performed to analyze the effect of pressure and temperature on the time required to impregnate a dry fiber bed of $9 \mu \mathrm{m}$. The pressure is varied between $0.25 \mathrm{MPa}$ and $1.25 \mathrm{MPa}$, the latter is the maximum achievable with the LAFP robot and roller used in this work. The temperature is varied from the melting temperature of PEEK up to the autoignition temperature of about $600{ }^{\circ} \mathrm{C}$. Figure 4.16 shows the results of the parametric study. The graph shows that the dry fiber bed is impregnated more quickly at a higher applied pressure and a higher temperature. Pressure is applied by the roller for about $0.25 \mathrm{~s}$ at a placement velocity of $100 \mathrm{~mm} / \mathrm{s}$, which means that at least a pressure of $0.75 \mathrm{MPa}$ at a temperature of $500{ }^{\circ} \mathrm{C}$ or at least a temperature of $400{ }^{\circ} \mathrm{C}$ at a pressure of 1.25 $\mathrm{MPa}$ are required. Nip-point temperatures exceeding $500{ }^{\circ} \mathrm{C}$ are not recommended, as material degradation is likely at these temperatures. Consequently, the minimum time required for impregnation is about $0.09 \mathrm{~s}$. For the current setup, this limits the 
placement speed to around $300 \mathrm{~mm} / \mathrm{s}$.

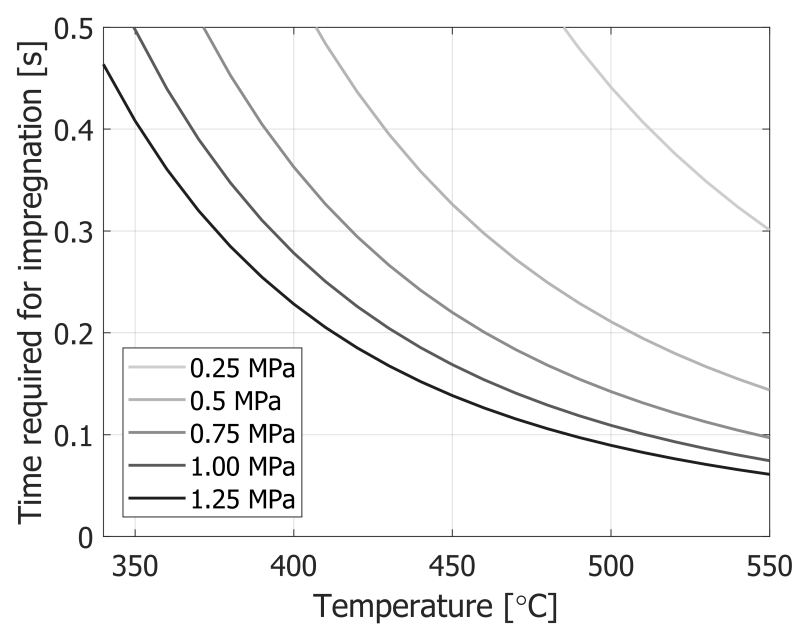

Figure 4.16 Parametric study of the effect of temperature and pressure on impregnation time.

A sensitivity analysis was performed on the initial fiber volume fraction $V_{\mathrm{f} 0}$ and the material parameters. A variation in fiber volume fraction of $\pm 2.5 \%$ was analyzed and for the permeability, the viscosity and the fiber bed compaction stress a variation of $\pm 10 \%$ was analyzed under the same experimental conditions as the convergence study. The result is shown in Figure 4.17. It can be seen that the initial fiber volume fraction greatly affects the impregnation. Only a small increase causes a large increase in impregnation time. The permeability and the viscosity affect almost linearly the impregnation, while a variation in the compaction stress scarcely affects the results.

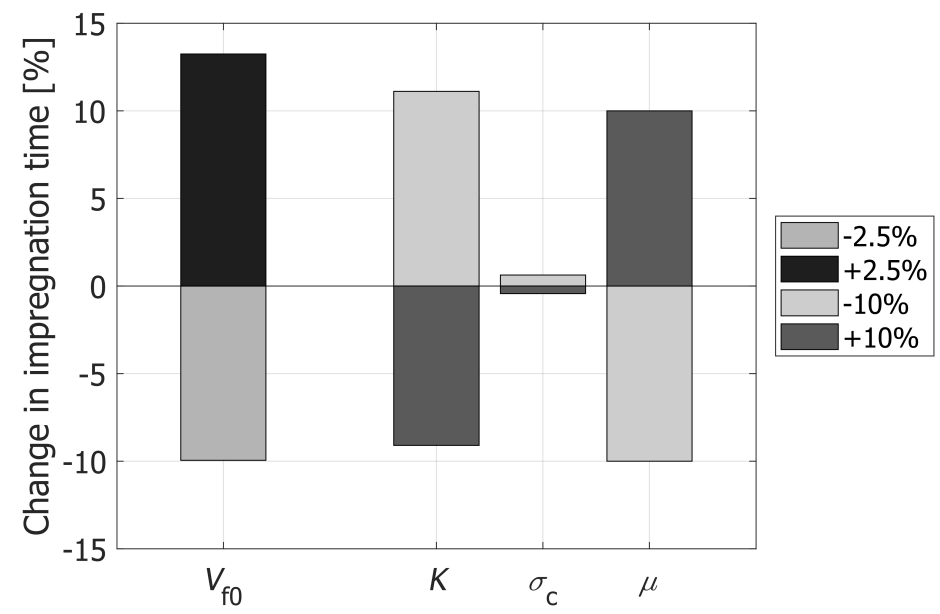

Figure 4.17 Sensitivity analysis. 


\subsubsection{Comparison with available intimate contact model and ex- perimental results}

The proposed intimate contact model based on impregnation of a dry fiber bed is used to predict the degree of intimate contact for the experimental configurations. The results will be compared with the intimate contact model developed by Yang and Pitchumani, for which the surface parameters of the laser-heated tape are used, along with the experimental results in this section.

The results of both models as well as the experimental results are given in Figure 4.18 for both DOEs. It can be observed from Figures 4.18(a) and 4.18(c) that the impregnation model underestimates the degree of intimate contact by up to $40 \%$. The difference is particularly large for the configurations with an experimental degree of intimate contact smaller than $55 \%$, as can be observed for configurations 1.2, 1.7, 2.3 and 2.5. The model of Yang and Pitchumani also underestimated the degree of intimate contact, although the predictions are closer to the experimental results. The trends that can be observed in the experimental results can also be observed in the results of both models.

The effects of the different parameters on the degree of intimate contact are shown for DOEs 1 and 2 in Figures 4.18(b) and 4.18(d) respectively. It can be seen that the correct sign of each effect is predicted by the model based on impregnation, except for the tool temperature and the fraction of heat on the tape in the first DOE. The model of Yang and Pitchumani predicted a negligible effect off the applied compaction force, which does not represents the experimental results. The effect of the compaction force is predicted by the model based on impregnation. Furthermore, the effect of some of the parameters, such as the nip-point temperature and the placement velocity, are overestimated by the model based on impregnation. The effects of these parameters are better predicted by the model of Yang and Pitchumani. Although some of the effects of parameters are overestimated by the model based on impregnation, its results seem to be slightly better than the results of the model based on flattening of surface asperities. 


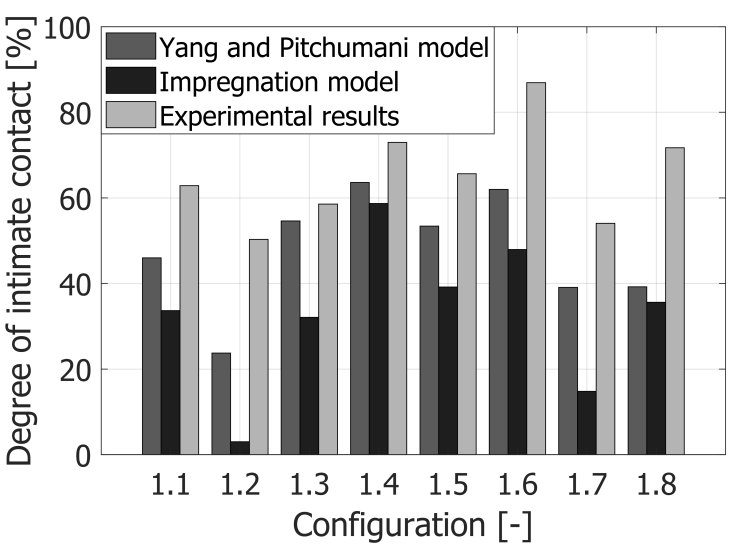

(a)

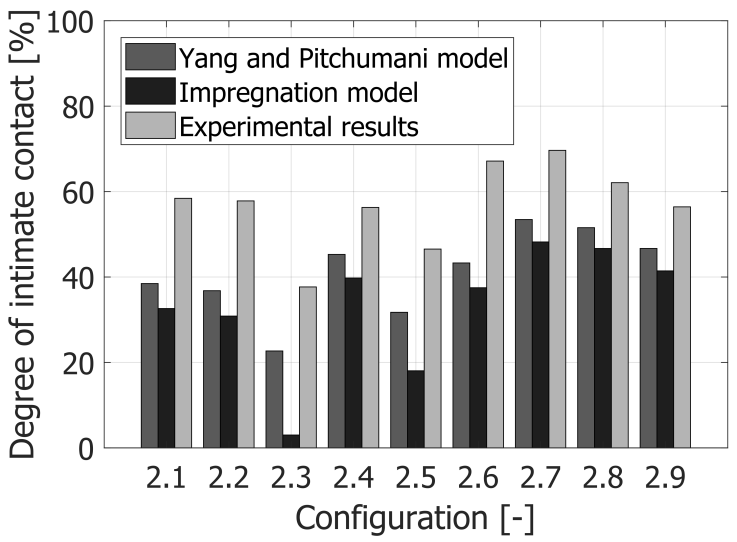

(c)

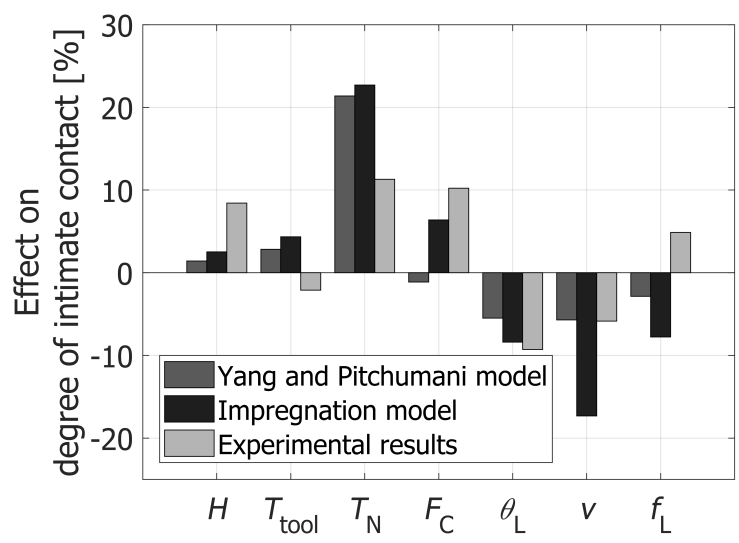

(a)

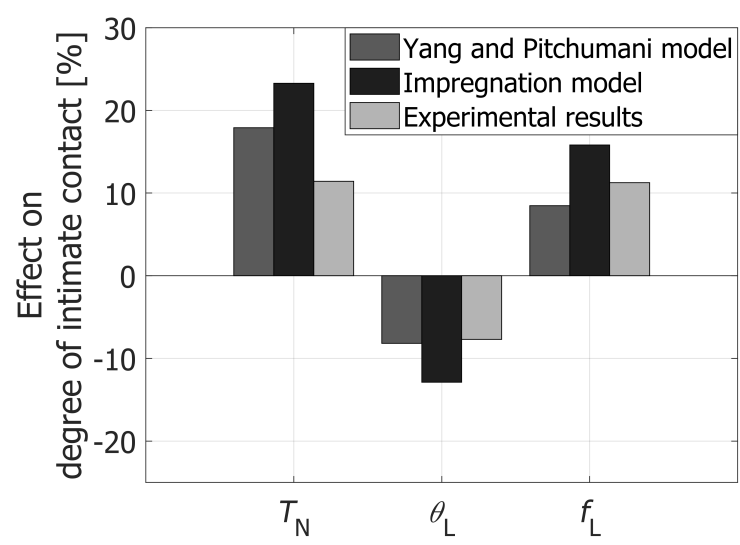

(d)

Figure 4.18 Comparison of the experimental results, the results of the Yang and Pitchumani model using the surface representation of the laser-heated tape and the results of the impregnation model. (a) Degree of intimate contact and (b) effect of the varied parameters of the first DOE. (c) Degree of intimate contact and $(d)$ effect of the varied parameters of the second DOE.

\subsection{Discussion}

A novel intimate contact model based on impregnation of dry fibers at the surface as the governing mechanism was introduced. Previous work showed that the tape deconsolidates during the heating phase of LAFP, resulting in a fiber rich and rough laser-heated surface. Consequently, matrix is required to flow through the fiber bed to wet the surface of the tape in order to be able to create intimate contact with previously placed plies. The model was compared with experimental results on intimate contact development during LAFP as a function of a number of process parameters. Although the degree of intimate contact was generally underestimated, the model was capable to qualitatively predict the effects of the different process parameters. The results presented in this Chapter are discussed in this section. First, the results of the impregnation model are compared with the currently available 
intimate contact models based on squeeze flow of surface asperities. Next areas of improvement for the proposed model based on impregnation are discussed. Finally, the experimental results on intimate contact development are discussed with available experimental work in literature.

Both the intimate contact model based on deformation of surface asperities and the proposed model based on impregnation were unable to quantitatively predict the intimate contact as obtained in the experimental analysis. Both models were, however, able to predict the effect of most of the process parameters correctly, with the results of the model based on impregnation being qualitatively slightly better. Although the model based on impregnation yields only slightly better results, it better represents the physical mechanisms governing intimate contact development for laser-heated (or deconsolidated tapes), for which wetting is primarily dominated by (re-)impregnation of the dry fiber surface.

Only simplified 1D impregnation was considered in this work and further development is required to be able to quantitatively predict intimate contact development. Three areas of improvement are discussed here, namely the material models, the dry fiber bed considered and the assumption of 1D impregnation.

Firstly, the material models required for modeling impregnation that are available in literature show a significant spread. Experimental determination of the permeability and compaction stress of unidirectional fiber beds is difficult. Therefore, theoretical models have been developed, but these also need to be verified with experimental data. The variation in permeability values reported in literature can span several decades [22-24, 27], and also compaction stress models differ significantly [23, 25-27]. The most appropriate models have been selected in this work. More accurate and experimentally verified material models for unidirectional carbon fiber beds with a thermoplastic matrix would be of great use for improving the proposed model and also modeling of impregnation of a unidirectional fiber bed by a thermoplastic matrix in general.

Secondly, only the tape is modeled in the current model. The previously placed plies are assumed to have a similar surface state and to be governed by the same impregnation mechanism based on the symmetry assumption. Deconsolidation of the laminate can be expected, but has not been verified experimentally. If the previously placed plies do not deconsolidate during the heating phase prior to the nip-point, this would promote intimate contact development due to the available matrix at the interface. Furthermore, it can be expected that the severity of the deconsolidation of both the tape and the previously placed plies are a function of the process parameters. This requires a more extensive analysis of the deconsolidation 
as a function of the process parameters.

Finally, a number of one-dimensional elements were considered to obtain the degree of intimate contact with the impregnation model. No transverse flow was considered between control volumes, while in the real process a transverse flow from fully impregnated control volumes to neighboring volumes would be possible. This may promote the degree of intimate contact development. Furthermore, the available matrix on the deconsolidated surface was neglected to simplify the model. This matrix would also promote intimate contact development. Moreover, it is assumed that the pressure on each control volume is equal. This can only be the case when the tape and roller can deform sufficiently. It is also possible that fully impregnated control volumes are pressurized more, which can cause a lack of pressure in neighboring control volumes. A $2 \mathrm{D}$ impregnation model might be better capable to include these phenomena. A 2D model might also be capable of describing the areas with partial impregnation more accurately.

To conclude, the trends of the experimental results are discussed briefly. The experimental results showed that the main parameters affecting the intimate contact development were the spot size, the nip-point temperature, the compaction force, the laser angle, the fraction of heat on the tape and the placement velocity. Although limited experimental work has been reported on intimate contact development, experimental work on interlaminar bond strength, which is considered to be the combination of intimate contact development and subsequent healing, confirms the observed effects of the different parameters. Stokes et al. showed a positive and a negative effect on the bond strength for increasing the nip-point temperature and placement velocity respectively [29]. Khan et al. confirmed the positive effect of an increased compaction force on the bond strength, while Grouve et al. and Schledjewski et al. also report a positive effect of a smaller laser angle and more heat on the tape on the bond strength $[4,12,30]$.

\subsection{Conclusion}

An experimental research has been performed to investigate the intimate contact development during LAFP. Cross-sectional microscopy analysis was used to assess the achieved intimate contact as a function of process parameters. The results were compared with an intimate contact model derived by Yang and Pitchumani based on deformation of surface asperities of the tape. The required parameters to describe the surface were obtained from cross-sectional micrographs of the tape's consolidation state prior to the nip-point. The model was not capable of quantitatively predicting 
the degree of intimate contact, however, the effect of most parameters could be predicted qualitatively, except for the effect of the applied compaction force.

The surface representation assumed in the intimate contact model was compared with the cross-sectional micrographs of the tape with a consolidation state prior to the nip-point. The representation did not resemble the actual tape surface. Furthermore, the tape surface showed dry fibers on the surface which required wetting in order to develop intimate contact. Therefore, an intimate contact model based on 1D impregnation was developed, based on this observation. Although the proposed model was not able to predict the degree of intimate contact quantitatively, it was able to qualitatively predict the effect of the different process parameters. The results were only slightly better than the available intimate contact models. However, the proposed model better represents the governing mechanism for intimate contact development and as such it could be the basis for further developments towards quantitative prediction of intimate contact.

\section{References}

[1] R. Schledjewski and A. K. Schlarb. In-situ consolidation of thermoplastic tape material effects of tape quality on resulting part properties. In Proceedings of the 2007 SAMPE Symposium and Exhibition (SAMPE 2007), volume 52. Baltimore, Maryland, USA, 2007.

[2] Z. Qureshi, T. Swait, R. Scaife, and H. M. El-Dessouky. In situ consolidation of thermoplastic prepreg tape using automated tape placement technology: Potential and possibilities. Composites Part B: Engineering, 66:255-267, 2014.

[3] A. J. Comer, D. Ray, W. O. Obande, D. Jones, J. Lyons, I. Rosca, R. M. $\mathrm{O}^{\prime}$ Higgins, and M. A. McCarthy. Mechanical characterisation of carbon fibrePEEK manufactured by laser-assisted automated-tape-placement and autoclave. Composites Part A: Applied Science and Manufacturing, 69:10-20, 2015.

[4] M. A. Khan, P. Mitschang, and R. Schledjewski. Parametric study on processing parameters and resulting part quality through thermoplastic tape placement process. Journal of Composite Materials, 47(4):485-499, 2013.

[5] M. B. Gruber, I. Z. Lockwood, T. L. Dolan, S. B. Funk, J. J. Tierney, P. Simacek, J. W. Gillespie Jr, S. G. Advani, B. J. Jensen, R. J. Cano, and B. W. Grimsley. Thermoplastic in situ placement requires better impregnated tapes and tows. In Proceedings of the 2012 International SAMPE Conference and Exhibition (SAMPE 2012). Baltimore, Maryland, USA, 2012.

[6] P. H. Dara and A. C. Loos. Thermoplastic matrix composite processing model. Report, Virginia Polytechnic Institute and State University, 1985. 
[7] W. I. Lee and G. S. Springer. A model of the manufacturing process of thermoplastic matrix composites. Journal of Composite Materials, 21(11):10171055, 1987.

[8] S. C. Mantell and G. S. Springer. Manufacturing process models for thermoplastic composites. Journal of Composite Materials, 26(16):2348-2377, 1992.

[9] F. Yang and R. Pitchumani. A fractal cantor set based description of interlaminar contact evolution during thermoplastic composites processing. Journal of Materials Science, 36(19):4661-4671, 2001.

[10] W. J. B. Grouve. Weld strength of laser-assisted tape-placed thermoplastic composites. Phd thesis, University of Twente, Enschede, The Netherlands, 2012.

[11] R. K. Roy. A primer on the Taguchi method. Competitive manufacturing series. Van Nostrand Reinhold, New York, 1990. ISBN 0442237294.

[12] W. J. B. Grouve, L. L. Warnet, B. Rietman, H. A. Visser, and R. Akkerman. Optimization of the tape placement process parameters for carbon-PPS composites. Composites Part A: Applied Science and Manufacturing, 50(0):44-53, 2013.

[13] C. M. Stokes-Griffin and P. Compston. Investigation of sub-melt temperature bonding of carbon-fibre/PEEK in an automated laser tape placement process. Composites Part A: Applied Science and Manufacturing, 84:17-25, 2016.

[14] M. A. Khan, P. Mitschang, and R. Schledjewski. Identification of some optimal parameters to achieve higher laminate quality through tape placement process. Advances in Polymer Technology, 29(2):98-111, 2010.

[15] R. B. Pipes, J. W. S. Hearle, A. J. Beaussart, A. M. Sastry, and R. K. Okine. A constitutive relation for the viscous flow of an oriented fiber assembly. Journal of Composite Materials, 25(9):1204-1217, 1991.

[16] T. L. Warren, A. Majumdar, and D. Krajcinovic. A fractal model for the rigidperfectly plastic contact of rough surfaces. Journal of Applied Mechanics, 63(1):4754, 1996.

[17] F. Yang and R. Pitchumani. Fractal description of interlaminar contact development during thermoplastic composites processing. Journal of Reinforced Plastics and Composites, 20(7):536-546, 2001.

[18] V. Michaud and J. A. E. Månson. Impregnation of compressible fiber mats with a thermoplastic resin. part I: Theory. Journal of Composite Materials, 35(13):11501173, 2001.

[19] J. L. Sommer and A. Mortensen. Forced unidirectional infiltration of deformable porous media. Journal of Fluid Mechanics, 311:193-217, 2006.

[20] J. L. Sommer. Infiltration of Deformable Porous Media. Ph.D. thesis, Massachusetts Institute of Technology, Massachusetts, 1992.

[21] H. R. Hertz. On the contact of rigid elastic solids and on hardness, Chapter 6: Assorted papers by H. Hertz. MacMillan, New York, USA, 1882.

[22] T. G. Gutowski, T. Morigaki, and Zhong C. The consolidation of laminate composites. Journal of Composite Materials, 21(2):172-188, 1987. 
[23] S. Kobayashi, T. Tsukada, and T. Morimoto. Resin impregnation behavior in carbon fiber reinforced polyamide 6 composite: Effects of yarn thickness, fabric lamination and sizing agent. Composites Part A: Applied Science and Manufacturing, 101(Supplement C):283-289, 2017.

[24] B.R. Gebart. Permeability of unidirectional reinforcements for rtm. Journal of Composite Materials, 26(8):1100-1133, 1992.

[25] M. Brzeski and P. Mitschang. Deconsolidation and its interdependent mechanisms of fibre reinforced polypropylene. Polymers and Polymer Composites, 23(8):515-524, 2015.

[26] T. G. Gutowski and G. Dillon. The elastic deformation of lubricated carbon fiber bundles: Comparison of theory and experiments. Journal of Composite Materials, 26(16):2330-2347, 1992.

[27] S. T. Jespersen, M. D. Wakeman, V. Michaud, D. Cramer, and J. A. E. Månson. Film stacking impregnation model for a novel net shape thermoplastic composite preforming process. Composites Science and Technology, 68(7):1822-1830, 2008.

[28] Z. Cai and T. G. Gutowski. The 3-d deformation behavior of a lubricated fiber bundle. Journal of Composite Materials, 26(8):1207-1237, 1992.

[29] C. M. Stokes-Griffin and P. Compston. The effect of processing temperature and placement rate on the short beam strength of carbon fibre-PEEK manufactured using a laser tape placement process. Composites Part A: Applied Science and Manufacturing, 78:274-283, 2015.

[30] R. Schledjewski and A. Miaris. Thermoplastic tape placement by means of diode laser heating. In Proceedings of the 2009 SAMPE Symposium and Exhibition (SAMPE 2009), volume 54. SAMPE, Baltimore, Maryland, USA, 2009.

\section{A Derivation impregnation model}

The derivation of the impregnation model used in Chapter 4 is given in this appendix.

\section{Assumptions}

- A 1D control volume with only through-thickness flow is considered.

- Capillary forces can be neglected with respect to the applied pressure.

- The pressure in the dry fiber bed is constant at atmospheric pressure.

- Body and inertial forces are neglected.

- The matrix behaves like a Newtonian fluid.

- The fiber bed is assumed to be a continuum.

- Impregnation is instantaneous at the impregnation front. 
- The dry fiber bed is completely dry and after impregnation completely impregnated without voids.

\section{Governing equations}

The main governing equation is Darcy's law [18]

$$
u_{1}-u_{\mathrm{s}}=-\frac{K\left(V_{\mathrm{f}}\right)}{m u\left(1-V_{\mathrm{f}}\right)} \frac{\partial P}{\partial z}
$$

with $V_{\mathrm{f}}(z)$ is the fiber volume fraction through the thickness, $u_{1}$ and $u_{\mathrm{s}}$ are the velocity of the liquid and the solid respectively. $K$ is the permeability of the solid phase as a function of the fiber volume fraction, $\mu$ is the viscosity of the liquid phase and $P$ is the pressure in the liquid. Furthermore the mass conservation of the liquid and solid phase given by

$$
\begin{aligned}
& \frac{\partial V_{\mathrm{f}}}{\partial t}+\frac{\partial\left(V_{\mathrm{f}} u_{\mathrm{s}}\right)}{\partial z}=0, \\
& -\frac{\partial V_{\mathrm{f}}}{\partial t}+\frac{\partial\left(\left(1-V_{\mathrm{f}}\right) u_{1}\right)}{\partial z}=0,
\end{aligned}
$$

is considered. Finally the stress equilibrium is considered

$$
\frac{\partial P}{\partial z}=-\frac{\partial \sigma_{\mathrm{c}}}{\partial z}
$$

with $\sigma_{\mathrm{c}}$ as the compaction stress.

\section{Differential equation}

First, the mass conservation of the liquid and the mass conservation of the solid, Equation 4.A.2 and 4.A.3, are summed:

$$
\frac{\partial V_{\mathrm{f}}}{\partial t}+\frac{\partial\left(V_{\mathrm{f}} u_{\mathrm{s}}\right)}{\partial x}-\frac{\partial V_{\mathrm{f}}}{\partial t}+\frac{\partial\left(\left(1-V_{\mathrm{f}}\right) u_{\mathrm{l}}\right)}{\partial z}=0
$$

which results in

$$
u_{1}-u_{\mathrm{s}}=\frac{u_{1}}{V_{\mathrm{f}}}
$$

The result can be substituted in Darcy's law, Equation 4.A.1, and rewritten to

$$
u_{1}\left(1-V_{\mathrm{f}}\right)=-\frac{K\left(V_{\mathrm{f}}\right) V_{\mathrm{f}}}{\mu} \frac{\partial P}{\partial z}
$$


This result can be substituted in the mass conservation of the liquid, Equation 4.A.3, to obtain the differential equation which describes the flow of a liquid through a porous medium:

$$
\frac{\partial V_{\mathrm{f}}}{\partial t}+\frac{\partial}{\partial z}\left(-\frac{K\left(V_{\mathrm{f}}\right) V_{\mathrm{f}}}{\mu} \frac{\partial \sigma_{\mathrm{c}}}{\partial z}\right)=0
$$

\section{Velocity of the impregnation front}

Darcy's law describes the flow of the matrix through the impregnated fiber bed and the dry part of the fiber bed is not part of the control volume. The domain of the matrix flowing through the fiber bed is increased, as the dry fiber bed is impregnated by the matrix. The velocity of the flow front can be calculated by substituting Equation 4.A.6 and Equation 4.A.4 in Darcy's law, Equation 4.A.1, which results in

$$
u_{1}\left(z=z_{\mathrm{I}}\right)=\left.\frac{K\left(V_{\mathrm{f}}\left(z_{\mathrm{I}}\right)\right) V_{\mathrm{f}}\left(z_{\mathrm{I}}\right)}{\mu\left(T\left(z_{\mathrm{I}}\right)\right)\left(1-V_{\mathrm{f}}\left(z_{\mathrm{I}}\right)\right)} \frac{\partial \sigma_{\mathrm{c}}}{\partial z}\right|_{z=z_{\mathrm{I}}} .
$$

\section{Change of variables}

As the domain is increasing, either the element size or the number of elements considered should increase. This can be incorporated easily by using a change of variables with respect to the size of the domain described by

$$
\xi=\frac{z}{z_{\mathrm{I}}(t)}
$$

Substitution of the change of variables in the equation for the velocity of the liquid at the impregnation front results in

$$
u_{1}(t, \xi=1)=\left.\left.\frac{K\left(V_{\mathrm{f}}(\xi=1)\right) V_{\mathrm{f}}(\xi=1)}{z_{\mathrm{I}}(t) \mu(T(\xi=1))\left(1-V_{\mathrm{f}}(\xi=1)\right)} \frac{\partial V_{\mathrm{f}}}{\partial \xi}\right|_{\xi=1} \frac{\partial \sigma_{\mathrm{c}}}{\partial V_{\mathrm{f}}}\right|_{\xi=1} .
$$

The differential equation, Equation 4.A.8, with the change of variables results in

$$
\frac{\partial V_{\mathrm{f}}}{\partial t}-\frac{\xi}{z_{\mathrm{I}}(t)} \frac{\partial z_{\mathrm{I}}(t)}{\partial t} \frac{\partial V_{\mathrm{f}}}{\partial \xi}+\frac{1}{\left(z_{\mathrm{I}}(t)\right)^{2}} \frac{\partial}{\partial \xi}\left(D\left(V_{\mathrm{f}}\right) \frac{\partial V_{\mathrm{f}}}{\partial \xi}\right)=0
$$

with

$$
D\left(V_{\mathrm{f}}\right)=-\frac{K\left(V_{\mathrm{f}}\right) \cdot V_{\mathrm{f}}}{\mu} \frac{\partial \sigma_{\mathrm{c}}}{\partial V_{\mathrm{f}}}
$$




\section{Finite difference description}

A finite difference method is used to solve the differential equation. A forward time and central space finite difference method is used and implemented in Matlab. The resulting finite difference equation is given by

$$
\begin{aligned}
& \left(V_{\mathrm{f}}\right)_{\xi_{i}}^{t_{n+1}}=\left(V_{\mathrm{f}}\right)_{\xi_{i}}^{t_{n}}+\Delta t \frac{\xi_{i}}{\left(z_{\mathrm{I}}\right)^{t_{n}}}\left(\frac{\partial z_{\mathrm{I}}}{\partial t}\right)^{t_{n}} \frac{\left(V_{\mathrm{f}}\right)_{\xi_{i+1}^{t_{n}}}^{t_{n}}-\left(V_{\mathrm{f}}\right)_{\xi_{i-1}^{t_{n}}}^{t_{n}}-}{2 \Delta \xi} \\
& \frac{\Delta t}{\left(\left(z_{\mathrm{I}}\right)^{t_{n}}\right)^{2}} \frac{D\left(\left(V_{\mathrm{f}}\right)_{\xi_{i+\frac{1}{2}}^{t_{n}}}^{t^{2}}\right)\left(\left(V_{\mathrm{f}}\right)_{\xi_{i+1}^{t_{n}}}^{t^{2}}-\left(V_{\mathrm{f}}\right)_{\xi_{i}}^{t_{n}}\right)-D\left(\left(V_{\mathrm{f}}\right)_{\xi_{i-\frac{1}{2}}^{t_{n}}}^{t_{2}}\right)\left(\left(V_{\mathrm{f}}\right)_{\xi_{i}}^{t_{n}}-\left(V_{\mathrm{f}}\right)_{\xi_{i-1}}^{t_{n}}\right)}{(\Delta \xi)^{2}},
\end{aligned}
$$

with

$$
D\left(\left(V_{\mathrm{f}}\right)_{\xi_{i}}^{t_{n}}\right)=-\frac{K\left(\left(V_{\mathrm{f}}\right)_{\xi_{i}}^{t_{n}}\right)\left(V_{\mathrm{f}}\right)_{\xi_{i}}^{t_{n}}}{\mu\left(T_{\xi_{i}}^{t_{n}}\right)} \frac{\partial \sigma\left(\left(V_{\mathrm{f}}\right)_{\xi_{i}}^{t_{n}}\right)}{\partial V_{\mathrm{f}}}
$$

The velocity of the impregnation front is calculated with

$$
\left(u_{1}\right)_{\tilde{\xi}_{I}}^{t_{n}}=\frac{K\left(\left(V_{f}\right)_{\xi_{I}}^{t_{n}}\right)\left(V_{f}\right)_{\tilde{\xi}_{I}}^{t_{n}}}{\left(z_{\mathrm{I}}\right)^{t_{n}} \mu\left(T_{\xi_{i}}^{t_{n}}\right)\left(1-\left(V_{\mathrm{f}}\right)_{\xi_{i}}^{t_{n}}\right)} \frac{\left(V_{\mathrm{r}}^{\mathrm{c}}\right)_{\xi_{I}}^{t_{n}}-\left(V_{\mathrm{r}}^{\mathrm{c}}\right)_{\xi_{I-1}}^{t_{n}}}{\Delta \xi} \frac{\partial \sigma\left(\left(V_{\mathrm{f}}\right)_{\tilde{\zeta}_{I}}^{t_{n}}\right)}{\partial V_{\mathrm{f}}}
$$

and with the velocity the position of the impregnation front can be calculated with

$$
\left(z_{\mathrm{I}}\right)^{t_{n+1}}=\left(z_{\mathrm{I}}\right)^{t_{n}}+\Delta t\left(u_{1}\right)_{\tilde{\xi}_{I}}^{t_{n}}
$$




\title{
Chapter 5
}

\section{Tape deformation during laser assisted fiber placement ${ }^{*}$}

\begin{abstract}
Gaps and overlaps should be prevented in laser assisted fiber placement in order to preclude interlaminar voids formation. Tape deformation during the process was investigated experimentally. The deformation was found to be a function only of the tape temperature and not of the applied pressure. This observation was not predicted by currently available models based on transverse squeeze flow. The results indicated that tape deformation takes place before the nip-point. An alternative tape deformation model was proposed based on spreading-induced fiber stresses. The model predicted the experimentally observed trend, however, further research is required in order to quantitatively predict tape deformation.
\end{abstract}

${ }^{*}$ Reproduced from: T. Kok, W.J.B. Grouve, L.L. Warnet, R. Akkerman. Tape deformation during laser assisted fiber placement. To be submitted to: Journal of Thermoplastic Composite Materials 


\subsection{Introduction}

Laser Assisted Fiber Placement (LAFP) is an additive manufacturing technique for thermoplastic composites. Pre-impregnated tapes are placed and consolidated simultaneously, which is termed in-situ consolidation, in this manufacturing technique. In this way, a ply is build up tape-by-tape and the part is build up ply-by-ply. Tapes should abut each other perfectly to prevent the formation of gaps and overlaps. Gaps are the result of tapes placed too far apart, while overlaps are the result of tapes placed too close to previous tapes. Gaps and overlaps cause a reduction in part performance, as well as irregularities on the ply surface, which hinder consolidation of subsequent plies.

For Advanced Fiber Placement (AFP) of thermoset based composite materials, tapes are usually placed such to leave a small gap between tapes. This is not a problem as these gaps are easily filled with resin during curing, resulting in a high-quality part. As no post-consolidation step is applied for in-situ consolidation of thermoplastic composites, the tapes need to be placed perfectly next to each other. Several researchers showed, based on experimental and modeling results, that gaps and overlaps cause wrinkling of plies, reducing the compressive and tensile strength as well as the fatigue performance $[1,2]$. In addition, local thickness variations may impede the intimate contact development during placement as the pressure cannot be uniformly applied, resulting in interlaminar voids [3]. Gaps and overlaps may also pose problems for laser heating. Local thickness variations can induce local absorptance of reflectance of the laser light, resulting in overheating or underheating of the material.

The formation of gaps and overlaps depends on three factors, namely the accuracy and consistency of the tape width, the machine accuracy to place the tape at the right place and the deformation of the tape during the process. The tape deforms due to the applied heat and pressure, required for consolidation. This change in tape width is a function of the process settings, such as the laser power, the applied compaction pressure and placement velocity $[4,5]$. The deformation of the tape due to the processing should be taken into account in the trajectories of the robot, to prevent formation of gaps and overlaps. This requires predictive modeling of the tape deformation during LAFP as a function of the applied process settings.

Although preventing the formation of gaps and overlaps is essential for the manufacturing of high-quality laminates, limited experimental research has been performed on tape deformation during LAFP. Khan reported an increase in tape width up to $5 \%$ for $1 / 2$ inch tapes [4]. The problem was also scarcely discussed from a modeling viewpoint. Ranganathan et al. proposed a squeeze flow model to predict 
the pressure field underneath the roller during fiber placement, including the tape deformation [5]. However, this was not confirmed with experimental results and the tape deformation reported by Khan was overestimated [4]. Wang et al. worked on the formation of gaps and overlaps during fiber placement; however, the presented experimental work focused on the removal of gaps and overlaps by compression molding. Other work on tape deformation was focused on modeling experimental squeeze flow of fiber reinforced composite tapes [6, 7].

The objective of this work is to experimentally investigate the tape deformation during LAFP as a function of process settings to be able to find the governing mechanism for tape deformation. Based on these observations a model to describe the behavior as a function of process settings can be developed. For this purpose an experimental investigation of the tape deformation during LAFP for varying process conditions has been performed. The currently available model by Ranganathan et al. will be compared to the experimental results and these results will be discussed.

\subsection{Experimental work}

An experiment was performed to investigate the effect of process settings on the tape deformation during LAFP. In this section the experimental procedure and results are discussed.

\subsubsection{Experimental procedure}

\section{Materials and equipment}

Tapes were placed on a press-consolidated laminate. The material used, for both the laminate and the fiber placement tape, was the TC1200 AS-4/PEEK prepreg tape with a fiber volume content of $59 \%$. The melting temperature of PEEK is about $343{ }^{\circ} \mathrm{C}$. A press-consolidation cycle, specified by the manufacturer, with 20 bars of pressure was used to manufacture laminates with a stacking sequence of $[0 / 90]_{2 s}$. Laminates were made from 12 inches wide tape, while the LAFP tape were provided as tape slitted to a quarter inch.

A Coriolis Composites robot equipped with a $1 \mathrm{~kW}$ laser was used to place quarterinch tapes. A thermal camera was mounted on the fiber placement end effector to measure the temperature during the process. A stiff PTFE roller was used to ensure that the specified compaction force was applied on the single tape. Furthermore, a Micro-Epsilon thermalIMAGER TIM 400thermal camera was mounted on the head 
of the end effector to record the temperature during the process.

\section{Specimen preparation}

A base ply was fiber-placed on the pre-consolidated $300 \times 300 \mathrm{~mm}^{2}$ laminate. Then the laminate was cut, perpendicular to the placed ply, in strips of about $20 \mathrm{~mm}$ using a water-cooled diamond-coated saw. A single quarter-inch tape with a length of $300 \mathrm{~mm}$ was fiber-placed on each strip and this was done to prevent any loss of compaction pressure to neighboring tapes. The specimen preparation is illustrated in Figure 5.1. A $100 \mathrm{~mm}$ long piece of tape was taken from the roll after placement of each tape as a reference to account for any variations in width of the input material. Three different placement strategies were considered, namely one where most of the laser energy was focused on the laminate, one where most of the laser energy was focused on the tape and one where the laser energy was equally divided between laminate and tape. This was achieved by varying the laser angle and position. The settings used for the different placement strategies are given in Table 5.1 and sketches of each strategy are shown in Figure 5.2. Furthermore, the applied compaction force was varied and three levels of $345 \mathrm{~N}, 435 \mathrm{~N}$ and $835 \mathrm{~N}$ were used. The nip-point temperature was varied between $350{ }^{\circ} \mathrm{C}$ and $550{ }^{\circ} \mathrm{C}$. For each placement strategy three different compaction forces and three to five nip-point temperature levels were used. The placement velocity was $100 \mathrm{~mm} / \mathrm{s}$ for all specimens.

Pre-consolidated laminate

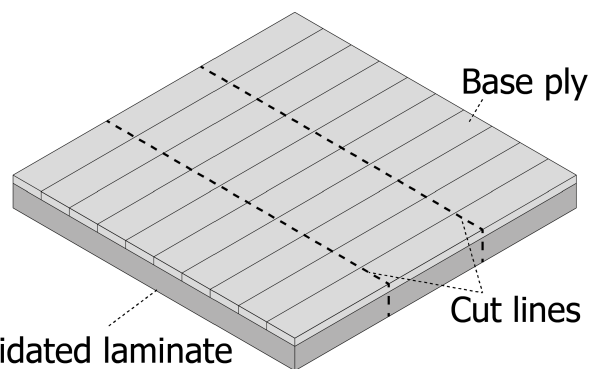

(a)

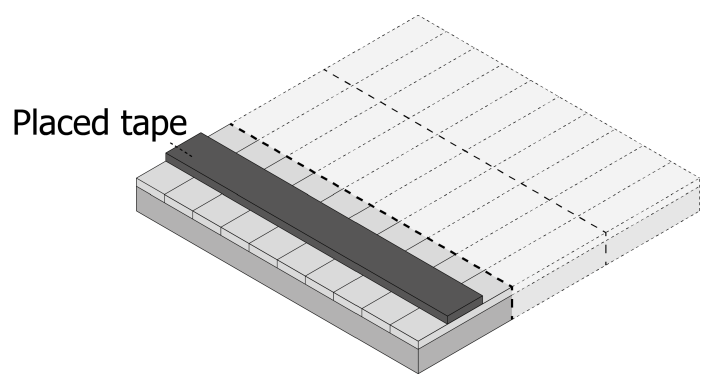

(b)

Figure 5.1 Sketch of the specimen preparation. (a) The pre-consolidated laminate with fiber-placed base ply and (b) the laminate was cut, perpendicular to the placement direction of the base ply, into strips and a single tape was placed on a strip. 
Table 5.1 Used settings for the placement strategies used for the tape deformation experiments.

\begin{tabular}{lccccc}
\hline & Machine settings & \multicolumn{3}{c}{ Configuration } \\
Parameter & Symbol & Unit & 1 & 2 & 3 \\
\hline Laser angle & $\theta_{\mathrm{L}}$ & {$[\mathrm{mm}]$} & 12.0 & 15.4 & 20.2 \\
Fraction of the spot on tape & $f_{\mathrm{L}}$ & {$[\%]$} & 2 & 37 & 22 \\
Spot size & $H$ & {$[\mathrm{~mm}]$} & 16 & 16 & 16 \\
\hline
\end{tabular}

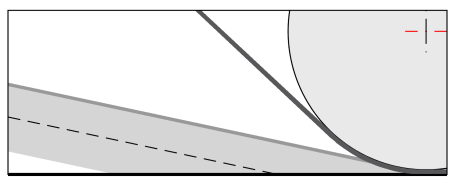

Configuration 1

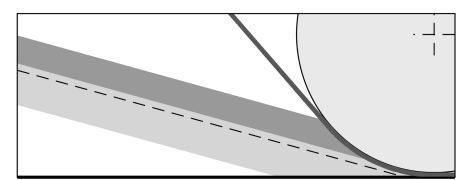

Configuration 2

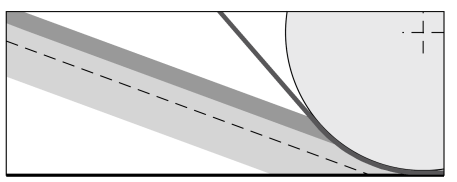

Configuration 3

Figure 5.2 Sketch of the placement strategies used showing the distribution of the laser energy between the tape and substrate. The part of the laser beam on the tape is indicated in dark grey, while the part on the substrate is indicated in light grey.

\section{Analysis}

A Keyence VHX-5000 microscope was used to make images of the top surface of the fiber-placed and reference tapes and the width of the tapes was measured from these images. The width increase of the fiber-placed tape was then obtained by subtracting the width of the corresponding unprocessed reference specimen from the width of the fiber-placed tape. Five measurements were taken for each specimen.

A thermal model, which was described in Chapter 2, was used to calculate the temperature distribution during the process. The tape specimens were placed perpendicularly to the base ply, which affects the reflection and absorption of the laser light. The refractive index was calibrated based on the thermal camera measurements, in order to account for the changed optical properties of the substrate. It was estimated to be about 1.25 as opposed to the 1.95 obtained from literature and used for the tape [8].

\subsubsection{Experimental results}

The measured temperature distribution varies for the three placement strategies used. The result on the measured laminate and tape temperature can be seen in Figure 5.3. The increasing marker size indicates the increasing laser power, resulting in an increasing tape and laminate temperature. The difference in temperature distribution can be observed. For configuration 1 a higher laminate than tape temperature was measured, while for configuration 2 the measured tape temperature is higher than 
the laminate temperature. The measured laminate temperature is also higher than the tape temperature for configuration 3, however, the difference is smaller than for configuration 1. Although it can be observed that the measured tape temperature can be lower than the melting temperature of PEEK, these tapes also deformed during the experiment. This is due to measuring the temperature during the process with a thermal camera. The nip-point is not always visible for the thermal camera and consequently the tape temperature can not always be measured at the nip-point [9]. Although, the temperature of the tape is measured as close to the nip-point as possible, it can be expected to heat up further before reaching the nip-point by reflections.

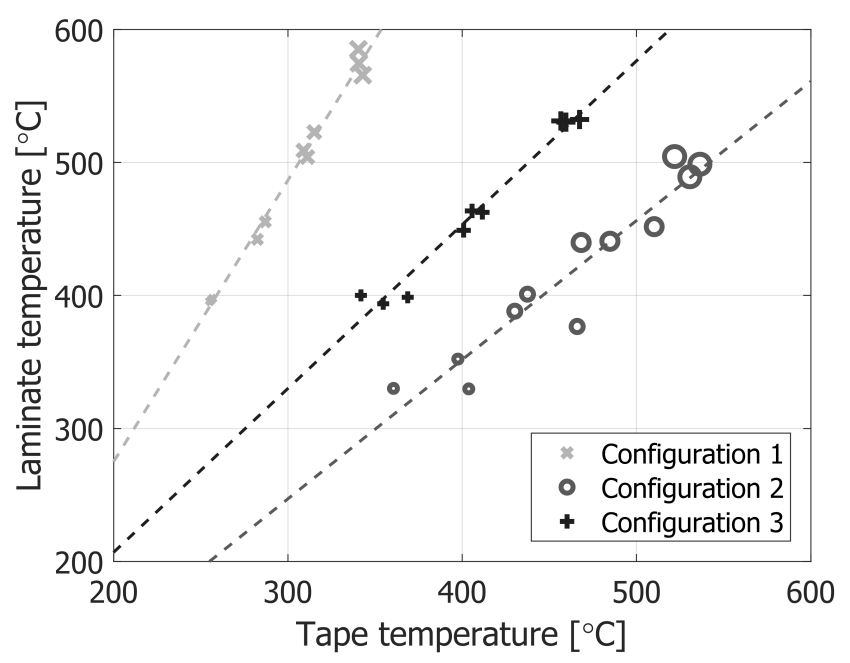

Figure 5.3 Measured tape versus measured laminate temperature for each configuration. The increasing size of the markers indicates the increasing laser power.

The resulting tape deformation as a function of the measured tape temperature for the three placement strategies is given in Figure 5.4(a). It can be observed that, irrespective of the configuration used, the tape width increases almost linearly with increasing tape temperature. Figure 5.4(b) shows the same graph, however, here the applied compaction force is indicated. This graph shows that the final width of the tape is not a function of the applied compaction force. This is counter-intuitive, as increasing the applied compaction force would be expected to increase the amount of deformation of the tape. The lowest compaction force used is already sufficient to deform the tape and increasing the compaction force does not result in more deformation of the tape. Apparently, the increased pressure is counteracted in some way and further deformation of the tape is prevented. 


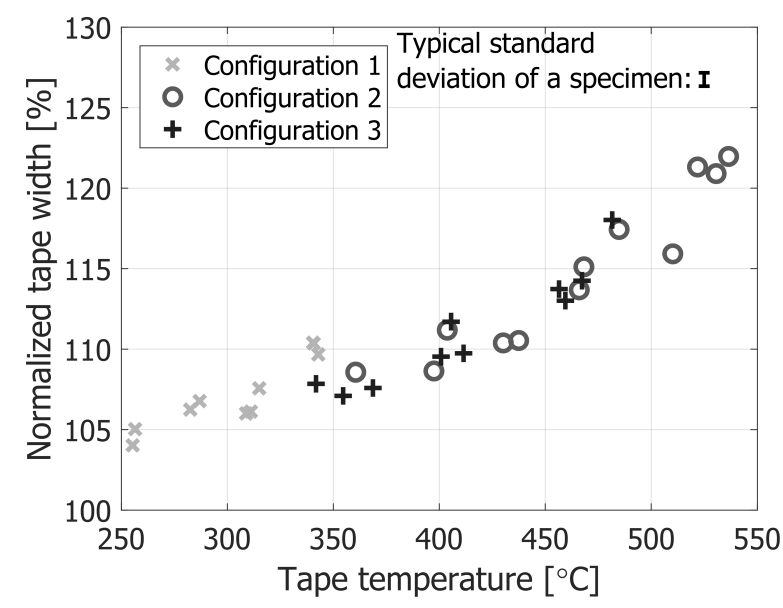

(a)

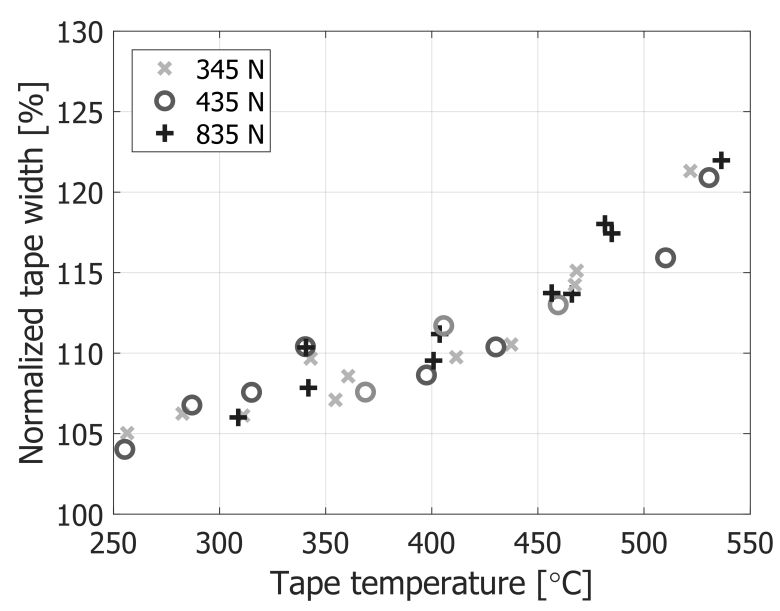

(b)

Figure 5.4 Experimental results of the tape deformation as a function of the tape temperature indicating (a) the three configurations used and (b) the different compaction forces used.

\subsection{Transverse squeeze flow modeling of tape defor- mation}

As mentioned before, only a limited amount of work can be found in literature on tape deformation during LAFP. Ranganathan et al. developed a squeeze flow model for AFP to predict the spreading of the tape, but no experimental validation of tape deformation was done [5]. This model is often used in literature,but mainly to obtain the pressure distribution for void compression models [10, 11]. Khan applied this model to predict tape deformation for fiber placement using a gas torch as heat source [4]. It was shown for the small number of specimens considered that tape deformation was a function of the gas volume and the placement velocity. The squeeze flow model developed by Ranganathan et al., was employed and the comparison with the experimental results showed that the tape width was overestimated by the model. This same model was employed in this study.

\subsubsection{Model definition}

Figure 5.5(a) is an illustration of the general 2D squeeze flow model, where a piece of material is deformed by transverse shear flow between two rigid plates under an applied compaction force or closing rate. Ranganathan et al. applied such a model to the fiber placement process by assuming only transverse deformation of the tape and no flow of material in the placement direction. The as-received tape has an initial tape width $w_{\mathrm{i}}$ and thickness $h_{\mathrm{i}}$ and is deformed to a tape width of $w_{\mathrm{f}}$ and thickness 
$h_{\mathrm{f}}$. Furthermore, an infinitely stiff roller was assumed and the resulting geometry is shown in Figure 5.5(b). The radius of the roller $r_{\mathrm{r}}$ describes the height evolution of the tape. The closing rate can be derived by differentiating the height evolution and for this the placement velocity $v$ is required. Any continuity of fibers is neglected. Additionally, the material was assumed to be incompressible.

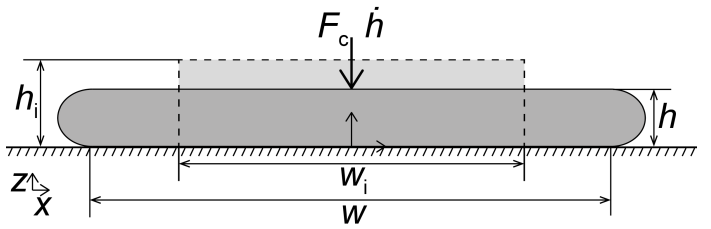

(a)

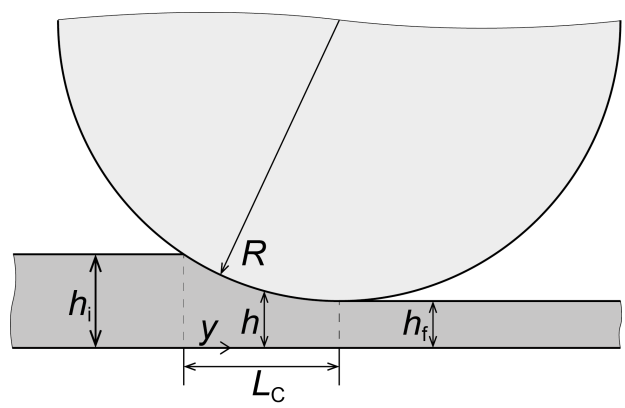

(b)

Figure 5.5 (a) Schematic representation of the squeeze flow model and (v) the assumed geometry of the flow underneath the roller, Ranganathan et al. [5].

The equation of motion is

$$
\frac{\partial P}{\partial x}=\frac{\partial \tau}{\partial z}
$$

with $P$ the pressure and $\tau$ the applied shear stress. The $\mathrm{x}$ and $\mathrm{z}$ directions are indicated in Figure 5.5. The full derivation for squeeze flow of a composite tape during a constant through-thickness temperature but varying with time and no-slip conditions is given in Appendix 5.A. The result is a relation between the compaction force and the width and width evolution rate:

$$
F_{\mathrm{C}}=\int_{0}^{\frac{L_{\mathrm{C}}}{v}}\left(\frac{\mu_{\mathrm{fm}} \dot{h}\left(w_{\mathrm{i}} h_{\mathrm{i}}\right)^{3}}{h^{6}}+P_{\mathrm{a}} \frac{w_{\mathrm{i}} h_{\mathrm{i}}}{h}\right) d t=\int_{0}^{\frac{L_{\mathrm{C}}}{v}}\left(\frac{\mu_{\mathrm{fm}} \dot{w} w^{4}}{\left(w_{\mathrm{i}} h_{\mathrm{i}}\right)^{2}}+P_{\mathrm{a}} w\right) d t .
$$

where $F_{\mathrm{C}}$ is the applied compaction force, $L_{\mathrm{C}}$ is the contact length underneath the roller, $v$ is the placement velocity and $w$ and $w$ are the width evolution and width evolution rate respectively. This equation can be solved based on the geometry and the mass conservation, as well as the known compaction force. The only material parameter required is the fiber-matrix viscosity $\mu_{\mathrm{fm}}$. An overview was given of the available fiber-matrix viscosity models for $\mathrm{C} / \mathrm{PEEK}$, as a function of the absolute temperature, in Chapter 4 . The dependency of the viscosity on temperature is described by an Arrhenius type of model:

$$
\mu_{\mathrm{fm}}=3.7 \cdot 10^{-3} \exp \left(\frac{11115}{T}\right)
$$


with the material parameters as determined by Khan et al. used in this work [4]. The required temperature distribution is obtained with the thermal model described in Chapter 2 and the machine settings given in Table 5.1. The other required parameters are given in Table 5.2.

Table 5.2 Parameters required for the squeeze flow model.

\begin{tabular}{lccc}
\hline Parameter & Symbol & Unit & Value \\
\hline Initial tape width & $w_{\mathrm{i}}$ & {$[\mathrm{mm}]$} & 6.35 \\
Initial tape thickness & $h_{\mathrm{i}}$ & {$[\mathrm{mm}]$} & 0.15 \\
Roller radius & $r_{\mathrm{r}}$ & {$[\mathrm{mm}]$} & 35 \\
Compaction force & $F_{\mathrm{c}}$ & {$[\mathrm{N}]$} & $335-835$ \\
\hline
\end{tabular}

\subsubsection{Solution procedure}

The temperature distribution during the process is calculated using a $2 \mathrm{D}$ optical and a 1D thermal model, as described in Chapter 2, based on the described process settings. The temperature distribution was averaged over the tape thickness and used to calculate the local fiber-matrix viscosity. The squeeze flow model, i.e. Equation 5.2, can be solved by substituting the assumed width evolution based on the roller geometry, the compaction force and the fiber matrix viscosity.

\subsubsection{Results}

Figure 5.6 shows, as an example, the results for the squeeze flow simulation with the machine settings of configuration 2, a laser power of $500 \mathrm{~W}$ and a compaction force of $835 \mathrm{~N}$. The deformation of the tape is shown in Figure 5.6(a), based on the temperature and pressure distribution shown in Figure 5.6(b). A deformation of over $15 \%$ is achieved, from $6.35 \mathrm{~mm}$ to $7.41 \mathrm{~mm}$. It can be observed that the contact length $L_{C}$, as shown in Figure 5.5(b), is only $1.2 \mathrm{~mm}$. Consequently, the contact area with the roller is small and a high pressure with a peak of over $125 \mathrm{MPa}$ can be observed. In this short length the temperature dropped by almost $50{ }^{\circ} \mathrm{C}$, by the tape is still far above its melting temperature after release of the pressure.

The model was used to obtain the final width as a function of the tape temperature for the three configurations used in the experimental works. The results are shown in Figure 5.7 and several observations can be made. First, the dependence on pressure is clear in the model. For each configuration there is a significant effect of the applied compaction force on the tape deformation. Second, the amount of deformation as a function of the tape temperature is different for each configuration. 


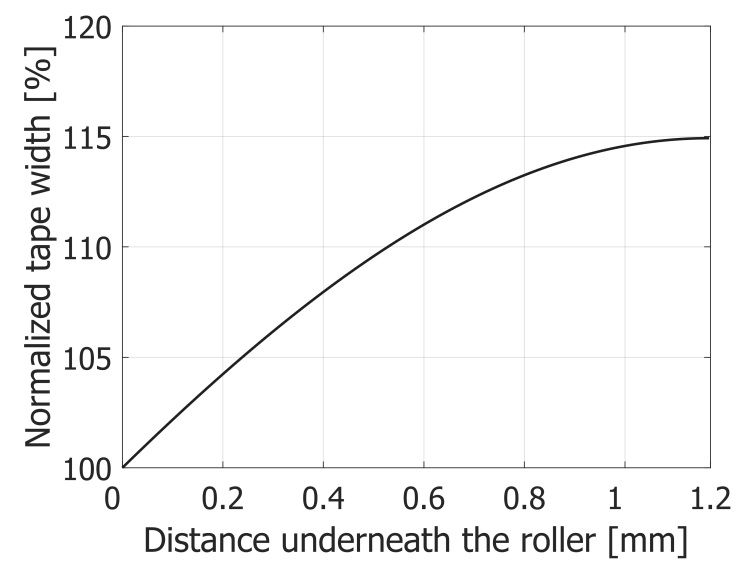

(a)

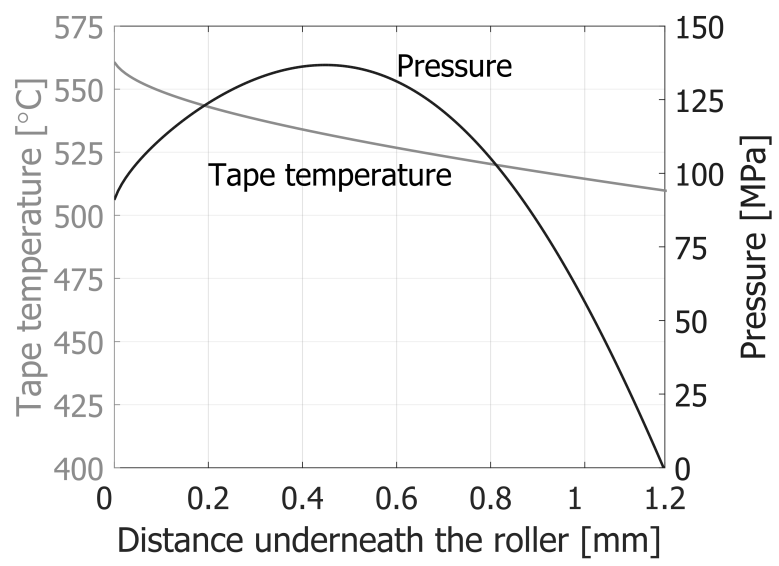

(b)

Figure 5.6 Squeeze flow model results for configuration 2 with a laser power of $500 \mathrm{~W}$ and a compaction force of 835 N. (a) Normalized tape width under the roller and (b) mean tape temperature and pressure distribution under the roller.

A different portion of the laser beam was aimed at the tape for each configuration and this resulted in different tape temperatures, although the same range of nippoint temperatures was used. The tape temperature determines the amount of tape deformation not only for the experiments but also for the model. Finally, the model underestimates the tape deformation for low tape temperatures for each configuration, while for high tape temperatures the predicted deformation is closer to the experimental results.

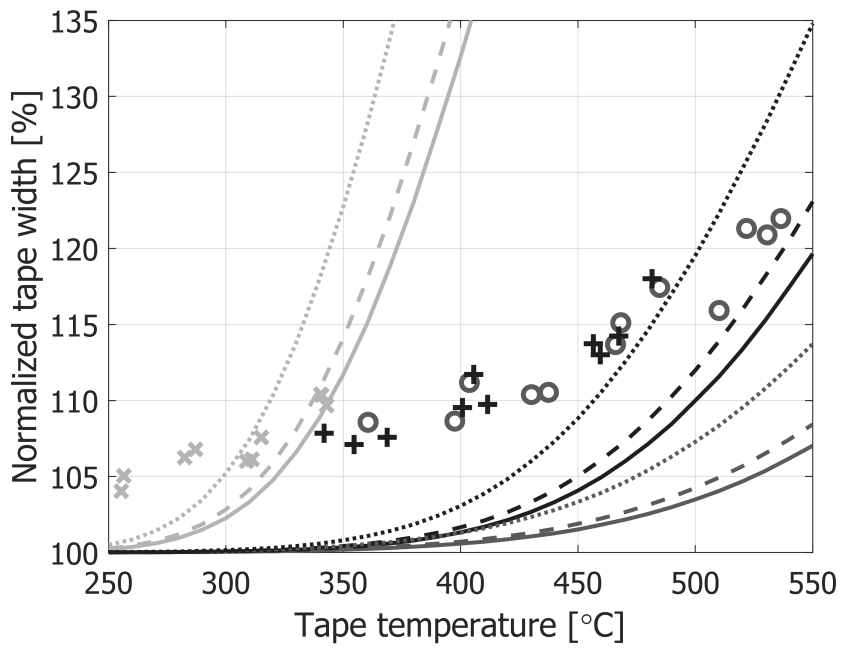

* Experimental results configuration 1

- Experimental results configuration 2

+ Experimental results configuration 3

Model results configuration 1, $345 \mathrm{~N}$

Model results configuration $1,435 \mathrm{~N}$

Model results configuration 1, $835 \mathrm{~N}$

- Model results configuration 2, $345 \mathrm{~N}$

- - Model results configuration 2, $435 \mathrm{~N}$

.. Model results configuration 2, $835 \mathrm{~N}$

Model results configuration 3, $345 \mathrm{~N}$

- - Model results configuration 3, $435 \mathrm{~N}$

......... Model results configuration 3, $835 \mathrm{~N}$

Figure 5.7 Comparison of the experimental tape spreading results with the squeeze flow model proposed by Ranganathan et al. [5]. 


\subsection{Discussion}

An experimental analysis was performed on the deformation of quarter-inch tapes during LAFP. The results show that the spreading of the tape is not affected by the applied compaction, but only by the tape temperature. The available squeeze flow model deviated from the experimental results and did not show the independence of tape deformation on the applied compaction force. In the following section the squeeze flow model results are discussed in brief. This discussion is followed by the formulation of a number of alternative hypotheses on tape deformation during LAFP, in order to explain the observed experimental results. Each of these hypotheses will be checked and discussed.

\subsubsection{Transverse squeeze flow model for tape deformation}

The currently used tape spreading model, developed by Ranganathan et al., is a squeeze flow model, for which the closing rate is governed by the geometry of a stiff roller. It assumed that all tape deformation takes place in short contact length underneath the roller as is illustrated in Figure 5.8(a). The fibers in the composites are taken into account only in the fiber-matrix viscosity; continuity of fibers under the roller is not taken into account. However, an increase in tape width of up to $20 \%$ in a contact length of around $1 \mathrm{~mm}$ requires also spreading of the fibers. The fibers at the edges need to be stretched, as the path of the fibers in the middle of the tape is shorter than the path of the fibers at the edges. For the example shown in Figure 5.6 a deformation of $15 \%$ within $1.2 \mathrm{~mm}$ requires a strain of over $7 \%$ in the fibers at the edges of the tape. This strain greatly exceeds the strain at break for the AS-4 fibers. Two conclusions can be drawn from this observation. First, the continuity of fibers can not be neglected and the required stretching of fibers should be incorporated in the tape spreading model. Second, since no fiber fracture is observed, the deformation of the tape has to take place over a longer distance where the fiber strain remains below the strain at break.

Two possibilities exist as the tape spreading takes place over distance. Either the contact underneath the roller is longer than assumed in the model of Ranganathan et al. or part of the deformation of the tape takes place before the tape enters the nippoint. The latter is possible, as the tape is melted before entering the nip-point and can, therefore, be deformed. In this case the required spreading of the fibers could drive the deformation of the tape before the nip-point. A sketch to illustrate the tape deformation before the nip-point is shown in Figure 5.8(b). The configurations used in the experimental research differed in terms of the amount of energy focused on the tape. Consequently, the length of the tape that is above the melted temperature, 


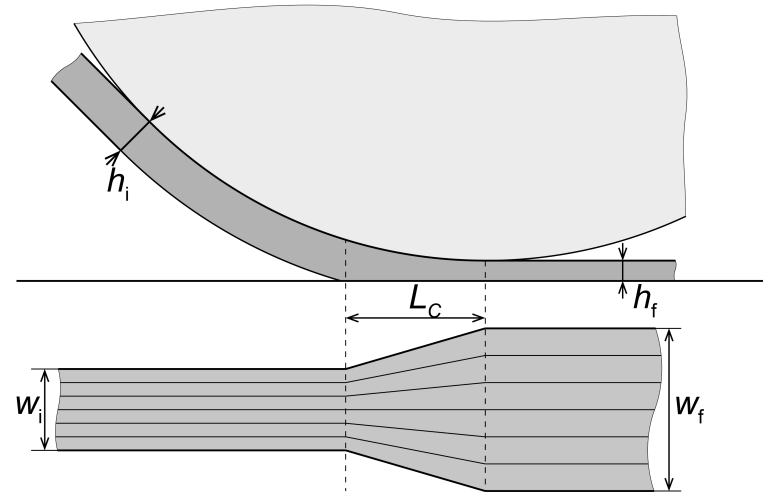

(a)

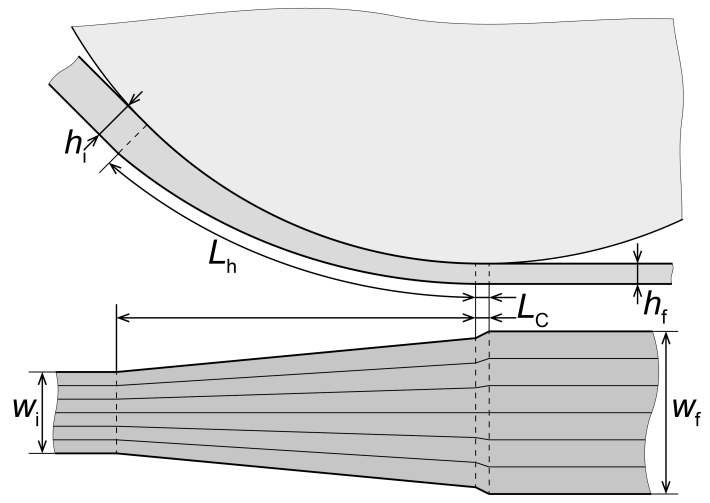

(b)

Figure 5.8 Schematic illustrations on the assumed tape deformation during AFP: (a) Tape deformation underneath the infinitely stiff roller for the model by Ranganathan et al. and (b) tape deformation based on the melted length before the nip-point.

indicated by $L_{\mathrm{h}}$ in Figure 5.8(b), varied for the different specimens. Figure 5.9 shows the heated length versus the measured tape temperature. The heated length is defined as the length of the tape with a through-thickness temperature above $350^{\circ} \mathrm{C}$, based on a thermal model. An almost linear relation can be observed between the length of the melted tape, which is termed heated length in this work, and the tape temperature. The tape deformation could, therefore, also be a function of the heated length instead of a function of the tape temperature.

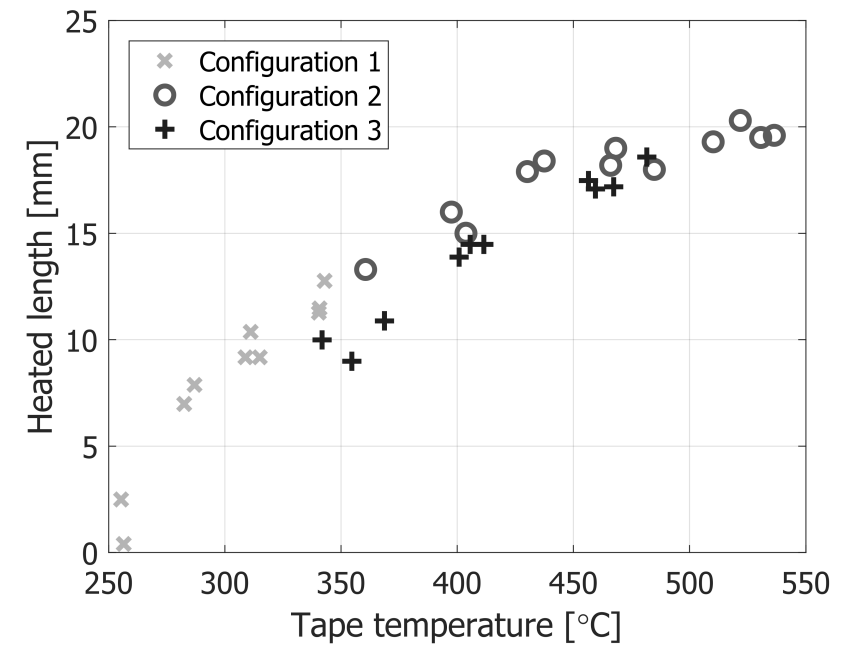

Figure 5.9 The modeled heated length as a function of the measured tape temperature. 


\subsubsection{Alternative tape deformation models}

The presented experimental work showed that transverse squeeze flow does not seem to model tape deformation during LAFP correctly. The question then remains, what is the governing mechanism for tape deformation? In the following sections several hypotheses will be checked based on incorporation of the required fiber spreading in modeling tape deformation. First, the method to describe the fiber spreading is derived. This is based on the stress required to stretch the fiber. Then different hypotheses for tape deformation during AFP are proposed and tested. For each hypothesis the required model is derived and the results are compared to the experimental results.

\section{Fiber spreading}

The spreading of the fibers is taken into account in the transverse squeeze flow models based on the stretching of the fibers. It was shown that the deformation observed in the experiments would require a strain exceeding the strain at break based on the transverse squeeze flow model assuming an infinitely stiff roller. However, the stress required to stretch the fibers counters the deformation. It is assumed that the tape deformation is linear, as shown in Figure 5.10, with all fibers perfectly aligned. Furthermore, the rule of mixtures was assumed for the stiffness of the tape with a stiffness of the AS- 4 fiber of $228 \mathrm{GPa}$ and the stiffness of the matrix was neglected. It is also assumed that the fibers in the center of the tape, which is not spread, are not strained. Only the main equations are shown here and the more extensive derivation is given in Appendix 5.B.

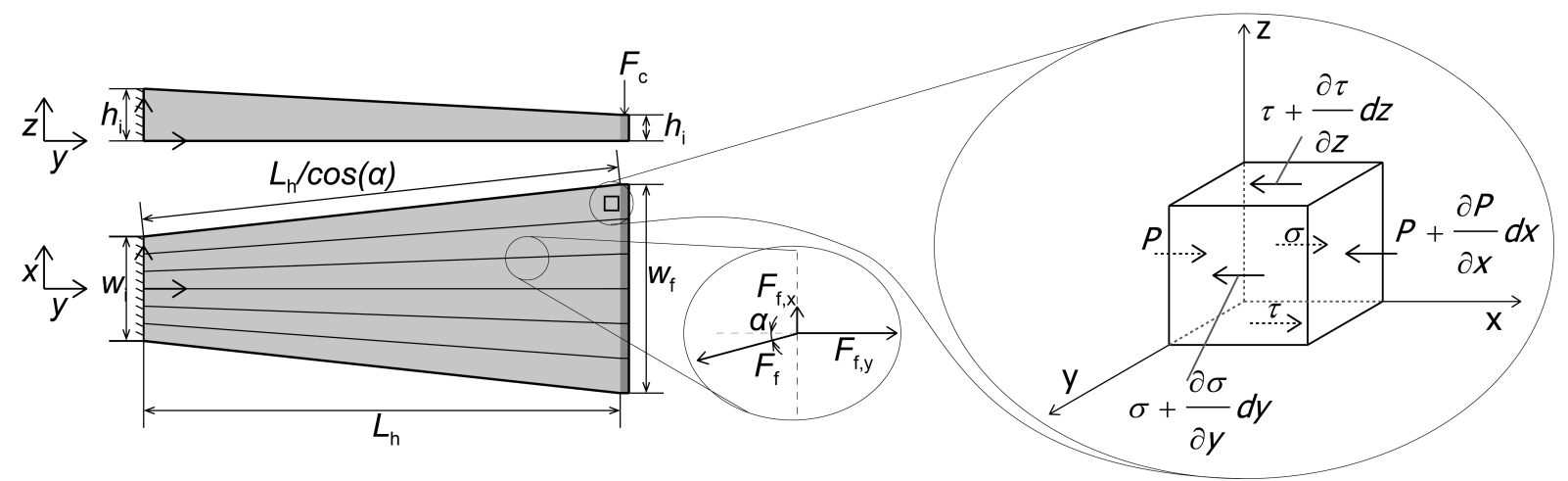

Figure 5.10 Schematic illustration of the tape deformation including spreading-induced fiber stresses.

The volume element in Figure 5.10 is considered with a pressure $P$, a body force $\sigma$ and a shear stress $\tau$. The result is the momentum equation assumed by Ranganathan 
et al. with the addition of a body force term to include the fiber stress:

$$
\frac{\partial \tau}{\partial z}=\frac{\partial P}{\partial x}+\frac{\partial \sigma}{\partial y}
$$

The fiber stress can derived from the strain applied to the fibers based on the linear deformation of the tape with a fiber angle $\alpha(x, y)$. Based on the geometry shown in Figure 5.10 and using a small angle approximation the stress caused by the fibers is given by

$$
\sigma(x, y)=\frac{E_{\mathrm{f}} V_{\mathrm{f}}}{2} \frac{x^{3}}{y^{3}}\left(1-\frac{w_{\mathrm{i}}}{w}\right)^{3}
$$

where $E_{\mathrm{f}}$ is the fiber stiffness, $V_{\mathrm{f}}$ is the fiber volume reaction, $w_{\mathrm{i}}$ is the initial width and $w$ is the width as a function of $y$. This fiber stress as a function of position can be implemented in the derivation of different tape deformation models in the following sections.

\subsubsection{Hypothesis 1}

The governing mechanism considered by Ranganathan et al. was the transverse squeeze flow in a short area underneath the infinitely stiff roller. Continuity of the fibers was not taken into account in terms of the spreading of the fibers. The first hypothesis is: Tape deformation during LAFP is governed by transverse squeeze flow with an infinitely stiff roller including spreading-induced fiber stresses.

\section{Transverse squeeze flow including spreading-induced fiber stress}

The same assumptions as for the transverse squeeze flow model are used, with the addition of the fiber stress as a body force in the equation of motion. The derivation is outlined in Appendix 5.B and the result is an equation for the compaction force given by

$$
\begin{aligned}
F_{\mathrm{C}}=2 \int_{0}^{\frac{L_{\mathrm{C}}}{v}} & \int_{0}^{\frac{w}{2}}(P) d x d y=\int_{0}^{L_{\mathrm{C}}}\left(\frac{\mu_{\mathrm{fm}} w^{4} \dot{w}}{\left(w_{\mathrm{i}} h_{\mathrm{i}}\right)^{2}}+P_{\mathrm{a}} w\right) d t+ \\
& \int_{0}^{L_{\mathrm{C}}}\left(\frac{3}{160} \frac{E_{\mathrm{f}} V_{\mathrm{f}} w^{4}}{(v t)^{4}}\left(1-\frac{w_{\mathrm{f}}}{w}\right)^{3}+\frac{3}{160} \frac{E_{\mathrm{f}} V_{\mathrm{f}} w^{2} w_{\mathrm{i}} \dot{w}}{v^{4} t^{3}}\left(1-\frac{w_{\mathrm{i}}}{w}\right)^{2}\right) d t .
\end{aligned}
$$

Two extra terms are added in this equation, originating from the fiber stress given by Equation 5.5. This model can be solved in a similar way as the original transverse 
squeeze flow model.

\section{Results}

The results of the transverse squeeze flow model based on the work of Ranganathan et al. including spreading-induced fiber stresses, are shown in Figure 5.11. It can be seen that only a small deformation of the tape is predicted. The final tape width is much less than the experimental results. The fibers almost completely block the deformation of the tape, as the tape has to be deformed over a length of at most $1.5 \mathrm{~mm}$. This hypothesis is, therefore, not correct as the tape deformation is greatly underestimated.

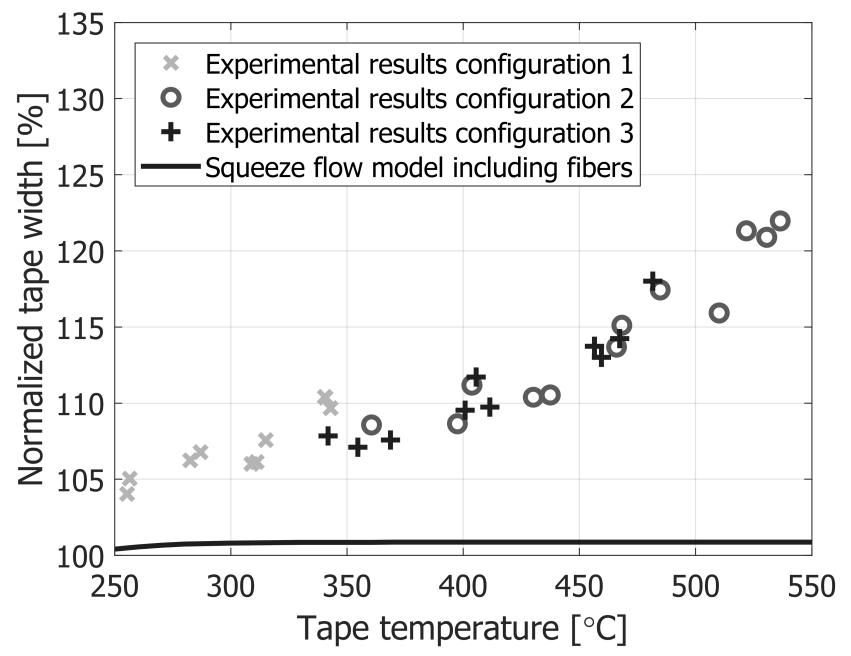

Figure 5.11 Comparison of the experimental results with the squeeze flow model including stretching of the fibers

\subsubsection{Hypothesis 2}

An infinitely stiff roller is assumed in the model of Ranganathan et al. Consequently, the tape deformation takes place over a short distance. Measurements were done with pressure sensitive film to investigate the contact length of the stiff PTFE roller. The measurements showed a contact length of about $8 \mathrm{~mm}$, which is considerably longer than the assumed contact length of around $1 \mathrm{~mm}$ with the infinitely stiff roller. The longer contact length underneath the roller provides a longer distance for the tape to deform and the fibers to spread. In this case a simple Hertzian contact can be assumed between the (slightly) deformable roller and the tape. Therefore, the following hypothesis is proposed: Tape deformation during LAFP is governed by transverse squeeze flow with the inclusion of fiber spreading, assuming a Hertzian contact between the roller and the tape. 


\section{Transverse squeeze flow model with a Hertzian contact}

The pressure distribution in 2D by for a Hertzian contact can be described as follows [12]:

$$
Q(y)=\frac{8 F_{\mathrm{c}} \sqrt{L_{\mathrm{C}} y-y^{2}}}{\pi L_{\mathrm{C}}^{2}} .
$$

Starting at the equation of motion, Equation 5.4, the transverse squeeze flow model for a Hertzian contact can be derived, which is elaborated in Appendix 5.C. The same assumptions as for the model in the previous section apply and the pressure distribution can be related to the known distribution for a Hertzian contact, resulting in the following equation relating the compaction force to the deformation:

$$
\begin{aligned}
F_{\mathrm{c}}= & \frac{\pi L_{\mathrm{C}}^{2}}{8 \sqrt{L_{\mathrm{C}}(v t)-(v t)^{2}}}\left(\frac{\mu_{\mathrm{fm}} w^{4} \dot{w}}{\left(w_{\mathrm{i}} h_{\mathrm{i}}\right)^{2}}+P_{\mathrm{a}} w\right)+ \\
& \frac{\pi L_{\mathrm{C}}^{2}}{8 \sqrt{L_{\mathrm{C}}(v t)-(v t)^{2}}}\left(\frac{3 E_{\mathrm{f}} V_{\mathrm{f}} w^{4}}{160(v t)^{4}}\left(1-\frac{w_{\mathrm{i}}}{w}\right)^{3}+\frac{3 E_{\mathrm{f}} V_{\mathrm{f}} w^{2} w_{\mathrm{i}} \dot{w}}{160 v^{4} t^{3}}\left(1-\frac{w_{\mathrm{i}}}{w}\right)^{2}\right) .
\end{aligned}
$$

\section{Results}

The results of the transverse squeeze flow model assuming a Hertzian contact with a contact length of $8 \mathrm{~mm}$ is shown in Figure 5.12. The behavior observed for the model results is interesting: for each configuration the results look similar to the transverse squeeze flow model assuming an infinitely stiff roller, neglecting spreading-induced fiber stresses. However, at higher tape temperatures the amount of tape deformation is limited by the spreading of the fibers. This is particularly clear for the results of configuration 1 . Up to about $350{ }^{\circ} \mathrm{C}$ the results are similar to the transverse squeeze flow model with a infinitely stiff roller, and above about $400{ }^{\circ} \mathrm{C}$ the amount of deformation is almost constant for each pressure level. The maximum deformation of the tape is underestimated in this hypothesis as well. This hypothesis is, therefore, also not correct. 


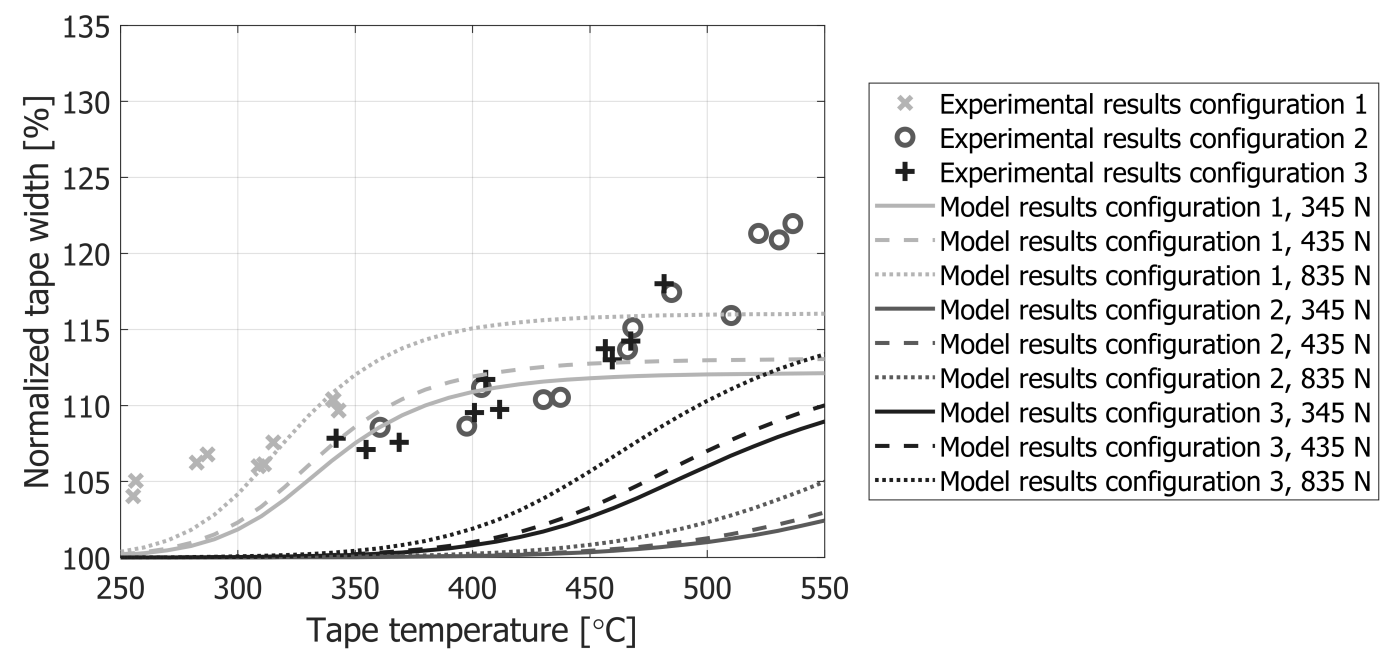

Figure 5.12 Comparison of the experimental results with a transverse squeeze flow model assuming a Hertzian contact and including spreading of the fibers in the composite.

\subsubsection{Hypothesis 3}

The three different models based on transverse squeeze flow could not explain the observed behavior for tape deformation during LAFP. Therefore, a different approach is used for the third hypothesis. Figure 5.9 showed the relation between the length of the tape in melt, the heated length, and the tape temperature. It might well be possible that the heated length and the tape deformation are directly related. In a Eulerian frame of reference, where the tape moves through the system, the deformation can be regarded as the quasi-static deformation of a melted tape with a certain length equal to the heated length $L_{\mathrm{h}}$ in Figure 5.8(b). The deformation taking place underneath the roller is negligible; all deformation is due to spreading of the fibers and takes place before the nip-point. The hypothesis is: Tape deformation during LAFP is based on the quasi-static deformation of a melted tape with a certain length.

\section{Quasi-static tape deformation model}

The quasi-static tape deformation model can be derived from the squeeze flow model assuming a Hertzian contact, as was described in the previous section. The term $\dot{w}$ is assumed to be zero, as the deformation is quasi-static, and the deformation is analyzed at $y=L_{\mathrm{h}}$ in Equation 5.8. This results in a much simpler equation

$$
\frac{F_{\mathrm{c}}}{L_{\mathrm{C}}}=\frac{3 E_{\mathrm{f}} V_{\mathrm{f}}}{160} \frac{w_{\mathrm{f}}^{5}}{L_{t}^{4}}\left(1-\frac{w_{\mathrm{i}}}{w_{\mathrm{f}}}\right)^{3}+P_{\mathrm{a}} w,
$$

where length $L_{C}$ is the assumed contact length of the roller with the tape. A more elaborate derivation is given in Appendix 5.D. 


\section{Results}

The results of the quasi-static tape deformation model are given in Figure 5.13. The average of the results is shown, including a $90 \%$ confidence interval. The tape deformation is overestimated, however, the linear trend with increasing tape temperature is clear. This trend differs from the previous models and represents the experimental results better.

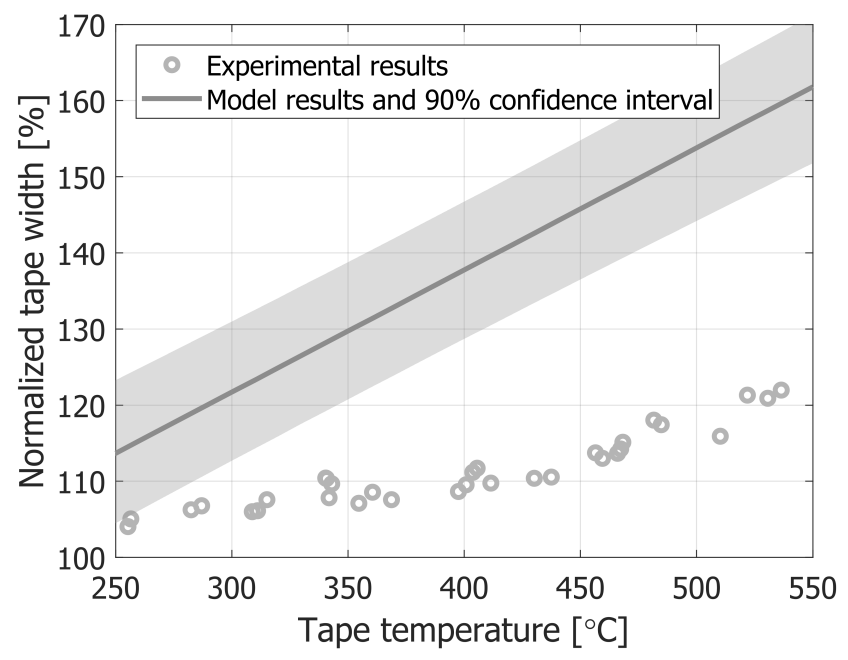

Figure 5.13 Comparison of the experimental results with the quasi-static tape deformation model.

The overestimation of the amount of deformation might be the result of an underestimation of the fiber stress or an overestimation of the heated length. The fiber stress might be underestimated as the fibers are assumed to be perfectly aligned, while in reality the fibers can be intermingled. This will cause more stress of the fibers, counteracting the tape deformation. Furthermore, it was assumed that the tape is melted as soon as the average through-thickness temperature is above $350{ }^{\circ} \mathrm{C}$, the melting temperature of PEEK. The melting of the crystalline structure was not taken into account. However, the melting upon heating with a laser is fast with heating rates in the order of $2000{ }^{\circ} \mathrm{C} \mathrm{s}^{-1}$ and it might be possible that, although the temperature of the tape is above $350{ }^{\circ} \mathrm{C}$, not all crystals have melted and the tape is not yet soft enough to be easily deformed. Consequently, the defined heated length of the tape could be over-predicted.

Figure 5.14 shows the results for the quasi-static tape deformation model using a heated length of only $40 \%$ of the heated length predicted by the thermal model. It can be seen that the modeling results match not only the trend of the experimental results, but also the amount of deformation. The proposed quasi-static model seems to be able to capture the observed trend in tape deformation. however, more work 
is required to quantitatively predict the tape deformation. Further research on the heated length and the stress caused by the fibers is required.

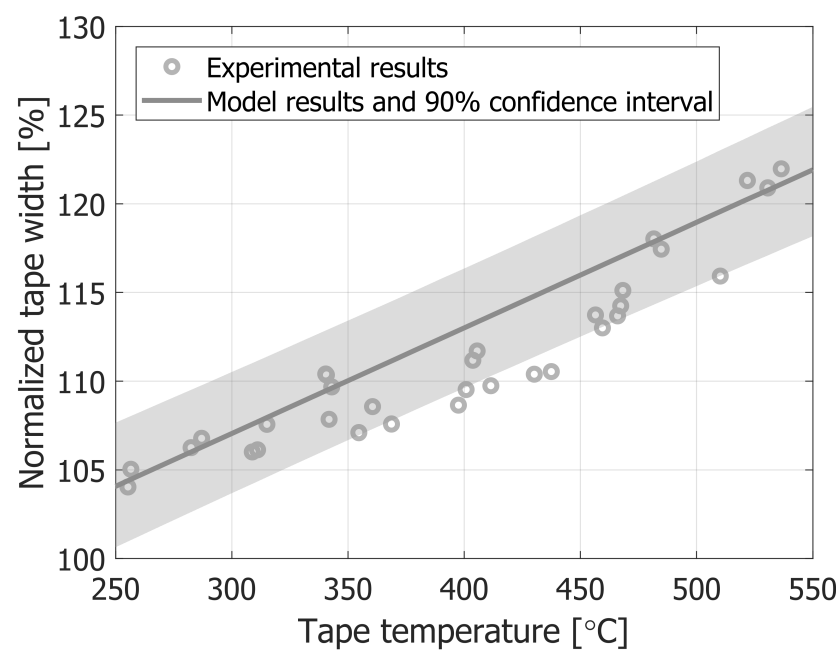

Figure 5.14 Comparison of the experimental results with the quasi-static tape deformation model with $40 \%$ of the predicted heated length.

\subsection{Conclusion}

An experimental investigation of tape deformation during LAFP has been performed. The results show that tape deformation is mainly a function of tape temperature and is hardly affected by the applied pressure. Models currently used to predict tape deformation based on squeeze flow, such as developed by Ranganathan et al., were not able to explain the experimental results. The model of Ranganathan et al. shows a clear dependence of tape deformation on both pressure and temperature, which was not the case in the experiments. Furthermore, for the squeeze flow model continuity of the fibers is neglected and deformation takes place over a short contact length. The calculated contact length would require a fiber strain exceeding the strain at break of carbon fibers. This indicates that the deformation cannot only take place underneath the roller, but must also occur before the nip-point.

An alternative tape deformation model was proposed that includes spreadinginduced fiber stresses. Using a Eulerian frame of reference, tape deformation was assumed to be quasi-static, which makes it a function of the length of the melted tape. The model results overestimate the experimental results by about $35 \%$, however the trend of tape deformation as a function of tape temperature can be observed in the model. Possible sources of error are the assumed heated length, which is likely to be shorter than calculated, and intermingling of the fiber bundles. Further research 
is required to completely explain the observed experimental behavior and to predict tape deformation as a function of process parameters.

\section{References}

[1] X. Li, S. R. Hallett, and M. R. Wisnom. Modelling the effect of gaps and overlaps in automated fibre placement AFP-manufactured laminates. Science and Engineering of Composite Materials, 22(2):115-129, 2015.

[2] M. Lan, D. Cartié, P. Davies, and C. Baley. Microstructure and tensile properties of carbon-epoxy laminates produced by automated fibre placement: Influence of a caul plate on the effects of gap and overlap embedded defects. Composites Part A: Applied Science and Manufacturing, 78:124-134, 2015.

[3] R. Schledjewski and A. K. Schlarb. Thermoplastic tape placement process challenges on the way to a fully automated lay-up of complex shaped parts. In Proceedings of the 2006 SAMPE Symposium and Exhibition (SAMPE 2006), volume 51. Long Beach, California, USA, 2006.

[4] M. A. Khan. Experimental and Simulative Description of the Thermoplastic Tape Placement Process with Online consolidation. Phd, Technischen Universität Kaiserslautern, Kaiserslautern, Germany, 2010.

[5] S. Ranganathan, S. G. Advani, and M. A. Lamontia. Non-isothermal process model for consolidation and void reduction during in-situ tow placement of thermoplastic composites. Journal of Composite Materials, 29(8):1040-1062, 1995.

[6] S. F. Shuler and S. G. Advani. Transverse squeeze flow of concentrated aligned fibers in viscous fluids. Journal of Non-Newtonian Fluid Mechanics, 65(1):47-74, 1996.

[7] E. L. Wang and T. G. Gutowski. Laps and gaps in thermoplastic composites processing. Composites Manufacturing, 2(2):69-78, 1991.

[8] C. M. Stokes-Griffin and P. Compston. Optical characterisation and modelling for oblique near-infrared laser heating of carbon fibre reinforced thermoplastic composites. Optics and Lasers in Engineering, 72:1-11, 2015.

[9] M. Di Francesco, L. Veldenz, G. Dell'Anno, and K. Potter. Heater power control for multi-material, variable speed automated fibre placement. Composites Part A: Applied Science and Manufacturing, 101:408-421, 2017.

[10] C. M. Stokes-Griffin. A Combined Optical-Thermal Model for Laser-Assisted Fibre Placement of Thermoplastic Composite Materials. Phd thesis, The Australian National University, Canberra, Australia, 2015.

[11] J. Tierney and J. W. Gillespie Jr. Modeling of heat transfer and void dynamics for the thermoplastic composite tow-placement process. Journal of Composite Materials, 37(19):1745-1768, 2003.

[12] H. R. Hertz. On the contact of rigid elastic solids and on hardness, Chapter 6: Assorted papers by H. Hertz. MacMillan, New York, USA, 1882. 


\section{A Transverse squeeze flow}

The transverse squeeze flow model to describe tape deformation during fiber placement, developed by Ranganathan et al., is described in this section [5]. The geometry of the fiber placement process including an infinitely stiff roller and the 2D geometry for the transverse squeeze flow were shown in Figure 5.5.

\section{Assumptions}

- A rigid roller is assumed and the height and closing rate can be obtain from the geometry in Figure 5.5(b).

- Flow in the axial direction of the fibers is neglected and a $2 \mathrm{D}$ problem is considered.

- No-slip contact of the tape with the roller and substrate are assumed.

- The tape is assumed to be incompressible.

- The material is assumed to have a high viscosity, hence a creeping flow is considered and inertia forces are neglected.

- The width of the tape is much larger than the height, so flow in the $\mathrm{z}$ direction is neglected.

- The molten tape is assumed to have a Newtonian viscosity.

\section{Equation of motion}

The equation of motion is given by

$$
\overbrace{\rho \frac{D \mathbf{v}}{D t}}^{\text {Inertia force }}=\overbrace{-\nabla P}^{\text {Hydrodynamic force }}+\overbrace{\nabla \cdot \tau}^{\text {Force due to stress }}+\overbrace{\mathbf{F}_{B}}^{\text {Body force }},
$$

where $\rho$ is the density, $\mathbf{v}$ the velocity vector, $P$ the pressure, $\tau$ the applied stresses and $F_{B}$ the body forces. When neglecting body and inertia forces the equation of motion in the $\mathrm{x}$ direction can be obtained simplifies to

$$
\frac{\partial P}{\partial x}=\frac{\partial \tau}{\partial z}
$$




\section{Conservation of mass}

The conservation of mass in given by

$$
\nabla \cdot \mathbf{v}=0
$$

For the two-dimensional system considered this yields

$$
\frac{\partial v_{\mathrm{x}}}{\partial x}+\frac{\partial v_{\mathrm{z}}}{\partial z}=0
$$

\section{Constitutive equation}

It is assumed that the viscosity of the tape material is independent of the strain rate and a Newtonian viscosity model can be used, given by

$$
\tau=\mu \dot{\gamma}
$$

\section{Tape thickness evolution and closing rate}

The tape thickness can be obtained from the assumed geometry of the LAFP process using a rigid roller, as shown in Figure 5.5(b). First the contact length $L_{C}$ can be derived geometrically:

$$
L_{\mathrm{C}}=\sqrt{r_{\mathrm{r}}-\left(r_{\mathrm{r}}-h_{\mathrm{i}}+h_{\mathrm{f}}\right)^{2}},
$$

where $r_{\mathrm{r}}$ is the radius of the roller, $h_{\mathrm{i}}$ is the tape thickness of the as-received tape and $h_{\mathrm{f}}$ is the final tape thickness. An equation for the thickness $h$ can also be obtained from the geometry:

$$
h(y)=r_{\mathrm{r}}+h_{\mathrm{f}}-\sqrt{r_{\mathrm{r}}^{2}-\left(L_{\mathrm{C}}-y\right)^{2}} .
$$

This equation can be differentiated with respect to time and the result is:

$$
\frac{d h}{d t}=-v \frac{\sqrt{r_{\mathrm{r}}^{2}-\left(r_{\mathrm{r}}-h+h_{\mathrm{f}}\right)^{2}}}{r_{\mathrm{r}}-h+h_{\mathrm{f}}},
$$

where $v$ is the placement velocity. 


\section{Boundary conditions}

The boundary conditions can be derived from the stated assumptions and Figure 5.5(a).

The no-slip boundary conditions of the material with both the roller and the substrate are stated as:

$$
\begin{aligned}
& v_{\mathrm{x}}(z=0)=0, \\
& v_{\mathrm{x}}(z=h)=0 .
\end{aligned}
$$

The substrate is assumed stationary while the velocity in the $\mathrm{z}$ direction of the upper plate is equal to the closing rate given by

$$
\begin{gathered}
v_{\mathrm{z}}(z=0)=0 \text { and } \\
v_{\mathrm{z}}(z=h)=\frac{\partial h}{\partial t} .
\end{gathered}
$$

The pressure boundary condition is given by

$$
P\left(x=\frac{w}{2}\right)=P_{\mathrm{a}} .
$$

\section{Velocity}

The constitutive equation of the material defined in Equation 5.A.5 can be inserted in the equation of motion defined in Equation 5.A.2 resulting in

$$
\frac{\partial P}{\partial x}=\frac{\partial}{\partial z}\left(\mu \frac{\partial v_{\mathrm{x}}}{\partial z}\right)
$$

The velocity profile through the thickness of the tape can be obtained by integrating this equation twice with respect to $z$ and by applying the boundary conditions defined in Equation 5.A.9a and 5.A.9b. This results in

$$
v_{\mathrm{x}}=\frac{1}{2 \mu} \frac{\partial P}{\partial x}\left(z^{2}-h z\right)
$$




\section{Pressure distribution}

The pressure distribution is obtained by substituting the equation for $v_{\mathrm{x}}$ in the equation for conservation of mass, Equation 5.A.4:

$$
\frac{\partial}{\partial x}\left(\frac{1}{2 \mu} \frac{\partial P}{\partial x}\left(z^{2}-h z\right)\right)+\frac{\partial v_{\mathrm{z}}}{\partial z}=0
$$

The result can be integrated with respect to $z$ over the thickness and the result is, making use of the boundary conditions for $v_{z}$ in Equation 5.A.10a and 5.A.10b:

$$
\frac{\partial}{\partial x}\left(\frac{h^{3}}{12 \mu} \frac{\partial P}{\partial x}\right)+\frac{\partial h}{\partial t}=0
$$

The pressure distribution can be obtained by integrating this equation twice with respect to $x$ and using the boundary condition specified in Equation 5.A.11

$$
P=\frac{6 \mu}{h^{3}} \frac{\partial h}{\partial t}\left(x^{2}-\left(\frac{w}{2}\right)^{2}\right)+P_{a} .
$$

\section{Compaction force}

The compaction force can be obtained by integrating the pressure distribution over the width of the tape and the time underneath the roller, which is the contact length $L_{C}$ divided by the placement velocity $v$. The result is:

$$
F_{\mathrm{C}}=2 \int_{0}^{\frac{L_{\mathrm{C}}}{v}} \int_{0}^{\frac{w}{2}}(P) d x d t=\int_{0}^{-\frac{L_{\mathrm{C}}}{v}}\left(\frac{\mu_{\mathrm{mf}} \dot{h}\left(w_{\mathrm{i}} h_{\mathrm{i}}\right)^{3}}{h^{6}}+P_{\mathrm{a}} \frac{w_{\mathrm{i}} h_{\mathrm{i}}}{h}\right) d t .
$$

\section{B Squeeze flow including spreading-induced fiber stresses with an infinitely stiff roller}

Spreading of the fibers is neglected in currently used transverse squeeze flow models to describe tape deformation during LAFP. In this appendix the derivation is given to describe fiber spreading based on the required strain in the fibers. An overview of the assumed geometry is shown in Figure 5.10. The spreading-induced fiber stress is incorporated in a transverse squeeze flow model assuming an infinitely stiff roller, as used by Ranganathan et al., which was described in Appendix 5.A. 


\section{Assumptions}

- The same assumptions as considered for the squeeze flow model in Appendix 5.A.

- The law of mixtures is assumed.

- The deformation of the tape is linear.

- The fibers are perfectly aligned.

\section{Equation of motion}

The momentum equation, neglecting body and inertia forces, in the $\mathrm{x}$ direction can be obtained from an element of the cross-section, as shown in Figure 5.10, and is described as

$$
\frac{\partial P}{\partial x}+\frac{\partial \sigma}{\partial y}=\frac{\partial \tau}{\partial z}
$$

\section{Conservation of mass}

The conservation of mass in given by the same equation as for the squeeze flow model described in Appendix 5.A.

\section{Constitutive equation}

The same Newtonian viscosity is used as for the squeeze flow model described in Appendix 5.A.

\section{Strain in the fibers}

The strain on the fibers is a function of the spreading of the tape, which can be described by the angle $\alpha$ in Figure 5.10:

$$
\varepsilon=\frac{\frac{L_{\mathrm{h}}}{\cos (\alpha)}-L_{\mathrm{h}}}{L_{\mathrm{h}}}=\frac{1-\cos (\alpha)}{\cos (\alpha)},
$$

where $L_{\mathrm{h}}$ is the heated length of the tape, as defined in Figure 5.10. 
The angle $\alpha$ can be derived from the assumed geometry:

$$
\alpha=\arctan \left(\frac{x}{y}\left(1-\frac{w_{\mathrm{i}}}{w}\right)\right)
$$

where $w$ is the tape width at $y$.

\section{Spreading-induced fiber stresses}

Stress in the fibers can be calculated based on the strain:

$$
\sigma=E_{\mathrm{f}} V_{\mathrm{f}} \varepsilon
$$

where $E_{\mathrm{f}}$ and $V_{\mathrm{f}}$ are the stiffness of the fibers and the fiber volume fraction respectively. The stress of the fibers in the $x$ direction can also be derived based on the geometry and making use of a small angle approximation:

$$
\sigma_{\mathrm{x}}=\sigma \sin (\alpha)=\frac{E_{\mathrm{f}} V_{\mathrm{f}}}{2} \frac{x^{3}}{y^{4}}\left(1-\frac{h}{h_{\mathrm{i}}}\right)^{3} .
$$

The derivative with respect to $y$ of $\sigma_{\mathrm{x}}$ is

$$
\frac{\partial \sigma_{\mathrm{x}}}{\partial y}=-\frac{3 E_{\mathrm{f}} V_{\mathrm{f}}}{2} \frac{x^{3}}{y^{4}}\left(1-\frac{h}{h_{\mathrm{i}}}\right)^{3}-\frac{3 E_{\mathrm{f}} V_{\mathrm{f}}}{2 h_{\mathrm{i}}} \frac{x^{3}}{y^{3}}\left(1-\frac{h}{h_{\mathrm{i}}}\right)^{2} \frac{\partial h}{\partial y}
$$

\section{Boundary conditions}

The same boundary conditions hold as for the transverse squeeze flow model described in Appendix 5.A.

\section{Velocity}

The constitutive equation of the material, Equation 5.A.5, can be substituted in Equation 5.B.1:

$$
\frac{\partial P}{\partial x}+\frac{\partial \sigma_{\mathrm{x}}}{\partial y}=\frac{\partial}{\partial z}\left(\mu \frac{\partial v_{\mathrm{x}}}{\partial z}\right)
$$

This equation is integrated twice with respect to $x$ and the velocity boundary 
conditions given in Equation 5.A.9a and 5.A.9b. This results in

$$
v_{\mathrm{x}}=\frac{1}{2 \mu} \frac{\partial P}{\partial x}\left(z^{2}-h z\right)+\frac{1}{2 \mu} \frac{\partial \sigma_{\mathrm{x}}}{\partial y}\left(z^{2}-h z\right) .
$$

\section{Pressure distribution}

The pressure distribution can be obtained by substituting the velocity distribution $v_{\mathrm{x}}$ from Equation 5.B.8 in the conservation of mass, Equation 5.A.3:

$$
\frac{\partial}{\partial x}\left(\frac{1}{2 \mu} \frac{\partial P}{\partial x}\left(z^{2}-h z\right)+\frac{1}{2 \mu} \frac{\partial \sigma_{x}}{\partial y}\left(z^{2}-h z\right)\right)+\frac{\partial v_{z}}{\partial z}=0 .
$$

This equation is first integrated with respect to $z$ over the thickness, and boundary conditions specified in Equation 5.A.10a and 5.A.10b:

$$
\frac{\partial}{\partial x}\left(\frac{h^{3}}{12 \mu} \frac{\partial P}{\partial x}+\frac{h^{3}}{12 \mu} \frac{\partial \sigma_{\mathrm{x}}}{\partial y}\right)+\frac{\partial h}{\partial t}=0
$$

The pressure distribution can be obtained by substituting for the fiber stress, Equation 5.B.6, and integrating twice with respect to $x$ and using the boundary condition specified in Equation 5.A.11:

$$
\begin{aligned}
P=\frac{6 \mu}{h^{3}} \frac{\partial h}{\partial t}\left(x^{2}-\left(\frac{w}{2}\right)^{2}\right)-P_{\mathrm{a}}+ & \\
& \quad \frac{3 E_{\mathrm{f}} V_{\mathrm{f}}}{8} \frac{x^{4}-\left(\frac{w}{2}\right)^{4}}{y^{4}}\left(1-\frac{h}{h_{\mathrm{i}}}\right)^{3}+\frac{3 E_{\mathrm{f}} V_{\mathrm{f}}}{8 h_{\mathrm{i}}} \frac{x^{4}-\left(\frac{w}{2}\right)^{4}}{y^{3}}\left(1-\frac{h}{h_{\mathrm{i}}}\right)^{2} \frac{\partial h}{\partial y} .
\end{aligned}
$$

\section{Compaction force}

The compaction force is obtained by integrating the pressure both to the width of the tape and over the contact length $L_{C}$ :

$$
\begin{aligned}
F_{\mathrm{C}}=2 \int_{0}^{\frac{L_{\mathrm{C}}}{v}} \int_{0}^{\frac{w}{2}}(P) d x d y=\int_{0}^{L_{\mathrm{C}}}\left(\frac{\mu w^{4} \dot{w}}{\left(w_{\mathrm{i}} h_{\mathrm{i}}\right)^{2}}-P_{\mathrm{a}} w\right) d t+ \\
\int_{0}^{L_{\mathrm{C}}}\left(\frac{3 E_{\mathrm{f}} V_{\mathrm{f}} w^{4}}{160(v t)^{4}}\left(1-\frac{w_{\mathrm{i}}}{w}\right)^{3}+\frac{3 E_{\mathrm{f}} V_{\mathrm{f}} w^{2} w_{\mathrm{i}} \dot{w}}{160 v^{4} t^{3}}\left(1-\frac{w_{\mathrm{i}}}{w}\right)^{2}\right) d t .
\end{aligned}
$$




\section{C Squeeze flow including spreading-induced fiber stresses with a Hertzian contact}

The derivation of the transverse squeeze flow model assuming a Hertzian contact is similar to the model assuming an infinitely stiff roller in Appendix 5.B. The same assumptions hold for this model as well. The described derivation is started at the obtained pressure distribution Equation 5.B.11 in Appendix 5.B.

\section{Hertzian contact}

The pressure distribution in 2D for a Hertzian contact is described by

$$
Q(y)=\frac{8 F_{\mathrm{c}} \sqrt{L_{\mathrm{C}}^{y}-y^{2}}}{\pi L_{\mathrm{c}}^{2}}[12] .
$$

\section{Compaction force}

The pressure distribution given by Equation 5.B.11 is integrated over the width

$$
\begin{aligned}
Q(t)=2 \int_{0}^{\frac{w}{2}}(P) d x= & \frac{\mu w^{4} \dot{w}}{\left(w_{\mathrm{i}} h_{\mathrm{i}}\right)^{2}}-P_{\mathrm{a}} w+ \\
& \frac{3 E_{\mathrm{f}} V_{\mathrm{f}} w^{4}}{160(v t)^{4}}\left(1-\frac{w}{w}\right)^{3}+\frac{3 E_{\mathrm{f}} V_{\mathrm{f}} w^{2} w_{\mathrm{i}} \dot{w}}{160 v^{4} t^{3}}\left(1-\frac{w}{w}\right)^{2}
\end{aligned}
$$

and the result is equal to the pressure distribution in 2D for a Hertzian contact given by Equation 5.C.2. The compaction force can then be derived as

$$
\begin{aligned}
F_{\mathrm{c}}= & \frac{\pi L_{\mathrm{C}}^{2}}{8 \sqrt{L_{\mathrm{C}}^{y}-y^{2}}}\left(\frac{\mu w^{4} \dot{w}}{\left(w_{\mathrm{i}} h_{\mathrm{i}}\right)^{2}}-P_{\mathrm{a}} w\right) \\
& \frac{\pi L_{\mathrm{C}}^{2}}{8 \sqrt{L_{\mathrm{C}}^{y}-y^{2}}}\left(\frac{3 E_{\mathrm{f}} V_{\mathrm{f}} w^{4}}{160(v t)^{4}}\left(1-\frac{w_{\mathrm{i}}}{w}\right)^{3}+\frac{3 E_{\mathrm{f}} V_{\mathrm{f}} w^{2} w_{\mathrm{i}} \dot{w}}{160 v^{4} t^{3}}\left(1-\frac{w_{\mathrm{i}}}{w}\right)^{2}\right) .
\end{aligned}
$$




\section{D Quasi static tape deformation model}

The quasi-static tape deformation model is derived from the pressure distribution for the squeeze flow model including fiber spreading in Appendix 5.B given by Equation 5.B.11. The same governing equations and assumptions hold for this model.

The pressure distribution can be integrated over the width of the tape and this should be equal to applied compaction force divided by the contact length:

$$
\begin{aligned}
\frac{F_{\mathrm{c}}}{L_{\mathrm{C}}}=2 \int_{0}^{\frac{w}{2}} P d x=-\frac{\mu w^{3}}{h^{3}} & \frac{\partial h}{\partial t}-P_{\mathrm{a}} w- \\
& \frac{3 E_{\mathrm{f}} V_{\mathrm{f}}}{160} \frac{w^{5}}{y^{4}}\left(1-\frac{h}{h_{\mathrm{i}}}\right)^{3}-\frac{3 E_{\mathrm{f}} V_{\mathrm{f}}}{160 h_{\mathrm{i}}} \frac{w^{5}}{y^{3}}\left(1-\frac{h}{h_{\mathrm{i}}}\right)^{2} \frac{\partial h}{\partial y} .
\end{aligned}
$$

When the deformation is quasi-static, the change in height is $0, y$ is the heated length $L_{\mathrm{h}}$ and the width is the final width $w_{\mathrm{f}}$. Equation 5.D.1 then reduces to:

$$
\frac{F_{\mathrm{c}}}{L_{\mathrm{C}}}=\frac{3 E_{\mathrm{f}} V_{\mathrm{f}}}{160} \frac{w_{\mathrm{f}}^{5}}{L_{\mathrm{h}}^{4}}\left(1-\frac{w_{\mathrm{i}}}{w_{\mathrm{f}}}\right)^{3}+P_{\mathrm{a}} w .
$$




\section{Chapter 6}

\section{Discussion}

The high heating and cooling rates as well as the limited time for consolidation make it difficult to achieve in-situ consolidation with LAFP. For that reason the process is not yet applied in the production of commercial aircraft. The work done in this thesis shows that the heating phase affects consolidation and that these effects cannot be neglected. The presented results provide a basis for further research on in-situ consolidation.

\subsection{Governing mechanisms for in-situ consolidation with Laser Assisted Fiber Placement}

Chapter 1 provides an overview of the currently established description of the mechanisms governing in-situ consolidation with LAFP. It is worth noting that most of the theory was developed in the 80s and 90s, based on observations made on the material and processing technology available at the time. The nature of AFP with fast heating and consolidation makes it difficult to observe and analyze the mechanisms during the process, hence most of the established theoretical descriptions are based on work performed at longer consolidation times and longer heating times. This thesis investigates the effects of the heating phase on the consolidation state of the tape and its effect on subsequent consolidation behavior under the compaction roller.

Figure 1.3 shows an overview of the governing mechanisms in LAFP and Figure 6.1 shows a revised overview, based on the experimental observations made in this thesis. Modifications of the theoretical descriptions were proposed from these observations in three areas, namely the assumed tape morphology, the considered mechanism for intimate contact development and the tape deformation mechanism. These three proposed modifications are further elaborated below. 

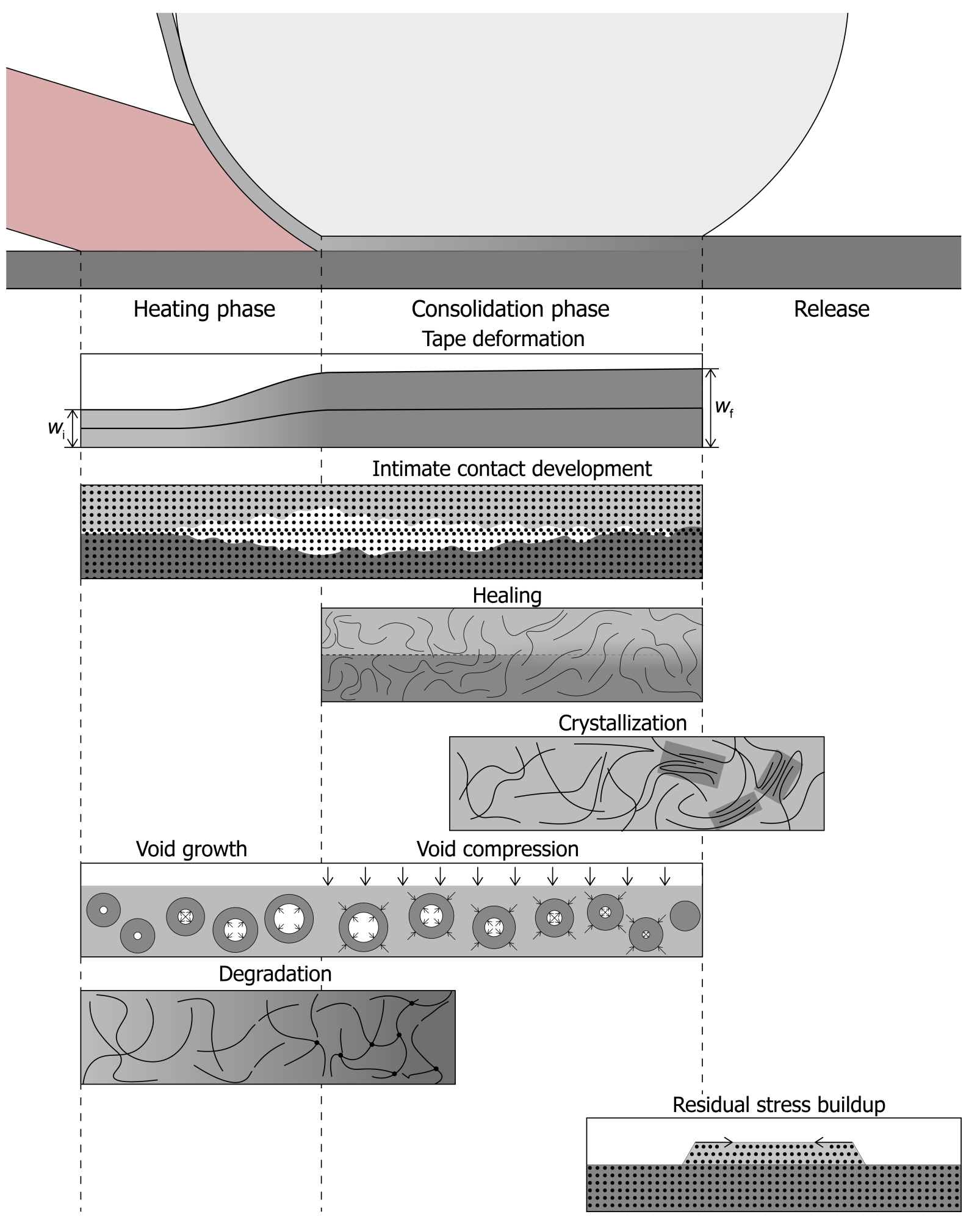

Figure 6.1 Overview of the governing mechanisms during LAFP.

Although the deconsolidation of composite prepregs upon heating without pressure is a known phenomenon in thermoplastic composite manufacturing, it was not 
considered to be relevant for the fast heating during LAFP. However, the experimental investigation in Chapter 3 showed that the C/PEEK tape deconsolidates during the short heating time of LAFP. The cost and effort of making a high-quality tape is partially lost during the heating phase. The observed morphological changes in the meso structure, such as an increase in surface roughness and increased void content, were similar to what has been observed in deconsolidation at longer time scales. However, the deconsolidation was local and only observed near the heated surface. Furthermore, it was observed that the tape surface was fiber-rich with a lack of matrix after laser heating. It was only observed for the tape surface and it can be expected that the substrate also deconsoliates, however, this could not be demonstrated. Two mechanisms are suggested as the main causes of deconsolidation at longer consolidation times: decompaction of the fiber bed and expansion of moisture and volatiles [1]. Further research is required to confirm the driving mechanism for the fast deconsolidation of the tape during LAFP.

The currently available tape has a smooth surface to improve interlaminar bonding. The increased roughness due to deconsolidation during heating is, however, expected to impede intimate contact development. Moreover, it seems that the heated surface, which has become matrix-poor, has to be wetted with matrix to facilitate interlaminar bonding with other plies. The percolation flow required to wet the fibers at the surface is not considered in current intimate contact models, which are based on the transverse squeeze flow of surface asperities. In Chapter 4 an experimental research is presented to investigate the effect of process parameters of LAFP on intimate contact development. Although the present intimate contact models do not consider impregnation, most of the experimentally observed trends were predicted for the various parameters. Based on the observations made on tape deconsolidation in Chapter 3, a 1D impregnation model was proposed to predict intimate contact development during LAFP. Although the obtained degree of intimate contact was underestimated, it was shown that this model was better able to capture the trends for the various process parameters involved in the development of intimate contact during LAFP. The percolation flow of matrix should be considered in intimate contact development for tapes with a fiber-rich surface with a lack of matrix. Further development of this modeling strategy is required in order to quantitatively predict intimate contact development.

Gaps and overlaps should be prevented during placement. Gaps introduce voids between tapes and overlaps cause irregularities on the surface of a ply which hinder intimate contact development and can cause overheating of the material [2]. Prevention of gaps and overlaps requires an accurate and consistent tape width, precise placement and the consideration of the tape width after placement. In Chapter 5 it was shown experimentally that the final width of the placed tape 
is a function of the tape temperature, while it is hardly affected by the applied compaction force. A dependence on the applied compaction force was to be expected, as the tape is molten allowing for viscous deformation. In the currently available tape deformation models, based on transverse squeeze flow, it is assumed that all deformation takes place underneath the roller and any deformation prior to the roller is neglected. Also, these models do not take into account the energy required to elongate the fibers as a result of the spreading deformation. The experimental results presented in Chapter 5 suggest that both assumptions are violated in practice, as the tape may already deform prior to the roller and spreading-induced fiber stresses should be taken into account. A model is proposed to include both effects. It was assumed that all deformation takes place before the nip-point and, consequently, tape deformation during LAFP was regarded as the deformation of a molten tape with a certain length. The model captured the observed trend, but overestimates the amount of deformation. Either the heated length seems to be overestimated or the stress required to spread the fibers seems to be underestimated. Further development of the deformation model is required to quantitatively predict the final tape width.

\subsection{Tape properties - consolidation quality}

The evolution of the tape state during processing plays an important role in consolidation. This thesis shows that the state of the tape evolves during the heating and consolidation phase, resulting in a final consolidation quality. The state of the tape can be defined by a number of properties and these properties affect the consolidation process. In this section an overview is given of the effect of a number of tape properties on the final consolidation quality, which can be used to define an ideal tape for in-situ consolidation and which indicates areas for future research.

The overview of the relation between tape properties and final consolidation quality is based mainly on observations in literature, which are supported by the presented results in this work. Table 6.1 shows the effects of a number of tape properties on the consolidation quality measures. More properties can be considered to characterize the tape quality, which can be found in [3]. Although only limited research has been performed in this thesis into the effects of different types of tapes, the observations made can help to derive the required tape properties.

It is obvious that the void content of the tape should be as low as possible, as intralaminar voids are difficult to compress and remove in the short time available during LAFP. Furthermore, the tape should have a rectangular shape with well consolidated and straight edges. The thickness and width of the tape should be 
accurate and consistent. Any variations in thickness impede uniform pressure application, which hinders void removal, intimate contact and bond development. Variations in tape width can result in gaps and overlaps, which also hinder uniform pressure application.

Table 6.1 Overview of the relation between tape properties and the consolidation quality in LAFP. An upward arrow $(\uparrow)$ or a downward arrow $(\downarrow)$ indicates an increase or decrease of a process parameter respectively. A cross sign $(\times)$ indicates no effect, while a question mark (?) indicates an unknown effect. The green color ( ) indicates a positive, while the red color ( indicates a negative effect. The grey color ( )indicates no effect. The double symbols are based on the work done in this thesis. Elaboration of the listed effects can be found in Section 6.2

\begin{tabular}{|c|c|c|c|c|c|c|}
\hline Tape properties & 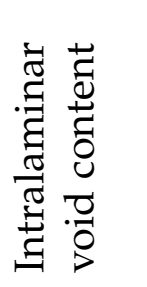 & 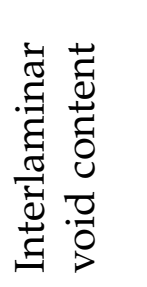 & 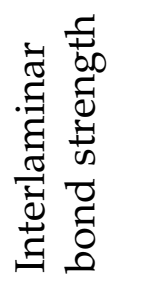 & 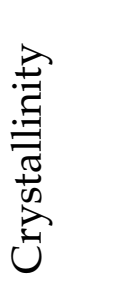 & 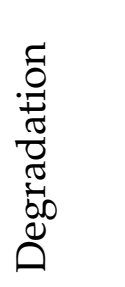 & 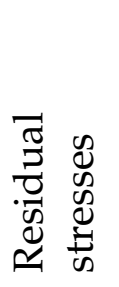 \\
\hline Thickness variations & $\uparrow[4]$ & $\uparrow[4-6]$ & $\downarrow^{[4]}$ & $x^{*}$ & $x^{*}$ & $?$ \\
\hline Width variations $\uparrow$ & $\uparrow$ & $\uparrow \uparrow[5]$ & $\downarrow^{*}$ & $?$ & $?$ & $?$ \\
\hline Edge quality $\uparrow$ & $\downarrow^{[5]}$ & $\downarrow^{[5]}$ & $\uparrow^{*}$ & $x^{*}$ & $\downarrow^{*}$ & $?$ \\
\hline Surface roughness $\uparrow$ & $x^{*}$ & $\uparrow[5-7]$ & $\downarrow^{[5-7]}$ & $x^{*}$ & $?$ & $?$ \\
\hline Resin rich layer $\uparrow$ & $?$ & $\downarrow^{[6]}$ & $\uparrow[4,6]$ & $x^{*}$ & $\downarrow^{*}$ & $?$ \\
\hline $\begin{array}{l}\text { More even fiber } \\
\text { distribution } \uparrow\end{array}$ & $\downarrow^{*}$ & $\downarrow^{*}$ & $?$ & $?$ & $x^{*}$ & $\downarrow^{*}$ \\
\hline Void content $\uparrow$ & $\uparrow[4,5]$ & $?$ & $?$ & $x^{*}$ & $x^{*}$ & $?$ \\
\hline Crystallinity $\uparrow$ & $\downarrow^{*}$ & $\downarrow^{*}$ & $\downarrow^{*}$ & $\uparrow *$ & $x^{*}$ & $?$ \\
\hline $\begin{array}{l}\text { Processing } \\
\text { temperature } \uparrow\end{array}$ & $\uparrow[8]$ & $\uparrow[8,9]$ & $\downarrow^{*}$ & $\downarrow^{*}$ & $x^{*}$ & 个* \\
\hline Viscosity $\uparrow$ & $\uparrow[8]$ & $\uparrow[8,9]$ & $\downarrow^{*}$ & $x^{*}$ & $x^{*}$ & $x^{*}$ \\
\hline
\end{tabular}

A uniform fiber distribution improves the load-carrying capabilities of AFP laminates as the stresses can be distributed better [4]. Matrix-poor or matrix-rich regions are less capable of transferring loads and are likely to magnify residual stresses. However, a matrix-rich layer on the surface of the tape is beneficial, as it improves both intimate contact development and healing resulting in an improved interlaminar bonding. Moreover, the tape may deconsolidate during LAFP, as is shown in Chapter 3, resulting in a fiber-rich surface with a lack of matrix. A percolation type of flow was required to wet such a surface, which is investigated in Chapter 4 . A more matrixrich surface layer might reduce the effects of deconsolidation and thus facilitate interlaminar bonding. 
The surface of the tape should not only be matrix-rich but also smooth to facilitate bonding. Intimate contact can be created easier with smooth matrix-rich surfaces as less deformation or impregnation is required. Furthermore, fewer air bubbles can be enclosed with a smoother surface, which results in a reduction in interlaminar voids. Deconsolidation during the heating phase should be prevented in order to let the tape enter the nip-point with the smooth matrix-rich surface intact. Further research is required in this area.

The initial crystallinity of the tape can be expected to affect in-situ consolidation. The crystalline fraction of the matrix has to be melted in order to enable the matrix to flow or to heal. A tape with a lower crystallinity can be expected to melt more easily and, therefore, processed more easily. However, if not all crystals can be melted in the short time, a tape with a higher initial crystallinity has a higher final crystallinity as well, although interlaminar bonding would be hindered.

The properties of the polymer used, mainly the processing temperature and the viscosity at this temperature, also affect the processability. The stringent requirements of the aerospace industry with respect to matrix properties, such as the high temperature performance and the environmental stability, limit the possible polymer types that can be used. In this work only PEEK has been considered, as this is used often in aerospace applications. A drawback is the high melting temperature of PEEK, which makes it difficult to process. High process temperatures are required to melt the PEEK matrix sufficiently to enable void compression, intimate contact development and healing. Therefore, high heating and cooling rates are required, which are energy consuming, but also impede crystallization and induce build-up of residual stresses. A polymer with a lower processing temperature and a lower viscosity at this temperature but similar mechanical properties, such as PEKK or engineered PEEK, can be used to ease consolidation, in order to achieve in-situ consolidation [9].

Summarizing, a tape is required with a rectangular shape without thickness variations and a smooth surface. The edges should be well impregnated and rectangular. The variation in width should also be minimal. Furthermore, the fibers should be distributed evenly over the thickness of the tape and well impregnated without any voids. Finally, a resin rich layer is beneficial on the tape surface to promote intimate contact development and interlaminar bonding. 


\subsection{Process parameters - consolidation quality}

Although the tape properties play an important role in consolidation, the state of the tape evolves under the process conditions. In this section, an overview is presented of the relation between process parameters and the measures of consolidation quality. The experimental work performed in this thesis provides part of the information presented and this is complemented with experimental, and sometimes modeling, results found in literature. Not all of the relations are described in the available literature; however, some of these relations can be predicted based on the effects of the various parameters on the temperature and pressure history. The other unknown relations should be the subject of future research.

Table 6.2 gives an overview of the relations between process parameters and the consolidation quality measures. The main contribution of the current work is on the interlaminar void content. Each quality measure is discussed in terms of the effect of each process parameter. The interlaminar void content and the interlaminar bond strength are discussed together, as these are based on similar mechanisms. The interlaminar void content is the result of the intimate contact modeling, while interlaminar bonding is the result of intimate contact development and subsequent healing. The intralaminar void content is then discussed, followed by polymer degradation, crystallinity and, finally residual stress development.

\section{Interlaminar void content and bond strength}

The observed effects of the process parameters are similar for both the interlaminar void content and interlaminar bond strength. This was to be expected as interlaminar bond strength development is regarded as a combination of intimate contact development and subsequent healing. In Table 6.2 a positive effect can be observed of an increasing compaction force on the bond strength. This can be related to the positive effect on the interlaminar void content, as intimate contact is improved with a higher compaction force, while healing is assumed to be unaffected by the applied pressure. Increasing the nip-point temperature promotes intimate contact and bond development, due to the reduction of both the viscosity and the relaxation time of the matrix with increasing temperature. In particular the tape temperature should be sufficiently high, as the tape is in contact with the roller and, consequently, cools quickly. The temperature of the tape can be increased by using a smaller laser angle and more heat focused on the tape. The positive effect of a heated tool for the bond strength, was not clearly observed in the intimate contact experiment in this work. The highest tool temperature considered in this work, however, was only $100{ }^{\circ} \mathrm{C}$ and higher temperatures might improve the intimate contact development more. It is 
important to note here that, for the experimental procedure employed in this work, a higher tool temperature results in a lower tape temperature. This is a consequence of choosing to control the nip-point temperature, which is the average of the substrate and tape temperature, as an input variable as opposed of using the input power. A different orientation and position of the laser might be required to take advantage of the heated tool in interlaminar bonding. Furthermore, a larger spot-size means a longer heating time, which increases the amount of heat put into the system for a certain nip-point temperature. As a result the cooling rate at the interface is reduced, hence intimate contact and interlaminar bond development are promoted. On the other hand, the heating time is reduced by increasing the placement velocity, thereby reducing the heat input. Furthermore, the time underneath the roller is reduced with increasing placement velocity, which negatively affects the the degree of intimate contact and bond strength.

\section{Intralaminar void content}

Intralaminar voids originate mainly from the void and moisture content of the asreceived tape and the fiber bed decompaction. The final intralaminar void content depends on possible void nucleation and growth, deconsolidation, in the heating and release phase and the compression of voids underneath the roller in the consolidation phase. Increasing the nip-point temperature reduces the viscosity, which promotes compression of voids and the fiber bed. The tool temperature has a similar effect. However, too high tool temperatures should be avoided as the tape should be solidified after the compaction roller to prevent expansion of voids and the fiber bed. The driving force for void compression is directly related to by the compaction force and an increase in compaction force will result in a lower void content. The effect of the laser parameters is more difficult to predict, as more heat in the tape can increase void growth and fiber bed decompaction before the nip-point on the one hand but on the other hand it can help compression of voids and the fiber bed underneath the roller.

\section{Crystallinity}

The final crystallinity of the part is mainly a function of the cooling rates of the material. The highest cooling rates are observed in the placed ply, while cooling rates inside the laminate are lower as the subsequent plies act as insulation. Furthermore, crystallization is promoted in the laminate by the reheating of previously placed plies. The cooling rates in the tape are reduced by applying more heat to the placed tape, which can be achieved by a higher nip-point temperature, a larger spot size and a 
higher fraction of heat focused on the tape. This promotes crystallization. In contrast, increasing the placement velocity increases the cooling rates and hence reduces the final crystallinity. It is expected that the applied pressure does not affect crystallinity development. The tool temperature can increase the crystallinity achieved during insitu consolidation by reducing the cooling rates within the placed plies. Furthermore, a heated tool can also be used for a subsequent annealing step.

\section{Degradation}

Degradation of the matrix due to overheating should be prevented during AFP. The maximum heat input during the process and, thereby, the nip-point temperature should be limited to prevent degradation. Varying he position and orientation of the laser can have different effects. Too much energy on the tape, with a low laser angle and a large fraction of the spot on the tape, increases the possibility of overheating of the tape, while a high laser angle and a large fraction of the spot on the laminate increase the possibility of overheating of the laminate. The energy density is higher for a smaller spot size and this increases the possibility of overheating of loose fibers or small irregularities on the surface of the substrate. Furthermore, is the degradation also governed by the time and by increasing the placement velocity the time available for degradation can be reduced. Finally, the compaction force does not affect matrix degradation.

\section{Residual stresses}

Residual stresses are unavoidable in thermoplastic composites. The high processing temperature in combination with the anisotropic thermal expansion results in thermal stress build-up. The temperature gradient through the thickness of the laminate during LAFP further affects the residual stress distribution. The parameters that increase the temperature gradient, such as the nip-point temperature, a larger fraction of the beam on the tape, a smaller spot size and a higher placement velocity, cause an increase in residual stresses [10]. An elevated tool temperature can be used to reduce the stress build up during placement [11]. Otherwise, the heated tool can also be used for an annealing step to relieve some of the residual stresses. It can be expected that the applied compaction force affects the stress build-up during placement, as this has been observed for the applied tape tension [12], however, the exact contributions have not been researched yet. 
Table 6.2 Overview of the relation between process parameters and consolidation quality. An upward arrow $(\uparrow)$ or a downward arrow $(\downarrow)$ indicates an increase or decrease of a process parameter respectively. A cross sign $(\times)$ indicates no effect, while a question mark (?) indicates an unknown effect. The green color $(\square)$ indicates a positive, while the red color $(\square)$ indicates a negative effect. The grey color ( )indicates no effect. The double symbols are based on the work done in this thesis.

\begin{tabular}{|c|c|c|c|c|c|c|}
\hline Process parameters & 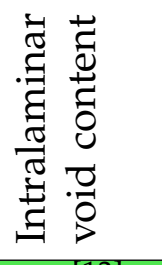 & 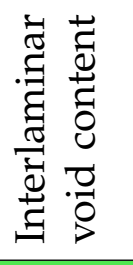 & 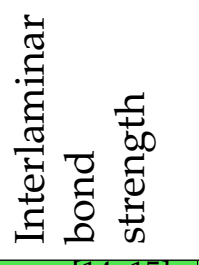 & 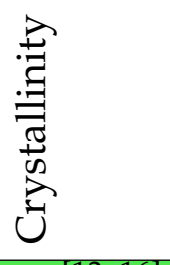 & 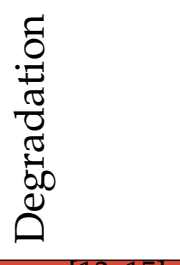 & 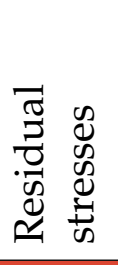 \\
\hline $\begin{array}{l}\text { Nip-point } \\
\text { temperature } \uparrow\end{array}$ & $\downarrow^{[13]}$ & $\downarrow \downarrow$ & $\uparrow \uparrow[14,15]$ & $\uparrow[13,16]$ & $\downarrow^{[13-15]}$ & $\uparrow^{*}$ \\
\hline Tool temperature $\uparrow$ & $\uparrow[11]$ & $\times x$ & $\uparrow[17]$ & $\uparrow[18-20]$ & $\uparrow^{*}$ & $\downarrow^{[10]}$ \\
\hline $\begin{array}{l}\text { Compaction force } \uparrow \\
\text { and roller stiffness } \uparrow\end{array}$ & $\downarrow^{[17,21]}$ & $\downarrow \downarrow$ & $\uparrow[17]$ & $x^{*}$ & $x^{*}$ & $?$ \\
\hline $\begin{array}{l}\text { Compaction force } \uparrow \\
\text { and roller stiffness }=\end{array}$ & $\downarrow^{[17,21]}$ & $\downarrow \downarrow$ & $\uparrow[17,22]$ & $x^{*}$ & $x^{*}$ & $?$ \\
\hline Laser angle $\uparrow$ & $?$ & $\uparrow \uparrow$ & $\downarrow[23,24]$ & $x^{[16]}$ & $\downarrow \uparrow *$ & ? \\
\hline $\begin{array}{l}\text { Fraction spot on the } \\
\text { tape } \uparrow\end{array}$ & $?$ & $\downarrow \downarrow$ & $\uparrow[23]$ & $\uparrow[16]$ & $\downarrow^{*}$ & {$[10]$} \\
\hline Laser spot size $\uparrow$ & $?$ & $\downarrow \downarrow$ & $\uparrow[25]$ & $\uparrow^{*}$ & $\downarrow^{*}$ & $\downarrow^{[10]}$ \\
\hline Placement velocity $\uparrow$ & $\uparrow[21,26]$ & $\uparrow \uparrow[26]$ & $\begin{array}{l}\downarrow[7,15,17] \\
\downarrow[20,22,27]\end{array}$ & $\downarrow^{[19]}$ & $\uparrow[19]$ & $\uparrow[10]$ \\
\hline
\end{tabular}

\subsection{Process optimization}

The models presented in this thesis can be used to analyze the LAFP process and to optimize the process settings. The degree of intimate contact and the tape width can be calculated based on the obtained temperature distribution for a certain configuration. This section presents an example by analyzing effect of the placement velocity on the optimal configuration of the LAFP process. It should be noted that the predictions of the degree of intimate contact in Chapter 4 underestimated the experimental results, so the shown results can be considered to be conservative predictions.

The effects of the orientation and the position of the laser on the degree of intimate contact and the tape deformation were analyzed. This was done for a placement velocity ranging from 25 to $500 \mathrm{~mm} / \mathrm{s}$, a compaction force of $500 \mathrm{~N}$ with a $60 \mathrm{sh}$ roller and a laser spot size of $28 \mathrm{~mm}$. The laser angle ranged from $10^{\circ}$ to $25^{\circ}$, while the position was defined as the distance $L_{l}$ of the center line of the laser to the nippoint. This distance ranges from $-15 \mathrm{~mm}$ up to $7 \mathrm{~mm}$ based on the definition in 
Figure 6.2. This means that at the lower range the laser is completely aimed at the laminate and not even hits the nip-point, while on the other end $75 \%$ of the laser spot is aimed at the tape. In the analysis it is shown that the tape can already heat up sufficiently via reflections. Furthermore, a sufficiently high interface temperature can be obtained in case the laminate temperature is high. The required laser power for each setting is based on two limits. First, the maximum temperature may not exceed $550{ }^{\circ} \mathrm{C}$ as above this temperature it is likely that the material degrades. Second, the temperature of the tape after release of the roller should be sufficiently low to prevent deconsolidation. For the sake of argument, the temperature of the released tape is set not to exceed $350{ }^{\circ} \mathrm{C}$.

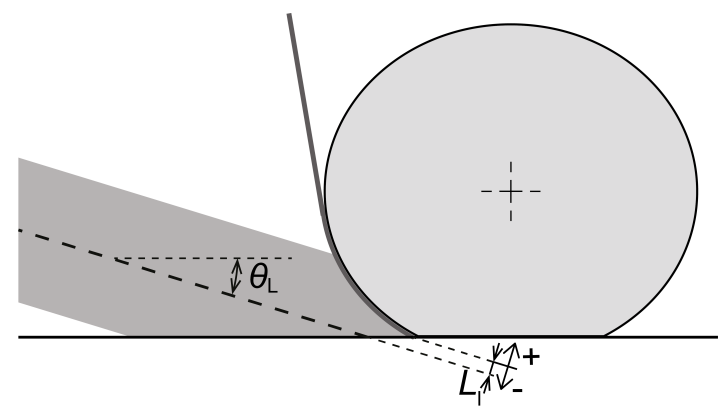

Figure 6.2 Definition of the laser angle and the distance to the laser center line and the nip-point.

Figure 6.3 shows the degree of intimate contact as a function of the laser position and orientation, at a placement velocity of $50 \mathrm{~mm} / \mathrm{s}$. It can be seen that the degree of intimate contact varies over the design space and an optimum is found at a laser angle of about $19^{\circ}$ with distance of about $-14 \mathrm{~mm}$ of the laser center line to the nippoint, i.e. the laser is only focused on the laminate. In this area the amount of laser power applied is limited by the temperature of the tape at the release of the roller, consequently this resulted in the longest time available for consolidation. The degree of intimate contact decreases near the edges and this is due to the fact that the temperature of the laminate is too low. Consequently, the interface temperature is not sufficient to promote intimate contact development. Such images can be generated for varying process settings, such as different placement velocities, laser spot sizes and also different materials.

The maximum degree of intimate contact that can be obtained for a certain velocity defines the maximum productivity of the LAFP process. For in-situ consolidation full consolidation is required, while a lower consolidation quality might be sufficient in case a post-consolidation step, such as stamp forming, is applied. Figure 6.4(a) shows the degree of intimate contact that can be obtained for three different configurations as a function of the placement velocity. The geometry of these configurations is shown in Figure 6.4(b). These configurations are either more optimal for lower or 


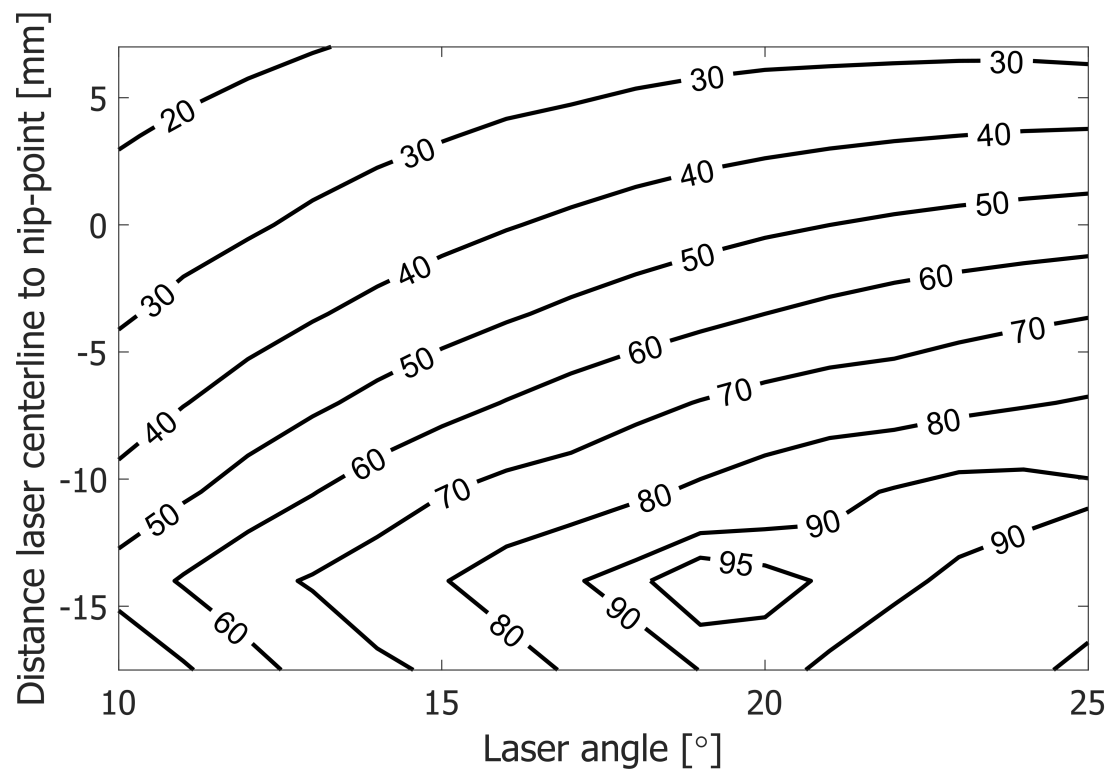

Figure 6.3 Degree of intimate contact for varying laser orientations and positions at $50 \mathrm{~mm} / \mathrm{s}$ with an optic of $28 \mathrm{~mm}$.

higher placement velocities. At low velocities full intimate contact can be obtained, however above $50 \mathrm{~mm} / \mathrm{s}$ the maximum degree of intimate contact drops. At low placement velocities the distance between the center line and the nip-point is large, i.e. the beam is focused on the laminate, while for higher placement velocities the distance is smaller, i.e. a portion of the laser beam is aimed at the tape to obtain a sufficiently high tape temperature.

Figure 6.4(c) shows the tape temperature at release of the roller. The closer the tape temperature is to the set limit of $350{ }^{\circ} \mathrm{C}$, the higher the temperature of the tape underneath the roller and the more time available for consolidation. At different velocities different settings are required to approach the limiting temperature, while the maximum temperature remains below $550{ }^{\circ} \mathrm{C}$. If the contact length underneath the roller would be longer, which is about $26 \mathrm{~mm}$ for shown results, it could improve the degree of intimate contact as a longer time would be available to consolidate and cool the tape.

Finally, Figure 6.4(d) shows the final tape width for the shown configurations. The deformation is considered to be only a function of the length of the melted tape before the nip-point in this thesis. The deformation is highest for the configuration optimized for higher placement velocities, which can be explained by the larger amount of the energy focused on the tape. For the other configurations the tape is not deformed at higher placement velocities, indicating that the tape was not melted before the nip-point. 


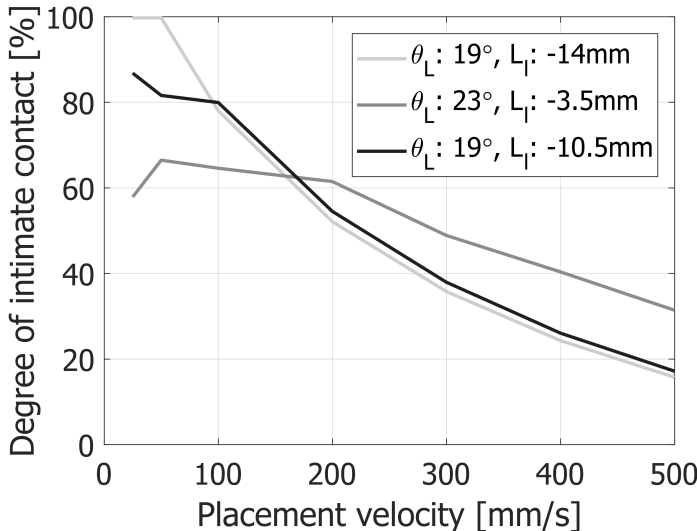

(a)

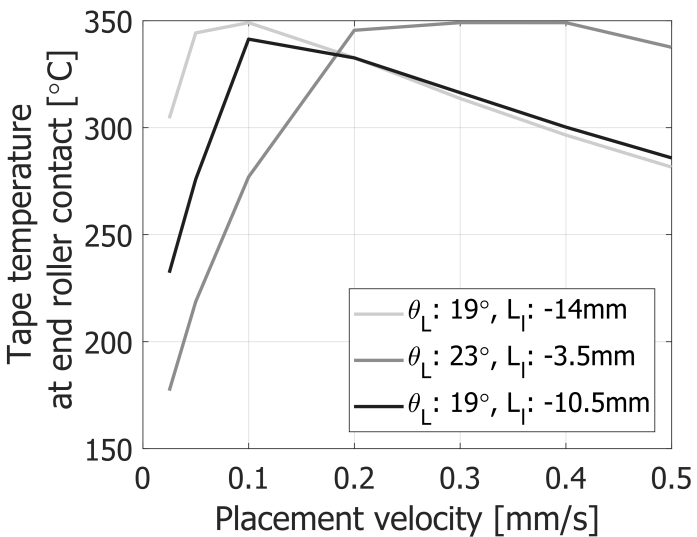

(c)

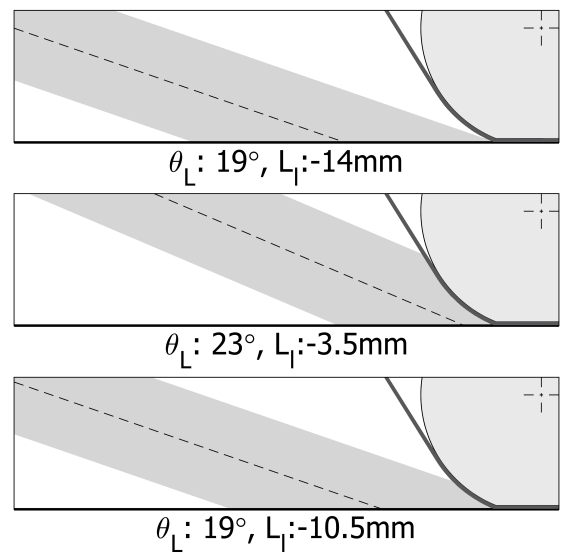

(b)

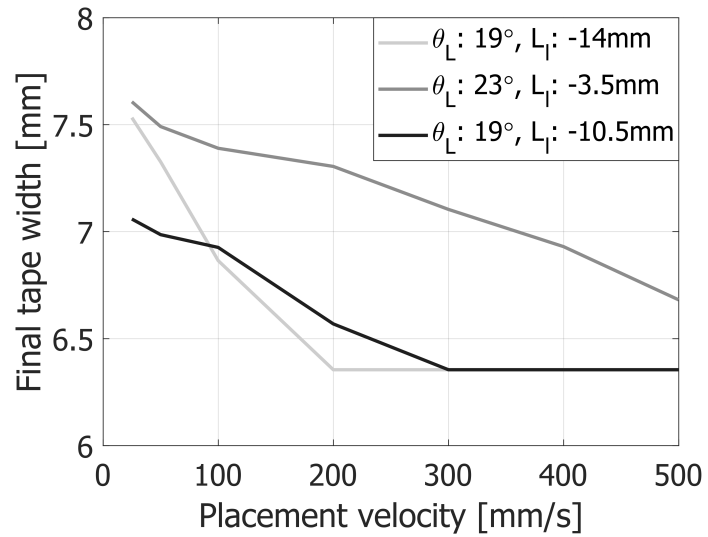

(d)

Figure 6.4 Three configurations for optimized for different placement velocities. (a) Degree of intimate contact as function of the velocity for three different configurations, $(\boldsymbol{b})$ the geometries of the three different configurations, (c) the tape temperature at release of the roller, (d) The final tape width.

The results presented here illustrate the possibilities of the models developed in this thesis. The modeling framework can be used to improve the process settings to optimize the consolidation quality and can be used to investigate the process limitations.

\section{References}

[1] M. Brzeski and P. Mitschang. Deconsolidation and its interdependent mechanisms of fibre reinforced polypropylene. Polymers and Polymer Composites, 23(8):515-524, 2015. 
[2] R. Schledjewski and A. K. Schlarb. Thermoplastic tape placement process challenges on the way to a fully automated lay-up of complex shaped parts. In Proceedings of the 2006 SAMPE Symposium and Exhibition (SAMPE 2006), volume 51. Long Beach, California, USA, 2006.

[3] G. Beresheim. Thermoplast-Tapelegen ganzheitliche Prozessanalyse und entwicklung. Phd, Technischen Universität Kaiserslautern, Kaiserslautern, Germany, 2002.

[4] M. A. Lamontia and M. B. Gruber. Remaining developments required for commercializing in situ thermoplastic atp. In Proceedings of the International 2007 SAMPE Symposium and Exhibition (SAMPE 2007), volume 52. Baltimore, Maryland, USA, 2007.

[5] R. Schledjewski and A. K. Schlarb. In-situ consolidation of thermoplastic tape material effects of tape quality on resulting part properties. In Proceedings of the 2007 SAMPE Symposium and Exhibition (SAMPE 2007), volume 52. Baltimore, Maryland, USA, 2007.

[6] M. B. Gruber, I. Z. Lockwood, T. L. Dolan, S. B. Funk, J. J. Tierney, P. Simacek, J. W. Gillespie Jr, S. G. Advani, B. J. Jensen, R. J. Cano, and B. W. Grimsley. Thermoplastic in situ placement requires better impregnated tapes and tows. In Proceedings of the 2012 International SAMPE Conference and Exhibition (SAMPE 2012). Baltimore, Maryland, USA, 2012.

[7] M. A. Lamontia, M. B. Gruber, J. J. Tierney, J. W. Gillespie Jr, B. J. Jensen, and R. J. Cano. In situ thermoplastic atp needs flat tapes and tows with few voids. In Proceedings of the 30th International SAMPE Europe Conference (SEICO 09), volume 30. Paris, France, 2009.

[8] P. Simacek, S. G. Advani, M. Gruber, and B. Jensen. A non-local void filling model to describe its dynamics during processing thermoplastic composites. Composites Part A: Applied Science and Manufacturing, 46:154-165, 2013.

[9] G. Gardiner. PEEK vs. PEKK vs. PAEK and continuous compression molding. URL www.compositesworld.com/blog/post/peek-vs-pekk-vs-paek-and-continuouscompression-molding, Retrieved on 1 June 2018.

[10] F. O. Sonmez, H. T. Hahn, and M. Akbulut. Analysis of process-induced residual stresses in tape placement. Journal of Thermoplastic Composite Materials, 15(6):525544, 2002.

[11] M. Brzeski, R. Holschuh, and R. Schledjewski. Effect of tool temperature on laminate properties during in situ consolidation placement process. In Proceedings of the 2010 SAMPE Symposium and Exhibition (SAMPE 2010). Seattle, Washington, USA, 2010.

[12] H. Lü, M. Schlottermüller, N. Himmel, and R. Schledjewski. Effects of tape tension on residual stress in thermoplastic composite filament winding. Journal of Thermoplastic Composite Materials, 18(6):469-487, 2005.

[13] V. Agarwal, R. L. McCullough, and J. M. Schultz. The thermoplastic laserassisted consolidation process-mechanical and microstructure characterization. 
Journal of Thermoplastic Composite Materials, 9(4):365-380, 1996.

[14] T. Kok, W.J.B. Grouve, L.L. Warnet, and R. Akkerman. Effect of ply orientation on bond strength in fiber-placed composites. In Proceedings of the 20th International Conference on Composite Materials (ICCM-20). Copenhagen, Denmark, 2015.

[15] C. M. Stokes-Griffin and P. Compston. The effect of processing temperature and placement rate on the short beam strength of carbon fibre-PEEK manufactured using a laser tape placement process. Composites Part A: Applied Science and Manufacturing, 78:274-283, 2015.

[16] C. M. Pistor and S. I. Güçeri. Crystallinity of on-line consolidated thermoplastic composites. Journal of Composite Materials, 33(4):306-324, 1999.

[17] M. A. Khan, P. Mitschang, and R. Schledjewski. Parametric study on processing parameters and resulting part quality through thermoplastic tape placement process. Journal of Composite Materials, 47(4):485-499, 2013.

[18] W. J. B. Grouve. Weld strength of laser-assisted tape-placed thermoplastic composites. Phd thesis, University of Twente, Enschede, The Netherlands, 2012.

[19] F. O. Sonmez and H. T. Hahn. Modeling of heat transfer and crystallization in thermoplastic composite tape placement process. Journal of Thermoplastic Composite Materials, 10(3):198-240, 1997.

[20] Z. Qureshi, T. Swait, R. Scaife, and H. M. El-Dessouky. In situ consolidation of thermoplastic prepreg tape using automated tape placement technology: Potential and possibilities. Composites Part B: Engineering, 66:255-267, 2014.

[21] J. Tierney and J. W. Gillespie Jr. Modeling of heat transfer and void dynamics for the thermoplastic composite tow-placement process. Journal of Composite Materials, 37(19):1745-1768, 2003.

[22] C. M. Stokes-Griffin. A Combined Optical-Thermal Model for Laser-Assisted Fibre Placement of Thermoplastic Composite Materials. Phd thesis, The Australian National University, Canberra, Australia, 2015.

[23] R. Schledjewski and A. Miaris. Thermoplastic tape placement by means of diode laser heating. In Proceedings of the 2009 SAMPE Symposium and Exhibition (SAMPE 2009), volume 54. SAMPE, Baltimore, Maryland, USA, 2009.

[24] W. J. B. Grouve, L. L. Warnet, B. Rietman, H. A. Visser, and R. Akkerman. Optimization of the tape placement process parameters for carbon-PPS composites. Composites Part A: Applied Science and Manufacturing, 50(0):44-53, 2013.

[25] Dennis Maurer and Peter Mitschang. Laser-powered tape placement process - simulation and optimization. Advanced Manufacturing: Polymer E Composites Science, 1(3):129-137, 2015.

[26] M Brzeski. Experimental and analytical investigation of deconsolidation for fiber reinforced thermoplastic composites. Phd thesis, Technischen Universität Kaiserslautern, Kaiserslautern, Germany, 2014.

[27] J. Tierney and J. W. Gillespie Jr. Modeling of in situ strength development for the 
thermoplastic composite tow placement process. Journal of Composite Materials, 40(16):1487-1506, 2006. 


\section{Chapter 7}

\section{Conclusions and recommendations}

\subsection{Conclusions}

This thesis focuses on the mechanisms governing void development during in-situ consolidation using LAFP. The objective was to identify and quantify the effects of the heating phase on the state of the thermoplastic composite tape and its consequences for subsequent void evolution. The main conclusions of the work presented in this thesis can be summarized as follows:.

- The fiber reinforced prepreg tape, used in this work, was found to deconsolidate during the heating phase of LAFP. As a result, the state of the tape was significantly affected (Chapter 3 ).

- Deconsolidation was limited to the laser-heated surface and resulted in a local increase in intralaminar void content and in a rough and matrix poor surface, for the processing settings considered in this work. A quantitative description of the fiber, matrix and void distribution through the thickness for different tape materials obtained (Chapter 3).

- As a result of the tape deconsolidation, a percolation type of flow is required to wet the dry fibers on the laser-heated tape surface in order to develop intimate contact. As such, intimate contact development, for tapes with a fiber-rich and matrix-poor surface, is best described by impregnation of a dry fiber bed (Chapter 4).

- Experiments showed that, for the materials and equipment used, tape deformation is governed mainly by the tape temperature, while the pressure had a negligible influence. It was shown that spreading of the tape takes part prior to the nip-point, i.e. during the heating phase. As an alternative modeling approach, the effect of fiber stresses, as a result of spreading, was included in the analysis (Chapter 5). 
- A deformable roller is not only beneficial in terms of a uniform pressure distribution, but can also reduce or even eliminate the shadow area at the nippoint. The cooling in the shadow area is thereby reduced, resulting in a higher interface temperature which is beneficial for consolidation (Chapter 2).

- A process model was developed to simulate in-situ consolidation. A thermal model, which consists of a geometrical sub-model, an optical sub-model and a heat transfer sub-model model, was used to calculate the temperature history during the process. Consolidation in terms of intimate contact development was modeled based on the percolation flow of matrix required to impregnated the dry fibers at the surface of the deconsolidated tape. Furthermore, tape deformation was assumed to take place before the nip-point and it was modeled based on the spreading-induced fiber stresses.

\subsection{Recommendations}

The presented work demonstrated the effects of the heating phase on in-situ consolidation with LAFP. Important experimental observations were done, which help to improve the understanding of the fundamental mechanisms to describe insitu consolidation. Although a first attempt was made to incorporate the observations in a modeling framework for LAFP, further research is required to further mature the proposed predictive models.

- Chapter 3 showed that the tape may deconsolidate during the heating phase. The mechanisms governing this deconsolidation should be identified in future research. A deconsolidation model can then be developed and incorporated in the modeling framework for LAFP. Furthermore, new tape prepreg materials, which show minimal deconsolidation, can be developed using the knowledge gained.

- Tape deconsolidation was demonstrated for one process condition. Process parameters, such as the placement rate, laser spot size, nip-point temperature, are expected to affect the severity of the deconsolidation. Further research is required to assess the effect of process settings on deconsolidation. The results can be used to further optimize the LAFP process.

- An overview of the effects of process parameters and tape quality on the obtained consolidation quality was given in Chapter 6. Although many topics have been addressed, several white spots for further research can be identified, such as the effect of compaction force on the residual stress development and the effects of laser settings on the intralaminar void content. Furthermore, the effects of the tape properties, in terms of fiber distribution, a resin rich surface layer and crystallinity, need further experimental research. 
- An intimate contact model based on impregnation was developed. The model was capable of predicting most of the observed experimental trends, but further development is required in order to use it as a predictive model.

- The proposed tape deformation model in Chapter 5 including spreadinginduced fiber stresses could not predict the tape deformation quantitatively. Further development of the tape deformation model, involving both squeeze flow and fiber spreading, is required. 



\section{Dankwoord}

Zo, dan is nu eindelijk het moment aangebroken om het laatste deel van mijn proefschrift op papier te zetten. Alhoewel ik het schrijven inmiddels aardig zat ben, is dit wel het mooie moment om terug te kijken op de afgelopen vier jaar (en een beetje). Vijf jaar geleden kwam ik op een ochtendje solliciteren bij het TPRC en na wikken en wegen besloot ik de kans aan te grijpen en een $\mathrm{PhD}$ te gaan doen. Niet alleen vanwege de gave opdracht, maar zeker ook vanwege de sfeer bij het TPRC. Het was natuurlijk een tijd om veel te leren en verder te ontwikkelen, maar zeker ook een tijd om veel leuke dingen te doen en toffe dingen mee te maken. Ik wil in dit stuk iedereen bedanken die op enige wijze een bijdrage heeft geleverd aan dit proefschrift. En iedereen die mij geholpen op een beetje een leuke manier door mijn PhD-tijd heen te komen. Hopelijk vergeet ik niemand, maar als dat wel zo is... Bij voorbaat mijn excuses en ik denk dat een avond biertjes drinken een hoop goed kan maken.

Als eerste wil ik mijn promotor Remko Akkerman bedanken. Vooral voor zijn, voor mijn gevoel grenzeloze, vertrouwen en ook de discussies van de laatste maanden over hoe mijn onderzoek het beste omgezet kon worden in dit proefschrift. Dat was intensief, maar daar heb ik veel van geleerd. Ik wil ook zeker mijn dagelijkse begeleiders Laurent Warnet en Wouter Grouve bedanken, want zonder jullie was dit proefschrift niet mogelijk geweest. Jullie zijn samen een steun en toeverlaat voor mij geweest en ik waardeer jullie onvoorwaardelijke hulp. Geheel in de stijl van Laurent begon ik met een A4tje en was ik vrij om zelf het onderzoek te bepalen, gelukkig met jullie hulp. De afgelopen jaren heb ik met een plezier met jullie samengewerkt een met hoop gezelligheid veel van jullie mogen leren.

Mijn onderzoek is gefinancierd door het TPRC en ik wil alle partners bedanken voor het mogelijk maken van mijn onderzoek. Het kunnen werken met mijn "eigen" robot was een unieke kans en een prachtige ervaring. Ook wil ik Harald Heerink bedanken, aangezien hij me 5 jaar geleden de mogelijkheid gaf om bij het TPRC te komen. Daarnaast wil ik ook de Technical Advisory Board van het TPRC bedanken voor jullie inzet voor al het onderzoek bij het TPRC en alle input in mijn project.

Naast Remko, Laurent en Wouter waren ook Sebastiaan Wijskamp en Mohammad Hosseini bereid om al mijn teksten te lezen in de leescommissie en daar wil ik jullie 
voor bedanken. Met jullie hulp heb ik alles op een, volgens mij, fatsoenlijke manier op papier kunnen zetten. Ik was er niet altijd blij mee, aangezien ik meestal met minstens zoveel commentaar terug kwam uit een overleg als de tekst die ik geschreven had, maar dit heeft wel geholpen om tot dit resultaat te komen. Also thanks to Lily Shaojie Liu, since I could join your reading committee, which helped me to prepare for the worst, and could be your paranymph.

Ik wil ook Gert-Jan Nevenzel, Edwar Boer, Ivo Vrooijink, Bert Vos en Laura Vargas bedanken voor het helpen met mijn werk in het lab bij het TPRC en op de UT. Ook wil ik de secretaresses van de universiteit, Debbie Vrieze-Zimmerman, Belinda Bruinink en Martina Tjapkes bedanken voor het makkelijker maken van mijn leven als $\mathrm{PhD}$ student. Daarbij mag ik de mensen bij het TPRC, Iris de Klerk, Bert Rietman, Selma Kalee, Renata Heerink en Nick van der Vall niet vergeten, dank voor jullie hulp. Ik wil ook de mensen van de universiteit bedanken waar ik mee samen heb mogen werken: Roy Visser, Ismet Baran en ook Ton Bor voor alle inspirerende studentassistent mogelijkheden. Gert-willem Römer heeft het eerste jaar mee gekeken, dank je daarvoor en ook dat je nu tijdens mijn verdediging weer tegenover me zit. Ook onze buren van Aniform, Rene ten Thije, Sebastiaan Haanappel en Dennis Brands, wil ik bedanken voor de tijd bij het TPRC.

Ik wil ook de studenten die ik heb begeleid bedanken voor het onderzoekswerk dat jullie voor mij hebben gedaan. Evan Vruggink, Gombo Knaap en Jan Rozendom, het was een plezier om jullie te begeleiden met jullie afstuderen. Tjitse Slange wil ik ook bedanken voor zijn samenwerking en hulp, samen hebben we heel wat uurtje besteed om de robot te begrijpen...

En dan de PhD-room, dé reden om bij het TPRC te komen werken. Dankzij jullie zijn mijn PhD-jaren ontzettend leuke jaren geworden, dank daarvoor. De samenstelling is behoorlijk veranderd over de jaren, maar dank gaat uit naar: Francisco Sacchetti, Devi Woldhuizen, Mohammed Iqbal Abdul Rasheed, Jeroen Houwers, Thijs Donderwinkel, Sander van Noorloos, Jon Lieben, Ulrich Sachs, Tjitse Slange, Mark Bouwman, Guillaume Vincent, Erik Krämer, Ramona Sitohang, Marten van der Werff, Jagadeesh Narayana Swamy, Vanessa Marinosci, Coen Hartjes en Rick Schrijver. We hebben veel toffe dingen gedaan, van wekelijks wakeboarden, via conferenties bezoeken, tot het dragelijk maken van EM symposia en dit zijn de dingen die mij het meest bij gaan blijven. Daarnaast wil ik ook mijn collega's op de UT bedanken, al zat ik niet dagelijks bij jullie op kantoor: Amin Zaami, Waqas Ali, Arka Bhakta, Yibo Su en Boukje de Gooijer.

En als laatste wil ik ook mijn familie en vrienden bedanken voor hun steun, en het feit dat ze al mijn gezeur over laser assisted fiber placement en mijn $\mathrm{PhD}$ altijd hebben 
willen aanhoren. Ook mijn paranimfen Peter en Bart bedanken, gaaf dat jullie erbij willen zijn. Enne.. dat kleine broertje heeft het toch maar geflikt!

Daag,

Thijs, augustus 2018. 



\section{Publications}

\section{Journal articles}

1. T. Kok, W. J. B. Grouve, L. L. Warnet, R. Akkerman. Tape deconsolidation during laser assisted fiber placement. Submitted to: Composites part B: Engineering (Chapter 3 of this thesis).

2. T. Kok, W. J. B. Grouve, L. L. Warnet, R. Akkerman. Intimate contact development during laser assisted fiber placement. To be submitted to: Composites part A: Applied Science and Manufacturing (Chapter 4 of this thesis).

3. T. Kok, W. J. B. Grouve, L. L. Warnet, R. Akkerman. Tape deformation during laser assisted fiber placement. To be submitted to: Journal of Thermoplastic Composite Materials (Chapter 5 of this thesis).

\section{Conference proceedings}

1. T. Kok, W. J. B. Grouve, L.L. Warnet, R. Akkerman. Effect of ply orientation on bond strength in fiber-placed composites. Proceedings of the 20th International Conference on Composite Materials (ICCM-20), 2015, Copenhagen, Denmark.

2. T. Kok, W. J. B. Grouve, L.L. Warnet, R. Akkerman. Intimate contact development in laser assisted fiber placement. Proceedings of the 17th European Conference on Composite Materials (ICCM-17), 2016, Münich, Germany.

3. T. Kok, W. J. B. Grouve, L. L. Warnet, R. Akkerman. Quantification of tape deconsolidation during laser assisted fiber placement. Proceedings of the 3rd International Symposium on Automated Composites Manufacturing (ACM3), 2017, Montreal, Canada. 